Silvia Staubli

Trusting the Polite

Comparisons across Eastern

and Western Europe

[transcript] Culture and Social Practice 
Silvia Staubli

Trusting the Police 
Silvia Staubli (PhD) teaches at the Department of Social Sciences, University of Fribourg. Her research covers the fields of institutions of social control, victimology, and research methods, amongst others. 
Silvia Staubli

\section{Trusting the Police}

Comparisons across Eastern and Western Europe

[transcript] 
Published with the support of the Swiss National Science Foundation

This work is licensed under

the Creative Commons Attribution-NonCommercial-NoDerivs 3.0 (BY-NC-ND) which means that the text may be used for non-commercial purposes, provided credit is given to the author. For details go to http://creativecommons.org/licenses/by-nc-nd/3.0/.

\section{Bibliographic information published by the Deutsche Nationalbibliothek}

The Deutsche Nationalbibliothek lists this publication in the Deutsche Nationalbibliografie; detailed bibliographic data are available in the Internet at http://dnb.d-nb.de

\section{(ㄷ) 2017 transcript Verlag, Bielefeld}

All rights reserved. No part of this book may be reprinted or reproduced or utilized in any form or by any electronic, mechanical, or other means, now known or hereafter invented, including photocopying and recording, or in any information storage or retrieval system, without permission in writing from the publisher.

Cover design: Kordula Röckenhaus, Bielefeld

Proofread by Ulrike Anderson

Typeset by Justine Buri, Bielefeld

Printed in Germany

Print-ISBN 978-3-8376-3782-3

PDF-ISBN 978-3-8394-3782-7 


\section{Table of Contents}

Preface $\mid 9$

Abstract $\mid 11$

Figures $\mid 13$

Tables $\mid 15$

Introduction | 19

The importance of trust in the police 19

Aim and research question $\mid 21$

Structure $\mid 22$

Theoretical considerations and state of research $\mid 25$

1. Reflections on research on trust in the police $\mid 25$

1.1 Introduction 25

1.2 Developments $\mid 25$

1.2.1 Police research $\mid 25$

1.2.2 Trust research $\mid 26$

1.3 Institutional versus organizational approaches $\mid 28$

1.3.1 Trust in the institution police 28

1.3.2 Attitudes toward the organization police 29

1.4 Filling the research gap: the attempt at a combination | 31

1.5 Cross-national research $\mid 33$

1.6 Summary $\mid 34$

2. Determinants of trust in the police $\mid 35$

2.1 Introduction $\mid 35$

2.2 Trust in the police as a government institution $\mid 36$

2.3 Confidence in the work of the police:

effectiveness and fairness $\mid 38$

2.3.1 Theories of procedural justice $\mid 39$

2.4 The role of encounters 43

2.4.1 Research overview $\mid 48$ 
2.4.1.1 Differences between police- and citizen-initiated contact 48

2.4.1.2 Treatment of crime victims $\mid 51$

2.4.1.3 Reporting crimes $\mid 52$

2.4.1.4 Negative experiences weigh more $\mid 53$

2.4.1.5 Individual influences: socio-demographic and other factors $\mid 56$

2.5 The impact of social trust $\mid 6_{1}$

2.5.1 Research overview $\mid 64$

2.6 Summary $\mid 65$

3. Model and hypotheses $\mid 67$

\section{Methodology $\mid 73$}

4. Data $\mid 73$

4.1 European Social Survey 2010 (ESS2010) | 73

4.1.1 Sample $\mid 73$

4.1.2 Variables $\mid 76$

4.1.2.1 Victims of crime $\mid 81$

4.2 Swiss Crime Survey 2011 (CS2011) $\mid 83$

4.2.1 Sample $\mid 84$

4.2.2 Variables $\mid 85$

\section{European perspective:}

East, West, and Switzerland compared | 89

5. Introduction $\mid 89$

6. Macro level patterns of trust in the police $\mid 90$

6.1 Introduction $\mid 90$

6.2 Distribution of trust in the police $\mid 90$

6.3 Governmental trust $\mid 91$

6.4 Social trust $\mid 93$

6.5 Summary $\mid 94$

7. Trust in the police at the individual level $\mid 94$

7.1 Introduction $\mid 94$

7.2 Local ratings and overall trust in the police $\mid 95$

7.3 Distribution across Eastern and Western Europe 99

7.4 The police as an arm of the government $\mid 102$

7.5 Police-initiated contact $\mid 105$

7.5.1 Individual influences 107 
7.5.2 Satisfaction with treatment received $\mid 110$

7.5.3 The impact of social trust $\mid 117$

7.6 Encounters and the influence of individual

and contextual factors $\mid 126$

7.7 Summary $\mid 135$

8. Summary $\mid 135$

\section{Ther perception of crime victims | 141}

9. Introduction $\mid 141$

10. Victims trust in the police $\mid 141$

11. Victim-initiated police contact in Switzerland $\mid 143$

12. Summary $\mid 150$

\section{Discussion | 151}

13. Reflection on hypotheses $\mid 151$

14. Views of local police work and general trust in the police $\mid 156$

15. Building and destroying trustworthiness 159

15.1 Officers as institutional representatives | 159

15.2 Police - versus victim-initiated contact $\mid 160$

15.3 A good reputation contrasts increasing attacks toward the police $\mid 161$

16. Cultural aspects $\mid 164$

17. Trends in opinions $\mid 166$

18. Limitations $\mid 169$

19. Conclusion and outlook $\mid 173$

References | 175

Appendices | 189

Appendix A: European Social Survey 189

Appendix B: Swiss Crime Survey 2011 | 197 



\section{Preface}

This book is based on my PhD thesis, which I successfully defended in autumn 2014 at the University of Zurich. In order to make it more readable, I re-designed and re-organized the content. The two major changes were firstly, that I deleted some background information on methods and moved others to the Appendices. Secondly, I incorporated results for Switzerland in each chapter, whereas before, they were collected and displayed in a single section. Subsequently, some country-specific information and in-depth analyses have been omitted. Readers interested specifically in the case of Switzerland should look at the original PhD version (Staubli 2014).

Even though the underlying data dates back to the year 2010, the topic has not lost its pertinence. Research on trust in justice and legitimacy increases every year and branches out into newer, related fields and topics. This book contributes to this field by comparing Eastern with Western Europe. In addition, results for Switzerland allow validation of more general results for a country marked by a high level of trust in the police.

Several people contributed to this publication in one way or another. I thank Prof. Dr. Martin Killias, Prof. Dr. em. Hans Geser, Dr. Robert Schäfer, Lorenz Biberstein, Dr. Matthias Bänziger, and Ulrike Anderson. 



\section{Abstract}

The underlying question posed in this book asks: What shapes people's perception of the police? The book aims to contribute to the field of trust and attitudinal research in several ways. Firstly, institutional approaches are considered, identifying the police as part of wider governmental institutions. Secondly, theories of procedural justice are examined. They argue that fair decisions and respectful treatment largely contribute to institutional legitimacy and trustworthiness. In contrast, arguments treating police's effectiveness as central to people's trust in them are called "instrumental". Whether the police are doing a good job, i.e. fighting crime effectively, is more important than the use of appropriate procedures and correct behavior. These approaches enter into the analyses in such a way that the global notion of trust in the police is linked to global statements about police's procedural fairness and effectiveness. Moreover, the level of satisfaction in concrete interactions with the police is taken into account.

Institutional representatives play an important role in the trust-building process, as mentioned in procedural justice theories. Going one step further, interactions with police officers are expected to be influenced by social trust. A culture marked by a general openness toward strangers may contribute not only to a higher trust in interactions with ordinary people, but may also be transferred to institutional representatives. Diverse research has confirmed the link between social trust and institutional trust, especially with regard to trust in political institutions, such as the government or political parties. However, the causal direction is unclear. Nevertheless, since studies dealing primarily with institutional trust in the police are rare, social trust is taken into account as an explanatory force in the upcoming analyses.

Studies within the field of police research are often based on local surveys. Cross-country analyses with data from large opinion polls are rather 
rare. Another aim is to link cross-national analyses to a concrete in-depth country study. A country study of Switzerland follows the search for correlations at a cross-country level. It tests whether the links can be proven in a single country marked by high levels of trust in the police. Finally, not only people's trust in the police, but also views of crime victims and victim-initiated police contacts, are analyzed. 


\section{Figures}

Figure 1: Overview of police research in the field of trust $\mid 30$

Figure 2: Theoretical model of trust in the police $\mid 67$

Figure 3: Description of clusters $\mid 75$

Figure 4: Linear relationship between items of trust in the police across Europe | 91

Figure 5: Linear relationship between trust in politics and trust in the police across Europe $\mid 92$

Figure 6: Linear relationship between social trust and trust in the police across Europe | 93

Figure 7: Confidence in national police work in Switzerland (ESS2010) and trust in the police $\mid 97$

Figure 8: Impact of confidence in local police work (CS2011) on trust in the police $\mid 97$

Figure 9: Mean levels of trust in the police items | 101

Figure 10: Percentage of self-reported police-initiated contact | 106

Figure 11: Percentage of satisfaction with treatment received by the police in an encounter $\mid 111$

Figure 12: Impact of satisfaction with treatment received by the police on confidence in their work $\mid 114$

Figure 13: Impact of satisfaction with treatment received by the police on trust in their procedural fairness $\mid 115$

Figure 14: Percentages of people answering that the police are not asked to explain their decisions $\mid 116$

Figure 15: Mean values of three indicators for social trust in Eastern and Western European countries | 117

Figure 16: Social trust, police contact, and confidence in police work in Western Europe | 121 
Figure 17: Social trust, police contact, and confidence in police work in Eastern Europe | 122

Figure 18: Social trust (trust in fairness), police contact, and confidence in police work in Switzerland | 122

Figure 19: Social trust, police contact, and trust in police's procedural fairness in Western Europe | 124

Figure 20: Social trust, police contact, and trust in police's procedural fairness in Eastern Europe | 124

Figure 21: Social trust, police contact, and trust in police's procedural fairness in Switzerland | 125

Figure 22: Satisfaction with control of neighborhood criminality over time in Switzerland 169 


\section{Tables}

Table 1: $\quad$ Sample size used $\mid 74$

Table 2: Dependent variables ESS2010 $\mid 77$

Table 3: Independent variables ESS2010 $\mid 77$

Table 4: Explanatory variables ESS2010: institutional trust $\mid 78$

Table 5: Explanatory variables ESS2010: social trust $\mid 78$

Table 6: Correlations between social trust items in Eastern and Western Europe $\mid 81$

Table 7: Correlations between social trust items in Switzerland | 81

Table 8: Comparison of victimization rates (burglary and assault) across countries, using different data sources 182

Table 9: Samples from CS2011 84

Table 10: Dependent variable CS2011 | 85

Table 11: Independent variables CS2011 86

Table 12: Criminal victimization CS2011 87

Table 13: Crime victims' attitudes CS2011 $\mid 87$

Table 14: Local and national evaluation of police work in Switzerland | 95

Table 15: Correlations between attitudes toward local police work and trust in the police $\mid 99$

Table 16: Correlation coefficients for institutional trust items | 103

Table 17: Factor loading of institutional trust items (single factor) $\mid 103$

Table 18: Factor loading of institutional trust items (two-factor orthogonal rotation) | 104

Table 19: Influence of socio-demographic variables on trust in the police in Eastern and Western Europe (linear multivariate regressions) $\mid 108$ 
Table 20: Influence of socio-demographic variables on trust in the police in Switzerland (linear multivariate regressions) | 110

Table 21: Impact of satisfaction with encounter on trust in the police (linear multivariate regression) | 113

Table 22: Correlation coefficients of social trust and trust in the police $\mid 118$

Table 23: Impact of social trust on trust in the police (linear multivariate regressions) | 119

Table 24: Impact of police encounters, social trust, governmental trust, and control variables on trust in the police in Western Europe (linear multivariate regressions) | 130

Table 25: Impact of police encounters, social trust, governmental trust, and control variables on trust in the police in Eastern Europe (linear multivariate regressions) | 131

Table 26: Impact of police encounters, social trust, governmental trust, and control variables on trust in the police in Switzerland (linear multivariate regression) | 134

Table 27: Impact of police encounters, governmental trust, and control variables on trust in the police in Western Europe, in samples of people with low, moderate, and high social trust (linear multivariate regressions) | 136 (Part 1) and 137 (Part 2)

Table 28: Impact of police encounters, governmental trust, and control variables on trust in the police in Eastern Europe, in samples of people with low, moderate, and high social trust (linear multivariate regressions) | 138 (Part 1) and 139 (Part 2)

Table 29: Impact of victimization on trust in the police 142

Table 30: Impact of victimization on satisfaction with police encounters $\mid 14^{2}$

Table 31: Victims' trust in the police according to different modes of victimization | 144

Table 32: Reporting to the police over a number of years according to different modes of victimization | 145

Table 33: Victims' satisfaction with treatment received by the police according to different modes of victimization | 147

Table 34: Information policy according to different modes of victimization | 147

Table 35: Impact of police contact on trust in the police in Switzerland according to different modes of offences against property 148 
Table 36: Impact of police contact on trust in the police according to different modes of offences against the person | 149 Table 37: Trust in the police in Europe over time $\mid 166$

Table 38: Trust in the police in Switzerland over time $\mid 168$ 



\section{Introduction}

\section{THE IMPORTANCE OF TRUST IN THE POLICE}

Police are a prominent topic in the media. Either they are described positively, such as when successfully apprehending a criminal, or they were portrayed critically, due to inappropriate behavior, for example. Images depicting discreditable behavior by officers, such as fighting back peaceful demonstrators and protesters, shed a negative light on the police and throw their role into question. Such situations, but also generally inadequate behavior and behavior perceived as unfair, affect police trustworthiness. In addition, in Switzerland, the media and the public closely observe police behavior. Moreover, a declining respect for officials in general is reported. Such critical opinions are contrasted by high rates of trust in the police in Western Europe and in Switzerland in particular. This leads to the question: What contributes to trust in the police and how are attitudes toward them shaped?

This book elaborates on opinions of the police, people's trust in and attitudes toward them. It considers encounters with the police and analyzes the role of social trust, i.e., people's individual trust in unknown fellow citizens. Before discussing theoretical considerations, I should like to highlight the relevance of the topic. Firstly, research has shown that trust in an institution is closely linked to the perception of its legitimacy. Secondly, trust and legitimacy themselves lead to better compliance with the law. Legal rules and decisions aimed at influencing the actions of those toward whom they are directed are only effective if they are obeyed (Hough et al. 2010). Hence, elaboration on the mechanism used to promote trust in the police and their perception as a legitimate institution is important. Furthermore, as everyday life has become more complex and uncertain in modern societies, resources and strategies on the institutional side have become increasingly necessary. In order to use them effectively, authorities 
need to be able to gain voluntary acceptance for most of their decisions and therefore rely heavily on legitimacy (Misztal 1996: 245). Several studies confirm that attitudes toward institutional trustworthiness are central to a willingness to accept decisions within political settings (cf. Tyler 1998). After all, institutional trust is linked to individual trust. Some authors see institutions as a source of trust between actors, which makes them objects of trust too (Freitag 2003; Robbins 2011). In their view, institutions play an important role in the absence of specific information about the trustee and form reliable commitments and mutual expectations of good will. Stable institutions encourage citizens to take small risks to learn who is trustworthy and how to distinguish them from those who are not. Once institutions are put in place, they are counted upon, because they are durable and can be taken for granted (Offe 1999: 66). This suggests that the police can be seen as guardians of security in a society, enabling people to trust strangers more easily. Despite this fact, and in relatively secure societies in the West, not everyone has a positive perception of the police. According to Hardin (2006), trust has three dimensions: how individuals choose to trust, at whom they direct their trust, and in which circumstances they exercise their trust. In other words, trust is a three-pronged relationship: A trusts B to do, or with respect to, X (Hardin 2006: 19). Applied to institutional trust (B) it can be said that, whether we (A) trust an institution or not depends on our perception of it. Moreover, it depends on our opinion of its trustworthiness. Several factors may contribute to such a perception. In cases of legal institutions, such as courts or the police, certain expectations about their roles and duties are attributed to them (X), based on what we have learned in school, from friends, or through media coverage. Trust in the police can therefore be seen as the population's belief that the police have good intentions toward citizens and are competent to act in specific ways in specific situations (Jackson et al. 2011b). Another source of information is a direct experience with institutional representatives (Giddens 1990). Police officers as representatives of the institution police can therefore influence the trust-building process. Procedural justice approaches derived from social psychology elaborate on such encounters by showing how perception of police encounters influences people's attitudes toward them. Institutional trustworthiness is the most important issue people consider when evaluating procedures used by authorities. Hence, opinions on the fairness of authorities form the basis for judgments about police legitimacy (Tyler 1998; Tyler/Huo 2002: 72-74). 
Literature on trust in government and in political institutions is broad, looking back at a long tradition, while research dealing specifically with trust in justice has only emerged in recent years. Projects such as "fiducia - justice needs trust" within the FP7, the EU's seventh framework program for research, helped to add the topic of trust in justice to the research agenda. It resulted in the module of trust in justice in round 5 of the European Social Survey 2010 and thus enabled a broad research community, myself included, to address the subject. The acceptance of this topic as a module in this large survey, which covers a variety of European countries, highlights the relevance of research on trust in the police.

\section{AIM AND RESEARCH QUESTION}

The aim of this book is to combine institutional approaches of trust in the police with those of attitudinal research, looking at the influence of perceptions and satisfaction with encounters. The underlying research question is: What influences trust in the police? As research on institutional trust stems primarily from political sciences or economics, research treating the police as part of governmental institutions, rather than focusing on them as an organization, is marginal within sociology and criminology. Before starting with analyses at the institutional and organizational levels, the question of whether trust in the police may be seen in a broader light of institutional trust in governmental institutions needs to be clarified. Furthermore, within research on attitudes toward the police, distinction between global and specific attitudes is often omitted. Moreover, the connection between them is only rarely analyzed. Hence, Brandl, Frank, Worden, and Bynum demanded back in 1994:

"Future research [...] should be directed toward understanding more clearly how global attitudes toward the police are formed, and how (if at all) global or specific attitudes can be influenced by the quality of police contacts. One potentially informative direction for such research would be analyses of socialization [...]." (Brandl et al. 1994: 132)

This thesis contributes to closing the research gap that still exists in two ways. Global trust in the institution police and abstract attitudes toward the organization are related to concrete experiences with the police, look- 
ing primarily at the impact of satisfaction with treatment received from the police on trust in them. While these analyses are addressed at the European level, taking several Eastern and Western European countries into account, a second step analyzes more closely the situation in one Western European country marked by high levels of trust in the police, i.e. Switzerland.

Most of the studies within this field of research are either based on local samples of cities or on large opinion polls aimed at comparing countries. Local samples allow testing of concrete questions allocated to the setting. In contrast, large polls and countrywide or cross-country analyses help to shed light on the "big picture". The structure of the underlying data of this thesis does not allow for consideration of a variety of questions of global and specific attitudes toward the police. Nevertheless, it is possible to link a general notion of trust in the police to questions about concrete experiences. Furthermore, such patterns are tested and enriched for Switzerland with more concrete data.

As one explanatory force, rather than asking for the socialization of individuals, as Brandl and colleagues (1994) demand it, social realities are taken into account. I argue that cultures shaped by high levels of social trust generate a positive basic attitude and openness that affects trust in institutions. Finally, I reflect on police as a part of other governmental institutions.

\section{StrUCtURE}

Trust in the police needs to be researched on a very abstract level or on the basis of individual cases, because every country's police system has its own particularities and hierarchies (Albrecht/Nogala 2001). This book addresses both of these aspects. In the first section, entitled "Theoretical considerations and state of research", I will elaborate on theoretical concepts and existing research. The first chapter builds on Albrecht and Nogala's (2001) argumentation of how police should be analyzed. On the one hand, the institutional approach views the police as part of a wider government, closely connected to other institutions. On the other hand, attitudinal research largely focuses on local settings, with regard to officers' (mis) behavior, for example. This book combines both approaches and adds an additional level by conducting cross-country research. The second chapter 
outlines three theoretical roots: trust in the police as trust in a governmental institution, trust in the police as confidence in their effectiveness, and finally trust in the police as trust in their procedural fairness. The core component of the argument is placed on encounters with the police, which are seen as crucial for building or destroying people's trust in the police. Moreover, I will test whether social trust, i.e. trust in unknown others, in their fairness and helpfulness, can be transformed into trust in police officers and trust in the police as a whole. In existing research, social trust is often treated as part of social capital. Since the interest is predominantly on its relationship with political institutions, it is rather seldom researched in the context of police. In order to close this research gap, I treat social trust as an explanatory force for trust in the police.

In order to achieve a better understanding of these arguments, I've incorporated them into a model displayed in a figure in the third chapter, where the hypotheses also are presented.

The second section provides information on the applied data sources. In addition to presenting the operationalization of indicators, I critically debate the use of certain items, such as social trust. Since "most people" is understood differently across countries and cultures, its universal applicability is questionable (Delhey/Newton/Welzel 2011). Other points to criticize are the combination of the three items as well as feelings at the time of response that should be considered as they may affect responsiveness (Alesina/La Ferrara 2002).

Results are presented in the two subsequent chapters. This third section, entitled “The European perspective", deals with trust in and attitudes toward the police in Eastern and Western Europe, as well as in Switzerland. In a first step, at the aggregated level, I search for patterns of trust in the police across countries. Scatterplots reveal similarities within Eastern and Western European countries. Based on these results, two clusters of Eastern and Western Europe are built. They form the basis for further analyses at the individual level. Before elaborating on the impact of police-initiated encounters on trust in and attitudes toward the police, a wider institutional trust is considered. I test whether people perceive political and legal institutions similarly. Finally, the impact of social trust on overall trust in the police, as well as its role in police encounters, is elaborated on. However, people's opinions of the police are not only affected by involuntary contact with the police. Several studies show that, in cases where the public contacts the police, in order to report a criminal 
offence for example, unfavorable behavior of officers plays a crucial role in destroying people's trust in them. This is especially true when victims of a crime report the offence. Therefore, section four turns its focus on victims of crime. A second database for Switzerland allows for an expansion of the scope, taking not only police-initiated contact into account, but also elaborating on the impact of reporting an offence, satisfaction with the handling of the case by the police, as well as their further information policy on trust in the police.

The concluding discussion section begins with a reflection on the hypotheses postulated at the beginning of the book. Next, several important results are addressed and discussed. Further, results are compared to trust rates over recent years. The section ends with a chapter on limitations, followed by some concluding remarks. 


\section{Theoretical considerations and state of research}

\section{Reflections on RESEARCh ON TRUSt IN THE POLICE}

\subsection{Introduction}

The field of police research is wide, thematically as well as with regard to methodological designs. Institutional approaches are primarily based on large opinion polls. The same is true for attitudinal studies dealing with procedural fairness, for example. However, several studies are conducted locally, examining people's attitudes toward their city's police. Research questions inform design. While large surveys that compare countries are mostly settled on an abstract level, dealing with overall levels of trust and attitudes toward the police, in local studies, a broad set of questions allows for a deeper elaboration of people's opinion of the police. A distinction between such levels and concepts is often missed. Therefore, the following will present an overview of institutional and organizational trust approaches, after a short introduction to the development of police and trust research. After illustrating the research gap, an attempt is made to synthesize the approaches.

\subsection{Developments}

\subsubsection{Police research}

For early classical sociologists, the police were largely an instrument used by the sovereign power to govern. The first sociological studies of police work arose in the 1960 s, when social and political changes affected most Western European countries. People took social and political conflicts to the streets. Concerns about rising crime and disorder became a public 
issue. In light of an increase in the public's questioning of authorities in general, the police became increasingly visible, controversial, and politicized in response to these tensions and pressures. During this time, studies began to be conducted, primarily by universities and motivated by critical and theoretical concerns about police behavior and the police as an institution. Research overwhelmingly originated in the U.S. and the UK. Nowadays, the majority of police studies relevant to the sociology of police, as well as to the field of criminology, still originate from English-speaking countries, with the U.S. in the lead. The dominance of academics in police research lasted until the mid-1980s. Afterwards, official police research done by governmental bodies like the Home Office in the UK, as well as think tanks and independent research organizations grew extensively. Theory-oriented academic research underwent a transformation, from an institutional understanding of the police to policing as a socially structured, dynamic, and multi-faceted process ${ }^{1}$ (Albrecht/Nogala 2001). This was accompanied by a shift in focus from social control approaches toward problem-oriented ones, leading to new research topics, such as attitudes toward the police, seen as an essential element for building and obtaining public safety. Collaboration between researchers within the police as well as with police-oriented researchers from other research institutions became common (Reiner 2000).

\subsubsection{Trust research}

For several years, categories of trust remained marginal in social science research. In 1988, Diego Gambetta stated:

“[...] in the social sciences the importance of trust is often acknowledged but seldom examined, and scholars tend to mention it in passing, to allude to it as a fundamental ingredient or lubricant, an unavoidable dimension of social interaction, only to move on to deal with less intractable matters." (Gambetta 1988: X)

1 While police refers to an institution, policing is targeted at police function, i.e. the organized form of maintaining security through surveillance and the threat of sanction (Pakes 2010: 42). In many societies, policing was only recently associated with the activities of the institution police; instead it was used to signify social regulation in the broadest sense, seen in its etymological relationship to the governance of the city or the state (Rowe 2008: 3-4). 
While in the 1960 s and 1970 s exploratory studies with empirical settings generated many conceptual problems of trust; from about 1980 to the second half of the 1990 there was a strong conceptual output, followed by many books and special issues applying and testing theoretically derived concepts (Möllering 2006: 128). Its reappearance as a central topic in the 1990 may also be seen as a reflection of political, social, and economic realities. The process of globalization and the collapse of communism were periods of uncertainty and therefore seen as sources of declining trust (Cook 2001). Industrial nations were forced to redefine and articulate new collective values and aspirations. Moreover, there was a need to search for new alternatives, as existing bases for social cooperation, solidarity, and consensus had eroded. Consequently, in social sciences, questions of how social trust is established and what kinds of social trust enhance economic and governmental performance increasingly became the central set of theoretical issues (Misztal 1996: 3-4). Especially in sociology, a growing interest in the domain of "soft" cultural variables has led to a new wave of interest in trust at the turn of the millennium, encouraged by characteristics of modern societies, highlighting the problem of trust (Sztompka 1999: 1-2) ${ }^{2}$. In such modern societies, money, authority, and knowledge play an important role in maintaining social order. While money determines market participants, political authority provides a legal system and the enforcement of the law, a framework that regulates the action of citizens. Finally, knowledge, based on observations and research on social and non-social realities, as well as its distribution through organizations, education, and the mass media, creates an awareness of current and future problems of actors, and about strategies to solve them. However, synthesis of these three media is not sufficient to explain social order patterns, as they are not able to explain informal modes of social coordination based on moral and cultural resources. Trust bridges this gap and provides such modes (Offe 1999).

2 | According to Sztompka (1999: 1-2), a paradigmatic shift has taken place in sociology. In earlier years, the focus was on psychological meanings of "hard", e.g. instrumental or positivistic images of action, found in behaviorism, the game, or rational choice theory. Later on, cultural sociology centered on a "soft" or humanistic, meaningful image of action, such as symbolic interactionism, phenomenology, hermeneutics, or cultural studies. 
While early work on trust focused on the individual level of trust, the focus later shifted toward trust in institutions or institutional actors, such as professionals and other agents. Moreover, the focus was expanded to individual trust in government, leading to the claim that the stability of governments depends on citizens' trust in them. Some work also sees trust as the basis of grand social theory, as the discussion of effects of trust on the atmosphere of cooperativeness in the larger society has shown (Hardin 2006: 39-40). Such research was centered on the search for explanations for a declining trust, as found in studies for the United States (cf. Putnam 1995).

\subsection{Institutional versus organizational approaches}

\subsubsection{Trust in the institution police}

Research on trust in institutions is rooted in multiple disciplines, such as political science, public administrations, and economics. It is primarily concerned with global or diffuse citizen attitudes such as "satisfaction with" or "confidence in" governmental agencies or institutions. As a global attitude does not imply having been in contact with the police, many of these studies are based on public opinion polls and are therefore distinct from research on service quality and justice (Maguire/Johnson 2010). Within political science, studies on trust in institutions have a long tradition, largely in analyzing trust in the government and its representatives. Often, any forms of institutional trust measured by opinion polls are combined, and no distinction is made between trust in institutions on the representational side of the political system (the parliament or political parties) and trust in institutions on the implementation side, such as the courts and the police (Rothstein/Stolle 2008) ${ }^{4}$. However, as citizens in modern democracies are more dependent on institutions of implementation, such a distinction is important.

3 | Hardin (2006) argues that we live in an age of distrust in the sense that we have more interaction with people whom we do not trust than with those whom we do trust (compared to earlier ages). However, we primarily have such interactions because we generally have far more interactions of all kinds.

4 | According to the authors, this is especially true for studies looking at the influence of social capital on institutional trust. 
Within criminology, trust in institutions, but also the role of procedural justice, treated here as part of the organizational approach, are relatively new topics. They found their way onto the agenda due to the spread of a neo-institutional account in economics, political science, and sociology at the end of the 1980s. Compared to "old-institutionalism", focused primarily on rational-choice models, "new-institutionalism" tends to emphasize the role of norms, trust, and reciprocity in economic transactions, as well as the role of non-market institutions (Hall/Tayler 1996; Karstedt 2010). Such a resurgence of institutional thinking outside the economy was also a consequence of transformation within modern society as well as the impact of institutional changes on issues of social life, as previously mentioned.

While institutional approaches deal with a rather general form of trust, studies within the policing field focus more on concrete attitudes, such as satisfaction with treatment received by the police, as shown in the next chapter.

\subsubsection{Attitudes toward the organization police}

The field of research addressing attitudes toward the police covers several traditions of theory and research, such as research on service quality, legitimacy, justice, and citizens satisfaction. Research in the field of service quality - only marginal within policing studies - in large part stems from the private sector, testing standardized instruments for measuring the quality of services (Maguire/Johnson 2010). Legitimacy is the "judgment that legal authorities are competent and honest (support or personal legitimacy) and that their professional role entitles them to make decisions which ought to be deferred to and obeyed (institutional legitimacy)" (Tyler 1998: 272-273). One of the defining characteristics of legitimacy is the notion of voluntary compliance. If the majority of people voluntarily chose not to comply voluntarily with the law or legal authorities, formal social control institutions would become overwhelmed (Maguire/Johnson 2010).

Research on procedural justice, based on the assumption that people focus more on procedures and are less interested in the outcomes of their experience, is closely linked to research on legitimacy. People will react more positively to an experience if they perceive a treatment by a judge or a police officer to be fair, regardless of the outcome. Receiving a fine perceived as being too high, for example, does not affect dissatisfaction with the police as strongly as a perceived discrimination in the treatment by an 
officer. The behavior of an officer is perceived as proper when he listens to people's arguments and considers them, when he is neutral and gives good reasons for his decision. Theories of distributive justice must to be distinguished from such a procedural justice approach. They argue that people would like fair outcomes and that the level of punishment should reflect their feelings about what they deserve (Tyler 1990: 6).

Political sciences and economics dominate the research on institutional trust. They primarily look at governmental ratings without focusing on the police separately. Attitudinal research within the policing field is based on specific assessment and includes research on service quality, justice, and legitimacy. An overview of the different approaches is given in Figure 1. Of course, police research as a whole covers many more fields of research, particularly within the police organization, touching upon topics such as the profession itself (cf. Pichonnaz 2014).

Figure 1: Overview of police research in the field of trust

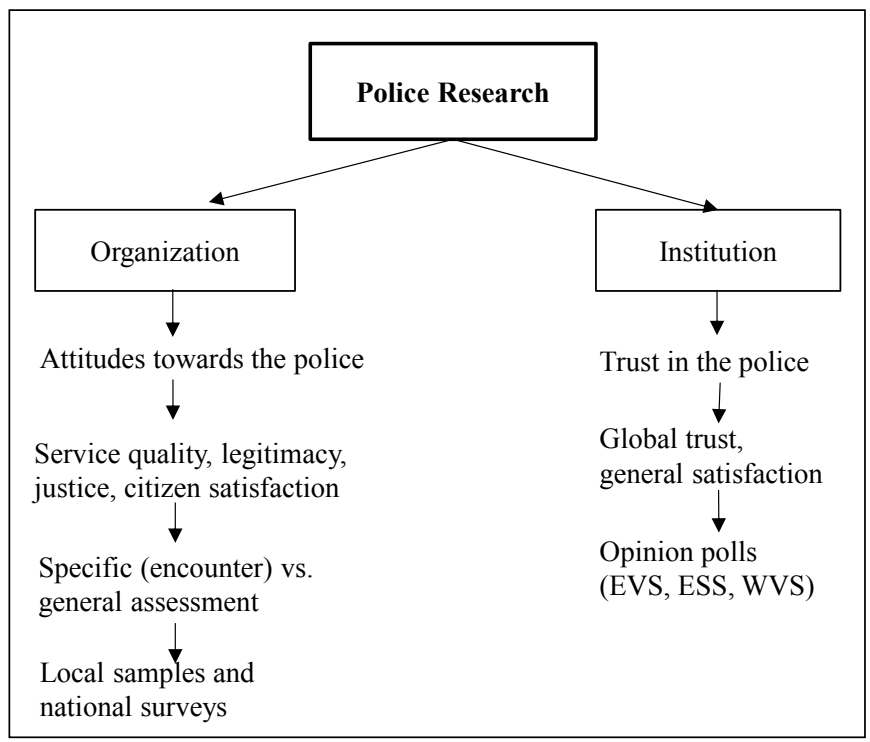




\subsection{Filling the research gap: the attempt at a combination}

The aim of this book is to link global measurements of trust in the police with questions about people's attitudes and experiences. Studies analyzing the interaction between global and specific attitudes toward the police are rare. Moreover, their analyses are often restricted to local police forces. Hence, the use of the notion "global attitude" is often unclear and misleading, pointing to a general attitude toward local police forces rather than to one at the national level, for example. Still, three studies are worth mentioning, as they give a first insight into the topic. Brandl et al. (1994) found that both global and specific attitudes toward the police produce similar levels of support for them. Reisig and Chandek (2001) showed that police behavior correlates with global satisfaction with the police, while they found no significant correlation for specific satisfaction and police behavior. Finally, Schuck and Rosenbaum (2005) chose to differentiate between global and neighborhood attitudes. As all of these studies have individual results with different interpretations, a closer look is warranted in order to acquire enough information to draw conclusions for the present study.

Based on data from two panel waves, Brandl et al. (1994) measured citizens' global attitudes toward the police in a large Midwestern city in the U.S. One question was about people's general satisfaction with the police in their neighborhood. They also considered specific attitudes when asking about the satisfaction level after contact with the police, differing between four forms: requesting information, requesting assistance, stopped and questioned, and following victimization. The comparison of global and specific attitudes shows that most of the differences are neither large nor statistically significant. Global and specific attitudes toward the police seem to relate in an asymmetrically reciprocal way: citizens' global attitudes toward the police affect their assessment of specific contact with the police, and assessments of specific contact affect their global attitudes, but the former effect was found to be stronger than the latter. Brandl and his colleagues argue that even if effects of specific attitudes on global attitudes are found, they may have been overestimated in previous research, as this research did not control for the confounding effects of prior global attitudes. This conclusion may be accurate; however, the expressiveness of the results is limited because - as the authors themselves admit - the majority of the respondents stem from neighborhoods dominated by African 
Americans and people with moderate incomes; people known to have low favorable global attitudes toward the police.

Reisig and Chandek (2001) used two samples of citizens with recently voluntary (breaking and entering complainant) or involuntary (traffic citation) contact with the police, in a medium-sized Midwestern city ${ }^{5}$. Analyzing citizen satisfaction, they asked how satisfied people were with the way the police department handled their most recent citation or complaint. For global satisfaction, they asked for a general satisfaction level with the city's police department. Results revealed that components of disconfirmation measured according to information from expectation and service-received scales - are directly associated with how satisfied respondents are with the way the police handled their most recent contact, either citation or complaint. However, when comparing the global and specific attitudes, results showed that disconfirmation performs poorly with regard to predicting global satisfaction, in cases of both voluntary and involuntary contact. What does count, is police behavior, which significantly correlated to both overall satisfaction with the police and specific rating.

Finally, the third U.S. study that deals with global and specific attitudes toward the police used data from the Minority Trust and Confidence in the Police Project (MTC), a multi-method study consisting of 479 interviews done by phone in Chicago in 2002 , designed to explore minority confidence in the police (Schuck/Rosenbaum 2005). In contrast to the studies by Brandl et al. (1994) and Reisig and Chandek (2001), the general attitude toward the police was measured with four general statements about the police, addressing its behavior (being rude and verbally and physically abusive toward people) and whether the police stopped people for no good reasons. For neighborhood-specific attitudes, they asked respondents several specified questions about their neighborhood police. Schuck and Rosenbaum (2005) found that the model separating general attitudes from neighborhood-specific attitudes - relational to the items measuring perceptions of police behavior and treatment - was more relevant. Furthermore, none of the general attitude indicators had a significant load on the neighborhood dimension and none of the neighborhood-specific indicators had a significant load on the general attitude dimension. Re-

5 | Like in the American study of Brandl et al. (1994) above, no further distinctions about the city are made, contrary to most of the studies from Europe. I assume that this is due to data protection rights, which might be stricter in the U.S. 
sults came out differently after the authors added variables pertaining to contact with the police. The final model shows that there was a strong positive association between global and neighborhood-specific attitudes about police demeanor and treatment. Both attitudinal measures presented concrete options linking attitude to police behavior. This is in contrast to the other two studies, which used only one question about a general level of satisfaction or trust.

Comparisons between the three studies are limited. Brandl et al. (1994) and Reisig and Chandek (2001) relate the global and specific attitudes toward the police to the same local police force, either neighborhood or city police. In the study by Schuck and Rosenbaum (2005), the distinction was between neighborhood police and the police in general. As they give no further information about what exactly is meant by "the police in general", these questions may relate to local police as well, as global satisfaction relates to questions about behavior mostly observable in the citizens' environment. However, when considering media coverage of negative police behavior, wider connotations with state or national police forces may also be possible.

\subsection{Cross-national research}

Linking organizational approaches to institutional ones is important and not yet well established in police research. Another missing link is multi-country research. One exception is the study by Grönlund and Setälä (2012), considering the aspect of corruption. Since every country has specific police organizations and specific laws framing their actions, it is understandable that comparative research is limited; even though, at an abstract level, comparative research is important and contributes largely to understanding fundamental concepts and approaches. Moreover, it has been a core element of sociological research since the beginning of sociology as a discipline (Arts/Halman 2004). The importance can be highlighted by the words of Melvin Kohn (1987):

"I argue that cross-national research is valuable, even indispensable, for establishing the generality of findings and the validity of interpretations derived from single-nation studies. In no other way can we be certain that what we believe to be social-structural regularities are not merely particularities, the product of some limited set of historical or cultural or political circumstances. I also argue that 
cross-national research is equally valuable, perhaps even more valuable, for forcing us to revise our interpretations to take account of cross-national differences and inconsistencies that could never be uncovered in single-nation research." (Kohn 1987: 713)

Kohn grouped cross-national research - studies that are "explicitly comparative, [...] that utilize systematically comparable data from two or more nations" (Kohn 1987: 714) - into four types: studies in which the nation or the country is either the object, the context, the unit of analyses, or transnational in character. In the first type, the primary interest lies in the particular countries included. Moreover, comparisons of institutions may be possible. Such research is contrasted in the second type, where the country builds the context of analyses. Here, the generality of findings and interpretations is tested. When the country is the unit of analyses, relationships among characteristics of nations are established. Countries are classified along certain dimensions. The focus is on the relationship between social institutions and processes with variations in national characteristics. As institutions and processes are studied intra-nationally, there is no need to treat each nation as a homogenous entity. Finally, transnational research treats nations as components of larger international systems.

This book is located within two of the aforementioned fields. In the first, the aim is to test the generality of trust in the police, as well as of attitudes about their procedural fairness and effectiveness. Eastern and Western European countries therefore build the context of analyses. In the second, in a country survey, Switzerland is the object of analyses. Besides proving general results found at the European level, certain additional aspects are taken into account.

\subsection{Summary}

Trust in and attitudes toward the police cover a rather wide field of research, from institutional approaches down to very specific local surveys. Research has shown that there is a positive association between global and neighborhood-specific attitudes about police demeanor and treatment. People make connections between trust in the police and concrete actions or behavior of their representatives. Therefore, trust in the police as a general attitude is linked to specific assessments. Studies linking concrete experiences with officers to a wider trust in the police institution are rare, 
using different concepts of global trust. With regard to specific patterns of police organizations, they are often based on local samples. The aim of this book is to contribute to filling this research gap twofold by linking police encounters with global trust in and attitudes toward them cross-nationally.

\section{Determinants of trust in the police}

\subsection{Introduction}

When analyzing trust, the "crucial variable is trustworthiness of those who are to be trusted or relied upon" (Hardin 2006: 59). Based on this argument, when analyzing trust in the police, their trustworthiness needs to be explored. Literature suggests a trustworthy actor as someone who is able, willing, and consistent in not exploiting the trustee's vulnerability (Möllering 2006: 46) while distrust is the belief that other's interests conflict strongly with one's own. People distrust if there is a lack of knowledge, due to the absence of experiences, for example (Hardin 2002).

From a sociological or political science perspective, the police are linked to many other systems and institutions, seen as a part of the wider social system and an instrument of executive governance (Albrecht/Nogala 2001). Trust in and attitudes toward the police can be understood as the distinction between organizational and institutional trust, as already discussed in Chapter 1: Reflections on research on trust in the police. While attitudes toward the organization police are bound to concrete ideas about the work of the police, such as the correct behavior of their representatives or their effectiveness, the institution police can be seen in the light of other governmental institutions.

Another perspective suggests that trust in institutions is always linked to its representatives, whether someone has good or bad experiences with them. The public ascribes specific knowledge to them as experts. They trust them if there is a reason to believe that it will be in the representatives interest to be trustworthy (Hardin 2002). With regard to the police, this means that people have or do not have a general belief that the police, and their officers as their representatives, understand the interests of the public and consider their interests when acting. Dissatisfaction with how a police officer has behaved in an encounter, treated someone unfairly in a 
traffic control scenario, for example, may therefore lead to disappointment and/or lower trust in the police as a whole.

This chapter describes different theoretical concepts of trust in the police that highlight the analyses undertaken later on. Moreover, an overview of existing research is given.

\subsection{Trust in the police as a government institution}

Viewed through institutional approaches, the police are one institution within a larger governmental body, which may be one reason why research seldom differentiates between it and legal and political institutions. ${ }^{6}$ Results from studies that consider such a differentiation point to three characteristics. First, in Western democracies, trust in legal institutions is clearly distinct from other institutional trust. Rothstein and Stolle (2002), using data from the third wave of the World Value Survey (1995-1997), found that institutions could be assigned to three factors of institutional trust: Political Institutions, Power-Checking Institutions, and Order Institutions. While the first one includes confidence in the Parliament, Government, and Political Parties, the second one combines confidence in the Press, TV, and the Civil Service. The third and final factor describes confidence in the Police, the Army, and Legal Institutions. Results from a German study confirm such a distinction between trust in legal and political institutions in modern societies. Based on ALLBUS data - a biennially survey about attitudes, behavior, and social structure in Germany - Reuband (2012) shows that trust in the police loaded together with the courts and justice on a single factor in 2011. The other two factors summarize the federal government, the Bundestag, and political parties, and the trade unions and employers' associations. Thereafter, he additionally undertook factor analyses on the same data for the year 2008, as earlier studies had not found such a clear distinction between the three institutional forms. Results show that the distinction between the police and the courts on one hand, as well as other state institutions, on the other hand, had not

6 I Institutions play an important role not only in research within political science and sociology; criminology has also always adopted institutional perspectives within its different sectors. Moreover, criminology has its roots in the study of institutions and their impact on "law making", "law breaking", and "reactions to law breaking" (Karstedt 2010: 337). 
yet been fully carried out in 2008. Furthermore, in analyses of the years between 1984 and 1995, institutions were perceived as one-dimensional. The author supposes that the population only learned over many years to perceive institutions with specific functions within the field of law and order as independent institutions, not subject to the dictates of the political system. In light of Germany's history with the police state in the GDR and its collapse in 1989 , the reason seems obvious.

While in Germany such a clear distinction only arose within the last few years, studies cannot confirm such a clear pattern for Central and Eastern European countries (Mishler/Rose 1997). One example is the study by Mishler and Rose (2001) based on pooled survey data from the fifth wave of the New Democracies Barometer (NDB) of $1998^{7}$. The single-factor model already explained more than $40 \%$ of variance. After extracting a second factor, the first one measures trust in state institutions, such as the parliament, prime minister and/or president, courts, police, parties, and the military. The second and much weaker factor reflects trust in civil institutions: the press and electronic media, and private enterprise. According to the authors, this uniformity in institutional trust resulted from people's lack of familiarity and experience with them, as not only states themselves, but also most national institutions have only emerged since the break-up of the Soviet Union in 1989.

Studies comparing national trust levels in Western Europe support these results, revealing that trust levels are different between legal and political institutions, either within or between countries (cf. Hudson 2006: 53). Hence, in institutional research that deals with democratic countries of the West, a distinction between trust in the police and trust in legal institutions, and especially a separation from trust in political institutions, is necessary and important. In order to account for institutional perspectives and their research results, I will analyze the relationship of institutional trust in Eastern and Western Europe, before the focus is turned to the role of encounters with the police.

While trust in the police can be seen as part of other governmental institutions, confidence in the work of the police is linked to the organiza-

7 | The size of the total sample $(11,499)$ covers seven Central and East European countries (Bulgaria, the Czech Republic, Slovakia, Hungary, Poland, Romania, and Slovenia). Aside from that, two successor states of the former Soviet Union, Belarus and Ukraine, were included as well. 
tion police and their members. In the next chapter, theoretical approaches of attitudes toward the police are described more closely.

\subsection{Confidence in the work of the police: effectiveness and fairness}

In sociological literature, trust is seen either as a psychological attribute or as a feature of social relationships and social systems, explained by behavior based on actions and orientations at the individual level (Misztal 1996: 14). However, there is no consensus among social scientists about the object of trust. For some authors, trust can relate to human beings only, while things, social and natural processes cannot relate to trust as they cannot deceive or betray us (Liebsch 2010). There is also a discussion on whether only people can be trusted or if trust can also be directed toward institutions such as schools and states (Khodyakov 2007). Opponents, such as Offe (1999), argue that institutions provide incentives and options to actors. According to him, the durability and validity of their constraints can be viewed with confidence. Trust, on the other hand, can only be extended to actors and the ways in which they perform and enact their roles within institutions. In this sense, I argue that the problem lies more within the term itself than with the concept as a whole. Ullmann-Margalit (2004) makes a similar argument. She believes that the future course of institutional actions has to do with reliance and confidence, and not with trust. She says that speaking of trust in an institution means the degree of confidence in its competence and performance, confidence that the institution will continue to pursue its claimed goals, regardless of the constitution of the personnel. Hence, trusting in an institution describes the belief in the impersonality of its performance and that its goals are compatible with our interests. This differentiates it from trusting an individual, which involves the expectation of a personal attitude toward us. She concludes that talking of trust on an institutional level is a misnomer (Ullmann-Margalit 2004: 77). However, questions in opinion polls do not distinguish between the two terms "trust" and "confidence". While the European Social Survey (ESS) asks about trust in an institution, the World Value Survey (WVS) uses the notion of confidence. In the following, in line with the European Social Survey (ESS), trust in the police is understood as a global and diffuse trust in the institution police. I will distinguish it from confidence in the police. Here, opinions about the police's procedural fairness and their 
effectiveness are subsumed. In accordance with Ullmann-Margalit, effectiveness is described as the notion of confidence, as it relates to police performance. This is also in line with studies on confidence in the police that are based on a specific question about how well the police are doing their job, rather than including a global trust measure (cf. Jackson et al. 2009).

Differentiation between opinions about police's effectiveness and procedural fairness is important. On the one hand, trust in the police means believing in their ability to protect and to serve. If citizens consider the police effective in tackling crime and disturbances, they will trust them. Becoming a victim of a crime can change one's opinion of the police's ability to protect and serve, leading to a deterioration of belief in their effectiveness. On the other hand, fair treatment by the police enhances satisfaction with the criminal justice system (Jackson et al. 2011b).

The behavior of an officer is indicative of his trustworthiness. The concept of procedural justice derived from social psychology elaborates on such behaviors in encounters between the public and officials, showing how important the perceptions of people in contact with the legal system are, influencing their attitudes toward them.

\subsubsection{Theories of procedural justice}

Studies of justice deal with motivations rather than focusing on police's effectiveness in fighting crime. For several years, research on distributive justice dominated the field, based on theories of social control and instrumental issues, dealing with fairness-oriented responses to outcomes. Social control perspectives argued that the use of threat or the application of sanctions are the best options to pressure people into following laws and accepting decisions by authority figures, such as police officers. The police were therefore seen as sufficiently empowered to secure public compliance with decisions, also with unsatisfactory or restrictive ones. The motivation for people to comply was simply based on the risk of being punished when not following the rules. In addition, as people were seen to react to the costs and benefits associated with accepting a decision, they were expected to comply, as the costs otherwise would be too high. It can be said that the strategy depended on creating potential additional costs for the person that outweigh any potential gains associated with not accepting police or court decisions (Tyler/Huo 2002: 7-10).

In early studies on personal experiences with the police, it was assumed that citizen satisfaction was determined largely by instrumental 
concerns such as the favorability of outcomes. The focus was primarily on economic aspects, such as how the police handle situations of criminal victimization, such as after a burglary. Alternatively, the impact of violated expectations toward outcomes was also taken into account (Tyler 1990: 71-73). However, such deterrence approaches of social control were marked by inherent serious weaknesses. The threat of sanctions in cases of non-compliance with the law required overall surveillance and control. Due to the variety of offences, the detection of illegal behavior and rule breaking has become more difficult. Illegal activities are difficult to discover, as they are not visible, such as drug dealing. Moreover, they often happen outside the public space. Applying sanctions becomes expensive and is even impossible in certain circumstances, while a voluntary compliance of rules and deference to legal authorities and their decision is less costly and easier to establish. This can more easily base on police's ability to gain consent and cooperation (Tyler/Huo 2002: 11-14). Broad acceptance of process-based approaches was therefore only a matter of time. In contrast to deterrence approaches, psychological models emphasize people's concerns with fairness when dealing with legal and political authorities. Like normative theories, such models view people as concerned with their ethical judgments about what is right or wrong (Tyler 1990: 71-73). Moreover, whether or not people feel in control of the situation, of the process or the decision made by a police officer, is central. People's judgment of the fairness of a procedure depends heavily on such feelings of control (Lind/Tyler 1988: 119). Research on procedural justice - also called procedural fairness - originally focused on dispute resolution in law. In the field of social psychology, Thibault and Walker first used the term "procedural justice" in 1975. They referred to social psychological consequences of procedural variation, with particular emphasis on procedural effects on fairness judgments (ibid: 6-7). Process-based models encourage voluntary deference to legal authorities with the goal of facilitating cooperation and consent. Moreover, decisions should be accepted voluntarily, based on the fair behavior and good faith of police officers and court representatives. The advantages of such process-based policing are twofold. First, it increases people's willingness to cooperate with and consent to the decisions of police officers and judges. Second, it lessens the likelihood of open defiance of these authorities or secret non-compliance with their decisions, and simultaneously decreases the likelihood of hostility toward legal authorities by lowering the risk that individuals will act aggressively 
(Tyler/Huo 2002: 2). Two perspectives can be differentiated between within the procedural fairness approach: an instrumental perspective and a normative one. On the one hand, the instrumental perspective suggests that assessments of procedural fairness are based on outcomes. People believe that a procedure is fair when they have control over decisions. The normative perspective, on the other hand, argues that there are aspects of people's experiences other than outcome; the focus is more on the procedures itself. Here, a feeling of lack of control leads to a perception of procedures as unfair (Tyler 1990: 7). Procedures are viewed as fair when people have the opportunity to explain their situation or tell their side of a story in a conflict, when they perceive the authorities as neutral, when they are treated with dignity and politeness, and when their rights as citizens are respected (Tyler 1990; Tyler/Jackson/Bradford 2013). Judgments about how hard authorities try to be fair are seen as a key overall factor in assessing procedural justice. Placing attributive motives on authorities suggests that personal qualities of authority are crucial. Furthermore, it contributes to the explanation of why people are similarly satisfied with informal forums, such as mediation, as with formal trials. In either case, by making positive inferences about the intentions of the third party, people will feel treated fairly (Tyler 1990: 151). In summary, three types of judgments influence people's reactions to their experiences with a police officer. The first one differentiates between issues of outcomes and issues of procedures; the second is the level of fairness or whether procedures are based on fairness at all; the final one addresses judgments involving issues of justice versus judgments that do not take justice into consideration. Other than that, various attitudes affected by the experience should be taken into account as well, such as personal satisfaction or dissatisfaction with the experience, its outcome, or the procedures used. Related to this are emotions regarding the authorities one is dealing with, whether someone feels anger, for example (ibid: 74-75).

Recent research confirms that people evaluate their experiences in procedural terms. Reisig and Chandek (2001) found that the perception of how one is treated in a traffic encounter or a breaking and entering complaint has the strongest influence on citizen satisfaction with the way police handle the encounter. In their study of residents in Oakland and Los Angeles, Tyler and Huo (2002) show that process issues have an impact on trust in courts and the police. They included two types of contact: making calls for assistance and stops for questioning or engaging in a law-break- 
ing activity. Trust in police motives were measured according to an index of five items concerning the opinions of the character of the police and the benevolence of their motives. Procedural justice and trust in police motives in encounters are found to have an impact on general opinions on legitimacy of the legal authority, on trust in others in the community, and on people's identification with society. The primary factor that shaped broader opinions was the assessment of processes people experienced. While the values measuring the outcome - fairness and favorability - are rather weak, those of quality - quality of decision-making and quality of treatment - strongly correlate with trust in the police (Tyler/Huo 2002: 132-134). In an earlier study by Tyler (1990), which took place in Chicago, $70 \%$ of citizen who initiated contact with the police themselves reported that the way the police treated them was very important. Responses were less favorable when people were asked to infer how hard police had tried to be fair with them. Moreover, he found that procedural justice is more important in cases of police stops than in cases where citizens call the police for help (Tyler 1990: 83).

In encounters with the police, the quality of treatment received is more important than the objective outcome (Hough et al. 2010). Sunshine and Tyler (2003) confirm this. They found that procedural fairness measured by items such as "[the police] treat everyone in your neighborhood with dignity and respect" (Sunshine/Tyler 2003: 542) was the primary driver of perceptions of police legitimacy. Distributive fairness and estimates of risk had no effect; neither did any demographic characteristic of the residents. Already, Tyler (1990) showed that procedural concerns consistently take precedence over distributive concerns. The only exception he found was satisfaction with the results of encounters, such as receiving a fine. Here, outcome issues were more important than issues of procedure. The evaluation of performance was influenced more strongly by procedural fairness than by the favorability or fairness of the outcome.

Theories of procedural justice emphasize the importance of encounters with the police in building trustworthiness. Treatment received by a police officer, whether it was perceived as fair or not, is crucial to people's judgment. The next chapter focuses on the interaction between the police and citizens in general by elaborating the role of institutional representatives. Moreover, rational choice approaches of individual trust and their role in trust in the police are presented. 


\subsection{The role of encounters}

The basic component in social interactions is expectation. Barber (1983: 9) distinguishes between three types: those of persistence and fulfilment of a natural and moral social order; role performance of those involved in social relationships as well as within the social system; and finally, the expectation that partners in interactions will carry out their fiduciary obligations and responsibilities. I will not be able to elaborate on the expectations of people interacting with the police, simply because the data that is used contains no such information. Nevertheless, role performance can be elaborated upon, which will partially be done in this chapter. Lastly, moral social order is considered in Chapter 2.5, which discusses the impact of social trust.

How can institutions in modern societies and democracies contribute to their trustworthiness? According to Giddens (1990), their trustworthiness is built on positive experiences with institution representatives. Experts representing the system encounter citizens at "access points" (Giddens 1990: 83), building the meeting ground of commitments, referring to a connection between citizens and representatives of the systems. Such encounters can be "facework" or "faceless commitments" (ibid: 79). While the first one refers to a face-to-face relationship between actors, "faceless commitments" indicate a relationship between an actor and various social groups, organizations, and institutions.

On the one hand, encounters are points of vulnerability. On the other hand, they enable building or maintaining trust. Facework commitments tend to be heavily dependent upon the demeanor of system representatives or operators, in the sense of an expected and adequate behavior. A doctor is expected to show his expertise, for example, or public transportation personnel are expected to be polite. Even when encounters between individuals or groups are not necessary intended to build trust, people are still involved at access points, through the differentiation between expert and expertise. Furthermore, mechanisms of trust in abstract systems - particularly trust in expert systems - are closely connected to the nature of modern institutions. In modern systems with a universe of events created by expert knowledge, reliance of a layperson generates a sense of security. It is a matter of a benefit-risk calculation. Institutionalization happens when social relations are "disembedded" from local contexts of interaction and are restructured across indefinite spans of time and space. Such dis- 
embedding mechanisms depend upon trust (ibid: 79). Therefore, a re-appropriation of disembedded social relations, of social relations at the access points, enables the constitution of trust in abstract systems (ibid: 88). As can be seen, encounters with police officers are important to people's trust-building process. Procedural justice theories emphasize the importance of correct treatment. When people feel treated wrongly or unfairly, their trust in the institution police as a whole is destroyed. However, to take a step backward, the interaction between a police officer and a citizen is an interaction between two people, determined by an individual trust. Rational choice perspectives define such trust between individuals as strategic. One famous representative is Russell Hardin (1992, 2002, 2004, and 2006). He distinguishes between three dimensions of trust: how individuals choose to trust, to whom they direct trust, and in which incidents they exercise trust. In other words, trust is a three-part relation: A trusts B to do, or with respect to, X. Trust is accordingly seen as an expectation and strategic calculation. Strategic trust is one of three concept of what would count as the right intentions toward the truster. The other two concepts are based on the moral commitment and the character of the trustee. ${ }^{8}$ The three concepts are seen as cognitive because all depend on assessments of the trustworthiness of the potentially trusted person. If trust is cognitive, we do not choose to trust. Rather, once we have a relevant knowledge of the moral commitments, the psychological or character disposition, or the encapsulation of the truster's interest, that knowledge constitutes our degree of trust or distrust. To say we trust someone means that we know or think we know relevant things about this person, especially about their motivations toward us. Therefore, one can mistakenly trust or distrust someone, merely because one has erroneous information about him or her. As a rule, we trust only those with whom we have an extensive rapport, sufficient to judge them trustworthy, and even then, we only trust them over a certain range of actions (Hardin 2006: 17-19).

Hardin (2002) argues that it is wrong to speak of trust in government and its institutions, as the knowledge demanded by the concept of trust is unavailable to ordinary citizens. In order to base the arguments of trust in government on the analogy of trust in individuals, trustworthiness of gov-

8 | In the following, analogous to Hardin (2006), "truster" refers to someone who trusts someone else, while "trustee" refers to the confider, the person somebody trusts. 
ernment agents and the knowledge of citizens about such trustworthiness must be considered. The central problem of the translation of individual-to-individual relationships to individual-to-group or individual-to-institution relationships is that trust in government or other institutions is based on reasons - derived from knowledge - to believe that their agents are trustworthy. However, such conditions of interactions and of knowledge are unable to be met. Still, the encapsulated interest approach can be transferred to institutional trust. Moreover, if individual trustworthiness correlates strongly with interests in individual-to-individual relations, it seems likely that it must also do so in intra-organizational relations, as they may be perceived as individual-to-individual relations in certain situations. If this is the case, the question of whether role holders in organizations are trustworthy correlates with the question of whether it is in their interest to do what they are expected or trusted to do. This interest can be seen in how their roles are designed, as individual role holders may be interchangeable. However, this may be difficult in modern institutions, as no one possesses sufficient knowledge about the large number of individual role holders. Moreover, only a few people understand agency structures and the roles within them. The solution is a form of trust called "quasi trust": Both individuals and institutions can be deemed trustworthy without people knowing and trusting them, if this is based on expectations derived from current and past actions. There is no need to understand the design of an institution in order to trust it, or to know how their structures produce correct actions by its agents. Moreover, it does not require knowledge of the agents in an ongoing relationship that could give us the bases for trust in them. Trust is generated based on the facts of the behavior, or the result of the behavior (Hardin 2002). Even if Hardin links his quasi trust to representatives' behavior, the argumentation is rather vague. He states:

"To be confident of it [the institution], we need only inductively generalize from what we think to be the facts of its behavior or even only from the apparent results of its behavior, as we inductively generalize that the winter will be cold." (Hardin 2002: 159)

Applied to trust in the police, this means that police officers, as representatives or agents, play a crucial role in building police's trustworthiness. The decision whether or not to trust an officer and the police as an organ- 
ization is simply based on the behavior of an officer. No knowledge about the laws behind a certain action and no understanding of police structures are needed in order to trust them. Hardin's concept clearly contrasts institutional approaches that link legal institutions with other governmental ones. When no knowledge about the institution and its rules is needed in order to judge the police, it is not important how well they are developed, whether the police are part of a larger governmental system, as in post-communist countries, or more or less ruled by individual laws emancipating them partly from political decisions, as in Western Democracies. What does count toward building or destroying trust in the police is the behavior of police officers, as well as the outcomes of such behaviors. The argumentation of this rather universal approach reminds us of the procedural justice theories outlined in Chapter 2.3.1: Theories of procedural justice, the core element of which is based on processes, looking at the role of fairness in procedures.

While Hardin primarily focuses on trust as a strategic calculation, Tyler and Huo (2002: 58-64) explore the other two concepts, creating a form of "motive-based trust", i.e. trust in a person's motives or character. It refers to internal, unobservable characteristics that are inferred from someone's actions. Tyler and Huo (2002) view this as an answer to the limited nature of instrumental judgments, such as those of strategic trust, where no attention is paid to intentions behind the actions, to a person's unobservable motivations and character. The authors argue that people want to understand such characteristics and motives of others, as they are seen to be influential to the future behavior of others. Therefore, inferences for other people's future actions can be made from an understanding of their behavior. However, as such motives and intentions are not observable, only the actions of others can be rated. Moreover, actions also do not communicate motivations directly. Another person's trustworthiness is rather seen as a combination of an observed behavior in a given situation, statements explaining the behavior, and general social knowledge. Still, there is always a certain amount of uncertainty about the motives and intentions underlying the actions of those one depends on. Motive-based trust is therefore linked to a state of perceived vulnerability or risk. When considering police stops, for example, those being controlled know hardly anything about the intentions behind the action. The police may be looking for a perpetrator of a crime recently committed or just be performing an ordinary control. 
Tyler and Huo (2002) see a difference to Hardin's (2002) concept of encapsulated interest in the disruption of a relationship. According to Hardin, this will lead to a disinterest on the part of the others to act in ways that meet our needs. In contrast, the concept of motive-based trust is seen as being more ethical or moral in nature, and therefore more robust. Converted to authorities, they are viewed as acting trustworthily in situations in which a person does not know whether they have acted in his or her interest ${ }^{9}$. Actions of authorities in concrete situations are therefore seen as linked to concerns other than instrumental ones, such as personal morality, professional integrity, and feelings of ethical responsibility (Tyler/ Huo 2002: 220).

Even if the argument made by Tyler and Huo (2002: 66-67) goes in a similar direction when applied to authorities, they still focus on knowledge, linking their motive-based trust to a certain expertise of officers needed in order to carry out their roles. Furthermore, they argue that police officers may have earned their authority because they developed personal relationships with people who came to know them through personal experience. This argumentation is linked to the goal of strengthening community-policing approaches and developing personal connections between police officers and the members of a community.

So far, theories of procedural fairness and of strategic trust highlight the importance of police encounters in shaping people's overall perception of the police. Unfortunately, the data that is used in the subsequent analyses does not allow for consideration of all of the aforementioned subtleties, such as police officers' motives. Nevertheless, the theoretical information given is important for understanding the role of police encounters. Next, the focus is turned on research. In the following, an overview of research results on police encounters is presented, taking into consideration aspects that later enter into analyses. The focus lies on the perception of the interaction, such as how satisfied an individual was with how police treated his or her case. I will describe why it is important to differentiate between contact where the public or victims have approached the police and encounters initiated by the police, e.g. in traffic controls.

9 | Though there are situations where someone knows that an authority is acting against a person's interests, Tyler and Huo (2002) argue that this knowledge is useless, as the involved citizen does not have the power to defend his or her interests. 


\subsubsection{Research overview}

A literature overview shows that studies from the United Kingdom and the United States dominate the field of police research. Moreover, within U.S. publications, many stem from Chicago (Tyler 1990; Rosenbaum et al. 2005; Skogan 2005; Skogan 2006). According to Schuck and Rosenbaum (2005), reasons may be found in the racial, ethnic, and socio-economic diversity of Chicago, as well as its recognized history of community policing innovation. Moreover, many efforts are underway to reform police departments, testing innovative reform and projects. However, in the meantime, research based on procedural justice approaches in particular has spread around the world. Studies exist for Ghana (Tankebe 2009; Boateng 2013), China (Wu/Sun 2009), or Australia (Murphy/Cherney 2011), just to name a few.

On average, individuals who had no contact with the police rated them more favorably than those who had contact (Homant/Kennedy/Fleming 1984; Reisig/Parks 2000). In their study conducted in three cities in Florida, Reisig and Parks (2000) show that those individuals who perceive a citizen-initiated police contact - such as a call for service or a traffic stop - as positive are more satisfied with the police than persons who had no contact with the police. Three items measured satisfaction with the police, covering the quality of police service in the neighborhood and whether or not they provided services that neighborhood residents wanted, as well as by a rating of the job the police were doing in terms of working with people in the neighborhood to solve local problems. Rosenbaum and his colleagues (2005) found no changes in attitudes due to having been in contact with the police for both police- and citizen-initiated scenarios.

\subsubsection{Differences between police- and citizen-initiated contact}

Most of the literature differentiates between citizen-initiated and police-initiated contact. Police contact initiated by citizens may concern reporting suspicious or anti-social behavior, seeking help after criminal victimization, or being involved in an accident. Police-initiated encounters may occur in traffic controls, identity checks on the street, or a violation of the law. Thus, when analyzing people's experience with police encounters and its influence on trust in them, it is important to distinguish between different kinds of contact. Moreover, depending on the type of contact, population expectations may differ. While a crime victim expects help and assistance from the police, someone stopped for a traffic control is 
annoyed at the time lost. Alternatively, in cases of violations of the law, the offender hopes that the police will treat him correctly. Since citizens ask for help and assistance when they contact the police, adequate care leads to a higher level of thankfulness (Tewksbury/West 2001). On the other hand, treatment perceived as unfair will lead to disappointment.

Studies looking at encounters between the public and the police are more numerous, often using specific questions about the type of contact as well as satisfaction with the police. Due to the frequent restriction to certain areas or cities, and with consideration for resident's relationship with local police forces, such studies only seldom use abstract measurements for investigating an overall trust in the police.

The impact of experiences on attitudes toward the police is more relevant in citizen-initiated contact than in police-initiated contact. In his Chicago study, Tyler (1990) showed that respondents generally felt less fairly treated when stopped by the police than when they called the police for help. In another study conducted in Chicago in 2001, Rosenbaum et al. (2005) found that respondents involved in negative citizen-initiated encounters developed negative attitudes toward the police, while negative police-initiated experiences were not associated with changes in respondents' attitudes. Vicarious experiences are also a factor. People adopted someone else's experiences by learning negatively or positively from them. The authors measured attitudes toward the police with an index of police performance in terms of being responsive to community concerns, preventing crime, and being polite to residents. The item measuring contact covered any form of contact, without any specification.

Another study based on the 2005/2006 Metropolitan Police Public Attitudes Survey data in London supports the finding that satisfaction rates after police-initiated contact are greater than after citizen-initiated ones. Of those stopped, searched, or arrested by the police, about $59 \%$ were satisfied with the way the police conducted themselves. The dissatisfaction rate was only $16 \%$. The validity of this result is weakened though by the fact that nearly a quarter of the interviewees chose the answer "don't know". The reasons for this unwillingness to give a clear answer remain vague. A negative attitude or dissatisfaction with the police based on repressed negative experiences is possible. Those who experienced other types of police-initiated contact reached a very high satisfaction rate of $72 \%$ (Bradford/Jackson/Stanko 2009). 
Studies that focus on contact initiated by the police include either "light" forms, such as traffic controls, or ask for any kind of contact without any specification. Reasons may be found in the fact that most of the police stops concern traffic offences, as shown in the study by Tyler (1990). Because most of the stopped citizens received at least a traffic ticket, nearly one in two were dissatisfied with the outcome. Nevertheless, nearly three-quarters of these unsatisfied people evaluated the outcome as fair and reported they deserved the ticket they received. In another study, Skogan (2005) considered two questions about police stops: having been in a car or on a motorcycle that the police stopped, and stopped and questioned by the police when out walking; a distinction not often found in studies. He proved the procedural justice thesis by showing that police fairness and politeness, as well their explanation of decisions, had an influence on the level of satisfaction. In another survey conducted in London in 2005/2006, Bradford, Jackson, and Stanko (2009) found several characteristics associated with increased chances of dissatisfaction with the police after being in contact with them. The largest influence found was whether the police took the matter seriously enough, followed by the police's response time. Overall, negative judgments were associated with negative assessments of ease of contact, wait time, whether the police took the matter seriously, and whether a follow-up took place.

Studies only seldom distinguish between local, state, or national police. One rare example is a paper by Reisig and Correia (1997), using three random samples from the same western state: one of state citizens in a geographically heterogeneous state, one of county residents, and finally one of people residing within the borders of a medium-sized city. They found no negative effect of receiving a traffic citation on the rating of police performance at the city and the county level. In contrast, at the state level, an unfavorable treatment in a traffic citation significantly lowered the likelihood of a positive evaluation of the police. For citizen-initiated contact, results were contrary: the impact of unfavorable evaluations from negative police contact experiences was lower the further away from one's immediate surrounding the policing happened. These results suggest that contextual variables are important predictors of police performance. Yet their effects differ across the three levels of policing examined. 


\subsubsection{Treatment of crime victims}

A major reason people contact the police is when they are seeking help, either to report accidents, because of disturbances, problems, suspicious activities in their neighborhood, or to report violent crimes and crimes against property (Tyler 1990). Therefore, the majority of studies focus on citizen-initiated police contact based on experiences and attitudes of victims of crimes (Bradford/Jackson/Stanko 2009). In general, as in contact initiated by the police, satisfaction with the treatment received by the police is important. Studies indicate that victims who were satisfied with how the police handled their case rated them more favorably than those who were dissatisfied (Furstenberg/Wellford 1973; Smith/Hawkins 1973; Brandl/Horvath 1991). It remains unclear whether the level of satisfaction differs between crime types. While a Swiss study reported less positive attitudes from victims of crimes against the person (Killias 1989), newer studies for England do not find any differences (Bradford/Jackson/Stanko 2009; Bradford 2010). Moreover, an early U.S. study even found that satisfaction with what the police did was the highest for victims of the most serious types of crimes against the person and lower for victims of property crime (Poister/McDavid 1978). According to the authors, this deviation from other results may be caused by their use of many more follow-up investigations for crimes against the person. In these cases, victims may more often perceive the police as showing greater efforts.

Studies confirmed that the behavior of police officers is important not only in police-initiated contact, but also in cases where the public approached the police (Skogan 1989; Brandl/Horvath 1991; Tewksbury/West 2001; Killias/Haymoz/Lamon 2007; Bradford/Jackson/Stanko 2009; Bradford 2010). In their study, Brandl and Horvath (1991), for example, investigated personal crimes and serious and minor property crimes. Results reveal a strong and dependable correlation between the degree of perceived professionalism and victims' satisfaction across all crime types. The more professional an officer was evaluated - measured according to an index of four items about officer's behavior - the greater the likelihood of victims' satisfaction. In addition, response time is also important for all groups of offences. However, the positive impact on satisfaction with the police was the strongest for personal crimes. Investigative efforts, on the other hand, were only influential in cases of property crimes. Moreover, information policy played a marginal role. Only informing victims of the actual state of investigation in cases of serious property crimes cor- 
related with their level of satisfaction with the police. Furthermore, the study confirms another aspect of the procedural justice theory: Police's willingness to give advice and to notify victims of progress in their case has a large effect on victims' satisfaction with the police. Other studies confirmed this as well (Skogan 1989; Sunshine/Tyler 2003; Bradford/ Jackson/Stanko 2009). As early as the 1980s, Skogan (1989) showed that if officers to whom victims were talking were rated as helpful, fair, polite, and informative, victims were generally more likely to perceive the police as similar to them and rate their job performance high.

In Switzerland, victims accuse the police of improper behavior less often (Schwarzenegger/Loewe-Baur 2014). Hence, sources of victims' dissatisfaction with the police may be based on other factors. Findings from Swiss Crime Surveys in 2000 and 2005 show that less than every tenth victim of a robbery complains about impolite treatment. Disinterest of the police in the case is responsible for the most dissatisfaction, followed by low efforts. Results are similar for victims of burglary. Insufficient effort by the police is an especially frequent complaint by victims of assaults and threats, while they are more satisfied with the interest shown by police officers (Killias/Haymoz/Lamon 2007).

\subsubsection{Reporting crimes}

The reporting of the crime is often at the beginning of victim-initiated police contact. A positive experience with the police when reporting an offence not only affects people's trust in the police but also results in a higher possibility of reporting again (Schwind 2010). Reporting as an indicator of trust in the police depends on the gravity of the crime and its consequences. Concerning crimes against property, the reporting rate is higher the greater the amount of loss. Concerning violent crimes, possible damage to reputation, after a sexual incident for example, prevents people from reporting. Hence, the level of reporting is highest for serious crimes against property and lowest for personal crimes (Killias/Kuhn/Aebi 2011). Analyses of Swiss Crime Survey data in 1989 confirm that victims that reported a crime to the police rated them more favorably than those who withdrew charges (Killias 1989). Subsequent further analyses confirm this (Killias/Berruex 1999). However, for both crimes against property and crimes against the person, other factors are more important. The chance that a burglary is reported to the police is seven times higher in cases of large financial losses, while a rural crime scene, a male victim, 
and a positive image of the police contribute to a decreased chance of reporting a burglary. Offences against the person are reported to the police less often overall. Age and the seriousness of a crime were both found to have the largest impact on reporting: Victims 35 years and older and victims of serious crimes have an approximately fourfold chance of reporting a crime against the person compared to younger people and in cases of less serious events. Furthermore, a positive image of the police leads to a twofold chance of reporting. Reasons for reporting depend primarily on the seriousness of the crime. Since insurance companies only replace losses after a formal report, insurance coverage is the most important reason to report for burglary victims. For victims of violence, the seriousness of the crime determines likelihood to report. On the other hand, reasons for not reporting an incident to the police are low seriousness and no damage involved.

In general, a positive perception of the police and the legal system as a whole, increases citizens' willingness to report crimes (Killias/Berruex 1999; Kääriäinen/Sirén 2011).

\subsubsection{Negative experiences weigh more}

As seen in the preceding chapters, experiences with institutional representatives are important, as they contribute to their level of trustworthiness. Particularly the form of treatment, whether someone perceives it as fair or not, plays a crucial role in shaping people's attitudes toward the police. Whether someone is treated fairly and respectfully by a police officer during a traffic control, for example, can directly affect the rating of such a contact, whether someone is satisfied with how the police have dealt with the case or not. Confirmation is provided by the study by Frank, Smith, and Novak (2005), which used open questions in order to find out which attitudes determine satisfaction with the police. While asking people who had been in contact with the police in the last six month preceding the survey, they found improper police behavior and factors related to the outcome of an encounter were most telling in people's general statements about how satisfied they were with the police as a whole.

A negative experience not only leads to dissatisfaction, but may also destroy trust. Study results on the impact of experiences are divided. While some studies show positive effects of positive contact, others largely report negative effects of negative contact. Finally, there are studies where the outcome is negative, independently of the rating of the contact. Correia, 
Reisig, and Lovrich (1996) found that contact with the police perceived as negative decreased the likelihood of positive perceptions of state police, regardless of the type of initiation (voluntary or involuntary). The variable measuring attitudes toward the police was directed toward state police, respectively to their performance on the job. The study by Schafer, Huebner, and Bynum (2003) also confirms a negative effect. Either through voluntary or involuntary interactions, citizens who were dissatisfied with the contact they had with the police showed less positive perceptions of traditional police services. Schafer, Huebner, and Bynum measured attitudes toward the police according to global satisfaction with police services (overall satisfaction with police service in neighborhood), satisfaction with traditional police operations (two items about the department's ability to provide traditional police services), and satisfaction with community police operations.

The impact of positive and negative experiences on trust and attitudes toward the police differs in weight: Negative effects are weighted more heavily than positive ones. This asymmetry hypothesis was tested and proven by Skogan (2006), among others. Skogan found in a neighborhood study in Chicago that, among self-initiated contact, the linear regression coefficient associated with a negative experience was more than twenty times that of a positive experience, in the opposite direction. Contrary to this, for being stopped by the police, the coefficient for a bad experience was only four times that of having a positive experience. Negative experiences therefore lead to more serious negative outcomes concerning trust in the police in cases of contact initiated by individuals. Altogether, having a negative experience is four to fourteen times more influential than having a positive experience, for either police- or citizen-initiated contact. However, it should be considered that confidence in the police here refers to the neighborhood police only.

As correctly supposed by Skogan (2006), other studies, such as those by Reisig and Parks (2000), show similar results. The negative effects of negatively rated stops were much higher (about six times) than those of the positive effects of positively rated stops. The same applies for the values of dissatisfaction and satisfaction related to calling the police. The discrepancy is lower, however (the values for dissatisfaction are about twice as high than those for satisfaction). Bradford (2011) partly confirms the asymmetry hypothesis. Using pooled data from all waves of the British Crime Survey (BCS) between 1984 and 2005/06, he finds a strong asym- 
metry in the effect of different levels of citizen satisfaction on attitudes toward the police in 1992, but a growing positive effect over the years. According to him, this must still be viewed in the light of an overall decline in the number of interactions.

Negative impacts of unfavorable experiences with the police on attitudes toward them holds true for Eastern European countries as well. However, several studies deal with countries marked by very low levels of trust in the police, such as Russia or the Ukraine (Beck/Chistyakova 2002). In Russia, for example, the already very negative image of the militsiya is further damaged by their impolite behavior (Zernova 2012).

Another factor responsible but not taken into account very often in studies is the attitude of citizens toward the police before coming into contact with them. Existing studies show that previous attitudes influence the evaluation of interactions with the police (Rosenbaum et al. 2005; Bradford 2010; Gau 2010; Myhill/Bradford 2012). In their 2001 Chicago study, Rosenbaum et al. (2005) showed that negative attitudes in the first wave were associated with negative citizen-initiated police contact. In addition, they were associated, in turn, with negative attitudes toward the police in wave two. Such a correlation could not be proven for police-initiated contact. Furthermore, Gau (2010) confirms the inter-temporal stability of attitudes toward the police. However, she also shows that the perceived quality of contact remained strong after controlling for attitudinal stability. In a newer panel study, Myhill and Bradford (2012) also compare the impact of police- and citizen-initiated contact. The use of two waves of panel data allows them to test for previous opinions preceding police-initiated contact. People who rated the police poorly in wave 1 were less likely to be satisfied and more likely to be dissatisfied with the police encounter. However, the difference was only statistically significant in the case of highly dissatisfied answers. Satisfaction with the contact was not influenced by the prior opinion of the respondents, as over half of those with an original negative statement were satisfied with the police contact later on. A comparison with those respondents who rated the police as fair in wave 1 shows that those with low levels of confidence were more likely to judge police contact negatively later on, while those with high levels of confidence were not more likely to judge them positively. Testing the asymmetry thesis in linear regression models, the authors further show that experiencing a police-initiated contact is entirely asymmetrical: Satisfactory interactions had no positive association with confidence, while un- 
satisfactory interactions had a significant negative statistical effect. This was not entirely the case in contact initiated by victims. Even if the effect was also asymmetrical with unsatisfactory contact, having a large negative effect on opinions of the police, the overall effect was smaller for satisfied victims. The authors follow that this positive impact - even when it is weaker than the negative effect - should not be ignored and that positive experiences are also important. For Switzerland, some local studies confirm the positive impact of positive police encounters on attitudes toward them (Roux 1991: 25; Biberstein 2010), but do not give information about possible negative impacts.

Overall, studies suggest a strong influence of bad experiences on negative ratings of the police and a low effect of positive experiences, primarily for victim-initiated police contact. However, it seems that police and citizen encounters often overlap. In the study by Skogan (2006), for example, more than one in two people stopped by the police contacted them about some matter over the course of a year.

\subsubsection{Individual influences: socio-demographic and other factors}

Socio-demographic characteristics, such as age, gender, income, or belonging to an ethnic minority, have an effect on people's attitudes toward the police. Individual characteristics are important because they directly relate to the frequency of police stops or whether people call them for assistance. Moreover, such characteristics are reasons for different or harsh treatments given to people in encounters with the police.

\section{Gender and age}

The influence of age and gender on being stopped by the police is not widely addressed in research, as the focus is more on the impact on trust in the police. In most of the studies, females are found to have a higher trust in the police than males (Percy 1980; Brandl/Horvath 1991; Cao/Frank/ Cullen 1996; Schafer/Huebner/Bynum 2003; Wu/Sun 2009). Studies rarely find that women have a deeper trust in the police than men; more often the reverse is true (cf. Correia/Reisig/Lovrich 1996). The expected greater positive attitude toward the police by women is partly explained by the fact that the police stop men more often than they stop women. This is because men have different leisure activities and are more often involved in criminal activities. Skogan (2005) proves that the distribution and frequency of stops by the police are strongly related to demographic 
and social factors of stopped people. Close to $30 \%$ of males but only $12 \%$ of females indicated that the police stopped them over the course of a year. Bradford, Jackson, and Stanko (2009) in their 2005/2006 London survey of 2005/2006 confirm this result. Finally, also Jackson and colleagues show that the police stop men more often than they stop women (Jackson et al. 2012).

A similar picture can be seen for youth: Young people are more likely to get into trouble of all kinds with the police, including stops and arrests. Moreover, they are more likely to become victims of violent crimes. Reisig and Correia (1997) further propose that age differences in opinions of the police reflect the value attached to freedom and autonomy of younger people, versus safety and security of elderly people. Skogan (2005) shows that there is a lot of variation within younger people concerning police stops. While the police stopped approximately only every fifth 34-year-old, the number increases with declining age of respondents. Bradford, Jackson, and Stanko (2009) found the highest percentage of police-initiated contact for 15 - to 24 -year-olds and the lowest for groups of $55^{-}$to 64 -yearolds and those older than 65 years. Jackson and colleagues also reveal that the younger Londoners are, the more frequently the police stopped them (Jackson et al. 2012). It comes as no surprise then that several studies found young people to have less favorable opinions of the police (Percy 1980; Brandl et al. 1994; Cao/Frank/Cullen 1996; Correia/Reisig/Lovrich 1996; Reisig/Correia 1997; Cao/Stack/Sun 1998; Schafer/Huebner/Bynum 2003; Wu/Sun 2009; Gau 2010).

Bradford (2011) raises an interesting point in his study about the development of citizen contact and confidence in the police in Great Britain between 1984 and 2005/06. He shows that, over the years, differences between gender and trust in the police, on the one hand, and between age groups and trust in the police, on the other hand, diminished sharply. The gap between age cohorts shrank until 2003/04, where very little variation in the proportion of very good ratings of local police work remains. This was predominantly caused by a reduction in trust amongst the oldest age group rating the police very positively in earlier years. A similar pattern is reported for Germany. Reuband (2012) found diminishing effects of age between 1984 and 2011. In addition to the results found by Bradford, the effect even changed in the other direction. While in 1984 trust in the police grew with age, citizens' trust in the police diminished in 2011 the older people were. A fundamental change in the relationship of citizens to the 
institutions may be one reason for this astonishing trend. This argument is supported by the fact that such a trend was reported for other German institutions as well.

\section{Belonging to a minority}

A large body of research deals with possible correlations between the police and minority groups. Several studies for United Kingdom and the United States confirmed that African Americans and other minorities have a more negative perception of the police than Caucasians (Furstenberg/Wellford 1973; Correia/Reisig/Lovrich 1996; Reisig/Correia 1997; Tuch/Weitzer 1997; Tyler 2001; Brown/Benedict 2002; Schafer/Huebner/ Bynum 2003; Rosenbaum et al. 2005; Schuck/Rosenbaum 2005; Weitzer/ Tuch 2005; Jackson et al. 2012). African Americans are more skeptical in their opinions of the police and report negative contact and even mistreatment by the police more frequently (Skogan 2006). In the study by Skogan (2005) in 2001, the police had stopped African Americans and English-speaking Latinos about ten percent more often than Caucasians during the past year. In another study conducted in Chicago, Rosenbaum and colleagues show no statistically significant racial and ethnical differences among the first sample, but more reported negative attitudes by African Americans and Hispanics in a sample of the second point of measurement (Rosenbaum et al. 2005). Moreover, vicarious experience had an influence as well. The authors asked the respondents whether they had heard about someone having a good experience or bad experience with the Chicago police in the past year. Compared to Caucasian residents, both African Americans and Hispanics reported fewer positive and more negative vicarious experiences with the police (ibid).

Results of the study by Weitzer and Tuch (2005) reveal a much lower level of satisfaction with city police amongst African Americans and Hispanics than amongst Caucasians. A similar pattern exists for satisfaction with the police in respondents' neighborhoods. The discrepancy in satisfaction between African Americans and Caucasians remained after controlling for demographic variables such as age. In addition, neighborhood safety and crime rates diminished the influence of race as well.

For United Kingdom, results from the study by Jackson and colleagues show that belonging to any of the included ethnic minority groups is associated with a higher chance of getting stopped or searched by the police compared to being a Caucasian (Jackson et al. 2012). 


\section{Other socio-demographics}

There are further socio-demographics found to have an influence on trust in the police not directly related to police stops. Such factors include education (Frank/Smith/Novak 2005; Kääriäinen 2007), income (Poister/ McDavid 1978; Cao/Frank/Cullen 1996), political orientation (Cao/Stack/ Sun 1998), religiosity (Schwarzenegger 1992), marital status (Poister/McDavid 1978; Cao/Stack/Sun 1998; Skogan 2005), and place of residence. Skogan (2005), for example, showed that education, marital status, and income correlate with the frequency of police stops. For Switzerland, Schwarzenegger (1992: 248) found a more positive attitude toward the police in Zurich amongst Catholics and members of other churches than amongst Protestants. People declaring themselves as nondenominational showed the most negative attitude. Kääriäinen (2007) reports that people living rurally have a lower level of trust in the police compared to those living in big cities.

Finally, citizens' leisure activities are also taken into account. Routine-activity and lifestyle approaches focus on victimization risk (Hindelang/Gottfredson/Garofalo 1978; Cohen/Felson 1979). People spending more time outside their homes, e.g. going out more often at night, have a higher chance of becoming a victim of a crime. Such a pattern may be transferable to citizen-police interactions; citizens meeting with friends at an above-average frequency may have a higher chance of being stopped or approached by the police. Furthermore, in a multilevel study, Kääriäinen (2007) showed that people meeting with others once or several times a week have a higher trust in the police compared to those going out only once a month or less often.

\section{Life satisfaction, criminal victimization, and fear of crime}

In addition to individual characteristics, such as socio-demographic features, one should not forget to control for individual well-being. People's trust in the police may have deteriorated after they became the victim of a crime. Furthermore, fear of something can create a lack of trust. Hence, criminal victimization and fear of crime may lead to a reduced trust in police's ability to fight crimes. On the positive side, satisfaction with life leads to an optimistic view of the world, a perception that the future will be better than the past (Uslaner 2002: 81). Happy and optimistic people are therefore expected to have a higher trust in the police and rate police interactions more positively than frustrated and unhappy people. 
The primary body of police studies focusing on criminal victimization and trust in the police are based on a procedural approach, looking at the victim-police interaction (see Chapter 2.4.1.2: Treatment of crime victims). In addition, several studies report negative impacts of victimization on attitudes toward and trust in the police (Poister/McDavid 1978; König 1980; Percy 1980; Killias 1989; Schwarzenegger 1992: 245; Cao/Frank/Cullen 1996; Kusow/Wilson/Martin 1997; Oskarsson 2010; Bradford 2011).

Fear of crime is expected to go hand in hand with lower trust in the police, linked to a lack of trust in their ability to fight crime (Cao/Frank/ Cullen 1996; Weitzer/Tuch 2005; Jackson et al. 2009). Such perceptions are rooted in criminal victimization experiences, amongst others. The victimization perspective implies that a person who became a victim of a criminal act develops a deeper fear of the same crime than someone who did not experience such an incident (Boers 1991). The assumption was proven for crime that is closely related with feelings of security at night in residential areas, such as robbery and sexual offences. However, in multivariate studies, when controlling for socio-demographic variables, effects were only marginal (ibid). This weak or non-existent link often found in studies may be caused by the fact that fear of crime accompanies a less risky lifestyle and therefore indirectly less risk. Such a link is difficult to discover, due to the cross-sectional character of crime surveys (Killias/ Kuhn/Aebi 2011). The fact that victims develop avoidance strategies supports the assumption that lifestyle and fear of crime are connected. Hindelang, Gottfredson, and Garofalo (1978) show that even though personal experiences with crime appeared to have an effect on perceptions of crime in one's immediate environment, such experiences did not eliminate the tendency to view crime as more of a problem non-locally than locally. Also, when looking at the impact on people's behavior, they found that victims report that they limited or changed their activities slightly more often. These differences became greater as the frames of references for the questions moved closer to the respondents personally. Further studies also show that repeated victimization has a positive impact on fear (Skogan 1987).

Satisfaction with life as a whole can be seen as a macro variable, linked to country-level characteristics, such as a functioning government, democracy, or social system. In contrast, numerous studies show that the individual situation determined by marital status, income, but also by negative experiences, such as a criminal victimization, plays a role (cf. Staubli/ 
Killias/Frey 2014). Three basic types of well-being can be differentiated between when treating life satisfaction as an individual trait. The shortterm reaction to pleasant experiences is affective. Eudemonia, in contrast, captures the normative philosophical idea of a good life. Finally, life satisfaction is an intermediate notion. It goes beyond immediate and affective reactions and has a cognitive element, as individuals are asked to consider how they subjectively evaluate their life as a whole (ibid). It follows that life satisfaction can have a moderating effect on interactions with the police. Happy people have a more positive attitude in general and therefore generally evaluate other persons more favorably. Furthermore, people satisfied with their life were found to have a more positive attitude toward the police in Japan and America (Schwarzenegger 1992: 247; Cao/Stack/Sun 1998).

\subsection{The impact of social trust}

Institutional trust is closely linked to individual trust, which is an elementary part of social life. It navigates a society's behavior and leads to reduced social complexity (Luhmann 2000: 93). Moreover, individual trust influences people's opinion of the performance of governmental institutions (Misztal 1996: 245). In addition to this direct link between individual and institutional trust, the importance of experiences with the police on people's perception of them were outlined in the preceding chapters. In accordance with approaches of strategic trust, the relationship between police officers and people in contact with them was described. Such a strategic form of trust refers to "particularized trust", a trust toward people someone knows personally (such as family members, friends, neighbors, and co-workers). Differentiated from this is "generalized trust", a rather abstract attitude toward people in general, beyond immediate familiarity. It includes strangers, such as people randomly met in the street, fellow citizens, or foreigners (Freitag/Traunmüller 2009). General trust, as linked to a group rather than an individual behavior and embedded in the social relations that occur between people, is called social trust (Welch et al. 2005). Social trust is therefore situated between individual and institutional trust. In this book, contrary to such a broadening in the definition by Welch and colleagues, social trust is understood as an individual trait. It is measured as general trust in unknown others, in their fairness and helpfulness.

In the sense of encapsulated interests (Hardin 2002), people have clear opinions and expectations of trustees. As this concept is directed 
toward trust in known individuals, Hardin admits difficulties in translating his rational concept toward individuals' trust in institutions (ibid). Other proponents point to the independence of trust from experiences. Even though Eric Uslaner (2002: 14, 17) does not deny that trust in fellow man can stem from interactions and therefore from experiences, he favors a "moral" trust, based on optimistic views of the world and a sense that we can make it better. Trust instincts are developed early in life with parents as teachers and are stable over time. As an opponent of strategic trust concepts, he argues that moralistic trust is not primarily based upon personal experiences, as it does not make sense to judge most people based on a few actions, particularly when they are of minor consequences. Moral trust can be seen as a dictate to treat others well, even in the absence of reciprocity. Values are not separated from experiences, but largely resistant to the difficulties of daily life. Trust must be learned, not earned.

Optimism, the base of generalized trust, has four components: a view that the future will be better than the past, the belief that we can control our environment to make it better, a sense of personal well-being, and a supportive community. People who are happy in their personal lives are more likely to have a positive attitude toward strangers, as their personal mood will translate into a more generalized sense of optimism (Uslaner 2002: 81). Uslaner (2002: 26) sees his distinctions as similar to Putnam's "bonding" and "bridging" of social capital: bonding with friends and people like us, but bridging with people who are different from ourselves. This implies that the central distinction between generalized and particularized trust can be found in how inclusive the moral community is.

Generalized trust as a two- or even one-part relationship must be a matter of relatively positive expectations of the trustworthiness, cooperativeness, or helpfulness of others. It gives a sense of running little risk when cooperating with others, so that we may more readily enter into relationships with them. The term "generalized trust" is just a claim that it makes sense to risk entering into exchanges even with those one cannot claim to trust in the encapsulated-interest sense, as no on-going relationship exists yet. It is not a claim that one trusts others but that one has optimistic expectations of being able to build relationships with certain others (Hardin 2002: 61-62). Several authors describe the importance of (generalized) trust. According to Simmel (1992: 393), trust can be seen as one of the most important synthetic strengths in a society. The necessity of trust is the reason for rules of correct behavior. If chaos and paralyzing fear are 
the only alternatives to trust, people need to trust each other (Luhmann 2000: 1). Trust as a positive expectation regarding other people's actions and intentions is seen as the basis for reduced social complexity (ibid: 93) and the building of social capital (Putnam 1995), amongst others.

Above all, the truster has to be seen as embedded in systems and structures consisting of social relationships, rules, and resources that can have strong constraining and/or empowering influences on him (Möllering 2006: 50). People who share the same norms and values belong to the same living environment (Lebenswelt). Living environment is defined as the area of reality seen as given, with every issue that is experienced as unquestioned and unproblematic. It is one part of a plurality of realities, taken for granted, and unquestionable. However, the consciousness of such realities is intentional and able to transfer from one reality to another. Through inter-subjective processes, an on-going correspondence about attitudes and the perception of the world between people of different realities is secured. Borders of other realities are marked via enclosed meanings and experiences (Berger/Luckmann 1974; Schütz/Luckmann 1979). When combining Uslaner's form of moral trust with such phenomenological approaches, I argue that the actions of people teaching their children a moral form of trust and the act of their children learning from them are embedded in a social world surrounding them.

Generalized trust becomes especially important with the development of modern societies, which are marked by a higher demand for cooperation in an interdependent world. Due to differentiations and segmentations of roles, the behavior of role holders has become less predictable, and role expectations more negotiable. Furthermore, due to a vast spectrum of potential choices, decisions have also become less predictable. Additionally, there is a growing anonymity and impersonality of those on whose actions personal existence and well-being depend, as well as a growing presence of strange and unfamiliar people in our environment due to migration, tourism, and travel. All these facts led to the development and necessity of trust as a form of social interaction. Moreover, trust has become a necessary strategy for dealing with institutions and organizations, also marked by a higher complexity, leading to inapproachability for ordinary people (Simmel 1992: Chapter V; Sztompka 1999: 11-14). Countries marked by a culture of optimism and openness toward others may also perceive their institutions more positively.

Gerben Bruinsma from the Netherlands Institute for the Study of Crime and Law Enforcement (NSCR) proved the importance of social 
trust within trust in justice research in his plenary speech at the 13th Annual Conference of the European Society of Criminology (ESC) in 2013 in Budapest. ${ }^{10} \mathrm{He}$ argued that more comparative research is needed within the field. According to him, trust in justice relates to other forms of trust, such as trust in political systems or social trust in fellow man, which have been hardly researched within criminology so far. Contrary to this missing link of social trust and trust in justice within criminology, individual trust is mostly bound to social capital in social science research (Welch et al. 2005: 457). This book tries to contribute to this research in order to close this gap.

\subsubsection{Research overview}

While Hardin (2002) sees social trust as related to experiences with institutions, Uslaner (2002) perceives it as independent of interactions. That social trust and trust in the police are directly correlated - independently of an experience with the police - is widely confirmed (Brehm/Rahn 1997; Kaase 1999; Newton/Norris 1999; Rothstein/Stolle 2008; Kääriäinen/Sirén 2011; Grönlund/Setälä 2012). However, study results are mixed. While some results support the arguments that generalized trust is a predictor of political trust or trust in legal institutions (Kaase 1999; Newton/ Norris 1999; Rothstein/Stolle 2008; Grönlund/Setälä 2012), others found the causation to be the reverse, with confidence in institutions influencing generalized trust (Brehm/Rahn 1997).

Results from Grönlund and Setälä (2012) reveal a clear connection between social trust and trust in the legal system. Countries marked by high social trust - measured as generalized trust - have a higher trust in the legal system than countries with low social trust. Their analyses are based on data from the second round of the European Social Survey of 2004, using 24 of the 26 countries included in the database. It is important to note that the results show a robust correlation between social trust and trust in the legal system across countries, in both Western and Eastern Europe. Rothstein and Stolle (2008) give further confirmation of a strong relationship between confidence in order-issuing institutions (the army, the police, and legal institutions) and generalized trust. Using the third wave of the 2000 World Value Survey, they view the impartiality of the

10 | "Research on Trust in the Criminal Justice System", Plenary Session III, 5. September 2013. 
institutions as the missing link. In highly corrupt countries, generalized trust is lower compared to countries with less corruption. In their multivariate model, they found that countries with high levels of generalized trust also have the most effective and impartial institutions and the longest running experience with democracy, as well as the most egalitarian socioeconomic outcomes.

Not many studies have analyzed the police separately from other institutions. One that has is Newton and Norris (1999). They analyzed pooled data from two waves of the World Value Survey (1980-1984 and 19901993). Results show that social trust relates positively but only weakly to confidence in the police at the individual level. A stronger but statistically non-significant correlation was found at the national level. The authors argue that a systemic effect may cause this difference between the individual and the aggregate level. The positive association between social trust and confidence in the police was found among all countries included in the analyses. In Norway, Sweden, and Canada, high social trust goes along with high public confidence in the police. While most Nordic countries belong to the group with high trust relationships, France, Belgium, and Italy showed the opposite tendency in the 1980 os, with slightly better values in the 1990 s. In these countries, suspicion of other citizens seems to go hand in hand with minimal confidence in the police.

Two theoretical approaches treat the impact of individual trust on trust in justice differently. While Hardin (2002) links it to experiences with institutional representatives, Uslaner's (2002) moral trust is rather stable and independent of interactions. Generalized trust allows people to move out of familiar relationships in which trust is based on knowledge accumulated from long-term experience with particular people. Their optimism is transferred onto institutions, leading to a higher trust in them. In both approaches, social trust and trust in governmental institutions are linked. Therefore, both approaches are considered in analyses.

\subsection{Summary}

When analyzing police encounters, a differentiation between contact initiated by the police and those by citizens is important. Most of the studies within the field of citizen-initiated contact concern crime victims reporting an offence to the police. The impact of negative experiences with the police leading to a lower level of satisfaction and trust in them is more 
often claimed for such victim-initiated contact, while dissatisfaction with police stops seem to have lower impacts.

Within satisfaction levels, the relationship to attitudes toward the police is asymmetric in the sense that positive experiences are not weighted as heavily as negative ones. In addition, attitudes prior to an encounter also have an influence on the satisfaction level. People who already have negative attitudes toward the police before they have contact with them evaluate the contact more negatively.

Several factors have an influence on the perception of encounters and trust in the police. While males, young people, and ethnic minorities have lower levels of trust in the police as compared to females, older people, and non-minorities, criminal victimization reduces peoples trust in the work of the police. People satisfied with their life, on the other hand, are associated with having a more positive general attitude, rating police more favorably.

Finally, cultural imprints determine perceptions. Societies with high levels of social trust are marked by higher institutional trust than is the case in low-trust countries. Theories of individual trust are based on others' trustworthiness. This is established by knowledge about the actor. Applied to institutions, representatives such as police officer are the focus. Here, knowledge is seen as less important. What counts more is the behavior of institutional agents. Trustworthiness of the police is therefore based on ratings about the behavior of police officers in encounters. People are satisfied when officers are perceived as fair, treating people respectfully and explaining their situation. Satisfaction with an encounter will translate into trust toward the police. Moreover, social realities shape the perception of such encounters. In cultures with high levels of social trust, an underlying openness may have a positive effect on the rating of the contact. 


\section{Model ANd hypotheses}

The underlying model of this book consists of different parts (visualized in Figure 2). In a first step, at an aggregated level, I analyze whether trust in the police is correlated with trust in further governmental institutions (H1). Second, I measure the impact of social trust on trust and confidence in the police at the macro level $\left(\mathrm{H}_{3}\right)$. Next, the focus changes to the individual level, where encounters with and trust in the police are analyzed $\left(\mathrm{H}_{5}\right)$. While data from the European Social Survey allow testing for police-initiated contact only, data from the Swiss Crime Survey 2011 consists of victim-initiated contact as well. Therefore, in a single section, such encounters are elaborated upon separately. Also, on the individual level, the impact of governmental trust $\left(\mathrm{H}_{2}\right)$ and social trust $\left(\mathrm{H}_{4}\right)$ are considered. Finally, the impact of ratings of local police work on overall trust in them is considered (H6). Again, this context can only be tested according to data from the Swiss Crime Survey 2011.

Figure 2: Theoretical model of trust in the police

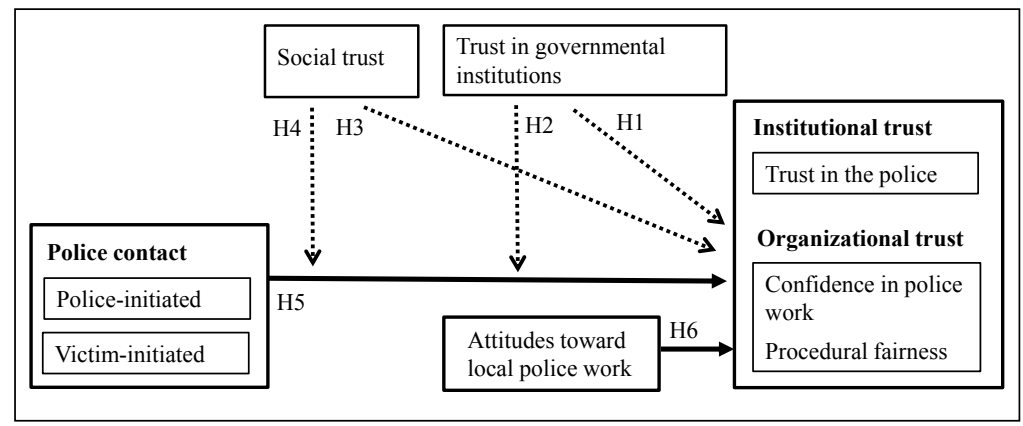

One focus of this book is to apply concepts of trust in the police across different countries. Nevertheless, most of the theories and approaches within the policing field stem from Anglo-Saxon countries. Furthermore, studies dealing with institutional trust at the macro level, comparing countries, often use data records from Western Democratic countries. Contrary to this, there are a few studies that focus on post-communist countries, expanding the development of institutional trust in Eastern Europe after the fall of the iron curtain (cf. Mishler/Rose 2001). Therefore, Eastern European countries are compared with Western. Furthermore, single analyses 
for Switzerland shed light on the impact of social trust and police encounters on the perception of them in a Western European country marked by high levels of institutional trust (Switzerland ranks together with the Scandinavian countries at the top end of the trust-in-the-police scale).

Based on the institutional approach, the police are seen as a segment of the state, as an instrument of executive governance. However, compared to other political institutions, the police and the legal institutions have a special task, namely to detect and to punish people who do not obey the law. Criminal justice institutions are therefore more permanent in character than other political institutions such as parliament (Rothstein/ Stolle 2002). Based on their different duties, political and criminal justice institutions are perceived unequally in Western Europe (Rothstein/Stolle 2002; Rothstein/Stolle 2008; Reuband 2012), while in Eastern Europe the police are instead perceived as part of the government (Mishler/Rose 2001). The correlation between trust in other governmental institutions and trust in the police is expected not only to exist at an aggregated level, but to persist at an individual level as well.

Assumption Trust in the police correlates to trust in other governmental institutions.

Hypothesis $1.1 \quad$ The police are perceived separately from political institutions in Western European countries, while they are perceived as similar in Eastern European countries.

Hypothesis 1.2 The higher the trust in political and legal institutions, the higher the trust in the police.

Hypotheses 2 Trust in governmental institutions affects the impact of trust in the police in cases of encounters between citizens and the police.

Studies on the relationship of social trust and trust in institutions are based on a moralistic approach, treating social trust as a rather stable cultural trait, unaffected by experiences with institutional representatives. Existing attitudes, such as negative stereotypes about the police, can affect assessment of police contact. Those people who have generally favorable opinions of the police are more likely to evaluate contact with them positively, while those with generally unfavorable opinions are more likely to give a negative evaluation (Brandl et al. 1994). When comparing countries, however, it is important to keep in mind not only the different laws 
and policies that may affect police officers' daily work, but also the possible influences on the "other side", of individuals' interaction with the police. Social realities not only shape individuals' everyday life; they play an important role at an aggregated country level as well, where they can be seen as cultural elements. The culture of a country marked by equality and openness toward officials may be an underlying factor influencing people's perception and evaluation of police contact and trust in police in general. Studies analyzing the relationship between social trust and trust in the police primarily deal with trust in the police as an institution, considering a general trust question. However, as attitudinal studies show, procedural fairness is very important in people's evaluation of the police and their trust in them. Furthermore, instrumental approaches look at the role of effectiveness. Hence, the positive impact of social trust is also expected to relate to procedural fairness and confidence in police work.

Countries with high levels of social trust have the most effective and impartial institutions, the longest experience with democracy, as well as the most egalitarian socioeconomic outcomes (Rothstein/Stolle 2008). It follows that western democracies are marked by high levels of social trust, while the former post-communist countries of Eastern Europe have a low level of social trust.

Assumption At the macro level, trust in the police is related to social trust.

Hypothesis 3 The higher a society's social trust, the higher its trust in the police, its confidence in the work of the police and in their procedural fairness.

Assumption In cases of police-initiated contact, social trust has a further impact on trust in the police on the individual level. Hypothesis 4 People's trust in the police, people's confidence in the work of the police, and people's confidence in their procedural fairness after being stopped by them improves as social trust levels increase.

The behavior of the representatives of an institution, especially in the Westernworld, is viewed as an indicator of their fair procedures, which results in trust (Jackson et al. 2011b). Research has shown that contact with the police in general, as well as the manner in which police handle a case after criminal victimization, has an impact on opinions of them 
(Tewksbury/West 2001; Skogan 2005). Interaction with the police, as either police-initiated or citizen-initiated, is a key element for affecting trust in them. The way the police deal with people has far-reaching implications concerning their trustworthiness. If people feel treated unfairly, their trust in the police will decline. Again, social realities are expected to moderate the evaluation of police contact, and subsequently people's trust in the police. Based on current research outlined in Chapter 2.4, the following hypotheses are derived:

Assumption An experience with the police has an influence on trust in them.

Hypothesis 5.1 The more favorably an encounter with the police is rated, the higher the trust in them, the confidence in their work and in their procedural fairness.

Hypothesis 5.2 The impact of unfavorable ratings on trust is stronger than the impact of favorable ones ("asymmetry" hypothesis).

Contact initiated by crime victims must be differentiated from general encounters between citizens and the police. In general, as in contact initiated by the police, satisfaction with the treatment received by the police is important. However, victims of crime are especially vulnerable and suspicious. Moreover, reporting a crime to the police should also be considered, as it is often the reason why victims get in touch with the police in first place. Moreover, research has shown that satisfaction with and trust in the police differs among offences. Thus, it follows:

Hypothesis 5.3 Victims of crimes against the person have lower trust in the police compared to victims of crimes against property.

Hypothesis 5.4 Reporting to the police does not correlate with trust in the police.

Hypothesis 5.5 Victims satisfied with how the police treated their case evaluate them better than those who are dissatisfied.

All of these hypotheses are tested according to two data sets. In the first, I undertake analyses according to data from the European Social Survey. Results for Eastern Europe, Western Europe, and Switzerland are dis- 
played together in order to enable a direct comparison. In the second, I elaborate on victim-initiated police contact more closely, based on data from the Swiss Crime Survey. Additionally, data from the Swiss Crime Survey 2011 allows for a linking of global and specific trust in the police. Based on elaborations in Chapter 1.4 I argue:

Hypothesis 6 The higher the rating of local police work in Switzerland, the higher the people's overall trust and confidence in them.

The next section presents some brief information about the data used. 



\section{Methodology}

\section{Data}

\subsection{European Social Survey 2010 (ESS2010)}

The European Social Survey is a biennial, multi-country survey covering over 30 nations. The first round was fielded in $2002 / 2003$, the fourth in $2008 / 2009$. This study will use data from the last (fifth) round in 2010/2011 (hereinafter "ESS2010"). In every round, a core module covers a certain topic. In the ESS2010, this module is about trust in justice. It refers to two important, interrelated, but conceptually distinct phenomena: trust and legitimacy (Jackson et al. 2011a). This module was created within the scope of the FP7 research project "fiducia - justice needs trust", covering several work packages. It is embedded in work package 11 called "Trust and Attitudes to Justice at Home" (European Social Survey 2010c).

\subsubsection{Sample}

The original ESS2010 data consists of 27 countries. Russia and the Ukraine were excluded from further analyses. They not only have very low levels of trust in the police, they may also be seen as special cases. On the one hand, it is currently debatable whether the (future) identity of the Ukraine is characterized by influences of the West or the East. Russia, on the other hand, can be seen as the mother of Eastern Europe, due to its history and its geographical location. Hence, it needs to be studied separately. Furthermore, no clear patterns for Mediterranean countries (Spain, Portugal, Cyprus, Greece, and Israel) were found (Staubli 2014). Therefore, the sample used for the analyses in this book consists of only 20 countries (Table 1). In addition, at the macro level, a linear relationship was detected across countries between trust in the police, confidence in the work of police, and in their procedural fairness. They scatter around 
two clusters marked by high and low trust in the police. Moreover, the two clusters can be differentiated between Eastern and Western European countries, with the exception of France and Estonia, which do not follow this pattern.

Table 1: Sample size used

\begin{tabular}{|c|c|c|c|c|}
\hline \multirow[b]{2}{*}{ Country } & \multicolumn{2}{|c|}{ Before weighting } & \multicolumn{2}{|c|}{ After weighting $^{1}$} \\
\hline & $\mathrm{n}$ & $\%$ & $\mathrm{n}$ & $\%$ \\
\hline \multicolumn{5}{|l|}{ Western Europe } \\
\hline Belgium & 1,704 & 3,4 & 901 & 1,7 \\
\hline Denmark & 1,793 & 3,5 & 453 & 0,9 \\
\hline Finland & 1,728 & 3,4 & 446 & 0,9 \\
\hline France & 2,422 & 4,8 & 5,272 & 10,1 \\
\hline Germany & 1,576 & 3,1 & 7,080 & 13,6 \\
\hline Ireland & 1,751 & 3,4 & 351 & 0,7 \\
\hline Netherlands & 2,595 & 5,1 & 1,366 & 2,6 \\
\hline Norway & 1,497 & 2,9 & 394 & 0,8 \\
\hline Sweden & 1,083 & 2,1 & 779 & 1,5 \\
\hline Switzerland & 1,506 & 3,0 & 660 & 1,3 \\
\hline United Kingdom & 1,561 & 3,1 & 5,119 & 9,9 \\
\hline \multicolumn{5}{|l|}{ Eastern Europe } \\
\hline Bulgaria & 2,434 & 4,8 & 654 & 1,3 \\
\hline Croatia & 1,829 & 3,6 & 375 & 0,7 \\
\hline Czech Republic & 3,031 & 6,0 & 901 & 1,7 \\
\hline Estonia & 1,885 & 3,7 & 114 & 0,2 \\
\hline Hungary & 1,548 & 3,0 & 854 & 1,6 \\
\hline Lithuania & 1,677 & 3,2 & 283 & 0,5 \\
\hline Poland & 1,403 & 2,8 & 3,238 & 6,2 \\
\hline Slovakia & 1,649 & 3,2 & 459 & 0,9 \\
\hline Slovenia & 2,715 & 5,3 & 176 & 0,3 \\
\hline Total & 50,782 & 100 & 51,970 & 100,0 \\
\hline
\end{tabular}

Note: Source: ESS2010

1 Population size weight; corrects for the fact that, despite the different sizes of their populations, most countries taking part in the ESS have very similar sample sizes

Cluster analyses have been performed to test whether the grouping found at the macro level can be confirmed statistically. The three dependent variables - trust in the police, confidence in police work, and trust in police's procedural fairness - were defined as the pattern criteria. As these items have a categorical or a continuous scale, rather than doing hierarchical cluster analyses, a two-step cluster analysis is preferred. There are various measures to quantify whether the cluster solution is good. In a good cluster, the distances between the elements within the cluster are close to 1, while the clusters themselves differ from one another. One measure of 
both cohesion and separation is the silhouette coefficient, ranging from -1 to +1 . For every country included in the analysis, the coefficient shows the difference between the smallest average between cluster distance and the average within cluster distance, divided by the larger of the two distances. The silhouette measure for a cluster is just the average of the silhouette measures for the countries within the cluster (Norušis 2012: 394-404). Based on this measure, the bar of cluster quality shows that the quality of the two clusters is good (results not shown here). Furthermore, it can be seen that procedural fairness is the most important item, followed by trust in the police and confidence in the work of police (the darker the color, the greater the importance, Figure 3).

Figure 3: Description of clusters

\begin{tabular}{|c|c|c|}
\hline \multicolumn{3}{|c|}{$\begin{array}{l}\text { Feature Importance } \\
0.95 \square 0.90 \square 0.85 \square 0.80 \square 0.75\end{array}$} \\
\hline Cluster & 1 & 2 \\
\hline Label & Eastern Europe & Western Europe \\
\hline Description & $\begin{array}{c}\text { Bulgaria, Croatia, } \\
\text { Czech Republic, } \\
\text { Estonia, Hungary, } \\
\text { Lithuania, Poland, } \\
\text { Slovakia, Slovenia, } \\
\text { France, Netherlands }\end{array}$ & $\begin{array}{l}\text { Belgium, Denmark, } \\
\text { Finland, Germany, } \\
\text { Ireland, Norway, } \\
\text { Sweden, Switzerland } \\
\text { United Kingdom }\end{array}$ \\
\hline Size & $\square \begin{array}{r}55.0 \% \\
(11)\end{array}$ & $\begin{array}{r}45.0 \% \\
(9)\end{array}$ \\
\hline \multirow[t]{3}{*}{ Features } & $\begin{array}{c}\text { Police is doing } \\
\text { good/bad job in } \\
\text { country (mean) } \\
3.41\end{array}$ & $\begin{array}{c}\text { Police is doing } \\
\text { good/bad job in } \\
\text { country (mean) } \\
3.79\end{array}$ \\
\hline & $\begin{array}{c}\text { Procedural Faimess } \\
2.62\end{array}$ & $\begin{array}{c}\text { Procedural Faimess } \\
2.95\end{array}$ \\
\hline & $\begin{array}{l}\text { Trust in police } \\
\text { (mean) } \\
5.10\end{array}$ & $\begin{array}{l}\text { Trust in police } \\
\text { (mean) } \\
6.90\end{array}$ \\
\hline
\end{tabular}

The size of the Western European cluster is 9, meaning that it consists of nine countries: Denmark, Finland, Norway, Sweden, Switzerland, Belgium, Germany, the United Kingdom, and Ireland. The Eastern European cluster consists of eleven countries, including: Bulgaria, Croatia, Czech Republic, Estonia, Hungary, Poland, Slovenia, Slovakia, and Lithuania. 
Due to its lower confidence in police's procedural fairness, France is included in the Eastern European cluster. Moreover, the Netherlands rate the work of their police worse compared to the other Western European countries, which is why it is listed with the Eastern Europe as well. Despite these facts, as the focus of analyses is on Eastern and Western European countries, and as the trust in the police level is at the center of the analyses, both France and the Netherlands are combined in the Western European cluster ${ }^{1}$.

\subsubsection{Variables}

The questions asked regarding trust in institutions covers trust in the country's parliament, legal system, police, politicians, political parties, the European Parliament, and the United Nations, were all measured on an eleven-point scale (see Table 4 further below). Confidence in police's effectiveness as well as trust in their procedural fairness were treated as two dependent variables. A five-point scale question was used to measure confidence in the work of police. Three questions measure procedural fairness on a four-point scale (Table 2). Response alternatives for all three procedural fairness questions are "not at all often, not very often, often, and very often". For the question about the explanation of decisions by the police, an additional answer category was given: "no one ever asks the police to explain their decisions and actions". However, this answer was not fielded in the Czech Republic or Norway and will therefore be treated as missing in the main analyses².

1 I In former analyses, France was excluded due to its outlying position. A comparison of results reveals that primary effects can be found in both clusters and that only the strength of effect sizes or numbers in correlations differs slightly. 2 | Descriptive statistics can be found in the Appendices. 
Table 2: Dependent variables ESS2010

\begin{tabular}{|l|l|}
\hline Variable & Question \\
\hline Trust in the police & $\begin{array}{l}\text { Using this card, please tell me on a score of 0-10 how much you } \\
\text { personally trust each of the institutions I read out. 0 means you } \\
\text { do not trust an institution at all, and 10 means you have } \\
\text { complete trust. }\end{array}$ \\
\hline Confidence in police work & $\begin{array}{l}\text { Taking into account all the things the police are expected to do, } \\
\text { would you say they are doing a good job or a bad job? A very } \\
\text { good job, a good job, neither good nor bad job, a bad job, a } \\
\text { very bad job. }\end{array}$ \\
\hline Procedural fairness $\quad$ Fair decisions & $\begin{array}{l}\text { Based on what you have heard or on your own experience how } \\
\text { often would you say the police generally treat people in } \\
\text { [country] with respect? } \\
\text { About how often would you say that the police make fair, } \\
\text { impartial decisions in the cases they deal with? }\end{array}$ \\
$\begin{array}{ll}\text { And when dealing with people in [country], how often would } \\
\text { you say the police generally explain their decisions and actions } \\
\text { when asked to do so? }\end{array}$ \\
\hline
\end{tabular}

Note: European Social Survey $2010 \mathrm{~b}$

Two items in the ESS data allow checking for the influence of personal experiences on trust in police. The first item asks whether someone has been approached, stopped, or contacted by police during the last two years preceding the survey. If someone had been in contact with the police, a five-point Likert-scale follow-up question took the level of satisfaction with the treatment received into account (one refers to very dissatisfied, five to very satisfied, Table 3 ).

\section{Table 3: Independent variables ESS2010}

\begin{tabular}{|ll|}
\hline Variable & Question \\
\hline Police encounter & $\begin{array}{l}\text { In the past 2 years, did the police in [country] approach } \\
\text { you, stop you or make contact with you for any reason? }\end{array}$ \\
Satisfaction with treatment & $\begin{array}{l}\text { How dissatisfied or satisfied were you with the way the } \\
\text { police treated you the last time this happened? }\end{array}$ \\
\hline
\end{tabular}

Note: European Social Survey $2010 b$

The institutional perspective views trust in the police as only one form of a wider governmental trust. It argues that the police are linked to other institutions and their performance, rather than to the performance of police's own representatives. Hence, analyses often include a combined variable of institutional items. Nevertheless, studies show that there is indeed a difference between political trust and trust in institutions issuing orders (Rothstein/ Stolle 2002; Reuband 2012). In the European Social Survey 2010, seven items of institutional trust allow checking for possible similarities (Table 4). 
Table 4: Explanatory variables ESS2010: institutional trust

\begin{tabular}{|ll|}
\hline Variable & Question \\
\hline & Using this card, please tell me on a score of $0-10$ how much you personally trust \\
& each of the institutions I read out. 0 means you do not trust an institution at all, \\
& and 10 means you have complete trust. Firstly... \\
& $\ldots$ [country]'s parliament? \\
Institutional trust $\quad \ldots$ the legal system? & $\ldots$ the police? \\
& $\ldots$ politicians? \\
& $\ldots$ political parties? \\
& $\ldots$ the European Parliament? \\
& $\ldots$ the United Nations?
\end{tabular}

Note: European Social Survey 2010b

Whether such a differentiation of people's trust in governmental institutions can be found for Western and Eastern Europe as well as whether there is a difference between the two clusters are analyzed in Chapter 7.4: The police as an arm of the government. For the preceding analyses at the macro level, I will calculate using the item trust in politics, which is based on trust in country's parliament, politicians, and political parties.

Not only is the use of institutional trust items discussed, but also the adequate application of social trust. The European Social Survey 2010 contains a social trust scale of three items on an eleven-point scale (Table 5).

Table 5: Explanatory variables ESS2010: social trust

\begin{tabular}{|c|c|}
\hline Variable & Question \\
\hline Generalized trust & $\begin{array}{l}\text { Generally speaking, would you say that most people can be trusted, or that } \\
\text { you can't be too careful in dealing with people? }\end{array}$ \\
\hline Trust in others' fairness & $\begin{array}{l}\text { Do you think that most people would try to take advantage of you if they } \\
\text { got the chance, or would they try to be fair? }\end{array}$ \\
\hline Trust in others' helpfulness & $\begin{array}{l}\text { Would you say that most of the time people try to be helpful or that they } \\
\text { are mostly looking out for themselves? }\end{array}$ \\
\hline
\end{tabular}

Note: European Social Survey 2010b

Elisabeth Neumann developed the first trust question measuring generalized trust in 1948. Since its implementation, the question has migrated from the American General Social Survey (GSS) to the World/European Values Survey (WVS/EVS) to the European Social Survey (ESS), just to name the most common. The responses are recorded either on a binary scale (GSS and WVS) or on an 11-point Likert scale (ESS) (Nannestad 2008). Despite its wide use, huge debates are ongoing about the adequate measurement of trust. The first argument is about the wording of the gen- 
eralized trust question, as it does not clarify at whom trust is aimed, in which situations, or under which circumstances (Delhey/Newton/Welzel 2011). Furthermore, ambiguous, culturally specific perceptions of the context may blur results. Consequently, possible influences of actual behavior, such as anxiety nourished by negative media coverage, should also be considered (ibid; Bjørnskov 2007). Additionally, the question seeks clarification on whether one- or two-part relations are meant (Hardin 2002). Moreover, one has to be aware that general good feelings felt at the time may provoke an affirmative answer. Unfortunately this cannot be tested with the question on hand. It would have been possible when using the binary outcome variable of the General Social Survey (cf. Alesina/La Ferrara 2002). According to Yamagishi, Kikuchi, and Kosugi (1999), the two ends of the general trust question do not represent two opposites of a single meaning. The statement that most people can be trusted includes a few people someone may not trust. Moreover, studies of trust scales have shown that trust and need for prudence constitute two separate factors.

A second argument debates the comparability of the three questions. According to Uslaner (2002), it is not adequate to use all three questions in testing the generalized trust level. The standard trust question is not the same as the question about whether most people would be fair or take advantage of one another, and whether most people would be helpful or just look out for themselves. Even if the multiple indicators of the same concept improve statistical reliability, there are crucial problems. Uslaner (2002) shows that the three questions do not measure the same thing: Saying people might be helpful is not the same thing as saying that someone trust strangers, and fairness is too ambiguous. In order to say someone is fair, more information about their values is needed, while you don't need to say that someone shares your values, just to say that they might help you out. Moreover, according to panel studies, the three questions don't display the same time trend. Uslaner (2002) gave statistical evidence that fairness and helpfulness may be less stable over time than trust in people. Another point to consider is that trust matters more when reaching out to people who are different from oneself than is the case with helpfulness or fairness. Smith (1997) shows in his examinations that the questions are answered differently when combined with certain topics. Trusting responses, for example, decline when the question is preceded by questions on crime and victimization. He concluded that the items are prone to context effects. However, several studies also indicate validity of the ques- 
tions. Ciriolo (2007), for example, examined the reliability of responses to the trust question by comparing the country's levels of trust found in the fourth wave of the European Values Survey (EVS), the World Value Survey (WVS), and in the first round of the European Social Survey (ESS). He reports a strong linear relationship between the measures of generalized trust in the three surveys. Furthermore, Uslaner (2002) shows that responses to the generalized trust question are stable over time.

Judging by the aforementioned studies, the questions appear adequate for measuring social trust. A third point of criticism can be added, however: the use of the items across countries. In their analyses, Reeskens and Hooghe (2008) found that the three items are metrically but not factorial invariant. They conclude that it is not possible to compare the country-specific means on the latent generalized concept, saying the items should not be compared across countries. They show very high social trust levels in the Scandinavian countries, lower levels in the Catholic countries of Western and Central Europe, and the lowest levels in Southern Europe. Therefore, it must be agreed that trust levels differ between regions. Different understandings may also be possible within a country. For Switzerland, however, Freitag and Bauer (2013) show that the meaning of generalized trust is the same for any of the French-, Italian- or German-speaking regions. One solution to Reeskens and Hooghes criticism is to use country clusters. A factor analysis (principal component) reveals one factor for both Eastern and Western European countries. Additional factors do not have eigenvalues larger than one and are therefore inadequate (results not shown here). However, the model adequacy is only mediocre for both clusters. The combined social trust component explains only $67 \%$ of the variance in the Western European cluster, while a slightly higher percentage can be reached in the Eastern European cluster (69\%). The individual items are significantly but only moderately strongly correlated in Western Europe, while in Eastern Europe generalized trust in particular is significantly highly related to general fairness (Table 6). Nevertheless, results from reliability analyses reveal that a combination of the three items into a scale of social trust is adequate for both Eastern and Western European countries. Results for Switzerland are similar to those in the Western European cluster, revealing one factor in a principal component analysis. Pearson's correlations are slightly smaller (Table 7), as is Cronbach's Alpha $(\alpha=.669$ ). 
Table 6: Correlations between social trust items

in Eastern and Western Europe

\begin{tabular}{|lcccccc|}
\hline & \multicolumn{3}{c}{ Western Europe } & \multicolumn{3}{c|}{ Eastern Europe } \\
\hline & $\begin{array}{l}\text { Generalized } \\
\text { trust }\end{array}$ & $\begin{array}{l}\text { General } \\
\text { fairness }\end{array}$ & $\begin{array}{l}\text { General } \\
\text { helpfulness }\end{array}$ & $\begin{array}{l}\text { Generalized } \\
\text { trust }\end{array}$ & $\begin{array}{l}\text { General } \\
\text { fairness }\end{array}$ & $\begin{array}{l}\text { General } \\
\text { helpfulness }\end{array}$ \\
\hline Generalized trust & 1,000 & $.446^{* * *}$ & $.406^{* * *}$ & 1,000 & $.563^{* * *}$ & $.497^{* * *}$ \\
General fairness & $.446^{* * *}$ & 1,000 & $.409^{* * *}$ & $.563^{* * *}$ & 1,000 & $.488^{* * *}$ \\
General helpfulness & $.406^{* * *}$ & $.409^{* * *}$ & 1,000 & $.497^{* * *}$ & $.488^{* * *}$ & 1,000 \\
\hline
\end{tabular}

Note: Source: ESS2010

Pearson's correlation coefficients; significance level: *** $p<0.001$

Table 7: Correlations between social trust items in Switzerland

\begin{tabular}{|llcc|}
\hline & $\begin{array}{l}\text { Generalized } \\
\text { trust }\end{array}$ & $\begin{array}{l}\text { General } \\
\text { fairness }\end{array}$ & $\begin{array}{l}\text { General } \\
\text { helpfulness }\end{array}$ \\
\hline Generalized trust & 1,000 & $.454 * * *$ & $.387 * * *$ \\
General fairness & $.454 * * *$ & 1,000 & $.471 * * *$ \\
General helpfulness & $.387 * * *$ & $.471 * * *$ & 1,000 \\
\hline
\end{tabular}

Note: Source: ESS2010

Pearson's correlation coefficients; significance level: *** $p<0.001$

The space between the arguments for and against a combination of the items is slim. Results from reliability tests face criticism. As a compromise, a social trust index will only be used for macro level analyses. At the individual level, the items are included individually first, testing their influence on trust in the police. Later on, in final regression analyses, the combined item is used, as socio-demographic and other variables are included in order to control for a possible different understanding of the notion of "other people" (Künzler 2013).

In addition to the mentioned explanatory variables shown above, items found to be influential as outlined in Chapter 2.4.1.5: Individual influences: socio-demographic and other factors are used in order to control for socio-demographics and other attributes such as going out. A description can be found in the Appendix A.

\subsubsection{Victims of crime}

In order to obtain information on people's experience with crime, they were asked whether they had been a victim of a crime in the last five years: "Have you or a member of your household been the victim of a burglary or 
assault in the last five years?" The question combines an offence against property with an offence against personal integrity.

Table 8: Comparison of victimization rates (burglary and assault) across countries, using different data sources

\begin{tabular}{|c|c|c|c|c|c|c|c|}
\hline Country & $\begin{array}{c}\text { ESS } \\
2010\end{array}$ & $\begin{array}{l}\text { ICVS } \\
2011^{1}\end{array}$ & ESS 2008 & ICVS old $^{1}$ & year & $\begin{array}{l}\text { Diffe- } \\
\text { rence }^{2}\end{array}$ & $\begin{array}{l}\text { Diff. 03-07 } \\
\text { Sourcebook }\end{array}$ \\
\hline Belgium & 21,7 & - & 24,1 & 19,1 & 2000 & 5,0 & \\
\hline Bulgaria & 15,8 & - & 15,2 & 14,8 & 2004 & 0,4 & \\
\hline Croatia & 4,6 & - & 6,1 & 12,8 & 2000 & $-6,7$ & 12,0 \\
\hline Czech Republic & 11,6 & - & 11,3 & 16,5 & 1996 & $-5,2$ & \\
\hline Denmark & 24,0 & 23,9 & 22,9 & 18,5 & 2000 & 0,1 & \\
\hline Estonia & 22,6 & - & 25,2 & 23,2 & 2004 & 2,0 & \\
\hline Finland & 27,1 & - & 27,4 & 13,3 & 2000 & 14,1 & -13.0 (burglary) \\
\hline France & 21,6 & - & 24,9 & 14,6 & 2005 & 10,3 & 10,0 \\
\hline Germany & 9,5 & 17,4 & 9,5 & 18,9 & 2005 & $-7,9$ & 8,0 \\
\hline Hungary & 14,2 & - & 12,4 & - & - & - & $-26,0$ \\
\hline Ireland & 12,3 & - & 17,4 & 22,2 & 2005 & $-4,8$ & \\
\hline Lithuania & 14,0 & - & - & - & - & - & \\
\hline Netherlands & 18,0 & 17,7 & 18,8 & 19,1 & 2000 & 0,3 & \\
\hline Norway & 18,6 & - & 20,2 & 15,4 & 2004 & 4,8 & \\
\hline Poland & 10,7 & - & 14,9 & 14,8 & 2004 & 0,1 & \\
\hline Slovakia & 11,9 & - & 9,3 & 15,3 & 1997 & $-6,0$ & \\
\hline Slovenia & 9,2 & - & 11,4 & 11,4 & 2001 & $-8,2$ & \\
\hline Sweden & 25,4 & 17,2 & 24,2 & 17,0 & 2000 & 8,2 & 10,0 \\
\hline Switzerland & 16,2 & 17,1 & 15,2 & 16,2 & 2005 & $-0,9$ & \\
\hline United Kingdom & 20,4 & 18,0 & 24,3 & 25,4 & 2000 & 2,4 & \\
\hline
\end{tabular}

Note: Percent of five-year prevalence rates, only countries included in Eastern and Western European cluster plus Switzerland displayed

${ }^{1}$ Added victimization rates of burglary and assault

${ }^{2}$ Either numbers from ESS2010 and ICVS2010 were compared, or the rates from ESS2008 with those of older ICVS's

As such, the explanatory power is weakened. In order to ascertain validity, results were compared with the outcome of the summarized questions of burglary and assault in the International Crime Victim Survey (ICVS) (Table 8). As for the year 2010, only data for six countries was available, results from older Crime Surveys were added, as well as results from the ESS round 4 from 2008. In order to ascertain changes in frequencies over the years, results from the European Sourcebook of Crime Statistics (Aebi/Killias 2010) were also consulted.

The rates from ESS2010 and those from ICVS2011 are similar, with the exception of Germany, where ESS2010 rates are much lower than the ones from the Crime Survey (9.5\% vs. 17.4\%). Contrary to this, Sweden 
has higher rates in the ESS2O10 (25.4\% vs. 17.2\%). While comparing the ESS2010 rates with those from ICVS2005 - for which no newer data is available - divergences are found for Ireland. In the year 2005, the fiveyear prevalence rate for victims of burglary or assault was $22.2 \%$. In the year 2011, the rate was only $12.3 \%$. When going back even further, the rates differ in several countries. Due to such a large period, an interpretation is difficult.

It can be followed that the comparison of the ESS2O10 data to those of the ICVS2011 brings to light differences for Germany (-7.9\%) and Sweden (+8.2\%). Furthermore, when comparing ESS2008 data with data from older Crime Surveys - those dating back in the 1990 s were not taken into account - the country with a difference larger than ten per cent is Finland $(+14.1 \%)$. Finally, no comparative data is available for Hungary.

Newer studies focusing on burglary show a clear declining trend for Finland since the year 2000 and in particular far lower rates compared to the other Nordic Countries, such as Denmark and Sweden, which have experienced sharp increases in burglary rates since 2005 (Sorensen 2011). This downward trend is also confirmed by the European Sourcebook of Crime Statistics (-15\% in domestic burglary, Aebi/Killias 2010: 52). However, the rates for assault also need to be considered, as the value in the ESS includes both burglary and assault. The rates in the Sourcebook show increasing trends between 2003 and 2007 for Finland (+17\%), Ireland $(+22 \%)$, and Sweden $(+25 \%)^{3}$ (ibid: 178$)$.

When comparing frequencies of the European Social Survey 2010 with those of the International Crime Victims Survey, they are too high in some and a little bit too low in other countries. This may have an impact on the results. However, as per cluster, this was only the case for certain countries; the overall impact on trust in the police may not be affected.

\subsection{Swiss Crime Survey 2011 (CS2011)}

International Crime Victim Surveys (ICVS) have been taking place since 1989 (van Dijk/Mayhew/Killias 1990). In the years that followed - 1996, 2000 , and 2005 - other ICVSs were conducted, in which Switzerland participated with larger samples. Therefore, each Swiss Crime Survey - with

3 | Rates for minor bodily injury are only displayed for a few countries. In Ireland, the rate increased $+13 \%$ between 2003 and 2007 . 
the exception of 1998 - took place at the same time as and in coordination with the International Surveys. The situation was different in 2011, where Switzerland did their survey independently, based on the original ICVS questionnaire, and not on a pared down version used by other countries. Therefore, comparisons with earlier waves of the ICVS as well as with the 2010 EU survey should be made with caution. Nevertheless, the Swiss Crime Survey 2011 could ensure a continuation (no such survey had taken place since 2005). Moreover, the redesign of the national police crime statistics (KRISTA) in Switzerland in 2009 resulted in nearly impossible comparisons between preceding and subsequent years. Through the continuation of the surveys, the Swiss Crime Survey helps to fill this gap.

\subsubsection{Sample}

The sampling was based on resident registers, which every community in Switzerland is required to keep. Based on a method developed by the Institute of Sociology at the University of Bern (Jann 2007), for the national sample, out of 318 communes representing the total Swiss population, a random sample of 199 was selected. In addition to the originally planned national sample of 2,000 interviews, the cantons were offered the opportunity to participate with additional surveys at their own cost. Furthermore, in order to enable comparisons between cities, the three major cities: Zurich, Winterthur, and Wädenswil, performed additional surveys. Subsequently, the city of Schaffhausen and the city of Neuchâtel also decided to participate as a communal subsample. In the end, the full sample consisted of more than 15,000 interviews (Table 9).

Table 9: Samples from CS2011

\begin{tabular}{|lll|}
\hline Level & $\begin{array}{l}\text { No. of } \\
\text { interviews }\end{array}$ & Region \\
\hline National & 2,035 & $\begin{array}{l}\text { Switzerland as a whole } \\
\text { Cantonal }\end{array}$ \\
500 each & $\begin{array}{l}\text { Aargau, Bern, Fribourg, Neuchâtel, Solothurn, St. Gall, Zurich } \\
\text { Cities of Zürich, Wädenswil, Winterthur, Schaffhausen, Neuenburg } \\
17 \text { communes in the Canton of Bern }\end{array}$ \\
Communal & 500 each & \\
\hline Total & 15,772 & \\
\hline
\end{tabular}

Note: Certain communes at the communal and cantonal level were randomly selected at the national level as well. Therefore, the samples of such national communes were also used for the samples at the cantonal and/or the communal level, which explains the lower number of total interviews. 
The analyses conducted for this book are primarily based on the full sample of 15,772 respondents, weighted by gender and age. However, the slight overrepresentation of certain cantons, communes, and cities will not be corrected for. As all regions of Switzerland, such as the French-, Italianand German-speaking parts are included, as well as major cities and rural areas, no large effects are expected. In order to be able to compare results with earlier years, use of the national sample is required. Results are indicated as stemming from national sample when needed.

\subsubsection{Variables}

One question asking about institutional trust was included in the Swiss Crime Survey 2011 (Table 10). Several answers were possible (coded yes/ no). The variable asking about trust in the police is treated as the dependent variable.

Table 10: Dependent variable CS2011

\begin{tabular}{|ll|}
\hline Variable & Question \\
\hline & In which public institution do you trust? \\
& $\ldots$.the government (Bundesrat) \\
& $\ldots$ the parliament \\
& ...the police \\
& $\ldots$. the court \\
& $\ldots$ none of them \\
& ...don't know/no answer \\
\hline
\end{tabular}

In addition to the questions about trust, several items cover the evaluation of police work: police surveillance, help by the police, changes in the quality of police work, and police presence (Table 11). While the first two questions consider police work in a hometown, the others are about police work in general. The question about how well the police are controlling crime in the area is termed confidence in police work, analogous to the variable in the European Social Survey 2010. 

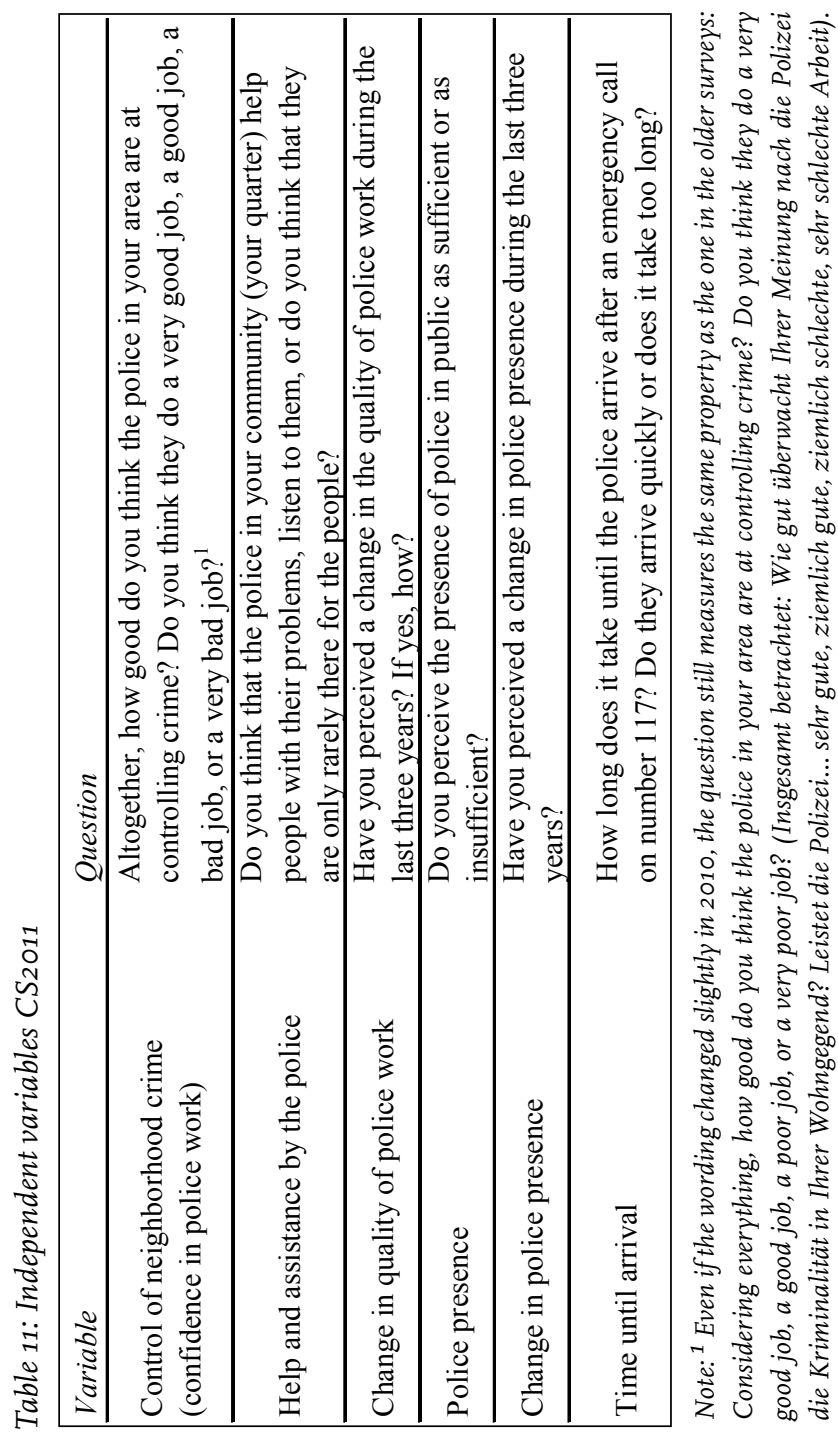

Victims of crime were asked if they had reported the offence to the police (Table 12), and if yes, whether they were satisfied with the treatment they received (Table 13). The question differs slightly from the one in the European Social Survey 2010, as it asks about the treatment of the case rather than personal treatment. This question targeted the most recent incident within the last three years preceding the survey (2009-2011). 
According to the results from prior research (cf. Chapter 2.4.1.5: Individual influences: socio-demographic and other factors), several control variables, such as gender, age, education, income, ethnicity, and religion, are considered, amongst others. Descriptive statistics for all mentioned variables can be found in Appendix B.

\section{Table 12: Criminal victimization CS2011}

\begin{tabular}{|ll|}
\hline Variable & Question \\
\hline Vehicle theft & $\begin{array}{l}\text { Over the past five years, which is since 2006, have you or other members of your } \\
\text { household ...? Please take your time to think about it. }\end{array}$ \\
\hline Theft from a vehicle & $\begin{array}{l}\text {...had any of their cars/vans/trucks stolen? Please take your time to think about it. } \\
\text {...had any of their mopeds/scooters/motorcycles /mofa's stolen? Please take your time to } \\
\text { think about it. }\end{array}$ \\
\hline theft of a part of the car, such as a car mirror or wheel?
\end{tabular}

\section{Table 13: Crime victims' attitudes CS2011}

\begin{tabular}{|ll|}
\hline Variable & Question \\
\hline Reporting to the police & $\begin{array}{l}\text { For this most recent incident, did you or anyone else } \\
\text { report it to the police? }\end{array}$ \\
\hline Satisfaction with treatment of case & $\begin{array}{l}\text { On the whole, were you satisfied with the way the } \\
\text { police dealt with the matter? }\end{array}$ \\
\hline Information policy & $\begin{array}{l}\text { Did the police keep you informed about follow up on } \\
\text { your case and the decisions that were made? } \\
\text { Should the police have done that? }\end{array}$ \\
\hline
\end{tabular}





\section{European perspective: East, West, and Switzerland compared}

\section{INTRODUCTION}

Trust in the police as either an institution or an organization, measured as global trust in the police, their procedural fairness and effectiveness, belong together. Moreover, interactions with police officers are important for establishing their trustworthiness. Finally, cultural aspects of social trust shape people's perceptions of the police and their evaluation of police encounters. In order to test the formulated hypotheses, correlations at the macro level are elaborated on in a first step. I will test whether a linearity of trust in the police exists across countries or if country patterns can be found.

Analyses that follow at the individual level first deal with the question of whether views of local police work affect people's overall trust in the institution police. As data from the European Social Survey do not allow us to answer this question, all analyses are based on data from the Swiss Crime Survey 2011. Hence, only Switzerland is focused on here. In the subsequent chapter, a short overview of the distribution of trust in the police across Europe is given. In addition, the correlation between trust in the police and trust in the wider government are analyzed. Afterwards, encounters are looked at more carefully, considering the impact of satisfaction with the encounter on trust in the police. Moreover, the impact of social trust between groups of people being stopped by the police and those without such an experience are analyzed. In a final regression analyses, all aspects found to be important so far, are taken into account. 


\section{Macro level patterns of trust in the police}

\subsection{Introduction}

Before doing analyses at the micro level, I test whether there are correlations across countries at the macro level. First, the relationship between the different trust in the police items are elaborated upon. Second, the focus is directed to dependencies between the three trust items and political trust. Third, I test whether social trust and trust in the police are correlated across countries.

For better visibility, scatters shown are based on adjusted scales rather than on the original ones. Nevertheless, in order to understand the relationships in full context, original scales are mentioned.

\subsection{Distribution of trust in the police}

In a first step, I will look at the distribution of the different trust items - trust in the police, confidence in the work of the police, and trust in police's procedural fairness - at an aggregated level. Results show that Western European countries are marked by high levels of trust in the police, trust in police's procedural fairness and in their work, while Eastern European countries have lower levels of trust (Figure 4). Amongst countries with high levels of procedural fairness, Finland stands out. Within the countries marked by lower levels of confidence in police work, the Czech Republic, Hungary, and Lithuania rank clearly lower than the other countries. While France shows a pattern of low levels of trust in the police, ranking therefore within the Eastern European country group, Estonia is on the top end of this group with moderate trust in the police. Furthermore, linear relationships are stronger for high-trust countries. Conversely, the variance is larger for countries located at the lower end of the trustin-the-police scale, which are primarily from Eastern Europe. Differences became more obvious when separating Eastern and Western European countries (not shown here). The explanation force is stronger for the Western European cluster than for the Eastern European, as the proportion of variance predictable through trust in the police is larger here. However, as all three items are seen as interdependent, analyses could have been done the other way round. 
Figure 4: Linear relationship between items of trust in the police across Europe

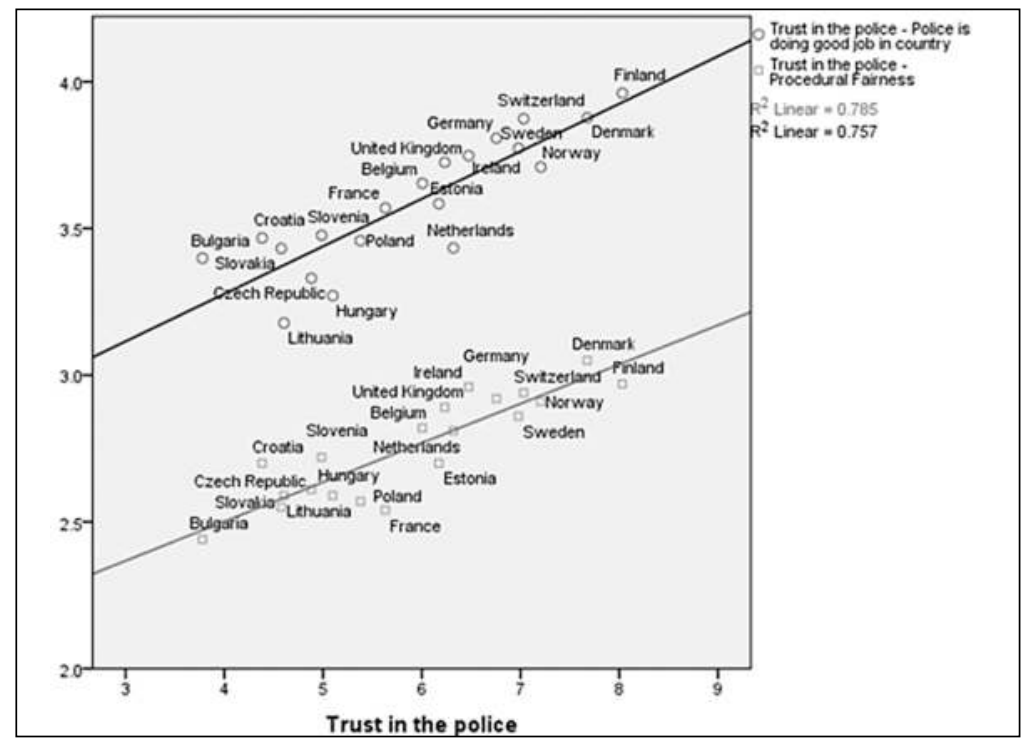

Note: Scales: Trust in the police 0-10, confidence in police work 1-5, procedural fairness 1-4

\subsection{Governmental trust}

In research on governmental institutions, the police are one institution among many. As the trust in the police item that underlies the following analyses can clearly be classified in this context, it seems important to test whether interconnectedness exists between trust in the police and trust in other institutions, such as trust in courts, the government, political parties, or politicians (subsumed here in trust in politics). When comparing clusters of Eastern and Western Europe, trust in politics in particular may have an influence on people's perception of the police. Research has shown that in Eastern Europe governmental institutions are perceived as being more similar, while people in the West differentiate more between them (Mishler/Rose 1997; Mishler/Rose 2001; Rothstein/Stolle 2002).

First analyses at the aggregated level show that trust in the police clearly relates to trust in politics, across all countries included (Figure 5). Scandinavian countries, together with Switzerland and the Netherlands, are not only marked by a high trust in the police but people also place a great deal of trust in the political institutions of their countries. However, there 
is a discrepancy in Finland, where the police are clearly trusted more than political institutions. Even though the linear relationship is also given for the other countries, all are marked by a higher trust in the police than in politics. A differentiation between the two clusters shows that the explanatory power is stronger for the Eastern European cluster, as the coefficients of determination $\left(\mathrm{R}^{2}\right)$ are higher. While the linear relationship is given for all countries in Eastern Europe, in Western Europe countries cluster around two groups: In the first group, trust in politics is lower than four, while it is higher than five in the second group (not shown here).

Results give a first hint of the interconnectedness of institutional trust items. The police are perceived as part of the wider government. The more people trust in political institutions, the more they trust in their police and vice versa. Hence, it is important to include trust in politics in further analyses. Later, at the individual level, more detailed analyses are conducted in order to get more information about this topic.

Figure 5: Linear relationship between trust in politics and trust in the police across Europe

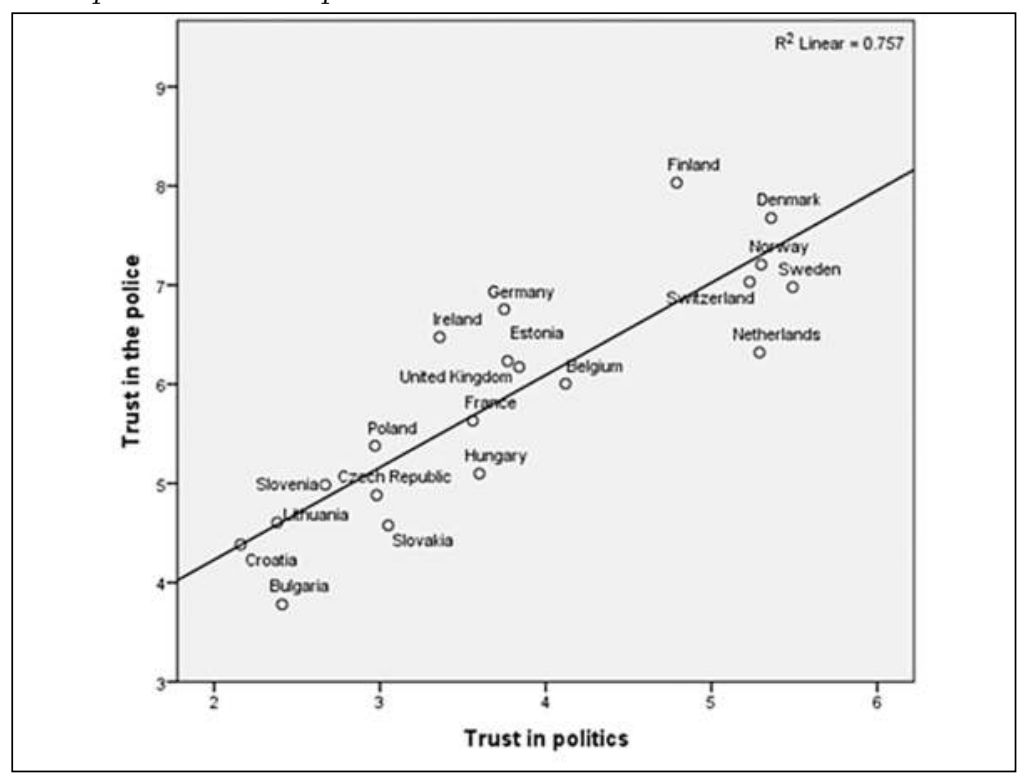

Note: Scale for both items: 0-10 


\subsection{Social trust}

Before considering encounters at the individual level, I tested whether there is a direct impact of social trust on trust in the police at the aggregated level. Results show that social trust correlates statistically significantly with trust in the police. Countries marked by a high level of social trust show a higher trust in the police than low-trust countries and vice versa (Figure 6).

Figure 6: Linear relationship between social trust and trust in the police across Europe

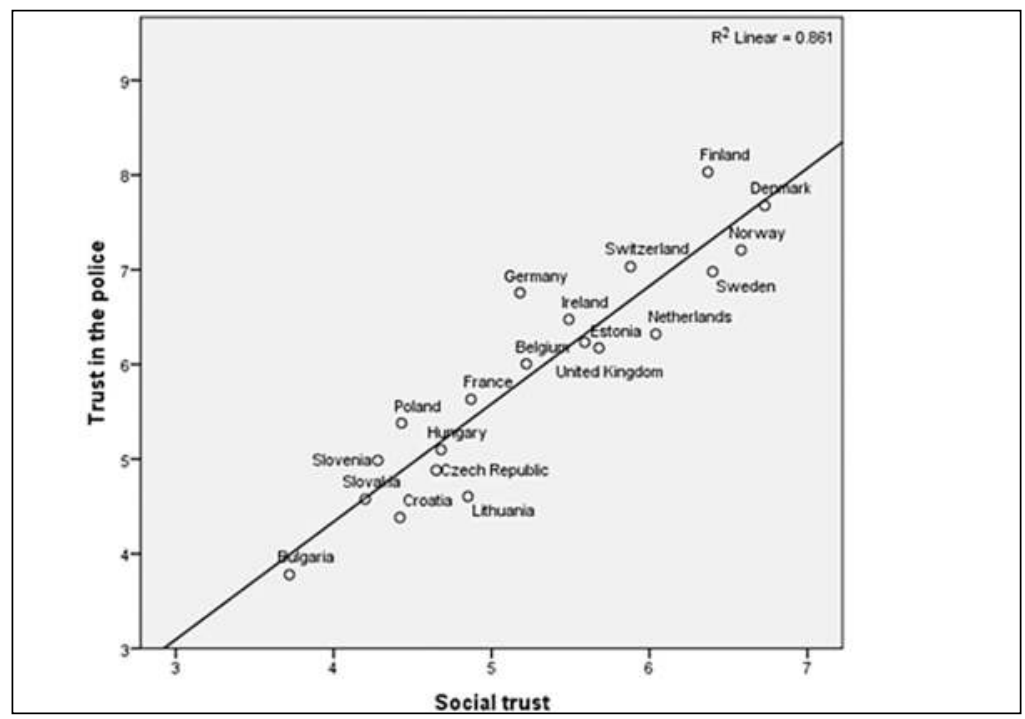

Note: Scale for both items: 0-10

The model explains $87 \%$ of the variance of trust in the police. With the exception of Bulgaria, which ranks outside the group of Eastern European countries, and excepting France and Estonia, a distinction between East and West becomes visible. Countries marked by a high social trust are Belgium, the Netherlands, Switzerland, Germany, the United Kingdom, and Ireland, as well as the four Scandinavian countries of Denmark, Finland, Norway, and Sweden. On the other hand, the Eastern European countries of Poland, Slovenia, Slovakia, Hungary, the Czech Republic, Croatia, Lithuania, and Bulgaria make up the second group of low-trust countries. France, on the one hand, is not only marked by lower trust in the police as 
compared to other Western European countries, but also by lower social trust. Estonia, on the other hand, groups within the Western European countries. Results for the split cluster reveal fewer differences than found for trust in politics in the preceding chapter (not shown here).

\subsection{Summary}

To summarize, results at the macro level show that political trust is correlated with trust in the police across countries. When doing analyses separately for the two clusters, two groups within the Western European cluster become visible: Scandinavian countries together with Switzerland are marked by a higher political trust, while the other countries are grouped around lower political trust levels. Furthermore, social trust also correlates significantly with trust in the police. In either relationship, two clusters became visible. While cluster one consists of Western European countries marked by high levels of trust in the police, high trust in politics, as well as high levels of political and social trust, Eastern European countries rank on the lower end, marked by lower trust levels. While all of the aforementioned scatterplots for social trust are based on a combined social trust item, in further analyses at the individual level, the single items of social trust are included.

\section{TRUST IN THE POLICE AT THE INDIVIDUAL LEVEL}

\subsection{Introduction}

So far, at the national level, linear relationships across Western and Eastern European countries were found for trust in the police with political and social trust. In a next step, correlations at the individual level are elaborated upon. I will start with analyses based on the Swiss Crime Survey 2011. This data includes questions about ratings of local police work, which could be combined with trust in the institution police. After that, a short description about the distribution of trust in the police across Europe is given. Next, factor analyses will test how trust in the police is related to other institutional trust items. In the last chapter, encounters initiated by the police are the central focus. After considering individual influences such as socio-demographics, I will test whether satisfaction with the treatment received by the police has an impact on trust in them. Finally, social trust is included in analyses as well. 


\subsection{Local ratings and overall trust in the police}

The study by Brandl, Frank, Worden, and Bynum (1994) showed that citizens' global attitudes toward the police affect their assessment of specific contact with the police, and assessments of specific contact affect their global attitudes. It is this aspect that is taken-up in this chapter. As I argue that police encounters affect people's trust in the police, in the following, the direction of analyzes is from "micro to macro", rather than vice versa. Unfortunately, the question of whether attitudes toward local police work may influence trust in the police in general cannot be answered with data from the European Social Survey 2010. However, the Swiss Crime Survey 2011 explicitly asked about how well the police were fighting crime in the neighborhood. When comparing such a rating with confidence in the work of the police as a whole - based on ESS2010 data - particularly the negative ratings differ (Table 14). While overall police work is rated unfavorably by only $3.2 \%$, a clear majority of people are dissatisfied with how the police are doing their job in the neighborhood (14.3\%). Since only the ESS2010 question includes a neutral answer option, this difference may be caused by the lack of this option in the Crime Survey 2011. However, studies examining the influence of such neutral options rather point to a real difference. Sturgis, Roberts, and Smith (2014) show that mostly those people who do not know the answer choose the neither/nor option. In their study, responsiveness did not change greatly when "don't know" as an answer category was explicitly given (such as in the ESS2010).

Table 14: Local and national evaluation of police work in Switzerland

\begin{tabular}{|lll|} 
& \multicolumn{2}{l|}{ Confidence in police work in... } \\
& $\begin{array}{l}\text { neighborhood } \\
\text { (CS2011) }\end{array}$ & $\begin{array}{l}\text { country } \\
\text { (ESS2010) }\end{array}$ \\
\hline Very bad & $2.4(311)$ & $0.7(11)$ \\
Bad & $11.9(1,528)$ & $2.5(38)$ \\
Neither good nor bad & & $15.7(235)$ \\
Good & $71.3(9,183)$ & $70.7(1,057)$ \\
Very good & $14.5(1,865)$ & $10.4(155)$ \\
\hline Total & $100.0(12,887)$ & $100.0(1,496)$ \\
\hline
\end{tabular}

Note: Source: ESS2010 and CS2011 (full sample)

Percent, number of cases in brackets 
When recalculating the percentages for overall confidence in the work of the police excluding the neutral answers, the difference becomes more obvious. While $85.8 \%$ rate police's work in the neighborhood as good, overall confidence reaches a total of $96.1 \%$. It follows that people differentiate between police work in general and that in the neighborhood, which is rated as less good. This may be based on personal experiences. The question about how well the police are controlling crime in the neighborhood is probably easier to answer compared to control of the crime in the country as a whole.

A good rating of the overall police work clearly goes hand in hand with an overall trust in the institution police (Figure 7). Close to $90 \%$ of those rating the work of the police in Switzerland very positively trust in the police, while about the same number $(87.8 \%)$ who give bad ratings show distrust. Similar results exist for the evaluation of police work in the neighborhood (Figure 8). Trust in the police is clearly higher amongst people who rate police work favorably. Results confirm that attitudes about local police work significantly correlate with an overall trust in the police. Consequently, Hypothesis 6, arguing that the better the rating of local police work in Switzerland the higher people's overall trust and confidence in them, is confirmed.

The last wave of the Crime Survey in 2011 allows for going beyond the question of how good the police are doing their job in the neighborhood, as detailed questions about residents' perception of police work are included. Such information might be helpful in understanding people's trust in the police. Thus, I will not omit results, but rather describe them shortly (a more detailed description can be found in Staubli 2014). Even if the majority of the Swiss population is satisfied with the presence of the police in the public, more than $40 \%$ report that it is insufficient. Especially elderly people and Swiss citizens wish for a higher police presence, compared to younger people and non-Swiss citizens. Contrary to this, assistance by the police receives very good ratings overall. About three-quarters of the population report that the police assist, help, and listen to them if they have a problem. Less than four percent are of the opinion that the police are not taking care of people.

Again, males and Swiss citizens are more critical than females and nonSwiss citizens. People are also satisfied with the time the police take to arrive on a crime scene: $43.4 \%$ report that the police are usually on site quickly, while $35.2 \%$ think that it depends on the situation. Questions about changes in police presence and their work during the last three years preceding the survey (2008 until 2010) reveal that approximately every other person has 
not perceived any changes or improvements. Around $17 \%$ even perceive a decrease in the presence of the police and in the quality of their work.

Figure 7: Confidence in national police work in Switzerland (ESS2010) and trust in the police

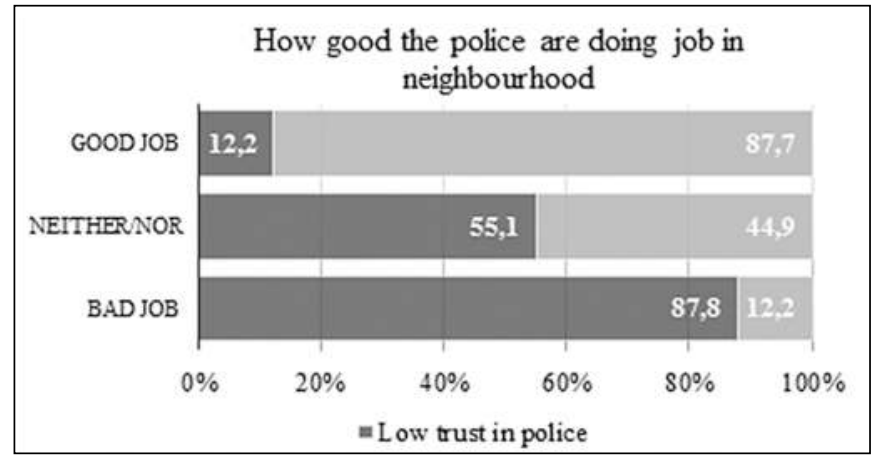

Note: Percent; total numbers: bad job $n=49$, neither $/$ nor $n=234$, good job $n=1,209$ Significance level: $p<0.001$

Figure 8: Impact of confidence in local police work (CS2011) on trust in the police

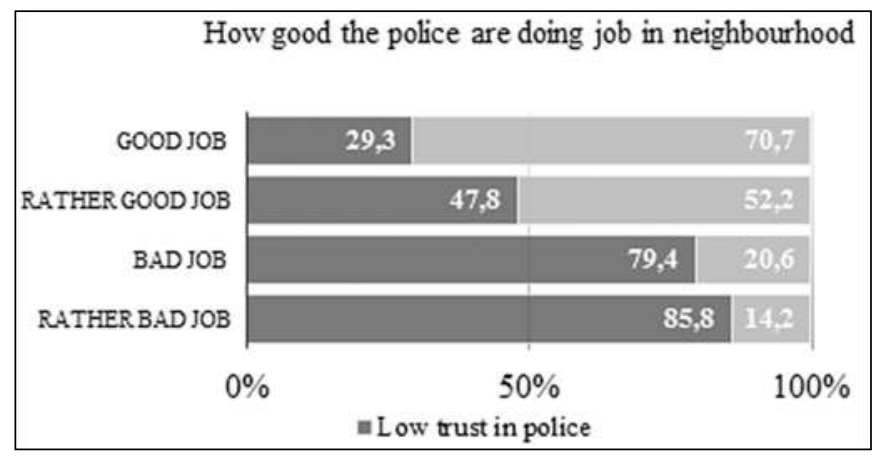

Note: Percent, total numbers: good job $n=1,865$, rather good job $n=9,183$, bad job $n=1,528$, rather bad job $n=311$; Significance level: $p<0.001$

Again, the number of non-responses is high, with about $35 \%$ not answering the question. As it was intended as an evaluation of police's visibility, based on the perceived number of police forces and officers, people who did not see, meet, or even recognize them, either as foot patrol or motorized, will understandably have problems answering this question. As for the other at- 
titudinal questions, females as well as residents that do not possess Swiss citizenship are more positive toward the police ${ }^{1}$.

All attitudinal variables mentioned correlate statistically significantly to trust in the police (Table 15). The better the rating of the police presence and the better the opinions regarding time until arrival after an emergency call, the better the overall trust in the police. Results reveal the largest discrepancy in attitudes toward the work of the police, especially their effectiveness. Less than every third person who perceives that police work has worsened considerably trust the police. Contrary to this, close to $90 \%$ of people who report a large improvement in the work of the police, trust them. A difference also exists for time until arrival, with unsatisfied people showing $24 \%$ lower trust in the police compared to satisfied people. Negative views about the presence of the police also lead to lower trust levels, but the differences are smaller compared to attitudes toward the work of the police.

Attitudinal questions about the work of the police relate closely to an overall trust in the institution police, as seen in this chapter. People dissatisfied with the presence of the police in the public and the quality of their work have lower trust compared to those who are satisfied. Such a correlation is even found for perceived changes in police presence and the quality of their work. Moreover, statistically significant correlations exist for response time, help, and assistance by the police, confirming Hypothesis 6 . Additionally, these results prove that evaluations of local police work correlate with overall attitudes toward them, confirming results in Brandl et al. (1994). Overall, Swiss citizens, men, and elderly people are less satisfied with police work, which is consistent with results found in other studies (Percy 1980; Brandl/Horvath 1991; Cao/Frank/Cullen 1996; Clerici/Killias 1999; Schafer/Huebner/Bynum 2003; Wu/Sun 2009).

1 I In this context, it is interesting to note that lawyers and representatives of the police claim that the number of police officers in Switzerland is too low (Mohler 2013). However, newer statistics show an increase in that number (Imbach/ Widmer/Tischhauser 2013). 
Table 15: Correlations between attitudes toward local police work and trust in the police

\begin{tabular}{|lll|}
\multicolumn{3}{l}{ Trust in the police } \\
& Yes & No \\
\hline Help and assistance in the community: the & & \\
police are... & $88.5(2,154)$ & $11.5(281)$ \\
...very much there for the people & $80.8(4,893)$ & $19.2(1,162)$ \\
...rather there for the people & $53.2(1,324)$ & $46.8(1,167)$ \\
...not there for the people & $30.0(112)$ & $70.0(261)$ \\
...not at all there for the people & & \\
\hline Time upon arrival & $81.9(2,781)$ & $18.1(613)$ \\
\hline The police are normally on site quickly & $56.9(949)$ & $43.1(720)$ \\
It takes too long for the police to appear & $69.6(1,916)$ & $30.3(838)$ \\
It depends on the event & $78.4(6,420)$ & $21.6(1,773)$ \\
\hline Presence of police in public & $67.7(4,143)$ & $32.3(1,978)$ \\
\hline Sufficient & & \\
Insufficient & $77.5(3,476)$ & $22.5(1,011)$ \\
\hline Change in police presence & $75.4(4,724)$ & $24.6(1,542)$ \\
\hline Increased & $63.3(1,463)$ & $36.7(848)$ \\
Remained the same & & \\
Decreased & $88.8(437)$ & $11.2(55)$ \\
Change in quality of police work & $83.9(2,012)$ & $16.1(386)$ \\
\hline Improved much & $74.3(4,333)$ & $25.7(1,498)$ \\
Improved slightly & $59.2(865)$ & $40.8(597)$ \\
Remained the same & $30.5(112)$ & $69.5(255)$ \\
Worsened slightly & & \\
Worsened much & & \\
\hline
\end{tabular}

Note: Source: CS2011 (full sample); Percent, number of cases in brackets;

Correlations for all items statistically significant $(p<0.001)$

\subsection{Distribution across Eastern and Western Europe}

There is a wide range in trust in the police amongst the selected Western and Eastern European countries, as already seen in the scatterplots in the chapters above. Results reveal the highest trust levels for the four Scandinavian countries (Finland, Denmark, Norway, and Sweden), together with Switzerland, all having a trust in the police higher than 7 on the eleven-point scale. Former post-soviet countries, such as Bulgaria and Croatia, range on the lower end of the scale. The overall mean trust in the police of 5.9 groups the countries not only into Eastern and Western European cat- 
egories, but also in countries marked by a high or low trust in the police, i.e. with a position on the trust scale smaller or greater than six.

The distribution of procedural fairness across countries is similar: All Western European countries have a mean level of 3 or higher, meaning the police often treat people in the country with respect, make fair decisions, and explain these decisions. Again, the division in countries marked by high and low trust in police's procedural fairness passes the separation between Western and Eastern Europe. However, due to the four-point scale, the variance is rather small here; also, a rating of 2 (= not very often) is not too bad. As all countries, except Bulgaria, have a mean value of procedural fairness larger than 2.5, it can be concluded that the police are viewed as being fair in Eastern Europe as well, even though it is less often than in the West.

The mean level of confidence in the work of police, based on the question of how well the police are performing their job in the country, is midfield. All countries range between 3 "neither good nor bad job" and 4 "good job", with the exception of Finland, Switzerland, and Denmark, where the police are clearly viewed as doing a good job. Even though the differences between the countries are again small, it must be noted that the four Scandinavian countries are not grouped together. Finland and Denmark are on the top end, but Sweden and Norway rank below Switzerland and Germany. Again, all Eastern European countries rank below the overall mean level of 3.6. Contrary to the above results, the Netherlands are also listed within this group, with a mean confidence level of 3.4 .

When combining all three variables in one figure, the slightly different ranges of trust, confidence, and procedural fairness between countries become more visible (Figure 9). Rates of confidence in the work of police in particular differ from trust in the police: High trust in the police does not necessarily mean that the evaluation of the work of the police is very good, and vice versa. Within Western Europe, Norway's and the Netherland's confidence in the work of the police is lower compared to their rank of trust in the police. Amongst Eastern European countries, the same is true for Hungary, while Croatia and Bulgaria have a higher confidence level compared to their trust in the police ranking. Estonia ranks higher than Belgium and France due to its higher level of trust in the police. Contrary to these variations, countries rank similarly according to trust in the police and people's opinion of police's procedural fairness. Nevertheless, for all trust and attitudinal items, Western European countries rank at the 
top of the scale, while those for Eastern Europe are at the bottom, with the exception of Estonia. Hence, for the analyses that follow, the selected countries are combined in two clusters, one for Eastern and one for Western European countries.

Figure 9: Mean levels of trust in the police items

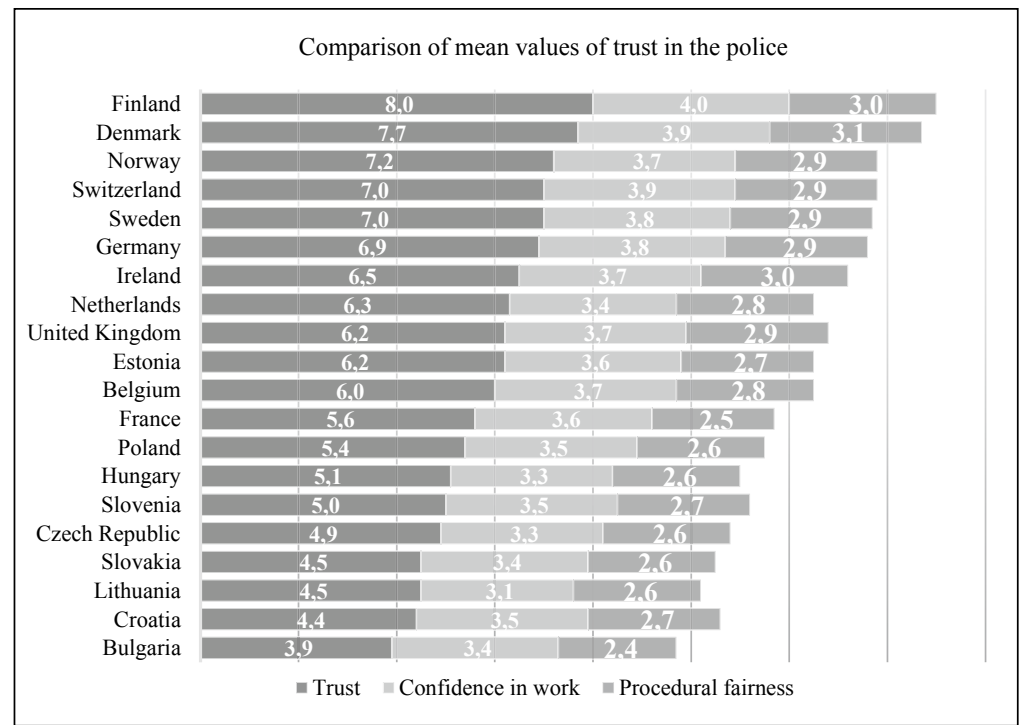

Note: Scales: Trust in the police 0-10, confidence in police work 1-5, procedural fairness 1-4

Already at the country level, a linear relationship between the different items of trust in the police was found. Results confirm significant correlations for the individual level as well. The correlation is highest for confidence in the work of the police and trust in them $\left(r_{S}=.451\right.$ in the West and $r_{S}=.482$ in the East), while it is smaller for procedural fairness and trust in the police, which is more evident in Western Europe (West: $r_{S}=.383$, East: $\left.r_{S}=.417\right)$. In literature, procedural fairness and police effectiveness are considered elements comprising trust in them. Therefore, the overall trust-in-the-police variable is only seldom used as the dependent variable in analyses. Rather, an index combining concepts of overall trust, procedural fairness, and effectiveness is used (cf. Jackson et al. 2012). However, as I differentiate between trust in the institution police and trust in the organization police, the three items of trust are treated as dependent variables in the following analyses. However, due to scaling, only the general 
trust in the police item is used as the dependent variable in multiple regression analyses.

Whether the police are perceived as part of the wider government here, or if people's perception of trust in the police differs from trust in political institution, is analyzed in the next chapter.

\subsection{The police as an arm of the government}

The institutional perspective sees trust in the police as only one form of a wider governmental trust. It argues that the police are linked to other institutions and their performance rather than to the performance of their representatives. Hence, analyses often include a combined index of institutional items. Nevertheless, studies have shown that there is indeed a difference in the perception of political institutions and institutions issuing order (Rothstein/Stolle 2002; Reuband 2012). Before continuing with analyses at the individual level, taking into account the influence of police encounters on trust in the police, I will analyze whether such a differentiation of people's trust in governmental institutions is found and whether there is a difference between Western and Eastern Europe. A measurement equivalence test by Schaap and Scheepers (2014) already confirmed that trust in the police is comparable within most of the ESS2O10 countries. Amongst the countries used here, only Finland and Bulgaria did not meet the criteria. This may be coupled with the fact that these countries are settled at the highest and lowest end in Europe concerning trust in the police levels.

A first look at the results reveals that, in Western Europe, trust in the police may at least be combined with trust in the legal system, but is different from trust in political institutions, supporting the results found by Reuband (2012) and Rothstein and Stolle (2002) (Table 16). The situation in Switzerland seems to be similar to those in the Western European cluster. Certain institutions are viewed as more similar than others, such as the legal system and trust in the police. Conversely, trust in the police and trust in political parties and politicians correlate only weakly. It can be deduced that trust in the police may be combined in an index, at least with trust in the legal system. 
Table 16: Correlation coefficients for institutional trust items

\begin{tabular}{|llllll|}
\hline & & \multicolumn{4}{c|}{ Trust in... } \\
& & $\begin{array}{l}\text { Country's } \\
\text { parliament }\end{array}$ & Politicians & $\begin{array}{l}\text { Political } \\
\text { parties }\end{array}$ & Legal system \\
\hline \multirow{2}{*}{ Trust in the police } & Western Europe & $.412^{* * * *}$ & $.395^{* *}$ & $.370^{* * *}$ & $.632^{* * * *}$ \\
\cline { 2 - 6 } & Eastern Europe & $.477^{* * *}$ & $.447^{* * *}$ & $.422^{* * *}$ & $.642^{* * *}$ \\
\cline { 2 - 6 } & Switzerland & $.406^{* * *}$ & $.427^{* * *}$ & $.330^{* * *}$ & $.614^{* * *}$ \\
\hline
\end{tabular}

Note: Source: ESS2010

A principal component analysis of trust in political institutions - trust in the EU and in the UNO were not considered - reveals one strong factor for all governmental institutions, saying that, in Western European countries, the police is not perceived distinctively from other governmental institutions concerning institutional trust (Table 17). The same is true of the Eastern European cluster and for Switzerland, where people evaluate governmental institutions holistically. Despite this fact, the coefficients of the single factor show that the factor loading is the lowest for trust in the police (Western Europe: .677, Eastern Europe: .700, Switzerland: .675). Furthermore, scatterplots reveal that a second factor would be adequate (not shown here). When considering a second factor, trust in political institutions (in the parliament, the politicians, and in political parties) splits from trust in institutions issuing order (the police and the legal system) ${ }^{2}$. Trust in the police in particular loads highly on the second factor of institutions issuing order (Western Europe: .913, Eastern Europe: .915, Switzerland: .895) (Table 18).

Table 17: Factor loading of institutional trust items (single factor)

\begin{tabular}{|llll|}
\hline & \multicolumn{3}{c|}{$\begin{array}{c}\text { Single factor } \\
\text { Governmental institution }\end{array}$} \\
\cline { 2 - 4 } Trust in & Western & Eastern & \multicolumn{1}{c|}{ Switzer- } \\
& Europe & Europe & land \\
\hline Country's parliament & 0,849 & 0,875 & 0,861 \\
Politicians & 0,888 & 0,893 & 0,832 \\
Political parties & 0,864 & 0,868 & 0,808 \\
Legal system & 0,789 & 0,821 & 0,773 \\
Trust in the police & 0,677 & 0,700 & 0,675 \\
Eigenvalue & 3,336 & 3,481 & 3,141 \\
\hline Total variance (\%) & 66,71 & 69,628 & 62,828 \\
\hline
\end{tabular}

Note: Source: ESS2010

2 The second factor can be taken into account despite its eigenvalue $<1$, as its loading of .875 is close to 1 . Furthermore, at $17 \%$, it contributes largely to the explanation of the variance. 
Table 18: Factor loading of institutional trust items (two-factor orthogonal rotation)

\begin{tabular}{|lllllll|}
\hline & \multicolumn{6}{c|}{ Two-factor orthogonal rotation } \\
\hline \multirow{2}{*}{ Trust in } & Western & Eastern & Switzer- & Western & Eastern & Switzer- \\
& Europe & Europe & land & Europe & Europe & land \\
\hline Country's parliament & 0,802 & 0,774 & 0,747 & 0,338 & 0,426 & 0,394 \\
Politicians & 0,907 & 0,913 & 0,876 & 0,261 & 0,271 & 0,273 \\
Political parties & 0,910 & 0,916 & 0,908 & 0,215 & 0,225 & 0,144 \\
Legal system & 0,400 & 0,446 & 0,348 & 0,794 & 0,774 & 0,816 \\
Trust in the police & 0,176 & 0,189 & 0,164 & 0,913 & 0,915 & 0,895 \\
\hline Eigenvalue & 3,336 & 3,481 & 3,141 & 0,843 & 0,768 & 0,875 \\
Total variance (\%) & 66,71 & 69,628 & 62,828 & 16,851 & 15,354 & 17,492 \\
\hline
\end{tabular}

Note: Source: ESS2010

A comparison of mean values of trust in governmental institutions reveals that institutions issuing order in particular achieve high trust levels in Switzerland with the police being trusted the most (70.3\%), followed by the legal system (62.8\%). Political institutions, on the other hand, are evaluated less favorably. In particular, trust in political parties is low in Switzerland (48.1\%), followed by trust in politicians $(50.1 \%)$, and the parliament $(58 \%)$. These numbers are lower compared to those found in the study Sicherheit $2010^{3}$ (72\% for the police and $69 \%$ for the courts, Szvircsev Tresch/Wenger 2010).

The above analyses reveal that, in Western Europe, trust in political and legal institutions may be considered the same, but a differentiation is not wrong. In Eastern Europe, they are more clearly perceived as similar, but still, results do not differ greatly from those in the West. Therefore, Hypothesis 1.1, that political and legal institutions are perceived differently in the West while no distinction is made in the East, must be rejected. The minimal difference between the two clusters may partly be explained by the exclusion of Ukraine and Russia, marked by very low levels of trust in the police. Analyses based on the sample before the exclusion of these two reveal an even clearer combination of these institutions in the East. It

3 | Trust in the institution police is part of the annually published series Sicherheit (Safety) by the Center of Security Studies at ETH Zurich and the Military Academy at ETH Zurich. Trust is linked to questions about Swiss people's feelings of security. Amongst Swiss institutions, the police are trusted the most, followed by the courts, and the Swiss Federal Council. The lowest level of trust is found for political parties and the media. Newest numbers can be found in Szvircsev Tresch and Wenger (2016: 88). 
can be concluded that Middle Eastern European countries went through a transformation following the fall of the iron curtain, becoming more democratic, which leads people to perceive the institutions differently from each other. However, for further clarification, more research with regard to the conditions of the single countries would be needed. Additionally, trust in the police and trust in the legal system can clearly be combined in the West. This would be pointless, as in the following analyses, the impact of encounters with the police on trust in them are analyzed. Hence, only the single item of trust in the police is used. However, the influence of trust in the legal system and trust in politics is taken into account in final multiple regression analyses.

Nothing can be said about the influence of police encounters so far. Several theoretical approaches emphasize their importance for building institutional trustworthiness (Giddens 1990; Hardin 2002; Tyler/Huo 2002). The next chapter elaborates on whether experiences with the police also affect overall trust in the police or whether they primarily influence trust in the police as an organization.

\subsection{Police-initiated contact}

There are large differences between the countries concerning the amount of contact citizens had with the police (Figure 10). While in Finland approximately every other person affirms "having been approached, stopped, or contacted by the police during the last two years" preceding the survey, in Bulgaria and Lithuania it was less than every fourth person. Finland ranges on the top end together with Sweden (49.6\%) and Belgium (47.8\%). Switzerland (42.9\%) and the Netherlands (42.5\%) are still above the $40 \%$ mark. Amongst the Scandinavian countries, Denmark can be considered an outlier, with only $30 \%$ police encounters. It differs in particular from Finland and Sweden, where about every second interviewee has been in contact with the police. Norway lies somewhere in between, with $38.1 \%$ encounter.

It might be argued that the total number of police officers in a country influences the number of encounters. A comparison with the statistics in the European Sourcebook reveals that this is probably not the case. Low numbers of officers contrast the high number of encounters in Finland and Sweden. Both countries have less than 200 officers per 100,000 citizens, while the number in Belgium is 300-399. The low number of encounters in Poland stands opposite the rate of 200-299 officers per 
100,000 population (Aebi/Killias 2010: 36 ). Since these numbers are from 2007 only, nothing can be said about the current state. Moreover, only certain countries are included in this corrected statistic of the European Sourcebook of Crime and Criminal Justice Statistics and civilian officers were excluded. A look at the annual rates between 2003 and 2006 shows that Denmark has around 180 officers per 100,000 population, which is more than Finland (around 155) but less than Sweden (around 190). The low number of encounters in Denmark, however, clearly contrasts with the number of officers. Of course, such comparisons must be drawn cautiously, as a rough overall number says nothing about the distribution of the officers across departments. Nevertheless, the number of officers per country is a topic that is brought up regularly, as a shortage of police officers is linked to low police presence. Moreover, additional services affect the private life of officers and are paired with dissatisfaction (Mohler 2013). Such stressors eventually lead to distinct behavior in the sense of inappropriate performance in interactions with citizens (Manzoni 2003).

Figure 10: Percentage of self-reported police-initiated contact

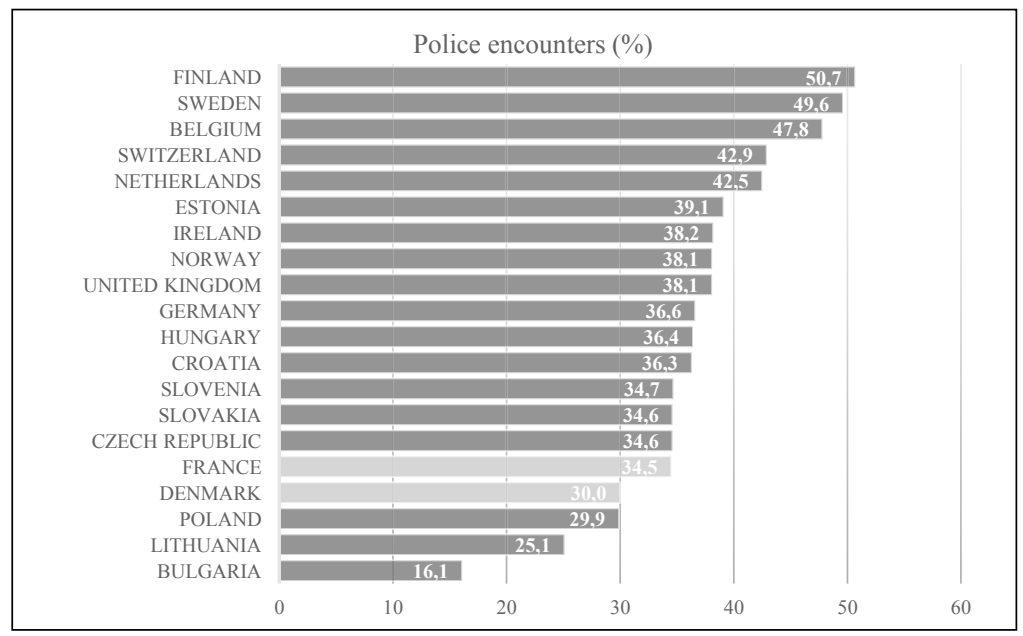

Many actions and interactions may happen during a police stop, influencing citizens' opinion of the police. Unfortunately, data does not provide further information on the circumstances of encounters but allows for a closer look at the satisfaction level of stopped people. Before, control items such as socio-demographics will be considered. 


\subsubsection{Individual influences}

Research has widely confirmed that socio-demographics, such as age, have an impact on how the police are viewed. Moreover, Skogan (2005) and others (Bradford/Jackson/Stanko 2009; Jackson et al. 2012) showed that such characteristics are also related to police contact, as males and younger people have a higher chance of being stopped by the police. Furthermore, a large body of research deals with minority issues (Furstenberg/Wellford 1973; Correia/Reisig/Lovrich 1996; Reisig/Correia 1997; Tuch/Weitzer 1997; Brown/Benedict 2002; Schafer/Huebner/Bynum 2003; Rosenbaum et al. 2005; Schuck/Rosenbaum 2005; Weitzer/Tuch 2005; Jackson et al. 2012).

Additionally, several studies report the negative impact of victimization on attitudes toward and trust in the police (Poister/McDavid 1978; König 1980; Percy 1980; Killias 1989; Schwarzenegger 1992; Cao/Frank/Cullen 1996; Kusow/Wilson/Martin 1997; Oskarsson 2010; Bradford 2011). Closely linked to a criminal victimization are fear of crime (Cao/Frank/Cullen 1996; Weitzer/Tuch 2005; Jackson et al. 2009) as well as avoidance behavior (Hindelang/Gottfredson/Garofalo 1978). Before controlling for socio-demographic and other individual characteristics in further linear regression analyses, their direct influence on trust in the police is analyzed. Moreover, I test how the influence changes between samples of people with and without police contact. Results for Eastern and Western Europe reveal clear differences in trust in the police between the contact and non-contact sample for gender, age, ethnic minority, and socially meeting with friends (Table 19).

Firstly, it can be seen that the higher trust in the police by Western females is caused by police encounters, while females with no police contact do not show a higher trust in the police. Furthermore, in Western Europe, young people between 14 and 25 years have a lower trust in the police than those over 60 in cases where they experienced a police stop $(B=-.483)$. Without such an experience, young age does not matter. In the East, the impact is only statistically significant in the non-contact group. Moreover, the same pattern is found for 26- to 39-year-olds. It can be concluded that, in Eastern Europe, factors other than the age came into play in cases of police contact. A further discrepancy in Western Europe can be seen with citizenship and ethnic minority. While possession of citizenship leads to a more critical view of the police in all samples, the statistically significant negative impact that belonging to an ethnic minority has on trust in the police becomes insignificant in cases of police encounters $(B=-.159)$. 
Table 19: Influence of socio-demographic variables on trust in the police in Eastern and Western Europe (linear multivariate regressions)

\begin{tabular}{|c|c|c|c|c|c|c|}
\hline & \multicolumn{3}{|c|}{ Western Europe } & \multicolumn{3}{|c|}{ Eastern Europe } \\
\hline & $\begin{array}{r}\text { Full } \\
\text { sample }\end{array}$ & $\begin{array}{r}\text { No } \\
\text { contact } \\
\end{array}$ & Contact & $\begin{array}{r}\text { Full } \\
\text { sample } \\
\end{array}$ & $\begin{array}{r}\text { No } \\
\text { contact } \\
\end{array}$ & Contact \\
\hline (Constant) & 6,641 & 6,951 & 5,868 & 4,474 & 4,733 & $\overline{3,532}$ \\
\hline Female & $.153 * * *$ & $-0,007$ & $.308 * * *$ & $.152 *$ & 0,119 & 0,123 \\
\hline \multicolumn{7}{|l|}{$\begin{array}{l}\text { Age groups } \\
\text { (ref: }>59 \text { years) }\end{array}$} \\
\hline $14-25$ years & $-.268 * * *$ & 0,023 & $-.483^{* * *}$ & $-.547 * * *$ & $-.506 * * *$ & $-0,335$ \\
\hline $26-39$ years & $-0,080$ & $-0,085$ & 0,010 & $-.376 * * *$ & $-.473 * * *$ & 0,034 \\
\hline $40-59$ years & $-.163 * * *$ & $-.103 *$ & $-.157 *$ & $-0,149$ & $-0,193$ & 0,214 \\
\hline Years of education & $-0,042$ & $-.092 *$ & 0,096 & 0,063 & 0,077 & 0,147 \\
\hline Citizen of country & $-.390 * * *$ & $-.439 * * *$ & $-.280 *$ & $-0,212$ & $-0,391$ & 0,143 \\
\hline Ethnic minority & $-.228 * *$ & $-.268 * *$ & $-0,159$ & 0,073 & 0,331 & $-0,468$ \\
\hline Income (ref: low) & $.282 * * *$ & $.203 * * *$ & $.426 * * *$ & $.342 * * *$ & $.418 * * *$ & 0,168 \\
\hline Religiousness (ref: low) & $.383 * * *$ & $.363^{* * *}$ & $.415^{* * *}$ & $.377 * * *$ & $.402 * * *$ & $0.305^{*}$ \\
\hline \multicolumn{7}{|l|}{$\begin{array}{l}\text { Political orientation } \\
\text { (ref: moderate) }\end{array}$} \\
\hline Left & $-.195 * * *$ & $-.147 * *$ & $-.246 * * *$ & $.206^{*}$ & 0,142 & 0,333 \\
\hline Right & $.190 * * *$ & $.264 * * *$ & 0,076 & $.298 * * *$ & 0,260 & $.373 *$ \\
\hline Life satisfaction (ref: low) & $.836 * * *$ & $.790 * * *$ & $.892 * * *$ & $.781 * * *$ & $.765 * * *$ & $.777 * * *$ \\
\hline Criminal victimization & $-.341 * * *$ & $-.194 * *$ & $-.322 * * *$ & $-.459 * * *$ & $-.379 *$ & $-.447^{* *}$ \\
\hline Fear of crime & $-.163 * * *$ & $-.129 *$ & $-.181 *$ & $-.500 * * *$ & $-.421 * * *$ & $-.590 * * *$ \\
\hline \multicolumn{7}{|l|}{$\begin{array}{l}\text { Going out (ref: once or } \\
\text { several times a month) }\end{array}$} \\
\hline Less than once a month & $-.255 * * *$ & $-.367 * * *$ & 0,019 & 0,030 & 0,074 & $-0,140$ \\
\hline $\begin{array}{l}\text { Once or several times a } \\
\text { week }\end{array}$ & 0,022 & 0,026 & 0,058 & 0,031 & $-0,029$ & 0,164 \\
\hline Every day & $-0,052$ & 0,018 & $-0,045$ & 0,167 & $.409^{*}$ & $-0,171$ \\
\hline \multicolumn{7}{|l|}{$\begin{array}{l}\text { Agglomeration type } \\
\text { (ref: core city) }\end{array}$} \\
\hline Agglomeration & $-0,066$ & $-0,019$ & $-0,137$ & 0,108 & 0,005 & 0,28 \\
\hline Town, small city & $-0,064$ & $-0,050$ & $-0,068$ & 0,152 & 0,159 & 0,121 \\
\hline Rural & $-0,082$ & $-0,043$ & $-0,131$ & 0,298 & $.255^{*}$ & $.344^{*}$ \\
\hline$\overline{a d j} \cdot R^{2}$ & 0,120 & 0,115 & 0,136 & 0,099 & 0,112 & 0,078 \\
\hline $\mathrm{N}$ & 18,441 & 11,190 & 7,229 & 5,022 & 3,385 & 1,630 \\
\hline
\end{tabular}

Note: Source: ESS2010: B-coefficient of OLS regression, dependent variable: trust in the police Including country dummies (not shown); excluded from the system: Germany and Poland, Countries weighted by design and population

${ }^{1}$ Years of education: $1=0-6$ years, $2=7-12$ years, $3=13-23$ years, $4<23$ years

In the East, no significant impact was found for either citizenship or ethnic minority. Furthermore, religiousness leads to a better view of the police in the West, independently of a police encounter. Contrary to this, in Eastern Europe, the positive impact of religiousness becomes insignificant in the contact sample. Once more, it can be assumed that encounters may be more problematic in the East than in the West, causing the pos- 
itive effects of socio-demographics to disappear. However, the different influence of political orientation on trust in the police in the West speaks against this argument. A settling on the left side of the political spectrum leads to lower trust in the police in all samples, with the strongest impact in the contact group. The positive influence of a right attitude on trust in the police disappears in the contact group. It can be followed that the effect of improper police behavior is stronger, bringing to fall the positive opinion of the police held by conservative people.

Finally, only in Western Europe does leisure behavior influence trust in the police. Particularly people meeting with friends or colleagues less than once a month have a negative opinion of the police, in cases where they were not in contact with them $(B=-.367)$. However, this negative influence disappears in the contact sample $(B=.019)$. It may be possible that such marginalized people were contacted by the police in order to help them, therefore contributing to a more positive image.

While in Western Europe, females who experienced an encounter with the police show higher trust rates, no difference among sexes was found for Switzerland (Table 20) ${ }^{4}$. Nevertheless, the police stop males significantly more often than females (Staubli 2014). Furthermore, other socio-demographics such as age, minority, political orientation, etc. only play marginal roles. In cases of police contact, only religiousness and life-satisfaction were found to have positive impacts on trust in the police. Compared to the Western European sample, life-satisfaction stands out, as its impact on trust in the police is rather strong in Switzerland.

The Swiss police stop young males more frequently than females. Young males may demonstrate conduct that is more often suspicious as well as a higher involvement in criminal activities, in combination with a certain lifestyle. Results further show that the more often someone meets with friends, the higher his or her chance of being stopped by the police. Those meeting with friends every day have a $25.9 \%$ higher chance of being stopped by the police than those meeting up less than once a month. More than half of those who reported going out every day had been stopped by the police, while that number was only about one quarter for those living more isolated and going out less than once a month (results not displayed).

4 While in cross-tabulation females were found to have a higher trust in the Swiss police than males (Staubli 2014), this correlation ceases here in linear multivariate regressions. 
This result may shed light on the significant correlation found between income and police stops, with high-income people being stopped more often than low-income people (48.5\% vs. $38.7 \%$ ).

Table 20: Influence of socio-demographic variables on trust in the police in Switzerland (linear multivariate regressions)

\begin{tabular}{|c|c|c|c|}
\hline & Full sample & No contact & Contact \\
\hline (Constant) & 6,485 & 7,456 & 4,427 \\
\hline Female & 0,147 & 0,164 & 0,006 \\
\hline \multicolumn{4}{|l|}{ Age groups (ref: $>59$ years) } \\
\hline $14-25$ years & $-0,510$ & $-.669 *$ & $-0,051$ \\
\hline $26-39$ years & $-0,295$ & $-0,252$ & $-0,040$ \\
\hline $40-59$ years & $-0,404$ & $-.440 *$ & $-0,084$ \\
\hline Years of education & 0,052 & $-0,023$ & 0,195 \\
\hline Citizen of country & $-0,808$ & $-.886^{* * *}$ & $-0,599$ \\
\hline Ethnic minority & 0,044 & 0,040 & 0,042 \\
\hline Income (ref: low) & 0,138 & 0,030 & 0,296 \\
\hline Religiousness (ref: low) & 0,274 & 0,076 & $.587 * *$ \\
\hline \multicolumn{4}{|l|}{ Political orientation (ref: moderate) } \\
\hline Left & $-0,140$ & $-0,100$ & $-0,096$ \\
\hline Right & 0,305 & 0,322 & 0,372 \\
\hline Life satisfaction (ref: low) & $1.412 * * *$ & 1,075 & $2.037 * * *$ \\
\hline Criminal victimization & $-0,380$ & $-0,408$ & $-0,271$ \\
\hline Fear of crime & $-0,214$ & $-0,240$ & $8,37 \mathrm{E}-05$ \\
\hline \multicolumn{4}{|c|}{$\begin{array}{l}\text { Going out (ref: once or several times a } \\
\text { month) }\end{array}$} \\
\hline Less than once a month & 0,025 & $-0,341$ & 0,001 \\
\hline Once or several times a week & $-0,114$ & $-0,181$ & $-0,349$ \\
\hline Every day & $-0,113$ & 0,067 & 0,222 \\
\hline \multicolumn{4}{|l|}{ Agglomeration type (ref: core city) } \\
\hline Agglomeration & $-0,129$ & $-0,303$ & 0,222 \\
\hline Town, small city & $-0,151$ & $-0,457$ & 0,360 \\
\hline Country village & $-0,175$ & $-0,042$ & $-0,274$ \\
\hline Countryside & 0,116 & $-0,189$ & 0,531 \\
\hline adj. $R^{2}$ & 0,059 & 0,066 & 0,046 \\
\hline $\mathrm{N}$ & 1,222 & 517 & 702 \\
\hline
\end{tabular}

Note: Source: ESS2010: B-coefficient of OLS regression, dependent variable: trust in the police

${ }^{1}$ Years of education: $1=0-6$ years, $2=7-12$ years, $3=13-23$ years, $4<23$ years

Next, I will analyze how satisfied people were with police encounters and whether or not such satisfaction has an impact on trust in the police.

\subsubsection{Satisfaction with treatment received}

Trust in the police is higher in Western than in Eastern Europe, as shown above. When looking at the levels of satisfaction with the treatment received in a police encounter, no such clear conclusion can be drawn. 
Amongst the Scandinavian countries, Finland and Sweden show the highest levels of satisfaction with about $80 \%$ of the contacted people reporting satisfaction with how they were treated by the police (Figure 11). Nevertheless, in Denmark and Norway people were ten percent less satisfied. The lowest level of satisfaction within Western European countries is found amongst French people (58\%), followed by Germans (64.3\%). Contrary to this lower ranking of Germany, Croatians (67.4\%) as well as people from Slovenia (67.9\%) have the highest satisfaction levels within Eastern European countries. Their numbers are similar to those of Switzerland $(67.2 \%)$ and the United Kingdom (67.7\%).

Figure 11: Percentage of satisfaction with treatment received by the police in an encounter

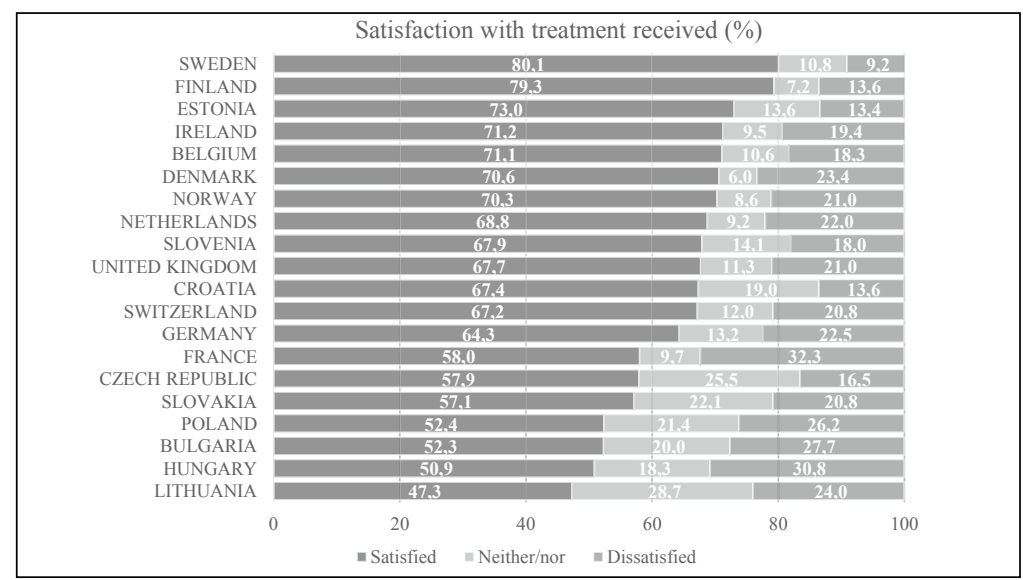

Concerning dissatisfaction, the people of France have the highest level of dissatisfaction overall, with about every third reporting being dissatisfied with how the police have treated them in an encounter. Amongst Western European countries, Denmark shows the largest proportion of dissatisfaction, with about every fourth of those stopped by the police being dissatisfied. Other countries with large groups of unsatisfied people are Hungary (30.8\%), Bulgaria (27.7\%), and Poland (26.2\%). The proportion of neutral respondents, having been neither satisfied nor dissatisfied, seems to be much larger in Eastern European countries.

There is ongoing discussion in the research community about whether only negative experiences with the police have a negative influence 
on trust in them or if a positive interaction will result in a better image and therefore in a higher trust as well (Skogan 2006; Bradford/Jackson/ Stanko 2009). While primarily studies conducted in Anglo-Saxon countries (Reisig/Chandek 2001; Skogan 2006; Bradford 2011) show that a negative impact of unfavorable ratings of police encounters on trust in them weighs more than positive ones, such results cannot be confirmed here. Thus far, analyses prove the asymmetry hypothesis for the Eastern European cluster only, as shown in Table 21. Dummy variables for each item of satisfaction with police contact were included in regression analyses, with neither satisfied nor dissatisfied as the reference category. The negative impact of dissatisfaction is strong in the East $(\mathrm{B}=-1.660)$. Satisfaction with treatment received also leads to a higher trust in the police, but the impact is slightly lower $(B=1.594)$. Amongst Western European countries, a favorable evaluation of police contact leads to a distinctly better opinion of the police ( $\mathrm{B}=1.560$ ), while the negative impact of dissatisfaction is much smaller ( $\mathrm{B}=-.444)$. Coefficients are even stronger for Switzerland, with no significant impact of negative ratings. It follows that Hypothesis 5.1 can only partly be confirmed.

The relationship found between satisfaction with the treatment received and trust in the police is surprising. Contrary to the expectation based on the asymmetry hypothesis, unfavorable ratings only count more than positive ones in the Eastern European cluster, where trust in the police is much lower anyway compared to Western European countries. Reasons may lie within the research design. As most of the studies within the field of attitudinal research are based on local or at least national samples, data used here stems from a large opinion poll. Furthermore, the question about police-initiated contact was rather general in nature, not specifying any form of contact. Conversely, local studies often operate on questions about concrete forms of contact, such as traffic stops. Hence, failure to differentiate between specific forms of police stops may blur results. People stopped by the police during a regular traffic control may react differently to officers than those approached because they had breached a law, e.g. driven too fast. While a traffic control may be annoying because it is time consuming, receiving a ticket can be perceived as unfair. Nevertheless, studies have shown that police stops most often concern traffic offences (Tyler 1990). 
Table 21: Impact of satisfaction with encounter on trust in the police (linear multivariate regression)

\begin{tabular}{|llrrrr|}
\hline & & B & Std. error & Beta & $\mathrm{t}$ \\
\hline Western Europe & (Constant) & 6,035 & 0,079 & & 76,694 \\
& Very satisfied & $1.560^{* * *}$ & 0,086 & 0,281 & 18,201 \\
& Satisfied & $0.864^{* * *}$ & 0,080 & 0,176 & 10,752 \\
& Dissatisfied & $-.566^{* * *}$ & 0,098 & $-0,077$ & $-5,752$ \\
& Very dissatisfied & $-.444^{* * *}$ & 0,102 & $-0,057$ & $-4,376$ \\
\hline & $\mathrm{R}^{2}$ & 0,163 & & & \\
& $\mathrm{~N}$ & 8,676 & & & \\
\hline Eastern Europe & (Constant) & 4,841 & 0,125 & & 38,593 \\
& Very satisfied & $1.594^{* * *}$ & 0,201 & 0,182 & 7,926 \\
& Satisfied & $.913^{* * *}$ & 0,136 & 0,175 & 6,714 \\
& Dissatisfied & $-.742^{* * *}$ & 0,180 & $-0,098$ & $-4,114$ \\
& Very dissatisfied & $-1.660^{* * *}$ & 0,197 & $-0,195$ & $-8,426$ \\
\hline & $\mathrm{R}^{2}$ & 0,149 & & & \\
& $\mathrm{~N}$ & 2,150 & & & 23,711 \\
& (Constant) & 5,709 & 0,241 & & 6,898 \\
& Very satisfied & 0,294 & 0,390 & 4,609 \\
& Satisfied & $2.026^{* * *}$ & 0,294 & $-0,042$ \\
& Dissatisfied & $1.262^{* * *}$ & 0,274 & 0,277 & 1,791 \\
\hline Switzerland & $-0,015$ & 0,363 & $-0,002$ & \\
& Very dissatisfied & 0,624 & 0,349 & 0,087 & \\
& $\mathrm{R}^{2}$ & 0,103 & & & \\
& $\mathrm{~N}$ & 1,502 & & & \\
\hline
\end{tabular}

Note: Source: ESS2010, sample of people stopped by the police Coefficients of OLS-regressions, dependent variable: trust in the police Reference category: being neither satisfied nor dissatisfied Western and Eastern European samples: country dummies included, not shown here Significance levels: $* 0.01<p<0.05, * * 0.001<p<0.01, * * * p<0.001$

The next analyses will look at the impact of satisfaction on ratings of police work and their procedural fairness. The strong impacts seen above are expected to appear here as well, as the above results have further shown a rather close relationship between people's trust in the police and opinions of police's work and their procedural justice. When visualizing the correlations according to values of cross-tabulations, it became obvious that, in fact, satisfied people rate police's work and their procedural fairness better, while the police are seen less positive amongst the unsatisfied individuals (Figure 12, Figure 13) $)^{5}$. This is the case in both parts of Europe. However, the impact of satisfaction on confidence in the police is stronger in the East than in the West. Even weaker impacts can be reported for Switzerland.

5 I In order to have enough cases to draw on, different forms of negative and positive answers were combined. For all correlations: $p<0.001$. 
Within the Western European cluster, results confirm the stronger positive impact of satisfaction already found for the institutional trust in the police. There is a large discrepancy in the evaluation of police work between satisfied and dissatisfied people. In Western Europe, $78.5 \%$ of satisfied people rate police work as very good, while only $48.7 \%$ of unsatisfied ones follow suit. Conversely, of those satisfied people, only $3.4 \%$ rate police work as negative, while $20.4 \%$ gave this rating in cases of dissatisfaction. Differences are even more pronounced in the East: On the one hand, satisfied people rate police work as positive $44.5 \%$ more often than dissatisfied people (63.4\% vs. $18.9 \%)$. Dissatisfied people, on the other hand, clearly rate police work negatively (41.7\%). Despite their dissatisfaction, $18.9 \%$ of respondents gave the police a good evaluation. As further results show, unfair decisions and disrespectful treatment by the police are reasons for dissatisfaction with them. Only about one-fourth of unsatisfied people in Eastern Europe attribute the police with procedural fairness, while more than $70 \%$ of those satisfied with the treatment received attribute them with the same. In the West, ratings of police work and trust in their procedural fairness are similar. Close to $90 \%$ of people satisfied with the treatment received in an encounter attribute the police with procedural fairness, while only about $62 \%$ of those being dissatisfied follow suit.

Figure 12: Impact of satisfaction with treatment received by the police on confidence in their work

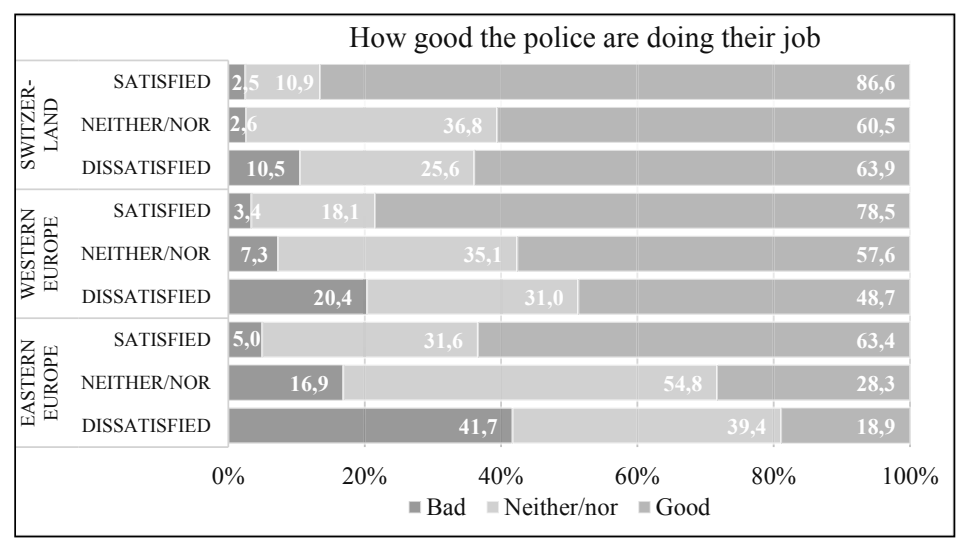


Figure 13: Impact of satisfaction with treatment received by the police on trust in their procedural fairness

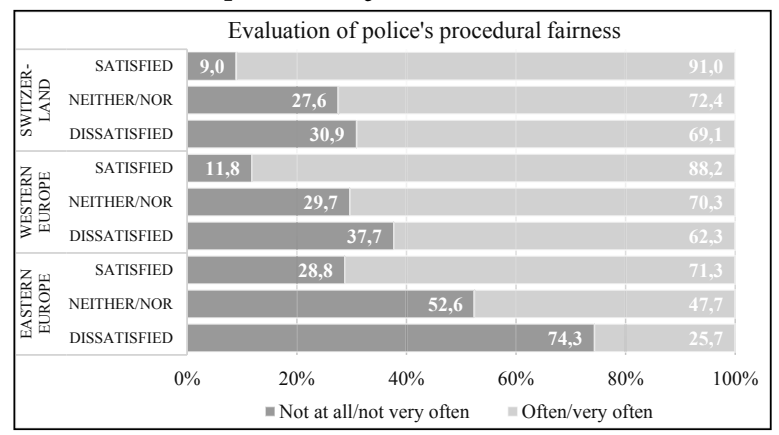

Results for Switzerland differ only marginally from those in Western Europe when it comes to the impact of satisfaction on trust in police's procedural fairness. Contrary to this, ratings are more positive for the evaluation of police work. While $86.6 \%$ of those with positive opinions report that the police are doing a good or very good job, the rate is more than $20 \%$ lower amongst those who are dissatisfied with how the police treated them (63.9\%). Even if this discrepancy is large, we should keep in mind that people rate the work of the police positively overall, with only a very low number of people giving negative feedback (27). Moreover, the difference is smaller compared to those in the Western European sample (29.8\%).

Results confirm the assumption that an experience with the police has an influence on trust in them. Favorable ratings of police contact lead to better ratings of police work and of their general procedural fairness. It follows that Hypothesis 5.2 is confirmed. However, as the questions about procedural fairness were asked independently of the interaction with the police, the direction of causation remains unclear. Positive views of police's general fairness may also lead to better evaluations of police contact. Furthermore, results confirm the asymmetry hypothesis for the Eastern European cluster only. Therefore, Hypothesis 5.1 is partly rejected.

The questionnaire only allows general statements rather than saying something about the type of the contact, whether the police stopped people on the street, verified their identities, stopped them during a traffic control, or based on unlawful behavior. Furthermore, there is the possibility that they contacted people in order to talk about a former incident, such as criminal victimization, meaning that they were already in contact 
with these people before. More information on victims' trust in the police is given in the section "The perception of crime victims".

The possibility of a cultural influence, consisting of an imbalance of power between an officer and the population in a country, is given by a fifth possible answer for the third item of procedural fairness. People were able to answer the question on whether the police in the country generally explain their decisions or not with "no one ever ask the police to explain their decisions" (treated as missing in the item of procedural fairness). While only small numbers of interviewees in Western European countries answered that it is uncommon to ask the police to explain their decisions, the number is much higher in Eastern Europe (Figure 14).

The question was not fielded in Norway and the Czech Republic. In most of the Western European countries, less than $2.5 \%$ of the people reported that it was uncommon to ask a police officer for an explanation. However, Germany (4.1\%) and Ireland (5.7\%) also show higher levels of respect toward the police compared to the other Western European countries. Another cultural factor that may shape the perception of the police is the openness of people toward their fellow man, as shown in the next chapter.

Figure 14: Percentages of people answering that the police are not asked to explain their decisions

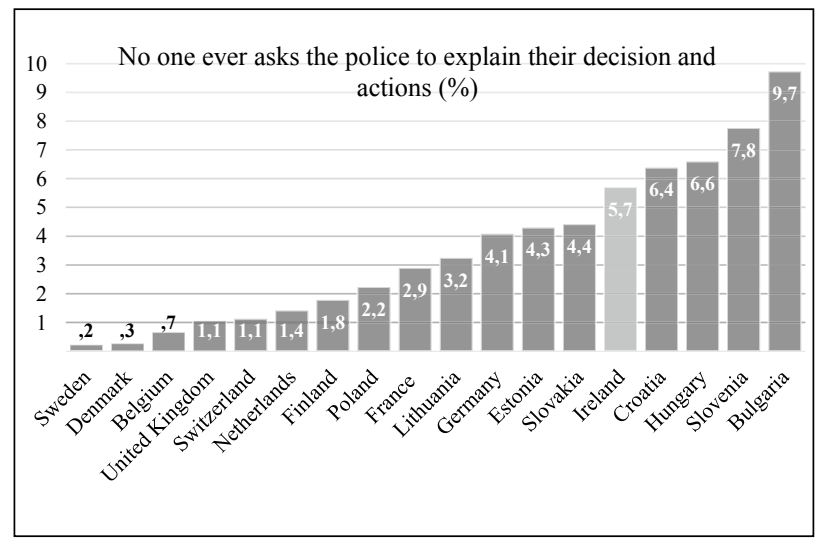




\subsubsection{The impact of social trust}

The distribution of the three items measuring social trust differs between and within countries, as shown in Figure 15. Residents of Eastern European countries are much more cautious concerning other people compared to those of Western Europe. Less than every third Bulgarian generally trusts other, unfamiliar people, while this number is seven out of ten in Denmark. The only exception is France with the third smallest mean value of generalized trust (4.3), while the level of trust in others' fairness is much higher (5.8). Within the three social trust items, respondents rate the fairness of their fellow man the highest overall, followed by their trustworthiness, and finally helpfulness at the lower end. Exceptions are Slovenia, Hungary, Ireland, and the United Kingdom, where the difference between trust in others' fairness and in their helpfulness is rather small.

Figure 15: Mean values of three indicators for social trust in Eastern and Western European countries

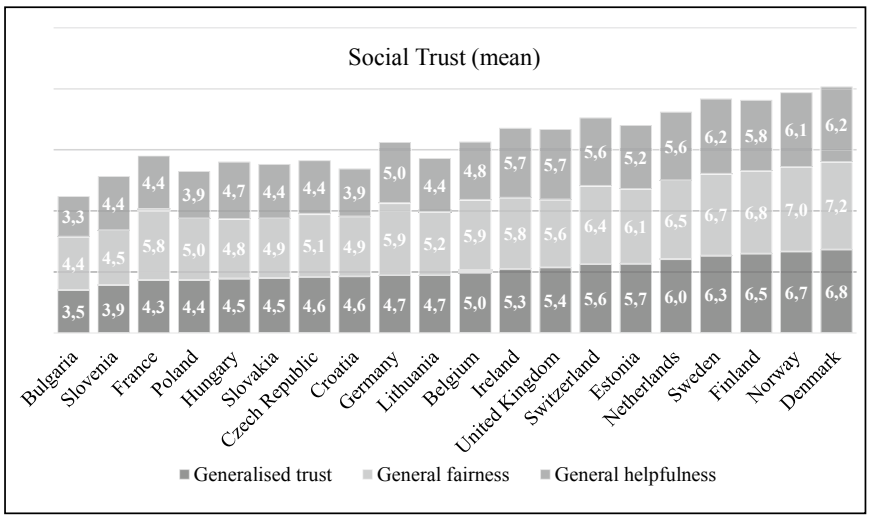

Furthermore, while high trust countries Scandinavia and the Netherlands have the same view of other people's trustworthiness, fairness, and helpfulness, the items scatter more diversely amongst the rest of the countries. The discrepancies are the largest for Belgium and Germany: Belgians rate their fellow citizen as rather fair $(58.7 \%)$, but only more than about every third think they are helpful (35\%), with the level of trustworthiness between the two $(43.2 \%)$. In addition, Germans differ similarly between levels of trust, helpfulness, and others' fairness (35.3\%, 36\%, and 54.9\%). These differences between and within countries highlight that, in em- 
pirical analyses, social trust items should be used separately rather than combined as an index.

Correlation coefficients for the explanatory variables of institutional trust and social trust are displayed in Table 22. Coefficients are similar in the Western and Eastern European clusters. It can be seen that confidence in police work does correlate negatively with all forms of social trust, in contrast to trust in the police and in procedural justice. Furthermore, Switzerland does not follow the pattern of Western Europe. Trust in other people's helpfulness and fairness correlates statistically significantly positively with confidence in police work, which is not the case in Western and Eastern Europe.

Table 22: Correlation coefficients of social trust and trust in the police

\begin{tabular}{|c|c|c|c|c|c|c|c|}
\hline & & \multicolumn{2}{|c|}{ Trust in police } & \multicolumn{2}{|c|}{ Confidence in police work } & \multicolumn{2}{|c|}{ Procedural fairness } \\
\hline \multicolumn{2}{|c|}{ Police encounter } & no & yes & no & yes & no & yes \\
\hline \multirow{3}{*}{$\begin{array}{l}\text { Generalized } \\
\text { trust }\end{array}$} & Western Europe & $.235^{* * *}$ & $.256^{* * *}$ & $-.089 * * *$ & $-.096^{* * *}$ & $.091^{* * *}$ & $.132^{* * *}$ \\
\hline & Eastern Europe & $.211^{* * *}$ & $.267^{* * *}$ & $-.112^{* * *}$ & $-.127 * * *$ & $.129 * * *$ & $.114^{* * *}$ \\
\hline & Switzerland & $.170^{* * *}$ & $.154^{* * *}$ & $.071^{*}$ & 0,065 & $.037 * * *$ & $.114^{* *}$ \\
\hline \multirow{3}{*}{$\begin{array}{l}\text { General } \\
\text { fairness }\end{array}$} & Western Europe & $.236^{* * *}$ & $.262^{* * *}$ & $-.092 * * *$ & $-.121 * * *$ & $.079^{* * *}$ & $.141^{* * *}$ \\
\hline & Eastern Europe & $.228^{* * *}$ & $.238^{* * *}$ & $-.116^{* * *}$ & $-.134 * * *$ & $.130^{* * *}$ & $.115^{* * *}$ \\
\hline & Switzerland & $.195 * * *$ & $.193^{* * *}$ & $.173^{* * *}$ & $.117 * *$ & $.127 * * *$ & $.175^{* * *}$ \\
\hline \multirow{4}{*}{$\begin{array}{l}\text { General } \\
\text { helpfulness }\end{array}$} & Western Europe & & & $-.122 * * *$ & $-.132 * * *$ & & \\
\hline & & $.218^{* * *}$ & $.257^{* * *}$ & & & $.095^{* * *}$ & $.156^{* * *}$ \\
\hline & Eastern Europe & $.192 * * *$ & $.227^{* * *}$ & $-.110 * * *$ & $-.123 * * *$ & $.135^{* * *}$ & $.147^{* * *}$ \\
\hline & Switzerland & $.205^{* * *}$ & $.206^{* * *}$ & $.168^{* * *}$ & $.133 * *$ & $.101 * *$ & $.174^{* * *}$ \\
\hline
\end{tabular}

Note: Source: ESS2010

Pearson's (trust in the police) and Spearman's (confidence in police work, procedural fairness) correlation coefficients

Significance levels: $* 0.01<p<0.05, * * 0.001<p<0.01, * * * p<0.001$

The more people evaluate their fellow men as trustworthy, fair, and helpful, the higher their trust in the police, in both Western and Eastern European countries, as well as in Switzerland (Table 23) ${ }^{6}$. These linear regression analyses confirm results found in analyses at the macro level, which showed a significant linear relationship between social trust and trust in the police. While the positive impact of generalized trust and general helpfulness on trust in the police is higher in the West, positive views of other people's fairness count slightly more in the East.

6 | Correlation coefficients can be found in Appendix A. 
However, when taking the experience of a police stop into account, splitting the sample into two groups - people with and people without police contact - results differ. While amongst Western European countries the positive impact of general fairness and general helpfulness on trust in the police rose amongst the contact sample, it declined for those not having been in contact with the police. Conversely, the positive impact of generalized trust on trust in the police declined in the contact sample, while it remained more or less the same amongst people not stopped by the police. Overall, the differences are only marginal. The East shows the contrary pattern, with a larger positive impact of general fairness amongst the group of people not having been in contact with the police. This may be due to different circumstances and experiences during police stops. It is conceivable that it is not the stops alone that are experienced as rather unfair and harsh, derived from larger percentages of dissatisfaction with how the police have treated people, as seen in the preceding chapter. Moreover, the direct intervention or rather non-intervention of bystanders may lead to larger negative evaluations of others' trustworthiness and helpfulness. Overall, compared to the West, numbers reveal larger differences between the two groups of people with and without police contact. Finally, the amount of variance of trust in the police explained by social trust is slightly larger for the contact sample in Western Europe, while, on the contrary, the impact is slightly stronger for the group of people not in contact with the police.

Table 23: Impact of social trust on trust in the police (linear multivariate regressions)

\begin{tabular}{|c|c|c|c|c|c|c|c|c|c|}
\hline & \multirow[t]{2}{*}{$\begin{array}{l}\text { Western } \\
\text { Europe }\end{array}$} & \multirow[t]{2}{*}{$\begin{array}{l}\text { Eastern } \\
\text { Europe }\end{array}$} & \multirow[t]{2}{*}{$\begin{array}{l}\text { Switzer- } \\
\text { land }\end{array}$} & \multicolumn{2}{|c|}{$\begin{array}{l}\text { Western Europe } \\
\text { Police encounter }\end{array}$} & \multicolumn{2}{|c|}{$\begin{array}{l}\text { Eastern Europe } \\
\text { Police encounter }\end{array}$} & \multicolumn{2}{|c|}{$\begin{array}{l}\text { Switzerland } \\
\text { Police encounter }\end{array}$} \\
\hline & & & & no & yes & no & yes & no & yes \\
\hline (Constant) & 4,792 & 3,877 & 5,088 & 4,007 & 4,432 & 4,149 & 3,284 & 5,376 & 4,735 \\
\hline $\begin{array}{l}\text { Generalized } \\
\text { trust }\end{array}$ & $.132 * * *$ & $.113 * * *$ & $.076^{* *}$ & $.141 * * *$ & $.118^{* * *}$ & $.089 * * *$ & $.168^{* * *}$ & $.094 * *$ & 0,066 \\
\hline $\begin{array}{l}\text { General } \\
\text { fairness }\end{array}$ & $.120^{* * *}$ & $.125 * * *$ & $.115^{* * *}$ & $.095^{* * *}$ & $.158^{* * *}$ & $.132 * * *$ & $.106^{* * *}$ & $.092 *$ & $.144^{* *}$ \\
\hline $\begin{array}{l}\text { General } \\
\text { helpfulness }\end{array}$ & $.149^{* * *}$ & $.098 * * *$ & $.140^{* * *}$ & $.141^{* * *}$ & $.151^{* * *}$ & $.084 * * *$ & $.127 * * *$ & $.124 * * *$ & $.147 * *$ \\
\hline$\overline{\mathrm{R}^{2}}$ & 0,145 & 0,106 & 0,07 & 0,144 & 0,149 & 0,114 & 0,106 & 0,066 & 0,076 \\
\hline $\mathrm{N}$ & 22,574 & 6,756 & 1,496 & 13,895 & 8,643 & 4,604 & 2,131 & 851 & 641 \\
\hline
\end{tabular}

Note: Source: ESS2010; B-coefficients of OLS-regression, dependent variable: trust in the police

Including country dummies for Western and Eastern Europe (not shown here) Significance levels: $* 0.01<p<0.05, * * 0.001<p<0.01, * * * p<0.001$ 
Results for Switzerland are similar to those for Western Europe when it comes to the impact of trust in general fairness and general helpfulness on trust in the police. However, it differs from Western Europe in the sense that the impact of generalized trust is weaker and loses its statistical significance in the encounter sample.

Next, confidence in the police is considered. Is the impact of social trust on the evaluation of police work similar? Results reveal that, in both Eastern and Western European countries, high general trust leads to higher general confidence in police work, compared to lower trust, independently of being in contact with the police (Figure 16, Figure $17^{7}$ ). When comparing the two groups of people with and without police contact in Western Europe, the ratings are worse amongst those stopped by the police. Moreover, the largest difference between the contact and the non-contact groups exists for people with low social trust. Here, positive ratings are $14.5 \%$ lower compared to those not trusting their fellow citizen and not having experienced a police stop (51.8\% vs. $66.3 \%)$. Contrary to this, differences are much smaller in the sample of people with high social trust (75.1\% vs. 80.1\%). This discrepancy becomes even clearer when looking at unfavorable evaluations. People in contact with the police give a bad evaluation of the police only very slightly more often compared to those not stopped by the police (3.7\% vs. $4.7 \%$ ). However, suspicious people with a police encounter evaluate police work 8.6\% more negatively (9.6\% vs. 18.2\%). Results for Eastern Europe also differ in the sense that, within the high trust group, those being stopped by the police demonstrate clearly less favorable evaluations of police work $(51.4 \%$ vs. $64 \%$ good work). However, as in the West, suspicious people with very low social trust also give a bad evaluation of the police much more often if they had contact with them (14.3\% vs. $25 \cdot 5 \%)$.

When comparing the groups with high social trust to those with low social trust, it is evident that the work of the police in Western Europe is evaluated as good $28.3 \%$ less often in cases where people were stopped by them, while the difference for the non-contact group is less than half that $(-13.8 \%)$. Contrary to this, in Eastern Europe, no such difference exists for good evaluations of police work. However, suspicious people being stopped by the police clearly give a bad evaluation of the work of the police more often than those with high trust and police contact (13.5\%), while

7 | As differences between the three items of social trust are only marginal, results from the combined social trust items are displayed. 
the difference for those with no police contact is clearly smaller (7.7\%). The same pattern is found for Western Europe. It can be deduced that, in an encounter, suspiciousness toward unknown others is transferred onto institutional representatives, such as police officers and their work.

Figure 16: Social trust, police contact, and confidence in police work in Western Europe

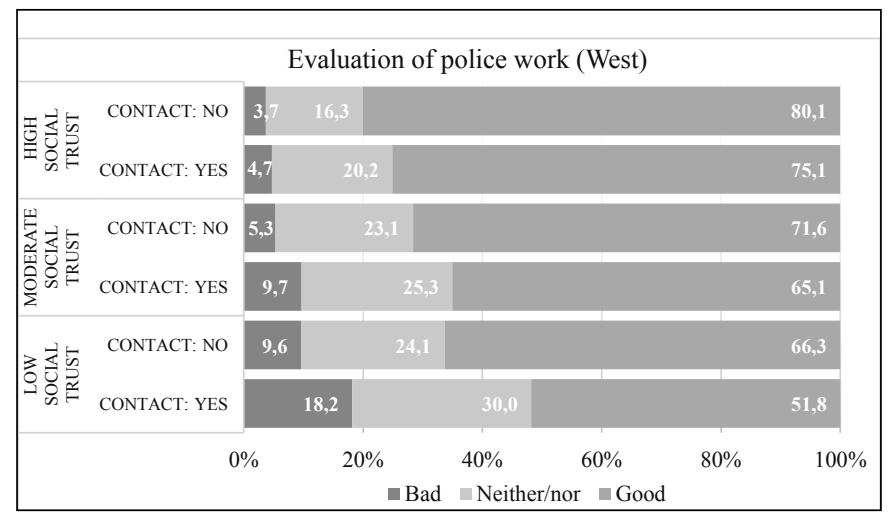

Note: Percent, total numbers of social trust: low $=2,166$, moderate $=12,640$, high $=7,721$ Significance level: for all $p<0.001$

In Switzerland, people with high trust toward the fairness of their fellow man rate the work of the police more positively compared to suspicious people (Figure 18$)^{8}$. Rates are higher compared to the ratings of the whole population $(81.3 \%)$. The work of the police is rated more favorably overall amongst people not stopped by the police than amongst those who had contact. The difference between suspicious and positive people is slightly larger in the non-contact group. Moreover, the difference in negative ratings between the two groups is smaller for suspicious people (5.4\% vs. $5.0 \%,-0.4 \%)$ than for those with high trust in others' fairness (3.9\% vs. $1.2 \%,-2.7 \%$ ).

8 While correlations between social trust and trust in the police were found for Switzerland, the impact on the evaluation of the work of the police is less clear; differences between the contact and no contact groups are rather small. In addition, due to the small number of negative ratings, the impact for general trust is significant only in cases of no contact $(p<0.05)$. Therefore, only the figure for fairness is displayed. Moreover, due to a smaller sample, social trust items were only dichotomized instead of trichotomized. 
Figure 17: Social trust, police contact, and confidence in police work in Eastern Europe

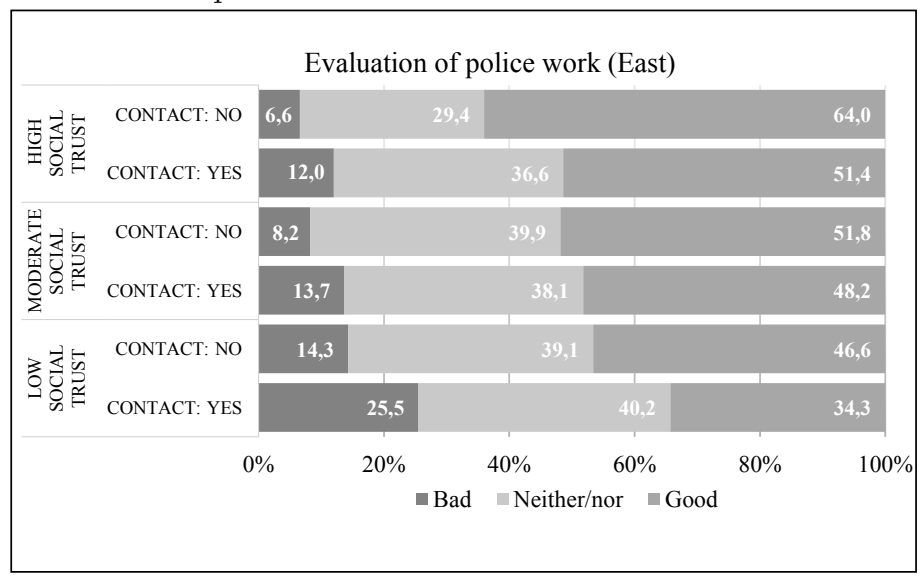

Note: Percent, total numbers of social trust: low $=1,659$, moderate $=3,773$, high $=1,313$ Significance level: for all $p<0.001$

Figure 18: Social trust (trust in fairness), police contact, and confidence in police work in Switzerland

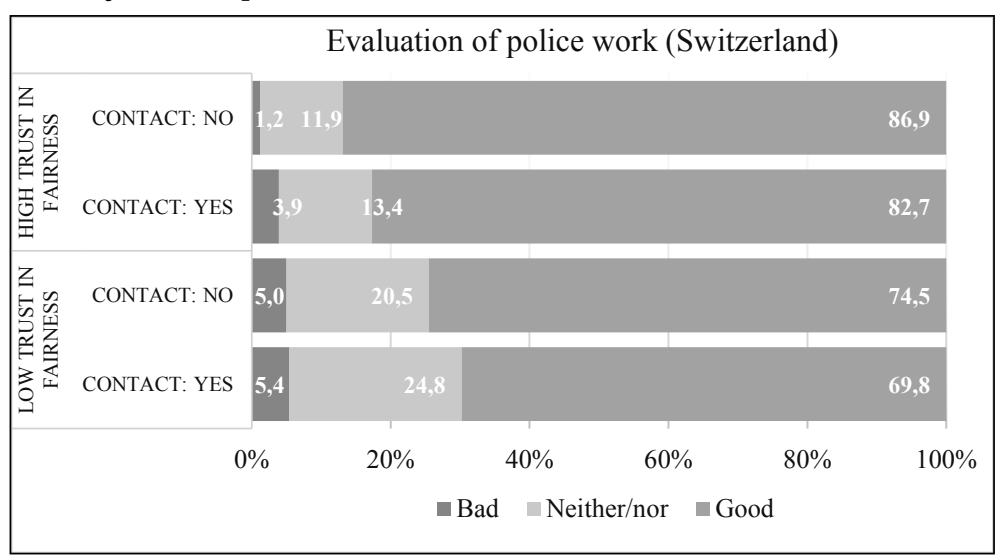

Note: Percent, total numbers: high trust $n=480$, low trust $n=1,011$

Significance levels: high general trust non-significant, low general trust $p<0.05$

Finally, the influence of social trust on procedural fairness is analyzed. In Western European countries, as shown in Figure 19, the number of people not crediting the police with being respectful and making fair decisions 
becomes larger the lower the social trust is and it is larger overall amongst those people with experience with the police. When looking at differences between people having been in contact with the police and those not stopped, it became obvious that the difference is largest for pessimistic people, where the negative evaluation becomes worse for those stopped by the police, with $8.3 \%$ fewer positive ratings of police's procedural fairness (57.8\% vs. $66.1 \%)$. Contrary to this, the evaluation of police's procedural fairness does not differ between the contact/non-contact groups of people with a moderate social trust in others. Finally, it is only small for those with high social trust (-3.6\%).

Again, results are contrary in Eastern European countries (Figure 20). First, the figures reveal that people assign general procedural fairness to the police less often overall than in the West, where about $83 \%$ of people rate the police as implementing procedural fairness. Secondly, the difference in the evaluation of police's procedural fairness between the groups of people the police stopped and those not being contacted is larger for those trusting their fellow man. Such people, with high social trust and experience with the police, rate the police $9.6 \%$ less as treating people respectfully, making fair decisions, and explaining their decisions compared to those that were not contacted (72.3\% vs. 62.7\%). On the other hand, the difference in evaluation is lower between the groups of pessimistic people not trusting their fellow man (-7.2\%).

Of the Swiss population, more than $80 \%$ believe that the police use procedural fairness, while less than $20 \%$ do not attribute fairness and respectfulness to the police. When looking at the results achieved for social trust and procedural fairness, it can be seen that suspicious people in particular attribute fair procedures to the police less often in cases where they experienced a police stop (Figure 21). 
Figure 19: Social trust, police contact, and trust in police's procedural fairness in Western Europe

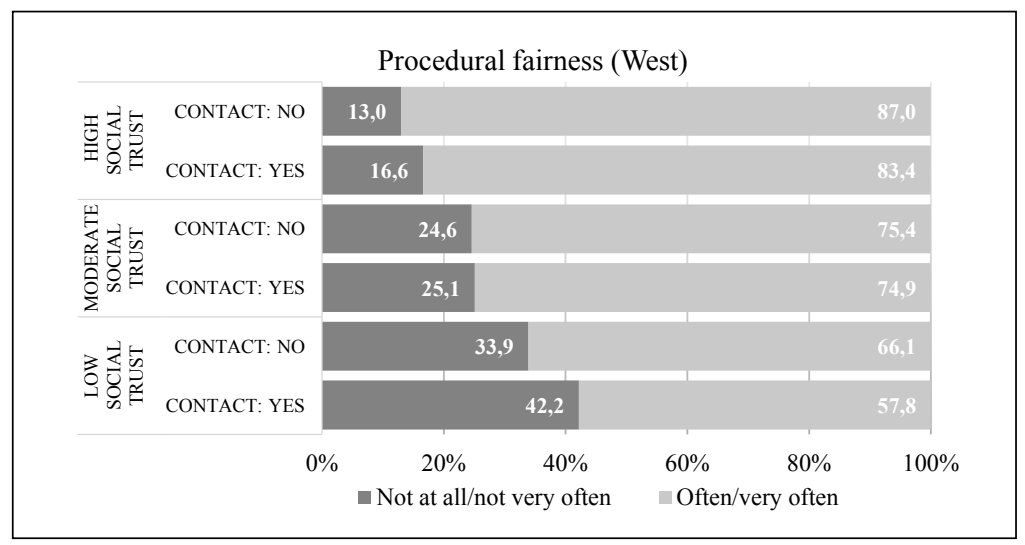

Note: Percent, total numbers of social trust: low $=1,898$, moderate $=10,975$, high $=6,696$ Significance level: low and high social trust: $p<0.001$, moderate: non-significant

Figure 20: Social trust, police contact, and trust in police's procedural fairness in Eastern Europe

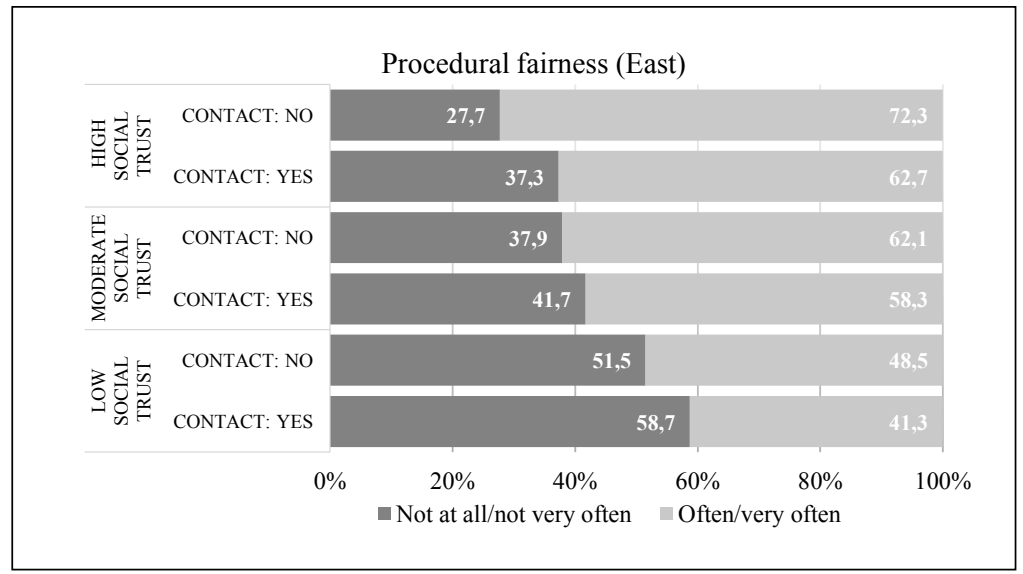

Note: Percent, total numbers of social trust: low $=1,238$, moderate $=2,948$, high $=1,039$ Significance level: low and high social trust: $p<0.01$, moderate: $p<0.05$ 
Figure 21: Social trust, police contact, and trust in police's procedural fairness in Switzerland

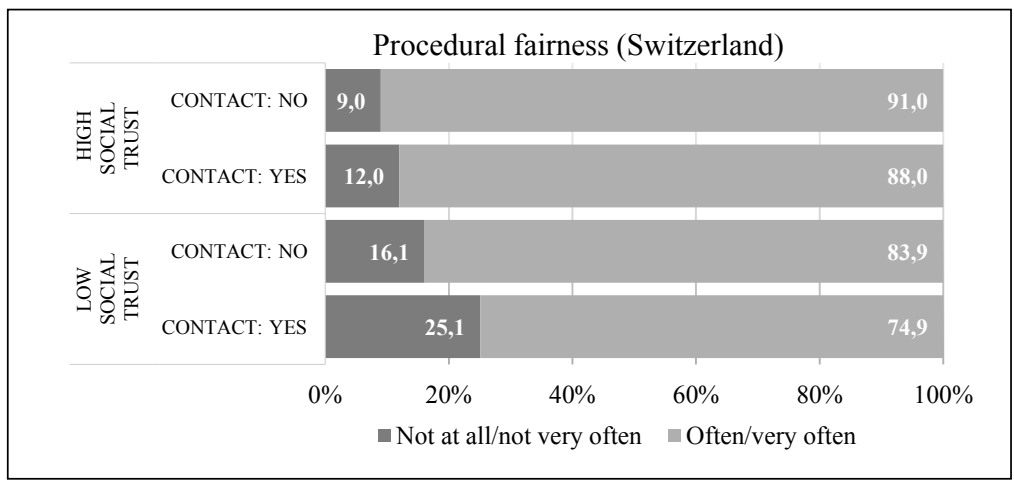

Note: Percent, total numbers of social trust: low $=473$, high $=1,024$

Significance level: low social trust: $p<0.05$, high social trust: non-significant

Thus far, it can be summarized that social trust measured by positive opinions of other people's trust, their fairness and helpfulness correlate with trust in the police, independently of a contact experience with the police. In both Western and Eastern Europe, as well as in the case of Switzerland, unfavorable evaluations of police work are especially strong among suspicious people being stopped by the police. Results reconfirm those of other studies (Kaase 1999; Newton/Norris 1999; Rothstein/Stolle 2008; Kääriäinen/Sirén 2011; Grönlund/Setälä 2012).

Social trust has a positive impact on trust in institutions like the police. Results confirm Hypothesis 4. However, results differ for trust in police's procedural fairness. In Western Europe and in Switzerland, the difference between the contact and the non-contact group is especially strong for people with low social trust. In Eastern Europe, the contrary is true. It is hard to explain these differences without further information on the circumstances of the police encounter and on people with different levels of social trust. It may, for example, being possible that very suspicious people in the West are part of subcultures encountering the police in more conflictive situations, such as demonstrations or illegal behaviors. Furthermore, several studies show that social trust is influenced by individual characteristics such as education, age, and income. Those with a higher level of education generally exhibit greater trust toward their fellow citizens. In addition, higher education leads to more trust in imme- 
diate social surroundings and to more trust targeted at people in general (Uslaner 2002; Rothstein/Stolle 2008; Freitag/Traunmüller 2009). With regard to age, several studies show that older people have a higher trust in their fellow citizens (Uslaner 2002; Rothstein/Stolle 2008). Freitag and Traunmüller (2009) found that older people trust foreigners as well as familiar people more. When it comes to cross-country effects, many studies have shown that income inequality is among the most robust determinants of trust. Anything that reduces the social distance between citizens of a country could be expected to lead to more individual trust (Bjørnskov 2007).

Cross-tabulations show statistically significant differences in social trust for age, education, ethnic minority, income, life satisfaction, criminal victimization, fear of crime, and going out for both Western and Eastern European clusters. Gender only differs in Western Europe, with females having a higher social trust than males. People with high social trust are marked by high religiousness, high income, and high life satisfaction overall. Furthermore, they are more often settled on the right side of the political scale, are well educated, meet frequently with friends, are a victim of a crime slightly less often, have a low fear of crime, and are less often a member of an ethnic minority (results not shown here). Individual characteristics also play a role in trust in the police. Therefore, the following chapter will examine whether these moderate results exist.

\subsection{Encounters and the influence of individual and contextual factors}

With all the information of the previous chapters in mind, I calculated linear regression models measuring the impact of satisfaction with the treatment received on overall trust in the police. I controlled for variables found to have an influence on the likelihood of being stopped by the police, as well as general socio-demographic variables shown to be directly related to trust in the police. Results for the Western European cluster found so far confirm the impact of satisfaction on trust in the police, with the positive impact being larger than the negative one (Table 24). Even though social trust and socio-demographic variables moderate, especially the high impact of very satisfied people, it still holds the strongest position in the final Model 5, 
leading to an $11 \%$ higher trust in the police ${ }^{9}$. Negative evaluations, on the other hand, are less strong.

Furthermore, results confirm the overall positive impact of social trust on trust in the police. Looking at the influence of social trust on the perception of police encounters, it can be seen - when comparing Models 1 and 2 - that social trust explains part of the level of satisfaction with police contact. In particular, it moderates the very satisfied score, which is. 157 points lower in Model 2, as well as those of dissatisfaction (minus. 161). The reduction for satisfied (minus. 041) and very dissatisfied (minus. 102) is smaller.

A strong impact can be seen for governmental trust, very largely influencing trust in the police (Model 3). In particular, it contributes to the influence of very satisfied people. Control variables in Model 4 reduce the values of satisfaction slightly. As numbers in the final model, after the inclusion of country dummies, do not change strongly, the found results are robust across countries. The final model explains $47 \%$ of the variance of trust in the police, which is very good ${ }^{10}$.

Concerning the impact of socio-demographic factors, the overall picture matches other research results. Statistically significant impacts are found for gender, with women having a higher trust in the police than men. Furthermore, the youngest age group has lower trust in the police compared to the over-6o-year-olds. A negative impact on the image of the police is furthermore found for education and a settling on the left side of the political scale. Contrary to this, high religiosity and satisfaction with life as a whole lead to a slightly better opinion of the police. While criminal victimization leads to a more negative opinion of the police, people who feel unsafe when walking alone in a local area after dark trust the police more.

9 | Even though this result clearly shows higher trust in the police for people very satisfied with treatment received by the police, it is targeted towards the mean level of trust in the police. Hence, no statements can be made about the position on the trust in the police scale. One possibility to achieve results that are more precise is the use of quantile regression (cf. Hohl 2009). Since I am not experienced in the method, I will not apply it here.

10 | Of course, this can be partly due to the high number of items included in the regression analyses. For a critical discussion on the interpretation of $\mathrm{R}^{2}$, cf. Baltes-Götz 2016. 
Table 24: Impact of police encounters, social trust, governmental trust, and control variables on trust in the police in Western Europe (linear multivariate regressions)

\begin{tabular}{|c|c|c|c|c|}
\hline & \multicolumn{4}{|c|}{ Trust in the police in Western Europe } \\
\hline & Model 1 & Model 2 & Model 3 & Model 4 \\
\hline (Constant) & $6.543 * * *$ & $4.298 * * *$ & $2.758^{* * *}$ & $3.478^{* * *}$ \\
\hline 1. Police-initiated contact & $-.893 * * *$ & $-.820^{* * *}$ & $-.688 * * *$ & $-.598 * * *$ \\
\hline \multicolumn{5}{|c|}{ 2. Satisfaction with contact (ref: neutral) ${ }^{l}$} \\
\hline Very satisfied & $1.602 * * *$ & $1.445^{* * *}$ & $1.136^{* * *}$ & $1.098^{* * *}$ \\
\hline Satisfied & $.815^{* * *}$ & $.774 * * *$ & $.615^{* * *}$ & $.606^{* * *}$ \\
\hline Dissatisfied & $-.734 * * *$ & $-.573 * * *$ & $-.402 * * *$ & $-.341 * * *$ \\
\hline Very dissatisfied & $-.419 * * *$ & $-.317 * *$ & $-.231 * *$ & $-.198 * * *$ \\
\hline 3. Social trust $(0-10)$ & & $.411^{* * *}$ & $.106^{* * *}$ & $.094^{* * *}$ \\
\hline \multicolumn{5}{|l|}{ 4. Governmental trust $(0-10)$} \\
\hline Trust in politics & & & $.033^{* * *}$ & $.044 * * *$ \\
\hline Trust in the legal system & & & $.503 * * *$ & $.483 * * *$ \\
\hline \multicolumn{5}{|l|}{ 5. Control variables } \\
\hline Female (ref: male) & & & & $.136^{* * *}$ \\
\hline \multicolumn{5}{|l|}{ Age groups (ref: $>59$ years) } \\
\hline $14-25$ years & & & & $-.345^{* * *}$ \\
\hline $26-39$ years & & & & 0,011 \\
\hline $40-59$ years & & & & $-.084 * *$ \\
\hline Years of education & & & & $-.189 * * *$ \\
\hline Citizen of country (ref: no) & & & & 0,115 \\
\hline Ethnic minority (ref: no) & & & & $-.435^{* * *}$ \\
\hline High income (ref: low) & & & & 0,045 \\
\hline Religiousness (ref: low) & & & & $.075^{* *}$ \\
\hline Political orientation: (ref: moderate) & & & & $-.262 * * *$ \\
\hline \multicolumn{5}{|l|}{ Left } \\
\hline Right & & & & $-0,012$ \\
\hline Life satisfaction (ref: low) & & & & $.188^{* * *}$ \\
\hline Criminal victimization (ref: no) & & & & $-.134 * * *$ \\
\hline Fear of crime (ref: no) & & & & $.160^{* * *}$ \\
\hline \multicolumn{5}{|l|}{ Going out (once/several times a month) } \\
\hline Up to once a month & & & & 0,020 \\
\hline Once/several times a week & & & & 0,011 \\
\hline Every day & & & & 0,011 \\
\hline \multicolumn{5}{|l|}{ Agglomeration type (ref: core city) } \\
\hline Agglomeration & & & & $-0,048$ \\
\hline Town, small city & & & & $-0,056$ \\
\hline Rural & & & & 0,058 \\
\hline adj. $R^{2}$ & 0,053 & 0,147 & 0,438 & 0,474 \\
\hline $\mathrm{N}$ & 17,818 & 17,818 & 17,818 & 17,818 \\
\hline
\end{tabular}

Note: Source: ESS2010: full sample; B-coefficients of OLS regression

Dependent variable: trust in the police

Model 4: including country dummies (not shown here)

Significance levels: $* 0.05<p>0.01, * * 0.01<p>0.001, * * * p>0.000$

${ }^{1}$ Question was only directed towards people stopped by the police

So far, analyses confirmed the asymmetry hypothesis for the Eastern Europe cluster only, showing that the negative impact of an unfavorable 
evaluation on trust in the police is stronger than the positive impact of a favorable one. This result rests stable in the final analyses (Table 25). Let us start again with the role of social trust. As in the West, it contributes to a positive opinion of the police, leading to higher trust in them. Furthermore, it moderates the value of the very dissatisfied people in particular. It leads to a reduction of. ${ }_{16} 3$ in the value between Model 1 and Model 2, while the positive impact of those being very satisfied remains nearly at the same high level. Model 3 shows the strong impact of governmental trust, especially trust in the legal system. Together with trust in politics, it strongly reduces the value of very dissatisfied people (minus. 6oo). At the same time, the impact of social trust on trust in the police becomes weak $(\mathrm{B}=.085)$. The explanation force of this model is already strong, at $\mathrm{R}^{2}=.443$. The inclusion of socio-demographics in Model 4 only slightly reduces the values found so far. Contrary to the West, far fewer variables reach statistical significance. As in the Western European cluster, young age leads to lower trust in the police. Moreover, criminal victimization but also fear of crime contributes negatively to the image of the police. Finally, people who meet socially with friends, colleagues, and family members on a daily basis have a higher trust in the police. Again, dummy variables for Model 5 do not lead to large changes in numbers, which prove the robustness of the results across countries. The final model explains $46 \%$ of the variance of trust in the police, which is slightly less than in the Western European cluster.

In a last step, results for Switzerland are compared with those of the Western and Eastern European cluster. As already seen in the chapter 7.5.2: Satisfaction with treatment received, dissatisfaction with the treatment received by the police does not have a negative impact on trust in the police in Switzerland, while it does in Western and Eastern Europe. This non-significant effect rests after controlling for social trust and several control variables (Table 26 ). In addition, the positive impact of very satisfied people is still the highest amongst the groups examined $(B=1.296)$. As in the analyses for Western and Eastern Europe, the positive impact of social trust on trust in the police diminishes after including institutional trust items but rests statistically significant. While the effects of trust in politics on trust in the police are very low in Western and Eastern Europe, they are close to zero in the case of Switzerland, which means they have no influence. Contrary to that, trust in the legal system seems to be important. Furthermore, in line with results for Western European countries, 
age does matter: The younger people are the less they trust in the police compared to those older than 59 years. In addition, with an increase in education the level of trust declines. Furthermore, the more satisfied people are with life, the higher their trust in the police.

No impact was found for gender, which contradicts the result for Western Europe and other studies in the field (Percy 1980; Brandl/Horvath 1991; Cao/Frank/Cullen 1996; Schafer/Huebner/Bynum 2003; Wu/Sun 2009). There must be other explanations for the fact that men were more often stopped by the police than women (Skogan 2005; Bradford/Jackson/ Stanko 2009; Jackson/Bradford/Stanko/Hohl 2012), which also occurs in Switzerland (Staubli 2014). In addition, religiousness does not seem to matter, which contradicts results from Schwarzenegger (1992).

A different result can also be reported for citizens of the country. While there is no impact in Western and Eastern Europe, in Switzerland, those possessing the Swiss citizenship have a lower trust in the police compared to those who are not citizens, even though they are less often stopped by the police (Staubli 2014). This result confirms earlier analyses, which showed that people born in Switzerland rate the police more negatively than immigrants, especially compared to those living in Switzerland for only a couple of years and coming from Mediterranean countries (Clerici/Killias 1999). Clerici and Killias (1999) show that - contrary to findings in other countries - foreigners rate the police even higher than Swiss citizens, which may partly be explained by the fact that immigrants have negative views of and experiences with the police in their countries of origin, especially refugees from unstable countries at war or affected by other conflicts. Therefore, when they compare the behavior of Swiss police officers with those in their countries of origin, it is understandable that the Swiss Police are rated far better.

Contrary to Western Europe, no significant effect was found for people belonging to the left side of the political spectrum. However, those on the right side have a higher trust in the police, which confirms the results found by Cao, Stack, and Sun (1998). Moreover, those going out less than once a month seem to trust the police less in Switzerland, which cannot be reported for the Western and Eastern European clusters.

Finally, regions in Switzerland were also controlled for. Results show that people from Zurich have a lower trust in the police compared to those from central Switzerland. This is in line with results found by Kääriäinen (2007) who showed that rurally people have a higher trust in the police compared to those living in urban areas. Nevertheless, no in- 
fluences were found for any of the samples for the general agglomeration type items.

Table 25: Impact of police encounters, social trust, governmental trust, and control variables on trust in the police in Eastern Europe (linear multivariate regressions)

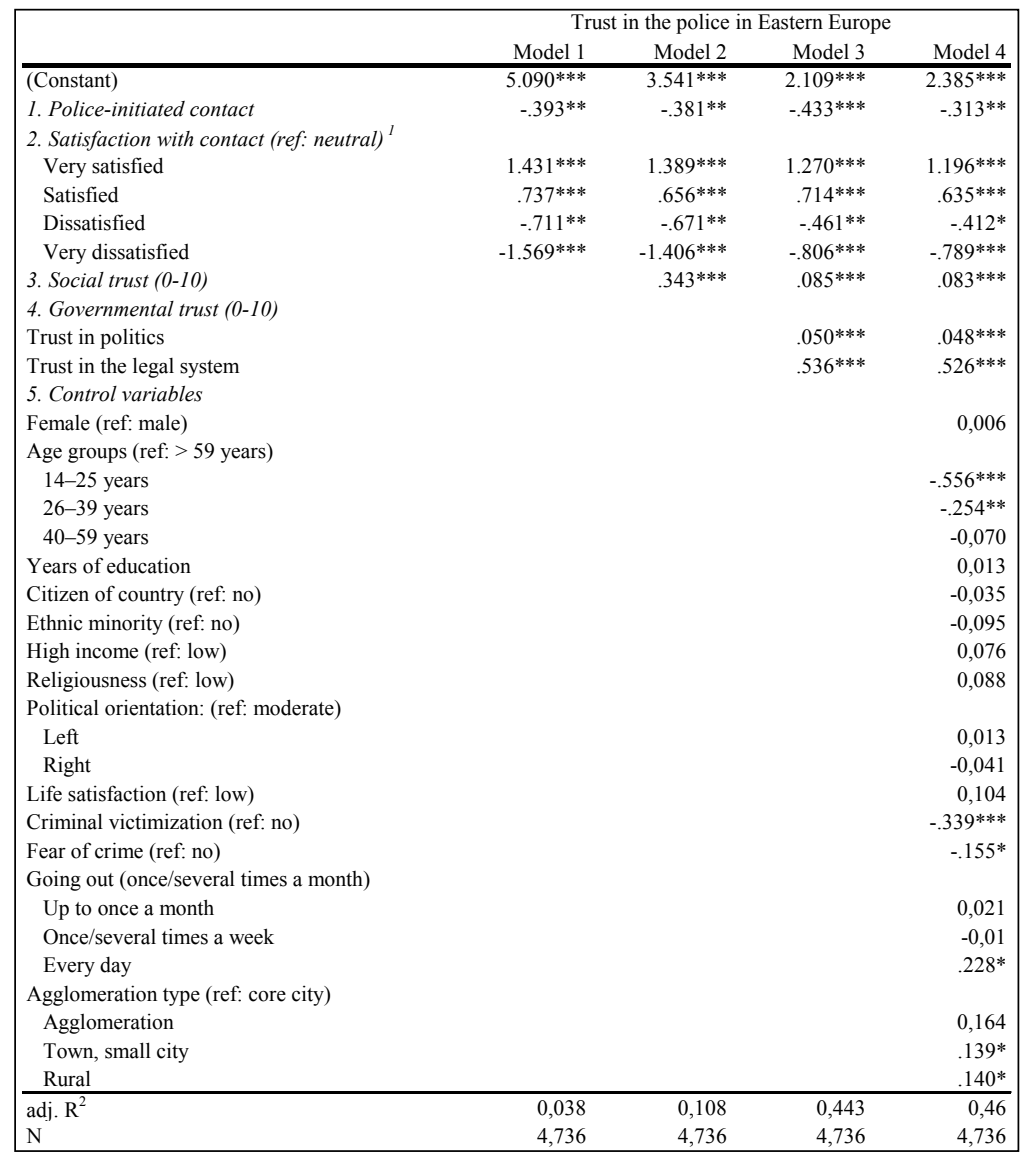

Note: Source: ESS2010: full sample; B-coefficients of OLS regression

Dependent variable: trust in the police

Model 4: including country dummies (not shown here)

Significance levels: $* 0.05<p>0.01, * * 0.01<p>0.001, * * * p>0.000$

${ }^{1}$ Question was only directed towards people stopped by the police 
The final model explains $43 \%$ of the variance of trust in the police in Switzerland. Standardized values of Model 4 reveal the largest explanation force for "trust in the legal system" ( $\beta=.568)$, followed by "very satisfied" ( $\beta=.204)$ (results not shown here). This confirms that opinions of the institution police are closely linked to opinions of justice as a whole. Moreover, very positive experiences with police officers strengthen opinions of the institution police as a whole.

Results in the preceding chapters have proved that social trust contributes not only to the explanation of trust in the police but also influences the level of satisfaction with treatment received in a police encounter. Different impacts on trust in the police were found for people with low, moderate, and high social trust. Based on these facts, I calculated the regression analyses for these subsamples of people with low, moderate, and high social trust individually. In addition, governmental trust was found to be related to trust in the police. Nevertheless, the overall distribution is similar to trust in the police, with people with low trust in the police having low governmental trust as well. Due to this very low variance, regression analyses for subsamples are inadequate.

Calculating the analyses with the trichotomous samples shows that the positive impact of satisfaction primarily evolves in people with low general trust in their fellow man (Table 27). Satisfied, low-trust people show an approximately 1.7 to 1.9 times higher trust in the police over all models compared to people reporting being neither satisfied nor dissatisfied with the way the police treated them. Such a positive impact can also be found for people with moderate social trust, but with weaker in numbers. There is also a smaller positive effect amongst high-trusting people. However, the positive number equals that of dissatisfaction. Thus, it can be concluded that the opinion of the police held by people who generally trust their fellow men is not largely affected by the level of satisfaction with treatment received in an encounter. Contrary to this, suspicious people who perceive a treatment as adequate are thankful and trust the police more. Of course, it may also be possible that the type of encounter differs between these two groups of people. As previously mentioned, very suspicious people may belong to subcultures that are contacted by the police in other circumstances than high-trusting people. However, in order to prove such an assumption, further information about the circumstances of encounters would be needed. 
As in the full sample above, the strength of trust in governmental institutions is confirmed here in Model 2, leading to an $\mathrm{R}^{2}$ of .37 to .39 . These models already explain about $38 \%$ of the variance of trust in the police. It moderates the high impact of satisfaction on trust in the police in particular. The influence of socio-demographic and other individual features, such as going out, contribute only marginally to these results, as shown in Model 3. Interestingly, these factors not only reduce the positive impact of satisfaction on trust in the police amongst high-trusting people $(\mathrm{B}=.381)$ but also lead to an increase in the negative impact of dissatisfaction ( $\mathrm{B}=-.430$ ). The negative impact of dissatisfaction becomes stronger than the positive impact of satisfaction, confirming the asymmetry hypothesis, at least for those people with high social trust. Effects do not change drastically when controlling for country effects in Model 4 , with the exception of the positive impact of satisfaction amongst those with low social trust, which becomes even stronger $(B=1.816)$. However, it can be stated that the results found here are more or less stable across countries.

Contrary to the West, dissatisfaction with the police was found to negatively influence trust in the police in Eastern European countries. The impact was about the same as the positive one of satisfaction. However, the strong negative effect was largely reduced after the inclusion of governmental trust. Can the positive impact of satisfaction also be explained by different levels of social trust? There is indeed a difference between people with a low, moderate, and high social trust (Table 28). However, contrary to Western Europe, the positive impact of satisfaction on trust in the police is especially high amongst the high-social-trust group, while the negative impact of dissatisfaction is found amongst the low-social-trust group. Even though this difference is reduced by the inclusion of further items, it still exists in the final Model $4(\mathrm{~B}=.923)$ and can therefore be seen as robust across countries. According to the variance explained, the largest value $\left(\mathrm{R}^{2}=.439\right)$ can be reached using the sample of people with low social trust, while in the West it was those with the highest social trust. For Switzerland, due to the smaller sample, no such analyses have been conducted. 
Table 26: Impact of police encounters, social trust, governmental trust, and control variables on trust in the police in Switzerland (linear multivariate regression)

\begin{tabular}{|c|c|c|c|c|}
\hline & \multicolumn{3}{|c|}{ Trust in the police in Switzerland } & \multirow[b]{2}{*}{ Model 4} \\
\hline & Model 1 & Model 2 & Model 3 & \\
\hline (Constant) & $7.234 * * *$ & $5.348^{* * *}$ & $3.161^{* * *}$ & $4.198^{* * *}$ \\
\hline 1. Police-initiated contact & $-1.234 * * *$ & $-1.116^{* * *}$ & $-.981 * * *$ & $-.861 * * *$ \\
\hline \multicolumn{5}{|c|}{ 2. Satisfaction with contact (ref: neutral) ${ }^{I}$} \\
\hline Very satisfied & $1.743^{* * *}$ & $1.586^{* * *}$ & $1.464 * * *$ & $1.296^{* * *}$ \\
\hline Satisfied & $1.000^{* *}$ & $.860^{* * *}$ & $.754 * * *$ & $.695^{* * *}$ \\
\hline Dissatisfied & $-0,471$ & $-0,466$ & $-0,141$ & $-0,113$ \\
\hline Very dissatisfied & 0,392 & 0,249 & $.679^{*}$ & 0,655 \\
\hline 3. Social trust $(0-10)$ & & $.317^{* * *}$ & $.136^{* * *}$ & $.107^{* *}$ \\
\hline \multicolumn{5}{|l|}{ 4. Governmental trust $(0-10)$} \\
\hline Trust in politics & & & 0,000 & 0,000 \\
\hline Trust in the legal system & & & $.507^{* * *}$ & $.519 * * *$ \\
\hline \multicolumn{5}{|l|}{ 5. Control variables } \\
\hline Female (ref: male) & & & & 0,043 \\
\hline \multicolumn{5}{|l|}{ Age groups (ref: $>59$ years) } \\
\hline $14-25$ years & & & & $-.586^{* *}$ \\
\hline $26-39$ years & & & & $-.440^{* *}$ \\
\hline $40-59$ years & & & & $-.421 * * *$ \\
\hline Years of education & & & & $-.211 *$ \\
\hline Citizen of country (ref: no) & & & & $-.468^{* *}$ \\
\hline Ethnic minority (ref: no) & & & & $-0,089$ \\
\hline High income (ref: low) & & & & $-0,011$ \\
\hline Religiousness (ref: low) & & & & 0,043 \\
\hline \multicolumn{5}{|l|}{ Political orientation (ref: moderate) } \\
\hline Left & & & & $-0,179$ \\
\hline Right & & & & $.273^{* *}$ \\
\hline Life satisfaction (ref: low) & & & & $.368 *$ \\
\hline Criminal victimization (ref: no) & & & & $-0,047$ \\
\hline Fear of crime (ref: no) & & & & 0,062 \\
\hline \multicolumn{5}{|c|}{ Going out (ref: once or several times a month) } \\
\hline Up to once a month & & & & $-.569 *$ \\
\hline Once/several times a week & & & & 0,116 \\
\hline Every day & & & & $-0,026$ \\
\hline \multicolumn{5}{|l|}{ Agglomeration type (ref: core city) } \\
\hline Agglomeration & & & & $-0,194$ \\
\hline Town, small city & & & & $-0,079$ \\
\hline Rural & & & & $-0,016$ \\
\hline \multicolumn{5}{|l|}{ Region (ref: Central part) } \\
\hline Region around Lake Geneva & & & & $-0,333$ \\
\hline Midlands & & & & $-0,228$ \\
\hline Northwest & & & & 0,172 \\
\hline Zurich & & & & $-.368 *$ \\
\hline Eastern part & & & & $-0,112$ \\
\hline Southern part & & & & 0,003 \\
\hline$\overline{\text { adj. } R^{2}}$ & 0,053 & 0,117 & 0,398 & 0,430 \\
\hline $\mathrm{N}$ & 1,194 & 1,194 & 1,194 & 1,194 \\
\hline
\end{tabular}

Note: Source: ESS2010, full sample $(n=1,194)$, Durbin-Watson $=2.059$; Coefficients of OLS regression, dependent variable: trust in the police

${ }^{1}$ Question was only directed towards people stopped by the police; Due to heteroscedasticity, Model 4 was re-calculated with adjusted standard errors; 'very dissatisfied' became non-significant, and 'social trust' reached only a $p<0.01$ instead of $p<0.001$; Significance levels: $* 0.01<p<0.05$, ** $0.001<p<0.01$, *** $p<0.001$ 
The impact of encounters with the police differs according to the level of social trust people have. Moreover, the impact of satisfaction with how the police have treated the case on trust in the police is different for the subsamples. It is expected that the groups of people belonging to the low- or high-social-trust sample differ between Western and Eastern Europe. The strong positive impact of satisfaction on trust in the police amongst people with very low social trust in the West may point to a marginalized group. In order to make well-founded statements, however, further analyses of these different social trust groups would be needed. Yet, this would go beyond the topic of this book.

\subsection{Summary}

Results confirm that non-voluntary police stops have a strong influence on trust in the police. Positive experiences in particular lead to higher trust. However, their influence becomes smaller when considering other institutional and attitudinal items. An overall trust in the police is closely linked to opinions of their work and their procedural fairness. Particularly, opinions of how well the police are doing their job are strong indicators of an overall trust in them. Moreover, trust in the police relates to trust in other institutional items, particularly to trust in the legal system.

\section{Summary}

While instrumental approaches link attitudes toward the police with opinions of their effectiveness, theories of procedural justice focus on correct and fair behavior. Results from analyses at the macro level confirm that both confidence in police work and trust in police's procedural fairness correlate significantly with an overall trust in the police. This is true across countries, even though the variance is larger amongst Eastern European and Mediterranean countries. What's more, results also suggest that there are correlations between social trust and trust in the police across countries. Significant results are also found for confidence in the work of police and procedural justice. However, the correlation with people's opinion of police work in particular is weaker, with larger variations between countries. 
Table 27 (Part 1): Impact of police encounters, governmental trust, and control variables on trust in the police in Western Europe, in samples of people with low, moderate, and high social trust (linear multivariate regressions)

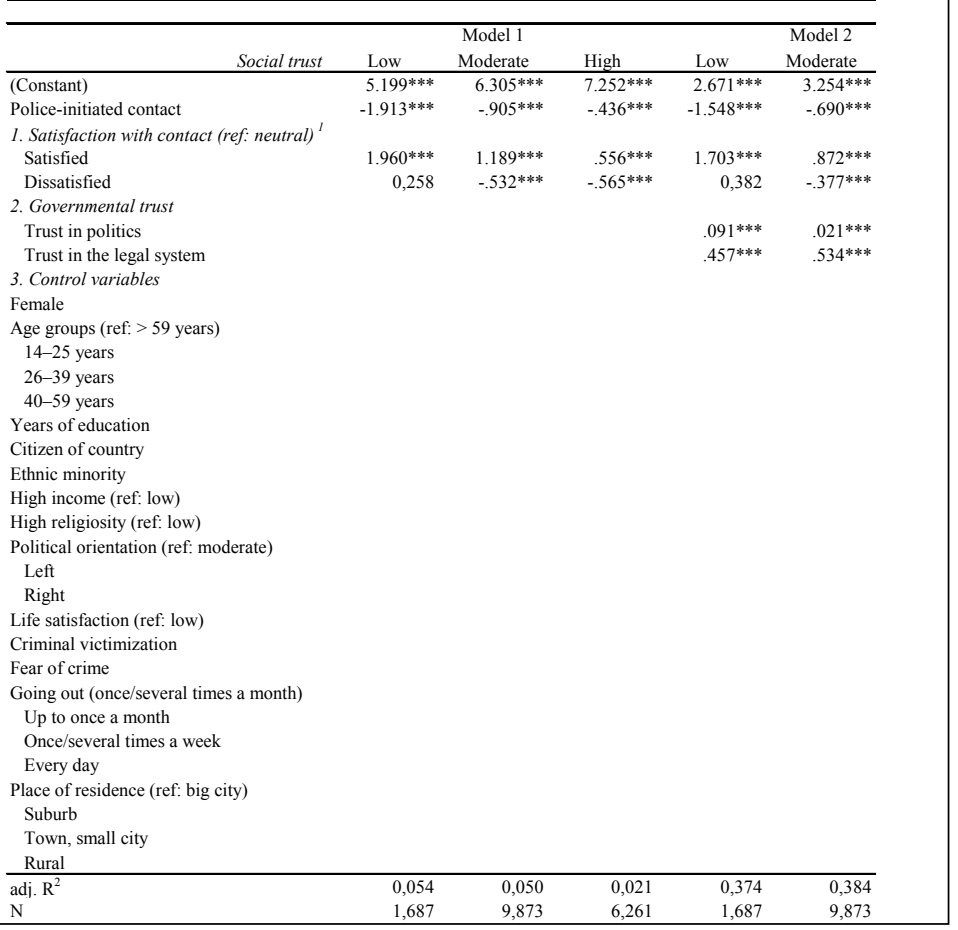

Note: Source: ESS2010: samples of low, moderate, and high social trust; $B$-coefficients of OLS regression, dependent variable: trust in the police

1 Question was only directed towards people stopped by the police; Significance levels: * $0.05<p>0.01, * * 0.01<p>0.001, * * * p>0.00$

Model 4 with country dummies (not shown), excluded by the system: low trust: France, moderate and high trust: Germany 
Table 27 (Part 2): Impact of police encounters, governmental trust, and control variables on trust in the police in Western Europe, in samples of people with low, moderate, and high social trust (linear multivariate regressions)

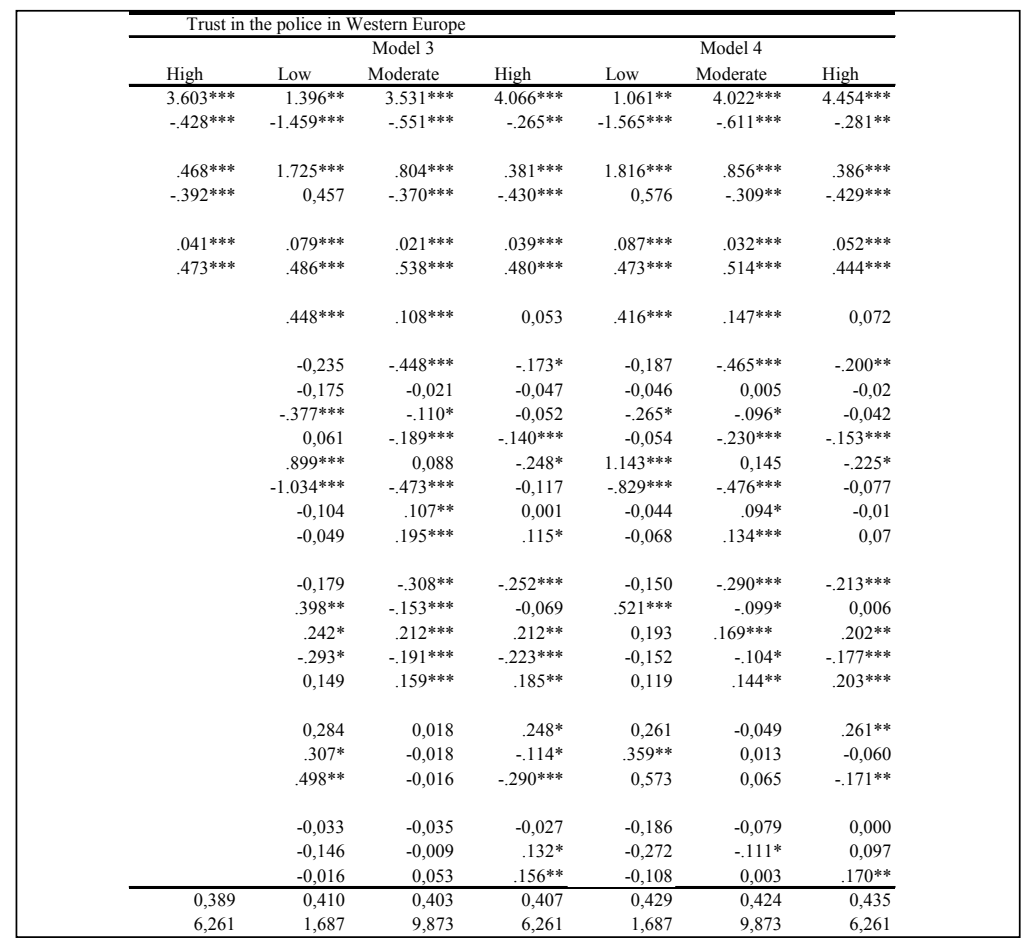

Note: Source: ESS2010: samples of low, moderate, and high social trust; B-coefficients of OLS regression, dependent variable: trust in the police

1 Question was only directed towards people stopped by the police; Significance levels: * $0.05<p>0.01, * * 0.01<p>0.001, * * * p>0.00$

Model 4 with country dummies (not shown), excluded by the system: low trust: France, moderate and high trust: Germany 
Table 28 (Part 1): Impact of police encounters, governmental trust, and control variables on trust in the police in Eastern Europe, in samples of people with low, moderate, and high social trust (linear multivariate regressions)

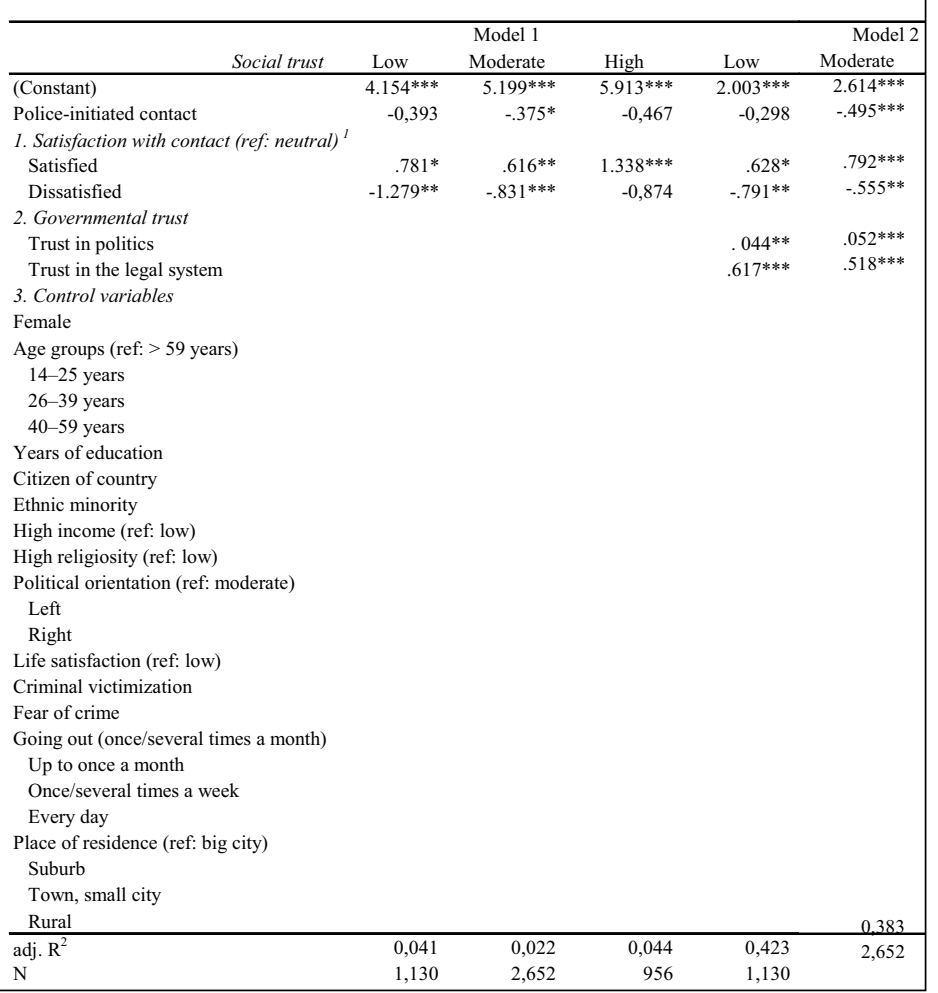

Note: Source: ESS2010: samples of low, moderate and high social trust; B-coefficients of OLS regression, dependent variable: trust in the police

${ }^{1}$ Question was only directed towards people stopped by the police; Significance levels: * $0.05<p>0.01, * * 0.01<p>0.001, * * * p>0.00$

Model 4 with country dummies (not shown), excluded by the system: low trust: France, moderate and high trust: Germany 
Table 28 (Part 2): Impact of police encounters, governmental trust, and control variables on trust in the police in Eastern Europe, in samples of people with low, moderate, and high social trust (linear multivariate regressions)

\begin{tabular}{|c|c|c|c|c|c|c|}
\hline \multicolumn{7}{|c|}{ Trust in the police in Eastern Europe } \\
\hline \multirow[b]{2}{*}{ High } & \multicolumn{3}{|c|}{ Model 3} & \multicolumn{3}{|c|}{ Model 4} \\
\hline & Low & Moderate & High & Low & Moderate & High \\
\hline $2.819^{* * * *}$ & $1.017^{* * *}$ & $3.077^{* * *}$ & $2.938^{* * *}$ & $1.244 * * *$ & $3.333 * * *$ & $2.868^{* * *}$ \\
\hline$-0,394$ & $-0,312$ & $-.336 *$ & $-0,187$ & $-0,280$ & $-.363 * *$ & $-0,183$ \\
\hline $1.044^{* * * *}$ & 0,586 & $.683 * * *$ & $.933^{* *}$ & $.592 *$ & $.718^{* * *}$ & $.923 * *$ \\
\hline$-0,439$ & $-.749^{*}$ & $-.494 * *$ & $-0,476$ & $-.795 * *$ & $-.482 * *$ & $-0,452$ \\
\hline $.055^{* * * *}$ & $.041^{*}$ & $.047 * * *$ & $.047 * * *$ & $.049 * *$ & $.050^{* * *}$ & $.044^{* * *}$ \\
\hline \multirow[t]{21}{*}{$.494 * * *$} & $.619^{* * *}$ & $.511 * * *$ & $.502 * * *$ & $.612 * * *$ & $.504 * * *$ & $.498^{* * *}$ \\
\hline & $-0,141$ & $-0,016$ & 0,110 & $-0,105$ & 0,003 & 0,118 \\
\hline & $-.517 *$ & $-.530 *$ & $-0,352$ & $-.633 * *$ & $-.620 * * *$ & $-0,371$ \\
\hline & $-0,327$ & $-0,205$ & $-0,176$ & $-.366^{*}$ & $-.246 * *$ & $-0,189$ \\
\hline & 0,084 & $-.214^{*}$ & 0,208 & 0,039 & $-.248^{*}$ & 0,205 \\
\hline & $.288^{*}$ & $-0,085$ & $-0,003$ & $.275^{*}$ & $-0,098$ & $-0,007$ \\
\hline & 0,506 & $-0,250$ & $-0,424$ & 0,633 & $-0,206$ & $-0,266$ \\
\hline & $-0,305$ & $-.377^{*}$ & 0,425 & $-0,129$ & $-0,255$ & 0,434 \\
\hline & $-0,017$ & 0,054 & $-0,020$ & 0,027 & 0,119 & 0,014 \\
\hline & 0,093 & $.243^{* *}$ & 0,181 & $-0,051$ & 0,132 & 0,196 \\
\hline & $-0,174$ & 0,071 & 0,038 & $-0,172$ & 0,069 & 0,058 \\
\hline & $-0,176$ & $-0,019$ & 0,020 & $-0,151$ & $-0,018$ & 0,027 \\
\hline & $-0,026$ & $.231 * *$ & 0,207 & $-0,084$ & $.165^{*}$ & 0,190 \\
\hline & $-0,272$ & $-.257 *$ & $-.644 * *$ & $-0,223$ & $-.278^{*}$ & $-.704 * * *$ \\
\hline & $-0,106$ & $-.343 * * *$ & 0,061 & $-0,052$ & $-.283 * *$ & 0,089 \\
\hline & $-0,017$ & $.005^{* * * *}$ & $.041^{* * *}$ & 0,046 & 0,032 & 0,050 \\
\hline & 0,181 & $-0,125$ & $-.062 * * *$ & 0,190 & $-0,071$ & $-0,026$ \\
\hline & 0,289 & 0,100 & $.015^{* * *}$ & 0,371 & 0,223 & 0,097 \\
\hline & 0,227 & $-0,127$ & $.473 * * *$ & 0,283 & $-0,012$ & 0,461 \\
\hline & $-0,025$ & $.195^{*}$ & $.069 * * *$ & 0,000 & $.210^{*}$ & 0,039 \\
\hline & 0,212 & 0,157 & $.037 * * *$ & 0,178 & 0,175 & 0,025 \\
\hline 0,421 & 0,428 & 0,400 & 0,429 & 0,439 & 0,410 & 0,427 \\
\hline 956 & 1,130 & 2,652 & 956 & 1,130 & 2,652 & 956 \\
\hline
\end{tabular}

Note: Source: ESS2010: samples of low, moderate and high social trust; B-coefficients of OLS regression, dependent variable: trust in the police

${ }^{1}$ Question was only directed towards people stopped by the police; Significance levels: * $0.05<p>0.01, * * 0.01<p>0.001, * * * * 0.00$

Model 4 with country dummies (not shown), excluded by the system: low trust: France, moderate and high trust: Germany 
Concerning institutional influences, trust in the police correlates positively, particularly with trust in legal institutions, but is also influenced by opinions of political institutions, in both Western and Eastern Europe.

Encounters shape people's perceptions of the police. People satisfied with treatment received in a police stop have higher trust in the police, in their procedural fairness, as well as higher confidence in their work. The asymmetry hypothesis stating that the negative impact of an unfavorable rating of a contact on trust in the police is stronger than the positive impact of a favorable evaluation is only confirmed for Eastern Europe. Contrary to expectations, in Western Europe, the positive impact is much stronger, while the negative impact has only very limited weight.

However, this perception differs when considering social trust. Overall, suspicious people who do not trust their fellow man have a more negative opinion of the police compared to persons with high social trust. Additionally, in the West, suspicious people who experienced a police encounter have lower trust in the police than such people who were not stopped by the police. In the East, such a difference in trust in the police amongst people with low social trust is the reverse. The group of suspicious people who did not experience a police encounter has a more negative image of the police than those stopped by the police. 


\section{The perception of crime victims}

\section{INTRODUCTION}

So far, it has been shown that trust in the police is influenced by several factors, such as satisfaction with the treatment received in a police stop. In the following, a special population subgroup is in the focus. Victims of crime can be seen as a special category when it comes to trust in the police. Firstly, they may see the role of the police more critical, not fulfilling their job properly. Secondly, when they approach the police, they seek help, which may distinguish them from people in regular police-citizen-contacts initiated by the police. I will start with information on victims' trust in the police. The following chapter deals with police encounters initiated by crime victims.

\section{Victims trust in the police}

When splitting the file of the ESS2010 into two groups of crime victims and non-crime victims, results show clear differences between them. Trust in the police is lower amongst victims in Western and Eastern Europe (Table 29) ${ }^{1}$. Furthermore, victims are significantly less satisfied with police encounters (Table 30).

1 | Victimization is measured as burglary and assault in the ESS2010. 
Table 29: Impact of victimization on trust in the police

\begin{tabular}{|llllll|}
\hline & \multicolumn{3}{c}{ Police doing good/bad job in country } & \multicolumn{2}{c|}{ Procedural fairness } \\
Victim & Bad & Neither/nor & Good & No & Yes \\
\hline \multicolumn{7}{c}{ Western Europe } \\
\hline Yes & $9.7(383)^{* * *}$ & $26.6(383)$ & $65.9(1,840)$ & $28.0(975)^{* * *}$ & $72.0(2,510)$ \\
No & $5.9(1,111)$ & $21.1(3,948)$ & $73.0(13,672)$ & $21.3(3,437)$ & $78.7(12,701)$ \\
\hline \multicolumn{5}{c}{ Eastern Europe } \\
\hline Yes & $19.2(153)^{* * *}$ & $42.6(340)$ & $38.2(305)$ & $54.2(354)^{* * *}$ & $45.8(299)$ \\
No & $10.5(623)$ & $37.5(2,230)$ & $52.0(3,092)$ & $39.6(1,794)$ & $60.4(2,737)$ \\
\hline \multicolumn{5}{c}{ Switzerland } \\
\hline Yes & $5.0(12)$ & $17.8(43)$ & $77.2(186)$ & $11.0(24)^{* *}$ & $89.0(194)$ \\
No & $2.9(36)$ & $15.3(191)$ & $81.9(1,024)$ & $6.0(67)$ & $94.0(1,046)$ \\
\hline
\end{tabular}

Note: Source: ESS2010, percent, number of cases in brackets

Significance levels: $* 0.01<p<0.05, * * 0.001<p<0.01, * * * p<0.001$

Table 30: Impact of victimization on satisfaction with police encounters

\begin{tabular}{|llll|}
\hline \multicolumn{4}{c|}{ Satisfaction with police contact } \\
\hline Victim & Dissatisfied & Neither/nor & Satisfied \\
\hline & \multicolumn{3}{c|}{ Western Europe*** } \\
\hline Yes & $27.7(639)$ & $11.4(263)$ & $60.9(1,402)$ \\
No & $21.4(1,364)$ & $10.9(696)$ & $67.7(4,308)$ \\
\hline \multicolumn{4}{c}{ Eastern Europe*** } \\
\hline Yes & $30.6(138)$ & $22.8(103)$ & $46.6(210)$ \\
No & $22.2(374)$ & $20.8(354)$ & $57.2(971)$ \\
\hline \multicolumn{4}{c}{ Switzerland $*$} \\
\hline Yes & $28.8(42)$ & $13.7(20)$ & $57.5(84)$ \\
No & $18.4(91)$ & $11.3(56)$ & $71.3(348)$ \\
\end{tabular}

Note: Source: ESS2010, percent, number of cases in brackets Significance levels: $* 0.01<p<0.05, * * 0.001<p<0.01$, *** $p<0.001$

For Switzerland, differences between victims and non-victims when it comes to the rating of the police are smaller overall compared to those in Western and Eastern Europe. Even when victims in Switzerland evaluate encounters with the police more negatively, their general attitudes toward the police seem to be less negative compared to victims in Europe as a whole. This may simply be caused by an overall more positive evaluation of Swiss police's work and their procedural fairness. Moreover, it is important to note here that there is no link between police encounters and criminal victimization. Further, data do not allow testing of whether the police contact happened before the incident or after. 
When comparing frequencies of the European Social Survey ESS2010 with those of the International Crime Victims Survey, they were found to be too high in some and a little bit too low in other countries (see Chapter 4.1.2.1: Victims of crime). This may have an impact on the results. However, as per cluster, this was only the case for certain countries; the overall impact on trust in the police may not be affected. Moreover, it is not the strength of impact that is of interest here, rather if there is an impact at all. This result of difference in trust in the police between crime victims and non-victims has been considered in multiple linear regression analyses before by including criminal victimization as a control variable. Moreover, the use of data from the Swiss Crime Survey 2011 allows consideration of not only contact initiated by the police but also crime victims' reporting to the police, as outlined in the following chapter.

\section{Victim-initiated police contact in Switzerland}

According to data from the European Social Survey ESS2010, 16.2\% (243) of the Swiss population was a victim of a burglary and/or an assault between 2006 and 2010. According to Swiss Crime Survey 2011 data, rates are similar when victimization rates of burglary and assault are added up (17.7\%). As the ESS2010 data does not allow for any further distinctions between different forms of criminal victimization, and neither includes information about victims contact with the police, data from the Swiss Crime Survey 2011 is used to fill this gap.

Criminal victimization is a serious event, greatly affecting people's well-being, especially in cases of violent crime. Such a crime can lead to a disruption in people's trust in the police in terms of failing to fulfill their duties of properly fighting crime. Results confirm that crime victims have lower trust in the police compared to non-victims. This is true for both crime against property and crimes against the person, such as assault or sexual offences (Table 31).

The rate of trust in the police of non-victims is about $73 \%$, while only about half of those whose car or motorcycle was stolen reported trusting the police $(55.1 \%)$. Clearly lower levels of trust are also reported for victims of sexual offences $\left(6_{1.3} \%\right)$, assaults $\left(6_{2} \%\right)$, or attempted burglary $\left(6_{3} .1 \%\right)$. Other offences against property, such as thefts or burglaries seem to lead to lower levels of trust but are not that strongly destructive with regard to 
police's trustworthiness. Results partly support studies where victims of crimes against the person had a less favorable opinion of the police (Killias $1989)$.

Table 31: Victims' trust in the police according to different modes of victimization

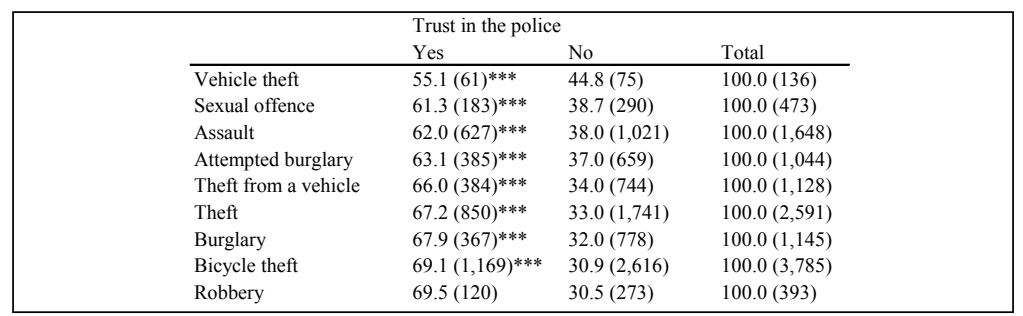

Note: Source: CS2011 (full sample)

Percent of four-year-prevalence rates (2006-2010), number of cases in brackets Significance levels: $* 0.01<p<0.05 * * 0.001<p<0.01$, *** $p<0.001$

In Hypothesis 5.3, I supposed that victims of crimes against the person have lower trust in the police compared to victims of crimes against property. Results only partly confirm this. Low trust in the police amongst victims of vehicle theft suggests that no clear difference in trust levels exists between victims of crimes against the person and victims of crimes against property. It may well be that these variations are based on different experiences with the police. The interaction with the police of someone whose bicycle was stolen may be minimal, resulting in eventual reporting of the offence. Furthermore, the chance that the stolen bike will be found and returned to the owner is small. A car or motorcycle, on the other hand, is more valuable. Hence, such victims have higher expectations of the police, hoping to get their stolen goods back. In order to shed light on this possibility, the rates of reporting are analyzed next. Moreover, the difference in police trust is only marginal between victims of robbery and non-victims and does not meet statistical significance. Reasons may lie in the high level of satisfaction with the treatment received. Robbery victims may also belong to a certain group, such as young people robbed at night while going out. The low influence of the victimization on trust in the police may stem from their involvement, in a group also attacking others, for example. However, further analyses to shed light on this possibility would go beyond the scope of this book. Another possibility is that rob- 
bery victims were satisfied with the treatment received by the police. This eventuality is analyzed later.

In Switzerland, the level of reporting a criminal offence to the police varies widely between different kinds of offences, as shown in Killias and Berruex (1999) and Killias et al. (2011). Results confirm those of the aforementioned studies: highest rates of reporting exist for burglary (79.7\%) as well as for vehicle thefts $(73.5 \% \text {, Table } 32)^{2}$. Contrary to this, offences against the person are rarely reported. For example, only every fourth victim of an assault has reported the offence to the police, and only one sexual offence was reported at all. In cases of sexual offences, people might be ashamed. Moreover, the chance that the offender will be convicted may be evaluated as low, despite the fact that the solve rate is much higher for offences against the person than against property ${ }^{3}$.

Table 32: Reporting to the police over a number of years according to different modes of victimization

\begin{tabular}{|lllll|}
\hline & \multicolumn{4}{c|}{ Reported to the police } \\
& $1989^{1}$ & $2000^{2}$ & $2005^{2}$ & 2010 \\
\hline Vehicle theft (car, motorbike) & 94,0 & 91,7 & 93,3 & $73.5(25)$ \\
Theft from a vehicle & - & 71,0 & - & $46.1(41)$ \\
Bicycle theft & 84,0 & 68,5 & 60,1 & $57.5(122)$ \\
Burglary (dwelling) & 79,0 & 73,1 & 68,0 & $79.7(68)$ \\
Attempted burglary & - & 45,0 & - & $36.0(32)$ \\
Theft (personal larceny) & 42,0 & 45,0 & - & $43.4(93)$ \\
Robbery & 67,0 & 59,4 & 31,3 & $44.6(17)$ \\
Sexual offence & & 10,0 & 18,8 & $-(1)$ \\
Assault & 26,0 & 32,0 & 22,4 & $24.1(43)$ \\
\hline
\end{tabular}

Note: Source: CS2011 (national sample)

Percent, number of cases in brackets for the year 2010 (not available for other years) Sources of numbers of earlier Crime Surveys: 1 Killias 1991; 2 Killias/Haymoz/Lamoz 2007

When looking at the trends since 1989 , it is interesting to note that in 2010 the rate of reported burglaries was, at $79.7 \%$, about the same as it was in 1989 (79\%), while it decreased in the years in between. On the other hand,

2 I In order to facilitate comparison with results from earlier years, analyses are based on data of the weighted national sample here.

3 | The 2013 solve rates are as follows: rape 77.6\%, bodily harm (mean value of heavy and light offences) $78.1 \%$, assault $82.4 \%$, thefts (without vehicle thefts) $16.2 \%$, robbery 33.8\% (Bundesamt für Statistik BFS 2014). 
robbery reporting rates declined steadily, down to a very low level of only $31.3 \%$ in 2005 , increasing again in 2010 (44.6\%). Major changes in reporting also exist for vehicle thefts, where the reduction since 1989 is more than twenty percent. In addition, bicycle thefts were reported less often in $2010(-26.5 \%$ from 1989$)$. However, due to the small number of cases, interpretations of changes should certainly be treated with caution. One possible explanation for the decline in the reporting of the offence with the largest number of cases - vehicle thefts - may be the increase of such thefts, at least between 1999 and 2004 (Killias/Kuhn/Aebi 2011), related to a possible lower solve rate. Moreover, bicycles were of a greater value to the owner back in 1989 , leading to a stronger feeling of loss, while bicycles have become affordable for everyone in recent years. Furthermore, results show that reporting an offence has no significant impact on trust in the police (not shown here), confirming Hypothesis 5.4: Reporting to the police does not correlate with trust in the police. Hence, the argument that reporting to the police is more dependent on personal attributes, such as the age in cases of violent crime (Simonin/Killias 2003) or the amount of damage in cases of burglaries (Killias/Berruex 1999), than on the existing image of the police is supported. However, the direction of causation remains unclear. It may well be possible that people's trust in the police affects their reporting behavior. Suspicious people would probably refrain from reporting an offence more often than people with high trust in the police. In the following, I will elaborate on victims' satisfaction with how the police have treated their case.

Those victims who reported their cases to the police were satisfied overall with the treatment received (Table 33). While victims of burglaries and attempted burglaries in particular seem to be positive $(81.3 \%, 84.8 \%)$, low satisfaction rates are found for assault (58.7\%). One source of victims' dissatisfaction is the information policy of the police. Only between $46.4 \%$ and $59.8 \%$ of victims of a crime received information about further steps taken (Table 34). Of those not informed, the majority express the wish to be informed about subsequent steps. This is especially true for victims of a robbery (73\%) but also for victims whose car or motorcycle was stolen, or who had something stolen out of their car (69\%). 
Table 33: Victims' satisfaction with treatment received by the police according to different modes of victimization

\begin{tabular}{|lll|}
\hline & \multicolumn{2}{l|}{ Satisfied with treatment of case } \\
\hline Yssault & $58.7(105)$ & No \\
Vehicle theft & $69.4(84)$ & $30.6(37)$ \\
Robbery & $71.7(66)$ & $28.3(26)$ \\
Sexual offence & $73.3(11)$ & $26.7(4)$ \\
Theft from a vehicle & $76.4(188)$ & $23.6(58)$ \\
Bicycle theft & $77.9(809)$ & $22.1(229)$ \\
Theft & $79.3(447)$ & $20.7(117)$ \\
Burglary & $81.3(283)$ & $18.7(65)$ \\
Attempted burglary & $84.8(140)$ & $15.2(25)$ \\
\hline
\end{tabular}

Note: Source: CS2011 (full sample)

Percent, number of cases in brackets

Table 34: Information policy according to different modes of victimization

\begin{tabular}{|c|c|c|c|c|}
\hline & \multicolumn{2}{|c|}{ Further information received } & \multicolumn{2}{|c|}{$\begin{array}{l}\text { Wish for further information } \\
\text { (no information received) }\end{array}$} \\
\hline & Yes & No & Yes & No \\
\hline Assault & $46.4(83)$ & $53.6(96)$ & $55.2(48)$ & $44.8(39)$ \\
\hline Attempted burglary & $47.6(78)$ & $52.4(86)$ & $46.3(37)$ & $53.8(43)$ \\
\hline Burglary & $48.8(167)$ & $51.2(175)$ & $57.2(95)$ & $42.8(71)$ \\
\hline Theft from a vehicle & $53.8(129)$ & $46.3(111)$ & $69.1(67)$ & $30.9(30)$ \\
\hline Robbery & $56.4(53)$ & $43.6(41)$ & $73.0(27)$ & $27.0(10)$ \\
\hline Bicycle theft & $56.8(581)$ & $43.2(441)$ & $53.7(211)$ & $46.3(182)$ \\
\hline Theft & $58.9(327)$ & $41.1(228)$ & $50.7(106)$ & $49.3(103)$ \\
\hline Vehicle theft & $59.8(73)$ & $40.2(49)$ & $68.9(31)$ & $31.1(14)$ \\
\hline
\end{tabular}

Note: Source: CS2011 (full sample), percent, number of cases in brackets

Results for sexual offence not displayed due to low amount of numbers (10 cases)

Criminal victimization is a serious event, leading to uncertainty and mental health problems in the vast majority of cases. Low self-esteem and increased fear of crime may be the outcome. Amongst victims of crime, consequences found are anxiety, depression, suicidal behavior, and posttraumatic stress disorder (PTSD), especially amongst victims of violent crime (Ruback/Thompson 2001). In addition, burglary has a serious effect on feelings of security (Maguire 1980). Victims contacting the police are therefore in a situation of uncertainty, looking for help. This requires certain sensitivity on the part of the police officer dealing with the case. Results clearly confirm how important the behavior of the police is in such circumstances: Dissatisfaction clearly leads to a lower level of trust in the police (Table 35). Contrary to expectations, this is not only true for serious 
cases of crimes against the person. The same can also be reported for offences against property. Dissatisfied victims whose possessions were stolen out of a car or motorcycle trust in the police in $46.6 \%$ of cases, while the rate for satisfied victims is about $20 \%$ higher (76.1\%). The significant differences between satisfied and dissatisfied victims' trust in the police are at least $20 \%$ (for thefts) and go up to $31 \%$ in cases of burglaries.

While satisfaction with treatment influences the level of trust in the police overall, confirming procedural justice theories, information policy is also found to be important, analogous to existing research (Skogan 1989; Sunshine/Tyler 2003; Bradford/Jackson/Stanko 2009). However, the information itself is only statistically significant in cases of bicycle thefts and burglaries. The number of informed burglary victims' trust in the police is even larger than the average trust in the police of the Swiss population (79\% vs. $72.7 \%$ ). Whether non-informed victims report a need for information or whether they say that it was not necessary is of great importance. Amongst those that would have wished to be informed, the number of individuals with a high level of trust in the police is significantly lower compared to those who report that there was no need for further information (Table 35). Again, the largest discrepancy in trust in the police is found for victims of attempted burglaries (33.9\%). On the other hand, victims of theft from a vehicle without a need for further information trust the police about the same as the average population (84\%), while the number is again much lower for those with an unsatisfied need for information (59.7\%).

Table 35: Impact of police contact on trust in the police in Switzerland according to different modes of offences against property

\begin{tabular}{|lllllll|}
\hline \multicolumn{7}{|c|}{ Trust in the police ("yes") } \\
\hline & \multicolumn{7}{c|}{ Satisfied with treatment of case Further information received } & $\begin{array}{l}\text { Wish for further information } \\
\text { (no information received) }\end{array}$ \\
\hline & Yes & No & Yes & No & Yes & No \\
\hline Vehicle theft & $64.8(59)^{*}$ & $45.5(25)$ & $61.7(50)$ & $52.3(34)$ & $59.3(67)$ & $50.0(17)$ \\
Attempted burglary & $70.7(99)^{* *}$ & $40.0(10)$ & $71.8(56)$ & $58.1(50)$ & $40.5(15)^{* *}$ & $74.4(32)$ \\
Theft & $72.0(322)^{* * *}$ & $50.4(59)$ & $69.1(226)$ & $65.4(149)$ & $54.7(58)^{* *}$ & $74.8(77)$ \\
Burglary & $73.5(208)^{* * *}$ & $41.5(27)$ & $79.0(132)^{* * * *}$ & $55.4(97)$ & $47.4(45)^{*}$ & $64.8(46)$ \\
Theft from a vehicle & $76.1(143)^{* * *}$ & $46.6(27)$ & $71.3(92)$ & $65.8(73)$ & $59.7(40)^{*}$ & $83.3(25)$ \\
Bicycle theft & $77.8(629)^{* * *}$ & $51.5(118)$ & $76.9(477)^{* * *}$ & $63.7(288)$ & $59.7(126)^{*}$ & $70.3(128)$ \\
\hline
\end{tabular}

Note: Source CS2011 (full sample), percent, number of cases in brackets

"Don't know / no answer" were treated as missing

Significance levels: $* 0.05>p>0.01, * * 0.01>p>0.001, * * * p<0.001$ 
When looking at offences against the person, the very high percentage of trust in the police amongst satisfied robbery victims attracts attention: More than $85 \%$ of victims who report being satisfied with how the police treated them trust in the police, while the number is significantly lower for unsatisfied victims (Table 36). Contrary to this remarkably high trust, the low trust level of unsatisfied victims of assault sticks out (39.2\%). Furthermore, an information policy perceived as negative leads to even worse trust in the police. Trust in the police amongst non-informed victims of an assault with the need for further information is only around $30 \%$. No statements can be made about sexual offences, as the already low number of 25 cases reported to the police leads to an even lower number of cases in follow-up questions, which is too small of a sample for testing the influence on trust in the police.

Table 36: Impact of police contact on trust in the police according to different modes of offences against the person

\begin{tabular}{|lllllll|}
\hline \multicolumn{7}{c|}{ Trust in the police ("yes") } \\
\hline & \multicolumn{7}{c}{ Satisfied with treatment of case } & Further information received & $\begin{array}{l}\text { Wish for further information } \\
\text { (no information received) }\end{array}$ \\
\hline & Yes & No & Yes & No & Yes & No \\
\hline Robbery & $86.4(57)^{*}$ & $65.4(17)$ & $84.9(45)$ & $70.7(29)$ & $66.7(18)$ & $70.0(7)$ \\
Assault & $76.2(80)^{* * *}$ & $39.2(29)$ & $71.1(59)^{* *}$ & $51.0(49)$ & $31.3(15)^{* * *}$ & $69.2(27)$ \\
\hline
\end{tabular}

Note: Source: CS2011 (full sample), percent, number of cases in brackets "Don't know / no answer" were treated as missing

Significance levels: $* 0.05>p>0.01, * * 0.01>p>0.001, * * * p<0.001$

It can be concluded that negative experiences with the police by victims whose possessions were stolen lead to a reduction in trust in the police, while the police, on the other hand, can gain trustworthiness when treating victims of robberies and assaults correctly. Thus, results confirm findings from other studies (Furstenberg/Wellford 1973; Smith/Hawkins 1973; Brandl/Horvath 1991). Moreover, Hypothesis 5.5 - , which states that victims satisfied with how the police have treated their case evaluate them better than those being dissatisfied - , is confirmed as well. 


\section{SUMMARY}

This part was dedicated to victims of crime and their view of the police. It was shown that they have a lower trust in the police compared to non-victims. For Switzerland, differences between victims and non-victims are overall smaller when it comes to the rating of the police compared to those in Western and Eastern Europe. Excepting involuntary contact, victims of crime in Switzerland show less favorable attitudes toward the police. This is reflected firstly in dissatisfaction with the treatment received and secondly in the information policy. It is important to note here that negative experiences with the police by victims whose possessions were stolen lead to a reduction in their trust, while the police, on the other hand, can gain trustworthiness when treating victims of robberies and assaults correctly. 


\section{Discussion}

\section{Reflection ON hypotheses}

The aim of this book was to elaborate on what constitutes people's trust in the police. The theoretical understanding that the police can either be seen as an institution, embedded into further governmental institutions, or as an organization, where particularly police officers, as representatives, play an important role when it comes to trust was highlighted. Results show that people in Europe generally trust in the police, more so in Western Europe than in Eastern European countries. The highest trust levels, with more than $70 \%$ of the population trusting in their police, can be reported for the four Scandinavian countries of Finland, Denmark, Norway, and Sweden, together with Switzerland. Contrary to that, in Eastern Europe, less than half trust the police.

Procedural justice theories highlight the importance of adequate behavior in citizen-police encounters. Disrespectful and unfair treatment and decisions correlate strongly to a negative opinion of the police and the courts. Results also confirm a cross-country correlation between global trust in the police and general opinions of their procedural fairness. Studies based on procedural justice approaches relativize the importance of instrumental concerns, such as fighting crime effectively. While such convictions hold for a long time, it is undisputed that the behavior of the police is more important than said instrumental concerns. Contrary to these rather popular beliefs, results here show that confidence in police work is equally important to people's overall trust in them, if not more so. Moreover, such an opinion of how well the police are doing their job explains a large portion of people's satisfaction with the treatment received in a concrete encounter.

Analyses at the macro level have shown that there is a linear relationship across countries between confidence in the work of the police, and 
in their procedural fairness, and global trust in the police. The higher the confidence in the work of the police and in their procedural fairness the higher a country's global trust in their police force, and vice versa. When comparing countries, no clear pattern was found for Mediterranean countries. Furthermore, more variance was found amongst non-Western European countries. While Western European countries are marked by high levels of trust and confidence in the police, Eastern European countries are situated at the lower end of the scale overall. Based on these results, two clusters were formed for Western and Eastern European countries, excluding Mediterranean countries. Furthermore, in order to prevent biases, countries situated at the extremes were excluded, i.e. Ukraine and Russia. Finally, Estonia and France cluster differently than the other countries. While Estonia aligns with Western European countries, France's low level of trust in the police clusters it within Eastern European countries. Nevertheless, France was counted to the West and Estonia to the East. The final Western European cluster consisted of Denmark, France, Finland, Norway, Sweden, Switzerland, Belgium, the Netherlands, Germany, the United Kingdom, and Ireland. The Eastern European cluster consisted of Bulgaria, Hungary, Czech Republic, Croatia, Estonia, Poland, Slovenia, Slovakia, and Lithuania. These two clusters formed the basis for further analyses.

Confidence in police's procedural fairness and in their work can be seen as constituting elements of trust in the police and vice versa. Therefore, when doing analyses on trust in the police, an index based on these three aspects might be adequate. Nevertheless, this book differentiates between attitudinal and institutional aspects. The police are understood as part of the wider government on the one hand, and as an organizational body, on the other hand. Institutional research has shown that trust in the police is embedded in trust in a functioning government. Therefore, it was first tested whether or not such an influence exists. Results show first that trust in the police is closely linked to trust in legal institutions, while perceptions of political systems are different. This result is reflected in the fact that the police are rated far better than political institutions, at least in Switzerland, where only about every third person trusts the parliament and less than $40 \%$ trust the government. Results from principal component analyses show that trust in political institutions can be separated from trust in legal institutions (the courts and the police), which confirms results from Rothstein and Stolle (2008), and shows that it is important to 
differentiate between institutions on the representational side and those on the implementation side. Contrary to expectations, this is true for both West and East clusters. One reason for these rather similar results may be the clustering. In the Eastern European cluster, I have primarily included the transformation countries of Central Europe, while the two extreme cases, Russia and the Ukraine, were omitted. Analyses based on the full Eastern European cluster show stronger discrepancies between the East and the West.

I assumed that the police are differentiated from political institutions in Western European countries, and perceived similarly in Eastern European countries. Nevertheless, an influence on trust in the police was expected:

Hypothesis 1.1 The police are perceived separately from political institutions in Western European countries, while they are perceived as similar in Eastern European countries.

Hypothesis 1.2 The higher the trust in political and legal institutions, the higher the trust in the police.

Results show that, in both the West and the East, trust in institutions issuing order - the legal system and the police - can be separated from trust in political institutions. People seem to differentiate between these institutions, even though the differences were only marginal. Despite the expectation, this is also true for the East. Therefore, Hypothesis 1.1 must be rejected. Results based on the inclusion of Russia and the Ukraine show a far more similar perception of government institutions, measured as trust in them. This shows that the included transformation countries are on their way to connecting with the West, at least with regard to people's understanding of government institutions.

The second hypothesis can be confirmed, as linear multiple regression analyses have shown a positive impact of trust in the legal system and trust in politics on trust in the police.

In a subsequent step, the impact of social trust was analyzed. It was argued that social trust has a positive impact on people's trust in the police. I derived the following hypothesis: 
Hypothesis 3 The higher a society's social trust, the higher its trust in the police, its confidence in the work of the police and in their procedural fairness.

Social trust is indeed higher in the West than in the East. Moreover, there is a linear relationship with trust in the police across all countries. In addition, a linear relationship was found between social trust and procedural fairness, while the correlation was weaker between social trust and confidence in the overall work of the police. Here, the variance was broader, particularly within Eastern European countries, and with the Netherlands as an outlier within Western Europe. The hypothesis can be confirmed.

After these initial analyses of explanatory items, the focus was on the interaction between the police, the public, and victims of crime. However, in the preceding chapter, it was tested whether attitudes about local police work affect overall trust in the police. Due to limitations in the ESS2010 data, these could only be done for Switzerland, based on data from the Swiss Crime Survey 2011. Results show that ratings of police work in the area indeed affect overall trust in the police, which confirms Hypothesis 6:

Hypothesis 6 The higher the rating of local police work in Switzerland, the higher the people's overall trust and confidence in them.

Concerning the impact of encounters with the police, it was assumed that an experience with the police would have an influence on trust in them. The following hypotheses were formulated:

Hypothesis 5.1 The more favorably an encounter with the police is rated, the higher the trust in them, the confidence in their work and in their procedural fairness.

Hypothesis 5.2 The impact of unfavorable ratings on trust is stronger than the impact of favorable ones ("asymmetry" hypothesis).

Thus far, with regard to the relationship between the different trust in the police items, primary analyses showed no large differences between the West and the East. However, clear differences were found when testing 
whether the impact of unfavorable ratings on trust is stronger than the impact of favorable ones (asymmetry hypothesis). In the Eastern European cluster, the negative impact of very dissatisfied people on trust in the police was slightly stronger than the positive effect of satisfied people. Contrary to this, in the West, the positive impact of satisfied people was obvious. Therefore, Hypothesis 5.1 was only partly confirmed. Considering the impact of the encounter on trust in the work and in procedural fairness, it was shown that there is a clear correlation between the level of satisfaction with the encounter and trust in the police. Those with favorable ratings of a police encounter evaluated the overall work of the police far better. Moreover, in cases in which they were satisfied, people attributed procedural fairness to the police far more. The contrary was true for people feeling dissatisfied with the police. While such correlations were found for both Eastern and Western Europe, the discrepancies are strikingly larger in the Eastern European cluster. Results clearly confirm Hypotheses 5.2. It was additionally tested whether socio-demographics also have an impact. Results show several differences between the contact and non-contact samples, as well as between Western Europe, Eastern Europe, and Switzerland. However, as these items were used as control variables only, they will not be discussed here.

Finally, trust in politics and social trust were used as explanatory forces in interactions with the police. It was expected that both would have a positive impact on trust in the police.

Hypotheses 2 Trust in governmental institutions affects the impact of trust in the police in cases of encounters between citizens and the police.

Hypothesis 4 People's trust in the police, people's confidence in the work of the police, and people's confidence in their procedural fairness after being stopped by them improves as social trust levels increase.

The positive role of social trust in police encounters is undeniable. People with higher social trust have higher trust in the police, whether or not they were stopped by them, whether they live in the East or the West. Nevertheless, results differ between Eastern and Western Europe when considering the two attitudinal items of procedural fairness and confidence in police work. In Western Europe, in cases of police encounters, people marked 
by low levels of social trust have an especially low trust in the police. In Eastern Europe, it is the reverse. Suspicious people have a lower trust in the police in the non-contact sample. Hypothesis 4 was confirmed.

Final analyses also show that trust in politics acts as a moderator when analyzing the impact of encounters on trust in the police, which confirms Hypotheses 2 as well.

In interactions with the police, it is important to differentiate not only between self-willed contact and contacts initiated by the police, but also between victims of crime. Hence, in the fourth section "The Perception of Crime Victims", attention was given to this special group of crime victims. As the European Social Survey 2010 contains only one question on criminal victimization, most of the analyses were based on the Swiss Crime Survey 2011. Results reveal that criminal victimization reduces overall trust in the police independently of the type of offence. Particularly, low rates of trust in the police can be reported for victims of thefts and burglaries. Dissatisfaction with how the police have treated a case clearly affects how they are viewed, leading to much lower trust in them. Furthermore, the information policy was found to have an effect as well. Particularly, victims whose need for further information was not met trust the police less. Interesting to note is the outstanding trust level of victims of offences against the person who were satisfied with the treatment they received. While Hypotheses 5.4 and 5.5 were confirmed, Hypothesis 5.3 was only partly confirmed:

Hypothesis 5.3 Victims of crimes against the person have lower trust in the police compared to victims of crimes against property.

Hypothesis 5.4 Reporting to the police does not correlate with trust in the police.

Hypothesis 5.5 Victims satisfied with how the police treated their case evaluate them better than those who are dissatisfied.

\section{VIEWS OF LOCAL POLICE WORK AND GENERAL TRUST IN THE POLICE}

Studies evaluating whether global opinions of the police are rooted in concrete beliefs about their work are sparse. The results found here support those that argue that global confidence in policing is rooted in specific 
assessments (Reisig/Chandek 2001; Jackson/Bradford 2010). However, effects differ across the three levels of policing examined. The level of satisfaction with the treatment received in a police-initiated encounter affects global trust in the police, trust in their overall procedural fairness, and confidence in their effectiveness. Dissatisfied people clearly rate the police as being fair and respectful less often, as well as that they do a good job overall. While such a pattern is found for Western and Eastern Europe, the differences were much stronger within the Eastern European cluster. This may be based on different forms of encounters or more severe negative treatments in Eastern Europe. However, since no further details are available about the type of contact, results must be seen as giving only a first hint toward the relationship of concrete experiences and overall trust and confidence in the police across Europe. Beyond this limitation, confidence in police's effectiveness was elaborated upon according to a general question about how well the police are doing their job, rather than using concrete questions about their technical competences, as was done in the study by Jackson and Bradford (2010), for example. Nevertheless, the separation of confidence in police's effectiveness from confidence in their procedural fairness is more important than the measurement of effectiveness.

A clearer picture can be drawn with regard to the analyses of Switzerland. Specific views about the quality of police work, their presence in the public - whether or not it is sufficient - opinions of their help and assistance in the community, as well as response time to a crime correlate strongly with a more general, overall level of trust in the police. Moreover, results again confirm that opinions about police's effectiveness are also important. Particularly those people who see a strong decrease in the quality of police work, as well as those reporting that the police are not there at all for the people in order to assist and to help them, do not trust in the police. The discrepancy is quite large: While more than two-thirds of these people do not trust in police, the level of trust reaches nearly ninety percent amongst those giving the most positive ratings concerning changes in police work and their help and assistance. Unfortunately, no analyses were possible elaborating on the impact of such concrete assessments on global views of police's fairness and effectiveness, because such questions were not part of the Swiss Crime Survey 2011 but only of the European Social Survey 2010.

Additionally, opinions of police work in the neighborhood correlate with global trust in the police. People with high confidence in police work 
in the neighborhood clearly report higher overall trust in the police. Conversely, dissatisfied people rate the work of the police in the neighborhood as unfavorable and trust the police less. In addition to the question about confidence in local police, a similar question about how people perceive the work of the police in the country allowed for a comparison of the two frequencies. Results show that, in Switzerland, local police work is evaluated more critically, while confidence in police's effectiveness at the country level is slightly greater ${ }^{1}$.

Nothing can be said about the robustness of such trust and attitudinal values. Misbehavior within the police organization may lead to a decline in people's trust. In Switzerland, the police were accused of several failures over the last years. The police commander of Lucerne was blamed for promoting an officer accused of domestic violence. In the end, he had to resign (Amrein 2013). Furthermore, several officers of the Zurich city police were arrested due to illegal credit card deals in the red-light district and accused of abuse of authority (Gyr/Schmid 2013). The media is an important player not only in the distribution of such information, but also in keeping the scandals alive. At the time, when news coverage of the red-light case in Zurich was heavy, the free daily newspaper 20 Minuten launched an online survey about people's trust in the police. They concluded that Swiss people's trust in the police is destroyed (Bernet 2013). However, such results are biased. Due to the selectiveness of respondents, they lack validity and representativeness ${ }^{2}$. Even if such negative events surrounding the police may affect certain people's feelings about the police, it is of limited duration. Moreover, people already distrusting the police may feel validated. On the contrary, the overall trust in the institution police is not largely affected, as results of the steady increase in trust in the police in Switzerland over the years demonstrate.

1 | When dealing with statements about police work in general and police work in the neighborhood in particular, it must be taken into account that Switzerland is a direct democracy with autonomous cantons that maintain their own police forces responsible for internal security and policing (Schmoll 1990: 95; Eisner/ Killias 2004). Hence, statements may differ when considering people's residency. 2 | On the website where results are displayed, no further information is given about the composition of respondents, such as the distribution of males and females or age groups, respectively. 


\section{BUILDING AND DESTROYING TRUSTWORTHINESS}

\subsection{Officers as institutional representatives}

Several theoretical approaches from either institutional research or the policing field point to the important role of representatives. People expect a certain demeanor from police officers. Not only should they successfully fight crime, pursue burglars and other offenders, they are expected to behave adequately and treat people friendly and fairly. With regard to the police and politicians, attitudes about the best approach to fight crime and to ensure security started to change in the 1980s: from social control perspectives toward approaches emphasizing to the importance of procedural fairness. Furthermore, institutional approaches have shown that representatives are the link between citizens and the system. As police officers are perceived as experts, a specific knowledge is ascribed to them. Hence, when people experience an encounter with a police officer, their perception of the whole police institution is affected, either positively or negatively. Results confirm that such encounters not only affect opinions of police's procedural fairness and confidence in their work, but also people's overall trust in the institution. In Eastern Europe, dissatisfaction with the police clearly leads to lower levels of trust in them. The more negatively the interaction with the police is evaluated by people, the lower their level of trust. On the other hand, in Western Europe, no negative impact was found. What's more, the more satisfied people are, the higher their trust in the police. Swiss people reporting a very high level of satisfaction with the police have a more than $20 \%$ higher mean trust in the police. Final analyses reveal that a large part of this high impact is explained by a general trust in the work of the police and trust in their procedural fairness, as well as trust in the legal system and politics. This leads to the conclusion that, even though encounters have an impact on people's perception of the police, this influence is limited. Strong positive attitudes about how well the police are doing their job in the country, about how respectfully they treat people, and how fair their decisions are, are robust parameters of people's trust in the police. Unfortunately, data does not allow for analysis of the contact itself, whether police officers indeed treated people correctly and fairly, or - in the eyes of the affected people - whether they were rude and impolite, making incorrect decisions. Still, the mediating role of trust in the work of the police and in their procedural fairness holds true in 
both countries. Based on this fact, it can be concluded that encounters, either positive or negative, either in Western democratic countries or in post-Soviet countries in Eastern Europe, only influence abstract trust in the police to a limited degree.

\subsection{Police - versus victim-initiated contact}

When analyzing interactions between citizens and the police, results show that satisfaction with the treatment received does shape trust in them. This becomes even clearer in cases where vulnerable or uncertain people ask the police for help. Crime victims contacting the police in order to get help are vulnerable, especially those having experienced violence or sexual assault, but the same is true for victims of burglary who have lost their feeling of security within their home. On the other hand, crime victims are aware of their needs and have a clear picture of what the police should do. In cases of thefts of personal belongings, a bicycle or a car, they hope to get their valuables back. In cases of violent crime, there is the additional hope of finding and punishing the offender. Due to high expectations toward the police, the disappointment on the side of the victim can be huge; consider a failure to return stolen possessions of high value to the victim. In cases of physical injury, the police may be seen as not doing enough to find the offender or not taking the case serious enough (Kilpatrick et al. 1987). Present outcomes for Switzerland confirm such results, showing that dissatisfaction with the treatment of a case is linked to lower levels of trust in the police, independent of the type of offence, for both victims of crimes against property and crimes against the person. On the positive side, victims that were satisfied with the police treatment partly reach above-average trust levels, which is especially true for victims of robbery. Furthermore, results clearly highlight the importance of information policy. Hence, certain sensitivity on the side of the police officer dealing with a case is essential, while a disinterest or mistreatment might destroy victims' trust in the police for years. Moreover, information policy is also important in contact initiated by the police. Every fourth person stopped by the police in Switzerland reports that the police do not explain their decisions. 


\subsection{A good reputation contrasts increasing attacks toward the police}

For several years, the primary task of the police was fighting crime effectively. In a culture dominated by social control approaches in order to enforce law, their power was broad. As a governmental authority, they had to be respected; criticism by the public was rare. The image of such an authoritarian ruler was damaged in Western Europe in the 1980s, with a growing dissatisfaction with the politics of government and local authorities. Political unrest and protests affected countries in Western Europe. The image of the police changed, particularly amongst the younger generation. As the longer arm of the government, and due to their actions against protesters, they were made a bogeyman, fighting alongside a conservative society suppressing individual freedoms. In the meantime, in democratic countries of the West, roles changed in several ways. Some years ago, the police were a strong authority with the power to make decisions that were not open to discussion. Nowadays, as cultures become much more egalitarian, people have somehow lost respect in institutional representatives. The work not only of police officers but also of emergency services is getting more difficult, as they are hindered and attacked by people they are trying to control or help as well as by bystanders. While there is no countrywide survey about attacks on the police in Switzerland, several analyses in local contexts indicate large increases. A higher sensitivity toward the topic on behalf of police officers may have led to higher reporting rates, as claimed by the author of a study from 2010 (Kühnis 2010). Criticism of the human rights organization augenauf goes in a similar direction. They argue that attacks did not increase but only the rate of reporting increased (cf. http://www.augenauf.ch/bs/archiv/poldiv/stgb285p.htm). Such an influence is indeed possible, as the Association of Swiss Police Officers (VSPB) launched an awareness campaign in 2009 (Verband Schweizerischer Polizeibeamter VSPB 2011).

Arguments of dramatic increases are often based on national numbers for offence of "violence and threat against public authorities and officials" (art. 285 of the Swiss Criminal Code) included in the criminal statistic. Since police officers are only one type of public official, statements should be taken with care. Nevertheless, a further look at the data provides an important hit regarding the problem. The age distribution of such offenders registered by the police show that about every third case falls in the age 
group of 18 - to 25 -year-olds. Moreover, the age span of 18 to 34 years covers more than $63 \%$ of the cases ${ }^{3}$. Hence, young people in particular commit attacks, probably rooted in disrespect. Furthermore, lighter forms of attacks, such as insults, may be the primary cause of the possible increase in attacks toward police officers. As a newer study from Germany has shown, registered case numbers of insults in Saxony increased greatly between 2005 and 2014 . Contrary to that, aggravated assault and battery peaked in 2011, with a marked decrease since then (Liebl 2016). The author speaks of a "Beleidigungsproblem" [insult/verbal abuse problem] toward the police. Nevertheless, results for Switzerland show that, overall, Swiss people trust the police and have positive attitudes toward them.

Can this prevailing high trust and confidence in the police be interpreted as the public viewing the Swiss police as legitimate? Since the core element of this book was trust, and as legitimacy was not included in analyses, no firm statements can be made here. Nevertheless, newer analyses of the ESS2010 data focusing on legitimacy, confirm that the population views the Swiss police as a legitimate force (Staubli 2016). Furthermore, a look at the results from Hough, Jackson, and Bradford (2013) provides interesting information on possible correlations between trust in procedural fairness and legitimacy - understood as people's moral alignment and felt obligation to obey - in Switzerland. Moral alignment was measured according to the question of whether the police generally have the same sense of right and wrong as the public. The feeling of obligation to obey, on the other hand, was based on the question of the extent to which it is people's duty to do what the police tell them, even if they do not understand or agree with the reasons. As numbers for both are high, it can be concluded that the overall legitimacy of the police is also high in Switzerland, analogous to trust in them. Moreover, moral alignment is significantly related to procedural fairness. The correlation for Switzerland achieves the third highest value of all included European countries. This means that people trust in police's procedural fairness if they perceive them as sharing the same culture or moral values. Conversely, the effect of procedural fairness and obligation to obey was rather small: In this, Switzerland takes the lowest rank across Europe (Hough/Jackson/Bradford 2013). This suggests that the impact of procedural fairness on perceived legitimacy is limited in

3 | Results are based on personal analyses of data from the Federal Office of Statistics (BFS). 
Switzerland. The police are not respected as a higher authority one has to obey, even if they are seen as treating people respectfully and fairly. Such a tendency was already shown by the question of whether people ask the police to explain their decisions. Only $1.1 \%$ of the Swiss respondents reported that no one ever asks the police for explanation, meaning that it is normal to ask the police why and how they have come to their decision (see Figure 14 Chapter 7.5.2: Satisfaction with treatment received).

Reasons for a possible increase in attacks on police officers may be found in their behavior itself. Heavy workloads due to additional services lead to disappointment and dissatisfaction (Mohler 2013) and to inappropriate behavior in interactions with citizens (Manzoni 2003). Moreover, studies reveal a large discrepancy between the high level of public trust in the police and police's self-evaluation. Kääriäinen and Sirén (2012) show that generalized trust in France, Switzerland, and the United Kingdom is significantly lower amongst police officers than amongst the rest of the population. Officers in Switzerland seem to be suspicious, not trusting in people they do not know. While it can be seen as part of their job not to trust anyone, negative experiences may also affect police officers' general trust in others.

With the development of modern democracies and societies, people's expectations of governmental institutions rose, while their respect declined. Alongside, an increase in tasks, a blurring of responsibilities replaced their core function of social control. The function and roles of the police became wide; multiple players, such as railway police and many other private forces, have evolved ${ }^{4}$. Additionally, broad media coverage and the spread of new media and smartphones that allowing recording of interactions (Meyer 2010) lead to permanent surveillance and guaranteed reporting of misbehavior, not tolerated at all by the public. In this sense, the media is an important controlling body.

4 | Reiner (2010) criticizes the often formulated assumption that policing changed from a rather narrow function of social control towards a plurality of tasks. According to him, policing has always covered a variety of tasks. The primary change rather happened from a sole responsibility of the police for crime, order, and security toward a "pluralized marketplace", as well as a shift in styles, program, and practices. 


\section{Cultural aspects}

Beyond the aspect of ethnic minorities, cultural factors only play a marginal role within studies on trust in the police. Since the key area is on the side of the police, their behavior, and its influence on people's assessment, social realities surrounding encounters are often omitted. What was elaborated on is the concept of social identities, seen as crucial for compliance with the police (Bradford 2014). A feeling of belonging to the same group as the officers, as either the same nation or community, enables establishment of social bonds. The establishment of such social bonds between officers and the public enables the building of a moral connection as the basis for trust in the police (Jackson/Bradford 2010). Such identities are constructs more or less easy to define and attachable to individuals involved in encounters. Other soft variables are more blurred. Social trust is more difficult to define, which is why its use is more disputed (cf. Chapter 4.1: European Social Survey 2010 [ESS2010]). Moreover, it has only started to find its way into broader research on trust in justice. In existing studies, social trust is primarily treated as part of social capital when elaborating on trust in governments. Several studies have proven that social trust and trust in governmental institutions go hand in hand (Kaase 1999; Newton/Norris 1999; Rothstein/Stolle 2008; Grönlund/Setälä 2012). Western democracies are marked by good evaluations of government and high social trust, while transition countries' trust is lower for political institution as well as toward unknown others. In most of the studies, the police are treated as one institution among many. Often a combined variable is constructed out of several institutions. It is no wonder that no study analyzes the police separately.

Based on Hardin's (2002) concept of encapsulated interest, encounters between police officers and a citizen or a crime victim can be seen as interactions between two people, based on concrete expectations. Social trust, on the other hand, understood here as the combination of trust in unknown others, in their helpfulness and fairness, is not bound to expectations. Due to its moral form, it is a dictate to treat others well. Learned early in life and based on optimism, it is a rather stable concept, largely resistant to the difficulties of daily life (Uslaner 2002). I concluded that optimistic people might transfer their positive view of others onto institutional representatives. Police officers may therefore be generally approached as positive and trustworthy in the way other people are. This is especially true for modern societies, marked by high complexity, where trust has be- 
come a necessary strategy for dealing with other people and institutions, often inaccessible to ordinary people (Sztompka 1999). Therefore, social trust was expected to be a moderator in citizen-police interactions in the West. Results confirm this approach by showing that clear differences exist between Western and Eastern Europe. In the West, the discrepancy between people with low or high social trust was stronger amongst the sample of people stopped by the police. Suspicious people gave far less positive ratings to the police in cases in which they encountered them. In the East, evaluations of people with low trust were more negative amongst those not stopped by the police. In transformation countries, where institutions are not met with the high trust found in the West, expectations toward the police might be generally lower. Hence, social trust does not act as a very strong mediator. It may also be possible that the chance of being stopped by the police is smaller for such people, based on a different behavior, such as not going out often.

Another open point is the link of social trust to social groups and identities. Linking the two approaches of morally founded (Uslaner 2002) and motive-based trust (Tyler/Huo 2002), it can be argued that people with high social trust toward others are more willing to see positive motives in the police and therefore can more easily establish a moral connection with them. However, this may only be true for people with a weak social identity, not defining themselves as belonging to one specific group. On the other hand, people with low social trust may have higher particularized trust with members who share the same group identity, as high trust in the in-group coincides with low trust in the out-group (Delhey/Newton/ Welzel 2011). A study by Freitag (2003) neglects this argumentation, at least for Switzerland. He shows that social trust relates to individual attributes rather than to group attachment, such as active membership in associations, as often claimed. It correlates with personal resources, general attitudes, psychological determinants, and social background.

Social trust and trust in the police correlate positively across all European countries. Furthermore, trustful people show higher confidence in the work of the police and in their procedural fairness. Results for Switzerland follow those of Western Europe. The lowest levels of trust in the police, only $60 \%$, are found for suspicious people with low general trust in the helpfulness of their fellow man and who experienced a police encounter. However, more research is needed in order to shed light on such correlations, especially with regard to what shapes social trust. 


\section{TRENDS IN OPINIONS}

The biannually conducted European Social Survey allows tracking of the development of people's trust over the years. Results show highest ratings for the year 2012 for all included European Countries (Table 37). In Western European countries, in particular, trust levels are stable at a high level, such as in Finland, or have even increased over time, such as in Switzerland, the United Kingdom, or the Netherlands. However, Eastern European countries also seem to be catching up, as seen in steadily increasing trust rates for Lithuania, Slovenia, or the Czech Republic. A clear loss of trust in the police during the last years can only be reported for Slovakia.

Table 37: Trust in the police in Europe over time

\begin{tabular}{|lccccccc|}
\hline & 2002 & 2004 & 2006 & 2008 & 2010 & 2012 & 2014 \\
\hline Finland & 8,0 & 8,0 & 8,0 & 8,0 & 8,0 & 8,1 & 7,9 \\
Denmark & 7,9 & 7,9 & 7,8 & 7,6 & 7,7 & 8,0 & 7,7 \\
Norway & 7,0 & 7,1 & 7,2 & 7,0 & 7,2 & 7,2 & 7,4 \\
Switzerland & 6,8 & 6,9 & 6,9 & 6,9 & 7,0 & 7,2 & 7,2 \\
Sweden & 6,8 & 6,5 & 6,5 & 6,6 & 7,0 & 6,7 & 6,9 \\
Germany & 6,7 & 6,5 & 6,6 & 6,8 & 6,9 & 6,9 & 6,7 \\
Netherlands & 5,8 & 6,0 & 6,2 & 6,3 & 6,3 & 6,4 & 6,4 \\
Ireland & 6,5 & 6,6 & 6,1 & 6,5 & 6,5 & 6,6 & 6,3 \\
United Kingdom & 6,0 & 6,1 & 6,0 & 6,2 & 6,2 & 6,5 & 6,3 \\
France & 5,9 & 5,7 & 5,7 & 5,8 & 5,6 & 5,9 & 6,1 \\
Estonia & & 5,7 & 5,5 & 6,1 & 6,2 & 5,9 & 6,1 \\
Belgium & 5,6 & 5,8 & 5,9 & 6,0 & 6,0 & 6,1 & 6,0 \\
Czech Republic & 5,0 & 4,2 & & 4,8 & 4,9 & 5,1 & 5,7 \\
Lithuania & & & & & 4,5 & 5,5 & 5,5 \\
Slovenia & 4,9 & 4,7 & 5,0 & 5,0 & 5,0 & 5,4 & 5,5 \\
Poland & 4,9 & 4,6 & 5,0 & 5,1 & 5,4 & 5,3 & 5,1 \\
Hungary & 4,9 & 5,2 & 5,1 & 4,3 & 5,1 & 5,3 & \\
Slovakia & & 4,4 & 4,7 & 4,9 & 4,6 & 4,1 & \\
Croatia & & & & 4,4 & 4,4 & & \\
Bulgaria & & & 3,9 & 3,3 & 3,9 & 3,6 & \\
\hline
\end{tabular}

Note: Source: European Social Survey

Mean values of scale 0-10, no data available where no number is displayed (no survey was conducted in these years in the respected country)

When using different data sources, percentages of trust differ, as shown for Switzerland in Table 38. When comparing trust rates of the ESS with those of the Sicherheit study, it can be seen that values in the latter are always slightly higher each year, while the values for 2010 are similar to those of the Crime Survey (CS) 2011. The previously formulated idea about the use of different scales as a possible explanation for differences (Staubli 2014) no longer holds, as both - the ESS and the Sicherheit study - use the common 
institutional trust item, asking for trust in different institutions, with either an eleven $\left(\right.$ ESS $^{5}$ ) or ten point scale (Sicherheit $\left.{ }^{6}\right)$. Contrary to that, the Crime Survey 2011 only asked about which institutions someone trusts, and not how strong this trust is on a scale ${ }^{7}$. In 2015, the question was shortened, asking only for trust in the police (Biberstein et al. 2016). The very high trust rate of $87.9 \%$ for 2015 may be explained by this reduction on institutional trust items. When listing the police amongst other governmental institutions, trust in the police may be connoted differently, as linked to political insitutions and other institutions issuing order, as results in this book have shown. Finally, in the World Value Survey (WVS) and the European Values Study (EVS) a four point Likert scale item allowed for the use of dichotomized items. A further distinction is the wording; both ask for "confidence in" rather than "trust in" the police ${ }^{8}$. However, an interchange of these notions is possible, at least for the survey in Switzerland, simply because no differentiation between trust and confidence exists in the German language, as seen in the translated questionnaires of the ESS, EVS, and WVS, speaking of Vertrauen ${ }^{9}$. Moreover, as Switzerland has only participated in the EVS and WVS three times so far, such differences can be ignored.

The explicit question about trust in the police was only part of the Swiss Crime Survey in 2011 and 2015. Hence, it does not allow for a comparison with earlier years. However, in most of the Surveys, the question

5 | ESS: Using this card, please tell me on a score of 0-10 how much you personally trust each of the institutions I read out. 0 means you do not trust an institution at all and 10 means you have complete trust (European Social Survey 2010b: 5).

6 I I am going to name a number of public organizations in Switzerland. For each one, could you tell me to what extent you trust them (Ich nenne Ihnen jetzt ein paar Einrichtungen vom öffentlichen Leben in der Schweiz und ich möchte wissen, inwiefern diese Ihr Vertrauen geniessen [Svirzev Tresch/Wenger 2016]).

7 | Which state institutions do you trust? Answers yes/no (Welchen staatlichen Institutionen vertrauen Sie?).

8 | WVS: I am going to name a number of organizations. For each one, could you tell me how much confidence you have in them: is it a great deal of confidence, quite a lot of confidence, not very much confidence, or none at all? (World Value Survey 2011: 8); EVS: Please look at this card and tell me, for each item listed, how much confidence you have in them, is it a great deal, quite a lot, not very much, or none at all? (European Values Study 2010: 15).

9 | In French confiance, in Italian fiducia. 
about resident's satisfaction with the control of crime in their neighborhood is included. When comparing the rates, it becomes obvious that the satisfaction level increased continuously since the 1990s, with the lowest rate of only $70 \%$ in 1998 , and more than 90\% positive ratings in 2015 (Figure 22).

Table 38: Trust in the police in Switzerland over time

\begin{tabular}{|c|c|c|c|c|c|}
\hline Year & WVS $^{1}$ & EVS $^{1}$ & CS & $\mathrm{ESS}^{2}$ & $\begin{array}{l}\text { Sicher- } \\
\text { heit }^{2,3}\end{array}$ \\
\hline 1995 & & & & & 6,9 \\
\hline 1996 & 69,8 & & & & \\
\hline 1997 & & & & & 6,5 \\
\hline 1998 & & & & & 6,5 \\
\hline 1999 & & & & & 6,7 \\
\hline 2000 & & & & & 6,8 \\
\hline 2001 & & & & & 7,0 \\
\hline 2002 & & & & 6,8 & 7,1 \\
\hline 2003 & & & & & 7,1 \\
\hline 2004 & & & & 6,9 & 7,2 \\
\hline 2005 & & & & & 7,1 \\
\hline 2006 & & & & 6,9 & 7,2 \\
\hline 2007 & 83,9 & & & & 7,3 \\
\hline 2008 & & 81,9 & & 6,9 & 7,2 \\
\hline 2009 & & & & & 6,9 \\
\hline 2010 & & & & 7,0 & 7,2 \\
\hline 2011 & & & 72,7 & & 7,1 \\
\hline 2012 & & & & 7,2 & 7,6 \\
\hline 2013 & & & & & 7,6 \\
\hline 2014 & & & & 7,2 & 7,5 \\
\hline 2015 & & & 87,9 & & 7,7 \\
\hline 2016 & & & & & 7,9 \\
\hline
\end{tabular}

Note: Percent and mean values; no data available where no number is displayed (no surveys conducted in these years in Switzerland) 1 Answers a great deal and quite a lot counted together

2 Mean values

3 Source: Szvircsev Tresch/Wenger (2010, 2016) 
Figure 22: Satisfaction with control of neighborhood criminality over time in Switzerland

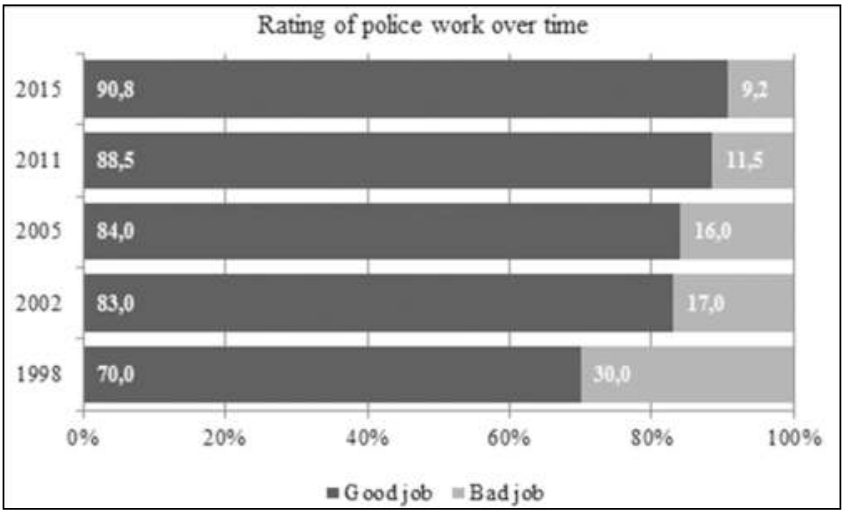

Note: Source: Swiss Crime Survey

A comparison of the 2010 rates for global trust and specific trust in the police - overall trust in the police and ratings of how well the police are doing their job in the neighborhood - shows that they are nearly identical (70.3\% mean trust and $72.3 \%$ good job, $\left.\mathrm{r}_{S}=.258, \mathrm{p}<0.001\right)$. Revisiting the discussion about how to measure trust in the police, two conclusions are possible. On the one hand, people may draw connections to local police forces in their neighborhood when they report their overall trust in the police. On the other hand, the two similar numbers in trust level may reflect two different levels of attitudes, but showing that people are rather satisfied with both, how the police are doing their job in their neighborhood as well as with the police as an organization or institution as a whole.

\section{Limitations}

In this study, several important results were found. However, interpretations are subject to several limitations. Firstly, a number of difficulties arise in cross-national research. One often-formulated problem is linked to data collection. Only process standardization can guarantee that data are comparable across countries. The European Social Survey uses a centralized structure resulting in a strong standardization in the fieldwork or sampling methods (European Social Survey ESS 2010c). Therefore, data sets are expected to be equivalent in each of the participating countries, 
or at least to display very low discrepancies. However, even when data is collected by identical methods, questions may be understood differently across countries. I previously dealt with this problem when discussing the use of the social trust items (see Chapter 4.1: European Social Survey 2010 [ESS2010]). Even though some studies have shown that the difference in the understanding of these items is tolerable, some variation is expected not only between but also within countries, as no homogeneity exists within national boundaries either. This leads to another important point that needs to be considered when interpreting results: National boundaries are not identical to cultural boundaries (de Vaus 2008). The differences found between the Eastern and the Western European cluster must therefore be seen as national rather than based on cultural parameters.

Returning to the different understandings of variables between and within countries, variations are not only expected for the explanatory variable of social trust, but also for the dependent variables of trust in the police, in their procedural fairness, and in their effectiveness. Questions measuring procedural fairness ask for respectful treatment and fair decision. However, no further specification about the meaning is given in the questionnaire. Respectful treatment was linked to "what you have heard or based on your own experience..." which opens up a rather broad fundus of connotations. For the concept of police's effectiveness, I used the variable asking for how well the police are doing their job. This question is linked to expectations ("Taking into account all the things the police are expected to do..." ${ }^{10}$ ). Again, this is a fairly general formulation. No solution is available for this problem as of yet, as the theoretical base, as well as many studies dealing with the concept of procedural fairness, stem from the U.S. and UK. It would be important to test the understanding of procedural fairness in different countries, not only of the West but also in Eastern Europe and the Mediterranean countries included in round five of the European Social Survey.

The European Social Survey offers a variety of variables and includes several countries all over Europe. Data are aimed at national analyses. Hence, the responsible body of the European Social Survey warns against combining countries in clusters (European Social Survey 2014). Nevertheless, in order to obtain an overview of the situation in Europe and in order

10 | For full wording of the questions, see Chapter 4.1: European Social Survey 2010 (ESS2010). 
to test theoretical approaches, in a first step, I used two clusters of Eastern and Western European countries. Of course, a great deal of information gets lost when doing analyses at such an abstract level. These kinds of analyses do not allow for consideration of country-related specifications, such as organizational approaches within the police. Moreover, the style of the government as well as a bad economic situation in the country may lead to dissatisfaction with the government as a whole, as demonstrated by results showing that views about the government are linked to trust in the police. The inclusion of results for one country alone, Switzerland, at least allowed proof of results found for the Western European cluster. The aforementioned weakness of the cluster approach could therefore be at least partially mitigated. However, I did no in-depth country analyses in order to prove results for Eastern Europe, as of yet marked by low levels of trust in the police. Hence, more country studies are needed in order to elaborate on the situation in further countries in either Eastern or Western Europe.

Another point to discuss is the inclusion of France. It is the Western European country with the lowest trust values toward the police, scattering within the Eastern European cluster. Why do French people trust their police so little? Ethnic discrimination by the police is an ongoing problem (Body-Gendrot 2010). As primarily immigrants are affected, especially those living in the banlieues, bad police practices alone cannot explain the overall low trust amongst the French public. In the light of a continuous shift to the right, as elections in 2014 have shown, the source may instead lie in an uncertainty and fear of crime in general. Dissatisfaction with the government as a whole may be transferred to the police. Results further support the cultural argument by showing that French people not only have a low trust in their police but also a very low level of social trust. While other people's fairness is not evaluated as poorly, general trust in unknown people is particularly low. Fukuyama (1995) already declared France a low-trust society; a country with a weak civil society coupled with a history of distrust in the state. While family ties are strong, it lacks intermediate groups between the family and the state. At the end of the discourse in Chapter 13, he admits that over the last decades a process of cultural homogenization has taken place, coupled with a change in a traditional weakness of associations. Even though social capital and thereby particularized trust may have become stronger in the meantime, results show that generalized trust is still low. 
As already briefly mentioned and discussed above, a second point of limitation is that results are always only as good as the data used to obtain them. Furthermore, they largely depend on applied methodologies. At the center of the analyses was the overall trust in the police, together with confidence in their procedural fairness and effectiveness. For analyses, standard survey questions such as "Overall, how much do you trust in the police?" were used. The use of such items would never cover the full range of trust in the police. Combined indexes considering a variety of items may lead to results that are more refined. Jackson et al. (2012), for example, demonstrate a close relationship between several items measuring trust in shared interests (motive-based trust), procedural fairness, and effectiveness. On-hand results may have become more diverse if I would have analyzed the variables of overall trust in the police, in their procedural fairness and effectiveness more carefully in the beginning based on further items included in the data set. Additionally, in the analyses, I did not consider items of motive-based trust. A feeling of "we and they [the police] are on the same side" (Jackson et al. 2012: 67) may in large part shape levels of satisfaction with encounters, and possibly relate to social trust.

Another area where information is lacking is in the circumstances of encounters between the public and the police. The question in the European Social Survey 2010 generally asks whether people have been approached, stopped, or contacted by the police within the last two years preceding the survey. No information is given about the reasons for police contact, whether the police verified a person or whether an unlawful behavior, such as exceeding the speed limit lead to a complaint. Receiving a fine, for example, will lead to further contact with the police and the justice system in the month following the encounter. Moreover, critical events, such as riots, for example in Sweden in 2008 (cf. BBC 2008) or in London in 2011, might lead to more problematic encounters between citizens and the police ${ }^{11}$. Such experiences are expected to shape attitudes toward the police, in either a positive or a negative way. However, positive

11 | The riots in Sweden fall between 2008 and 2010 for which police encounter questions were asked. This is not the case for the London riots, which only happened during August 2011. That such riots will not only lead to a higher chance of critical interactions with the police but also affect public opinion of the police in general can be seen in the study by Hohl, Stanko, and Newburn (2012). They analyzed the effects of the London disruption on public opinion of the police. 
attitudes toward the police may already be limited prior to (problematic) police contact. This is supported by results showing that, in Western Europe, people with low social trust in particular rate police encounters negatively. Nevertheless, it may well be possible that such people with low trust but also people with an overall negative attitude toward life as a whole enter unfavorably into encounters with the police, for example, behaving aggressively, which may influence the interaction as a whole, leading to dissatisfaction with police treatment ${ }^{12}$. Further in-depth analyses should particularly consider the circumstances of encounters, such as the place, the persons involved, and the behavior of the involved police officers, but also the behavior of the citizens. Additionally, multi-level analyses would allow testing for effects at the neighborhood and country level.

Finally, results showed a close connection between overall trust in the police, on the one hand, and confidence in their procedural fairness as well as with confidence in their work, on the other. However, implicit in the ratings of the police work and their procedural fairness is an image of the police based not only on experiences, but also influenced by media coverage or stories told by friends and families. Such reflections may have a particular impact on people's evaluation of police's procedural fairness whether they treat people correctly, make fair decisions, and explain their decisions - in cases where people were not yet in contact with the police.

\section{ConClusion AND OUtLOOK}

This book is about the perception of the police by the public, by individuals who have experienced a police stop, and by victims of a crime. A lot of research has been done within this field of trust and attitudinal studies. However, most of the studies understand the police as either an organizational or an institutional body. In addition, cross-country research is limited. My aim was therefore twofold. Firstly, I combined institutional with organizational approaches, verifying them empirically. Secondly, Eastern countries were compared to Western European countries. Moreover, re-

12 | This may again especially be the case in demonstrations or riots, as an outcome of demonstrations or triggered by another event. However, despite former negative attitudes toward the police, problematic policing itself can contribute to the occurrence of riots (Klein 2012). 
sults were proved by looking at one high-trust country, Switzerland. Another open subject was the relationship between global trust in the police and concrete perceptions of the organization. Finally, I wanted to elaborate on the role of social trust. Treated as part of social capital, its relation to trust in government is widely confirmed. However, its role in trust in the police has been considered only marginally thus far.

Results show that trust in the police correlates with trust in further governmental institutions. From an organizational point of view, encounters between citizens and police officers affect individuals perceptions of the police, especially with regard to satisfaction with the treatment received. Results further show that social trust not only affects trust in the police, but also the evaluation of police encounters. Finally, it can be said that attitudes about local police work relate to overall trust in the police.

However, many open questions remain, as several questions could only be answered within a limited scope. In further police research, surveys should, for example, combine specific questions about police encounters and about social trust. Furthermore, other soft variables, such as value dimensions (Schwartz 1994) and other cultural factors, should be considered, shedding more light on how people's perception of the police is shaped. 


\section{References}

Aebi, Marcelo F./Killias, Martin (eds.) (2010 [1999]): European Sourcebook of Crime and Criminal Justice Statistics. Den Haag: Wetenschappelijk Onderzoek-en Dokumentatiecentrum.

Albrecht, Hans-Jörg/Nogala, Detlef (2001): "Police, Sociology of." In: Neil J. Smelser/Paul B. Baltes (eds.), International Encyclopedia of the Social and Behavioral Sciences, Amsterdam: Elsevier, Pergamon, pp. 11532-11535.

Alesina, Alberto/La Ferrara, Eliana (2002): "Who trusts others?" In: Journal of Public Economics, 85, pp. 207-234.

Amrein, Marcel (2013): "Der Luzerner Polizeichef muss gehen: Vorkommnisse im Korps haben das Vertrauen in den Kommandanten untergraben." In: Neue Zürcher Zeitung, December 4, p. 11.

Arts, Wilhelmus Antonius/Halman, Loek (2004): "Chapter One: European Values at the Turn of the Millenium. An Introduction." In: Wilhelmus Antonius Arts/Loek Halman (eds.), European Values at the turn of the millennium, Boston: Brill, pp. 1-24.

Augenauf: "Gewalt \& Drohung gegen Beamte: Statistisches zu Art. 285 StGB”, augenauf (http://www.augenauf.ch/bs/archiv/poldiv/stgb285p. htm).

Baltes-Götz, Bernhard (2016): Lineare Regressionsanalyse mit SPSS. Universität Trier: Zentrum für Informations-, Medien- und Kommunikationstechnologie (ZIMK) (http://www.uni-trier.de/fileadmin/urt/ doku/linreg/linreg.pdf)

Barber, Bernhard (1983): The logic and limits of trust. New Brunswick, N.J: Rutgers University Press.

BBC (2008): "Swedish city hit by youth riots", BBC, December 19, 2008 (http://news.bbc.co.uk/2/hi/europe/7791553.stm). 
Beck, Adrian/Chistyakova, Yulia (2002): "Crime and Policing in PostSoviet Societies: Bridging the Police/Public Divide.” In: Policing and Society, 12/2, pp. 123-137.

Berger, Peter L./Luckmann, Thomas (1974 [1966]): Die gesellschaftliche Konstruktion der Wirklichkeit: Eine Theorie der Wissenssoziologie. Frankfurt am Main: Fischer Taschenbuch.

Bernet, Christoph (2013): "Image der Polizei ist im Keller“, In: 2omin, December 10 (http://www.2omin.ch/schweiz/news/story/14258792).

Biberstein, Lorenz (2010). Die Einstellung von Jugendlichen zur Polizei im Kanton Zürich: Untersuchung und Bericht im Auftrag der Kantonspolizei Zürich. Zürich: Kriminologisches Institut.

Biberstein, Lorenz/Killias, Martin/Walser, Simone/Iadanza, Sandro/ Pfammatter, Andrea (2016): Studie zur Kriminalität und Opfererfahrungen der Schweizer Bevölkerung. Analysen im Rahmen der schweizerischen Sicherheitsbefragung 2015. Lenzburg: Killias Research \& Consulting.

Bjørnskov, Christian (2007): “Determinants of generalized trust: A crosscountry comparison.” In: Public Choice, 130/1-2, pp. 1-21.

Boateng, Francis D. (2013): "Restoring the lost hope: a multidimensional approach for building public trust in the police.” In: The Journal of the Institute of Justice \& International Studies, 13, pp. 33-46.

Body-Gendrot, Sophie (2010): "Police marginality, racial logics and discrimination in the banlieues of France." In: Ethnic and Racial Studies, 33/4, pp. 656-674.

Boers, Klaus (1991): Kriminalitätsfurcht: Über den Entstehungszusammenhang und die Folgen eines sozialen Problems. Pfaffenweiler: Centaurus-Verlagsgesellschaft.

Bradford, Ben (2010): “The Quality of Police Contact: Procedural Justice Concerns Among Victims of Crime in London” (http://papers.ssrn. com/sol3/papers.cfm?abstract_id=1596754).

Bradford, Ben (2011): "Convergence, not Divergence? Trends and Trajectories in Public Contact and Confidence in the Police.” In: British Journal of Criminology, 51/1, pp. 179-200.

Bradford, Ben (2014): "Policing and social identity: procedural justice, inclusion and cooperation between police and public.” In: Policing and Society, 24/1, pp. 22-43. 
Bradford, Ben/Jackson, Jonathan/Stanko, Elizabeth A. (2009): “Contact and confidence: revisiting the impact of public encounters with the police." In: Policing and Society, 19/1, pp. 20-46.

Brandl, Steven G./Frank, James/Worden, Robert E./Bynum, Timothy S. (1994): "Global and Specific Attitudes toward the Police: Disentangling the Relationship.” In: Justice Quarterly, 11/1, pp. 119-134.

Brandl, Steven G./Horvath, Frank (1991): "Crime-Victim Evaluation of Police Investigative Performance.” In: Journal of Criminal Justice, 19, pp. 109-121.

Brehm, John/Rahn, Wendy (1997): “Individual-Level Evidence for the Causes and Consequences of Social Capital.” In: American Journal of Political Science, 41/3, pp. 999-1023.

Brown, Ben/Benedict, Wm. Reed (2002): “Perceptions of the police: Past findings, methodological issues, conceptual issues and policy implications.” In: Policing: An International Journal of Police Strategies \& Management, 25/3, pp. 543-580.

Bundesamt für Statistik BFS (ed.) (2014): Polizeiliche Kriminalstatistik (PKS): Jahresbericht 2013. Neuchâtel: Office fédéral de la statistique (OFS).

Cao, Liqun/Frank, James/Cullen, Francis T. (1996): "Race, community context and confidence in the police." In: American Journal of Police, 15/1, pp. 3-22.

Cao, Liqun/Stack, Steven/Sun, Yi (1998): "Public Attitudes Toward the Police: A Comparative Study between Japan and America.” In: Journal of Criminal Justice, 26/4, pp. 279-289.

Ciriolo, Emanuele (2007): Trust: deep-rooted community attitude or reciprocity-based behavioral norm? Paper presented at the Internal Seminar of the Department of Applied Economics (DULBEA), Université Libre de Bruxelles (http://www2.depfid.unisi.it/Ciriolo1.pdf)

Clerici, Christian/Killias, Martin (1999): “Zum Bild der Polizei in der Öffentlichkeit.“ In: Crimiscope, 5, pp. 1-7.

Cohen, Lawrence E./Felson, Marcus (1979): “Social Change and Crime Rate Trends: A Routine Activity Approach.” In: American Sociological Review, 44/4, pp. 588-608.

Cook, Karen S. (2001): “Trust in Society.” In: Karen S. Cook (ed.), Trust in Society, New York: Russel Sage Foundation, p. xi. 
Correia, Mark E./Reisig, Michael D./Lovrich, Nicholas P. (1996): "Public Perceptions of State Police: An Analysis of Individual-Level and Contextual Variables." In: Journal of Criminal Justice, 24/1, pp. 17-28.

Delhey, Jan/Newton, Kenneth/Welzel, Christian (2011): "How General Is Trust in 'Most People'? Solving the Radius of Trust Problem.” In: American Sociological Review, 76/5, pp. 786-807.

de Vaus, David (2008): “Comparative and Cross-National Designs.” In: Pertti Alasuutari/Leonard Bickman/Julia Brannen (eds.), The SAGE handbook of social research methods, Los Angeles, London: Sage, pp. 249-264.

Eisner, Manuel/Killias, Martin (2004): “Switzerland.” In: European Journal of Criminology, 1/2, pp. 257-293.

European Social Survey (2014): Weighting European Social Survey Data (http://www.europeansocialsurvey.org/docs/methodology/ESS_ weighting_data_1.pdf).

European Social Survey (2010a): Appendix A2: Income, ESS5 - 2010 ed. 1.0 (http://www.europeansocialsurvey.org/docs/round5/survey/ESS5_ appendix_a2_eo3_o.pdf).

European Social Survey (2010b): Appendix A6: Variables and Questions, ESS 5 - 2010 ed. 1.0 (http://www.europeansocialsurvey.org/docs/ round5/survey/ESS5_appendix_a6_eo3_o.pdf).

European Social Survey (2010c). ESS 5 - 2010 Documentation Report: The ESS Data Archive (http://www.europeansocialsurvey.org/docs/ round5/survey/ESS5_data_documentation_report_eo3_o.pdf)

European Values Study (2010): EVS 2008 - Master Questionnaire (http:// www.europeanvaluesstudy.eu).

Frank, James/Smith, Brad W./Novak, Kenneth J. (2005): "Exploring the Basis of Citizens' Attitudes Toward the Police.” In: Police Quarterly, 8/2, pp. 206-228.

Freitag, Markus (2003): "Beyond Tocqueville: The Origins of Social Capital in Switzerland.” In: European Sociological Review, 19/2, pp. 217232.

Freitag, Markus/Bauer, Paul C. (2013): “Testing for Measurement Equivalence in Surveys: Dimensions of Social Trust across Cultural Contexts.” In: Public Opinion Quarterly, 77, pp. 24-44.

Freitag, Markus/Traunmüller, Richard (2009): “Spheres of trust: An empirical analysis of the foundations of particularized and generalized trust.” In: European Journal of Political Research, 48/6, pp. 782-803. 
Fukuyama, Francis (1995): Trust: The social virtues and the creation of prosperity. New York: Free Press.

Furstenberg, Frank F. Jr./Wellford, Charles F. (1973): “Calling the Police: The Evaluation of Police Service." In: Law and Society Review, 7/3, pp. 393-406.

Gambetta, Diego (ed.). (1988): Trust making and breaking cooperative relations. New York: Blackwell.

Gau, Jacinta M. (2010): “A longitudinal analysis of citizens' attitudes about police.” In: Policing: An International Journal of Police Strategies \& Management, 33/2, pp. 236-252.

Giddens, Anthony (1990): The consequences of modernity. Stanford, California: Stanford University Press.

Grönlund, Kimmo/Setälä, Maija (2012): “In Honest Officials We Trust: Institutional Confidence in Europe.” In: The American Review of Public Administration, 42/5, pp. 523-542.

Gyr, Marcel/Schmid, Andreas (2013). "Gegen sechs weitere Polizisten wird ermittelt”. In: Neue Zürcher Zeitung, November 20, p. 19.

Hall, Peter A./Tayler, Rosemary C. R. (1996). "Political Science and the Three New Institutionalisms.” In: Political Studies, XLIV, pp. 936-957.

Hardin, Russel (1992): The Street Level Epistemology of Trust. Analyse \& Kritik, 14, pp. 152-176.

Hardin, Russel (2002): Trust and trustworthiness. New York: Russell Sage Foundation.

Hardin, Russel (ed.). (2004). Distrust. New York: Russell Sage Foundation.

Hardin, Russel (2006): Trust. Cambridge: Polity Press.

Hindelang, Michael J./Gottfredson, Michael R./Garofalo, James (1978). Victims of personal crime: An empirical foundation for a theory of personal victimization. Cambridge, Mass: Ballinger.

Hohl, Katrin (2009): Beyond the average case: The mean focus fallacy of standard linear regression and the use of quantile regression for the social sciences (http://ssrn.com/abstract=1434418).

Hohl, Katrin/Stanko, Betsy/Newburn, Tim (2012): “The Effect of the 2011 London Disorder on Public Opinion of Police and Attitudes Towards Crime, Disorder, and Sentencing." In: Policing, 7/1, pp. 12-20. 
Homant, Robert J./Kennedy, Daniel B./Fleming, Roger M. (1984): “The Effect of Victimization and the Police Response on Citizens' Attitudes towards the Police." In: Journal of Police Science and Administration, $12 / 3$, pp. 323-332.

Hough, Mike/Jackson, Jonathan/Bradford, Ben (2013): “The Governance of Criminal Justice, Legitimacy and Trust.” In: Sophie Body-Gendrot/ Mike Hough/Klára Kerezsi/René Lévy/Sonja Snacken/ (eds.), The Routledge Handbook of European Criminology. Oxon: Routledge (http://papers.ssrn.com/sol3/papers.cfm?abstract_id=2141811).

Hough, Mike/Jackson, Jonathan/Bradford, Ben/Myhill, Andy/Quinton, Paul (2010): "Procedural Justice, Trust, and Institutional Legitimacy." In: Policing, 4/3, pp. 203-210.

Hudson, John (2006): "Institutional Trust and Subjective Well-Being across the EU.” In: KYKLOS, 59/1, pp. 43-62.

Imbach, Florian/Widmer, Simon/Tischhauser, Pascal (2013). "Schweizer Polizei rüstet auf: Eine neue Statistik zeigt, dass Bestand landesweit um 2,3 Prozent zugelegt hat“. In: Sonntagszeitung, June 1 (http://info. sonntagszeitung.ch/archiv/detail/?newsid=253473).

Jackson, Jonathan/Bradford, Ben (2010): "What is Trust and Confidence in the Police?” In: Policing, 4/3, pp. 241-248.

Jackson, Jonathan/Bradford, Ben/Hohl, Katrin/Farrall, Stephen (2009): "Does the Fear of Crime Erode Public Confidence in Policing?" In: Policing, 3/1, pp. 100-111.

Jackson, Jonathan/Bradford, Ben/Kuha, Jouni/Stares, Sally/Widdop, Sally/Fitzgerald, Rory/Yordanova, Maria/Galev, Todor (2011a): "Developing European indicators of trust in justice." In: European Journal of Criminology, 8/4, pp. 267-285.

Jackson, Jonathan/Bradford, Ben/Stanko, Betsy/Hohl, Katrin (2012): Just authority: Trust in the police in England and Wales. New York, NY: Routledge.

Jackson, Jonathan/Pooler, Tia/Hohl, Katrin/Bradford, Ben/Kuha, Jouni/ Hough, Mike (2011b): Trust in Justice: Topline Results from Round 5 of the European Social Survey. ESS Topline Results Series, 1.

Jann, Ben (2007): “Überlegungen zum Berner Stichprobenplan.” In: Swiss Journal of Sociology, 33/2, pp. 307-325.

Kääriäinen, Juha Tapio (2007): “Trust in the Police in 16 European Countries: A Multilevel Analysis.” In: European Journal of Criminology, 4/4, pp. 409-435. 
Kääriäinen, Juha/Sirén, Reino (2011): “Trust in the police, generalized trust and reporting crime." In: European Journal of Criminology, 8/1, pp. 65-81.

Kääriäinen, Juha/Sirén, Reino (2012): “Do the police trust in citizens? European comparisons.” In: European Journal of Criminology, 9/3, pp. 276-289.

Kaase, Max (1999): "Interpersonal trust, political trust and non-institutionalised political participation in Western Europe.” In: West European Politics, 22, pp. 1-21.

Karstedt, Susanne (2010). "New Institutionalism in Criminology: Approaches, Theories and Themes.” In: Eugene McLaughlin/Tim Newburn (eds.), The SAGE handbook of criminological theory, Los Angeles: Sage, pp. 337-359.

Khodyakov, Dmitry (2007): “Trust as a Process: A Three-Dimensional Approach." In: Sociology, 41/1, pp. 115-132.

Killias, Martin (1989): Les Suisses face au crime. Leurs expérience et attitudes à la lumière des enquêtes suisses de victimisation. Grüsch: Rüegger.

Killias, Martin (1991): "Swiss Victimology Research in the 1980ies - An Overview.” In: Günter Kaiser/Helmut Kury/Hans-Jörg Albrecht (eds.), Victims and Criminal Justice, Freiburg, Breisgau: Max-Planck-Institut für Ausländisches und Internationales Strafrecht, pp. 71-94.

Killias, Martin/Berruex, Thierry (1999): “Die Anzeige bei der Polizei: Keine Frage des Zufalls.” In: Crimiscope, 3, pp. 1-6.

Killias, Martin/Haymoz, Sandrine/Lamon, Philippe (2007): Swiss Crime Survey. Die Kriminalität in der Schweiz im Lichte der Opferbefragungen von 1984-2005. Bern: Stämpfli.

Killias, Martin/Kuhn, André/Aebi, Marcelo F. (2011 [2002]): Grundriss der Kriminologie: Eine europäische Perspektive. Bern: Stämpfli.

Killias, Martin/Staubli, Silvia/Biberstein, Lorenz/Bänziger, Matthias/Iadanza, Sandro (2011): Studie zur Kriminalität und Opfererfahrungen der Schweizer Bevölkerung. Analysen im Rahmen der schweizerischen Opferbefragung 2011. Zürich: Kriminologisches Institut.

Kilpatrick, Dean G./Saunders, Benjamin E./Veronen, Lois J./Best, Connie L./Von, Judith M. (1987): “Criminal Victimization: Lifetime Prevalence, Reporting to Police, and Psychological Impact.” In: Crime \& Delinquency, 33/4, pp. 479-489. 
Klein, Axel (2012): "Policing as a causal factor - a fresh view on riots and social unrest.” In: Safer Communities, 11/1, pp. 17-23.

Kohn, Melvin L. (1987): “Cross-National Research as an Analytic Strategy: American Sociological Association, 1987 Presidential Address.” In: American Sociological Review, 52/6, pp. 713-731.

König, Daniel L. (1980): “The Effects of Criminal Victimization and Judicial or Police Contacts on Public Attitudes Toward Local Police.” In: Journal of Criminal Justice, 8, pp. 243-249.

Kühnis, Patrick (2010). "Jeder dritte Stadtpolizist hat Angst, im Dienst angegriffen zu werden.” In: Tages Anzeiger, October 13 (http://www. tagesanzeiger.ch/zuerich/stadt/Jeder-dritte-Stadtpolizist-hat-Angstim-Dienst-angegriffen-zu-werden-/story/26366121).

Künzler, Daniel (2013): “Wie gut reisen Theorien und Konzepte?" In: Newsletter Studienbereich Soziologie, Sozialpolitik und Sozialarbeit, 13, pp. 6-12.

Kusow, Abdi M./Wilson, Leon C./Martin, David E. (1997): “Determinants of citizen satisfaction with the police: The effects of residential location.” In: Policing: An International Journal of Police Strategies \& Management, $20 / 4$, pp. 655-664.

Liebl, Karlhans (2016): “Gewalt gegen Polizisten: Dramatischer Anstieg oder Veränderung aufgrund gesellschaftlicher Entwicklungen?” In: Soziale Probleme 1/27, pp. 75-94

Liebsch, Burkhard (2010): "Violated Trust and the Self: A Negativistic Approach.” In: Arne Grøn/Claudia Welz (eds.), Trust, Sociality, Selfhood, Tübingen: Mohr Siebeck, pp. 173-192.

Lind, E. Allan/Tyler, Tom R. (1988): The social psychology of procedural justice. New York: Plenum Press.

Luhmann, Niklas (2000 [1968]): Vertrauen: Ein Mechanismus der Reduktion sozialer Komplexität. Stuttgart: Lucius \& Lucius.

Maguire, Edward R./Johnson, Devon (2010): “Measuring public perceptions of the police." In: Policing: An International Journal of Police Strategies \& Management, 33/4, pp. 703-730.

Maguire, Mike (1980): “The Impact of Burglary upon Victims.” In: British Journal of Criminology, 20/3, pp. 261-275.

Manzoni, Patrick (2003): Gewalt zwischen Polizei und Bevölkerung: Einflüsse von Arbeitsbelastungen, Arbeitszufriedenheit und Burnout auf polizeiliche Gewaltausübung und Opfererfahrungen. Zürich, Chur: Rüegger. 
Meyer, Michaël (2010): Copwatching et perception publique de la police. L'intervention policière comme performance sous surveillance. November, 21 (http://www.ethnographiques.org/2010/Meyer).

Mishler, William/Rose, Richard (1997): “Trust, Distrust and Skepticism: Popular Evaluations of Civil and Political Institutions in Post-Communist Societies.” In: The Journal of Politics, 59/2, pp. 418-451.

Mishler, William/Rose, Richard (2001): "What Are the Origins of Political Trust? Testing Institutional and Cultural Theories in Post-Communist Societies.” In: Comparative Political Studies, 34/1, pp. 30-62.

Misztal, Barbara A. (1996): Trust in Modern Societies. The Search for the Bases of Social Order. Cambridge, MA: Polity Press.

Mohler, Markus H. F. (2013): “Ungenügende Polizeibestände: Lösungsansatz unter Respektierung der verfassungsrechtlichen Kompetenzordnung." In: Sicherheit\&Recht, 2, pp. 62-8o.

Möllering, Guido (2006): Trust: Reason, routine, reflexivity. Amsterdam: Elsevier.

Murphy, Kristina/Cherney, Adrian (2011): “Fostering cooperation with the police: How do ethnic minorities in Australia respond to procedural justice-based policing? In: Australian \& New Zealand Journal of Criminology, 44/2, pp. 235-255.

Myhill, Andy/Bradford, Ben (2012): "Can police enhance public confidence by improving quality of service? Results from two surveys in England and Wales.” In: Policing and Society, 22/4, pp. 397-425.

Nannestad, Peter (2008): "What Have We Learned About Generalized Trust, If Anything?” In: Annual Review of Political Science, 11/1, pp. 413-436.

Newton, Kenneth/Norris, Pippa (1999): “Confidence in Public Institutions: Faith, Culture or Performance?” In: Susan Jane Pharr/Robert Putnam (eds.), Disaffected Democracies, Princeton: Princeton University Press, pp. 52-87.

Norušis, Marija J. (2012): IBM SPSS Statistics 19 statistical procedures companion. Upper Saddle River, NJ: Prentice Hall.

Offe, Claus (1999): “How can we trust our fellow citizens?” In: Mark E. Warren (ed.), Democracy and trust, Cambridge: Cambridge University Press, pp. 42-87.

Oskarsson, Sven (2010): "Generalized trust and political support: A crossnational investigation.” In: Acta Politica, 45/4, pp. 423-443. 
Pakes, Francis J. (2010 [2004]): Comparative criminal justice. Cullompton, Devon, UK, Portland, Or: Willan.

Percy, Stephen L. (1980): “Response Time and Citizen Evaluation of Police.” In: Journal of Police Science and Administration, 8/1, pp. 75-86.

Pichonnaz, David (2014): Former pour réformer: Sociologie de l'hétérodoxie policière et de l'entrée dans la profession: Thèse de Doctorat. Université de Fribourg.

Poister, Theodore H./McDavid, James C. (1978): “Victims' Evaluations of Police Performance.” In: Journal of Criminal Justice, 6, pp. 133-149.

Putnam, Robert D. (1995): “Bowling Alone: America's Declining Social Capital.” In: Journal of Democracy, 6, pp. 65-78.

Reeskens, Tim/Hooghe, Mark (2008): “Cross-cultural measurement equivalence of generalized trust. Evidence from the European Social Survey (2002 and 2004)." In: Social Indicators Research, 85/3, pp. 515532.

Reiner, Robert (2010 [1985]): The politics of the police. Oxford: Oxford University Press.

Reisig, Michael D./Chandek, Meghan Stroshine (2001): "The effects of expectancy disconfirmation on outcome satisfaction in police-citizen encounters." In: Policing: An International Journal of Police Strategies \& Management, 24/1, pp. 88-99.

Reisig, Michael D./Correia, Mark E. (1997): "Public evaluations of police performance: an analysis across three levels of policing." In: Policing: An International Journal of Police Strategies \& Management, 20/2, pp. 311-325.

Reisig, Michael D./Parks, Roger B. (2000): “Experience, quality of life, and neighborhood context: A hierarchical analysis of satisfaction with police.” In: Justice Quarterly, 17/3, pp. 607-630.

Reuband, Karl-Heinz (2012): "Vertrauen in die Polizei und staatliche Institutionen: Konstanz und Wandel in den Einstellungen der Bevölkerung 1984-2011." In: Soziale Probleme, 23/1, pp. 5-39.

Robbins, Blaine G. (2011): "Neither government nor community alone: A test of state-centered models of generalized trust." In: Rationality and Society, 23/3, pp. 304-346.

Rosenbaum, Dennis P./Schuck, Amie M./Costello, Sandra K./Hawkins, Darnell F./ Ring, Marianne K. (2005): "Attitudes Toward the Police: The Effects of Direct and Vicarious Experience.” In: Police Quarterly, $8 / 3$, pp. 343-365. 
Rothstein, Bo/Stolle, Dietlind (2002): How Political Institutions Create and Destroy Social Capital: An Institutional Theory of Generalised Trust (http://www.apsanet.org/ ep/papers/2003winner.pdf).

Rothstein, Bo/Stolle, Dietlind (2008): “The State and Social Capital: An Institutional Theory of Generalized Trust.” In: Comparative Politics, 40/4, pp. 441-459.

Roux, Viviane (1991): L'image de la police cantonale valaisanne. Lausanne: Institut de police scientifique et de criminologie, Université de Lausanne.

Rowe, Michael (2008): Introduction to policing. Los Angeles, London: Sage.

Ruback, R. Barry/Thompson, Martie P. (2001): Social and psychological consequences of violent victimization. Thousand Oaks: Sage.

Schaap, Dorian/Scheepers, Peer (2014): “Comparing Citizens' Trust in the Police Across European Countries: An Assessment of Cross-Country Measurement Equivalence." In: International Criminal Justice Review, 24/1, pp. 82-98.

Schafer, Joseph A./Huebner, Beth M./Bynum, Timothy S. (2003): "Citizen Perceptions of Police Services: Race, Neighborhood Context, and Community Policing." In: Police Quarterly, 6/4, pp. 440-468.

Schmoll, G. (ed.). (1990): Geschichte der Schweizer Polizei: Band 1: Ursprünge und Traditionen. Muttenz: Bürger und Polizei.

Schuck, Amie M./Rosenbaum, Dennis P. (2005): “Global and Neighborhood Attitudes Toward the Police: Differentiation by Race, Ethnicity and Type of Contact.” In: Journal of Quantitative Criminology, 21/4, pp. 391-418.

Schütz, Alfred/Luckmann, Thomas (1979): Strukturen der Lebenswelt. Frankfurt am Main: Suhrkamp.

Schwartz, Shalom H. (1994): "Are There Universal Aspects in the Structure and Contents of Human Values?" In: Journal of Social Issues, 50/4, pp. 19-45.

Schwarzenegger, Christian (1992): Die Einstellungen der Bevölkerung zur Kriminalität und Verbrechenskontrolle: Ergebnisse einer repräsentativen Befragung der Zürcher Kantonsbevölkerung im internationalen Vergleich. Freiburg i. Br: Max-Planck-Institut für Ausländisches und Internationales Strafrecht. 
Schwarzenegger, Christian/Loewe-Baur, Mjriam (2014): “Zufriedenheit von Opfern von Einbruchdiebstählen und Beteiligten an Verkehrsunfällen mit der Tätigkeit der Polizei” (http://www.rwi.uzh.ch/lehrefor schung/alphabetisch/schwarzenegger/forschung.html\#19).

Schwind, Hans-Dieter (2010 [1986]): Kriminologie: Eine praxisorientierte Einführung mit Beispielen. Heidelberg: Kriminalistik.

Simmel, Georg (1992 [1908]): Soziologie: Untersuchungen über die Formen der Vergesellschaftung. Frankfurt am Main: Suhrkamp.

Simonin, Mathieu/Killias, Martin (2003): “Anzeige von Gewaltdelikten: Eine Frage der Tatumstände oder der Merkmale von Täter und Opfer? “ In: Crimiscope, 22, pp. 1-6.

Skogan, Wesley G. (1987): “The Impact of Victimization on Fear.” In: Crime and Delinquency, 33/1, pp. 135-154.

Skogan, Wesley G. (1989): “The Impact of Police on Victims.” In: Emilio Viano (ed.), Crime and its Victims, New York: Hemisphere, pp. 71-77.

Skogan, Wesley G. (2005): “Citizen Satisfaction with Police Encounter.” In: Police Quarterly, 8/3, pp. 298-321.

Skogan, Wesley G. (2006): "Asymmetry in the Impact of Encounters with Police.” In: Policing and Society, 16/2, pp. 99-126.

Smith, Paul E./Hawkins, Richard O. (1973): "Victimization, Types of Citizen-Police Contacts, and Attitudes towards the Police.” In: Law and Society Review, 8/1, pp. 135-152.

Smith, Tom W. (1997): "Factors Relating to Misanthropy in Contemporary American Society.” In: Social Science Research, 26, pp. 170-196.

Sorensen, David W.M. (2011): Rounding Up Suspects in the Rise of Danish Burglary: A Statistical Analysis of the 2008/09 Increase in Residential Break-ins. Report for the Danish Crime Prevention Council and The Ministry of Justice. Copenhagen: University of Copenhagen.

Staubli, Silvia (2014): Trust in and Attitudes towards the Police: Empirical Analyses for Europe with a Special Focus on Switzerland. Doctoral Thesis. Zurich: University of Zurich.

Staubli, Silvia (2016): "Investigations on the Legitimacy of the Swiss Police: Actual Debates and Empirical Evidence.” In: Mathieu Deflem (ed.), The Politics of Policing: Between Force and Legitimacy, Sociology of Crime, Law, and Deviance, Bingley, UK: Emerald, pp. 97-114.

Staubli, Silvia/Killias, Martin/Frey, Bruno S. (2014): "Happiness and Victimization: An Empirical Study for Switzerland.” In: European Journal of Criminology, 11/1, pp. 57-72. 
Sturgis, Patrick/Roberts, Caroline/Smith, Patten (2014): “Middle Alternatives Revisited: How the neither/nor Response Acts as a Way of Saying 'I Don't Know'?” In: Sociological Methods \& Research, 43/1, pp. 15-38.

Sunshine, Jason/Tyler, Tom R. (2003): “The Role of Procedural Justice and Legitimacy in Shaping Public Support for Policing.” In: Law \& Society Review, 37/3, pp. 513-548.

Sztompka, Piotr (1999): Trust: a sociological theory. Cambridge: Cambridge University Press.

Szvircsev Tresch, Tibor/Wenger, Andreas (eds.) (2016): Sicherheit 2016: Aussen-, Sicherheits- und Verteidigungspolitische Meinungsbildung im Trend. Zürich: ETH Zürich: Center for Security Studies und Militärakademie.

Szvircsev Tresch, Tibor/Wenger, Andreas (eds.) (2010): Sicherheit 2010: Aussen-, Sicherheits- und Verteidigungspolitische Meinungsbildung im Trend. Zürich: ETH Zürich: Center for Security Studies und Militärakademie.

Tankebe, Justice (2009): "Self-Help, Policing, and Procedural Justice: Ghanaian Vigilantism and the Rule of Law.” In: Law \& Society Review, 43/2, pp. 245-270.

Tewksbury, Richard/West, Angela (2001): “Crime victims' satisfaction with police services: An assessment in one urban community." In: The Justice Professional, 14/4, pp. 271-285.

Tuch, Steven A./Weitzer, Ronald (1997): "Trends: Racial Differences in Attitudes Toward the Police.” In: The Public Opinion Quarterly, 61/4, pp. 642-663.

Tyler, Tom R. (1990): Why people obey the law. New Haven: Yale University Press.

Tyler, Tom R. (1998): “Trust and Democratic Governance: Chapter 11.” In: Valerie A. Braithwaite/Margaret Levi (eds.), Trust and governance, New York: Russell Sage Foundation, pp. 269-294.

Tyler, Tom R. (2001): "Public trust and confidence in legal authorities: What do majority and minority group members want from the law and legal institutions?” In: Behavioral Sciences and the Law, 19, pp. $215^{-235}$.

Tyler, Tom R./Huo, Yuen J. (2002): Trust in the law: Encouraging public cooperation with the police and courts. New York: Russell Sage Foundation. 
Tyler, Tom R./Jackson, Jonathan/Bradford, Ben (2013): "Psychology of procedural justice and cooperation.” In: Gerben Bruinsma/David Weisburd (eds.), Encyclopedia of Criminology and Criminal Justice, New York: Springer, pp. 1-16.

Ullmann-Margalit, Edna (2004): “Trust, Distrust, and In Between.” In: Russel Hardin (ed.), Distrust, New York: Russell Sage Foundation, pp. 60-82.

Uslaner, Eric M. (2002): The moral foundations of trust. Cambridge: Cambridge University Press.

van Dijk, Jan/Mayhew, Pat/Killias, Martin (1990): Experiences of crime across the world: Key findings from the 1989 International Crime Survey. Deventer: Kluwer Law and Taxation.

Verband Schweizerischer Polizeibeamter VSPB (2011): Sensibilisierungskampagne Stopp der Gewalt gegen Polizisten/innen. Bern: VSPB.

Weitzer, Ronald/Tuch, Steven A. (2005): “Determinants of Public Satisfaction with the Police." In: Police Quarterly, 8/3, pp. 279-297.

Welch, Michael R./Rivera, Roberto E. N./Conway, Brian P./Yonkoski, Jennifer/Lupton, Paul M./Giancola, Russell (2005): "Determinants and Consequences of Social Trust.” In: Sociological Inquiry, 75/4, pp.453473 .

World Value Survey (2011): Questionnaire: revised master (http://www. worldvaluessurvey.org/).

Wu, Yuning/Sun, Ivan Y. (2009): "Citizen Trust in Police: The Case of China.” In: Police Quarterly, 12/2, pp. 170-191.

Yamagishi, Toshio/Kikuchi, Masako/Kosugi, Motoko (1999): “Trust, gullibility, and social intelligence.” In: Asian Journal of Social Psychology, 2, pp. 145-161.

Zernova, Margarita (2012): “The public image of the contemporary Russian police: Impact of personal experiences of policing, wider social implications and the potential for change." In: Policing: An International Journal of Police Strategies \& Management, 35/2, pp. 216-230. 


\section{Appendices}

\section{Appendix A: European Social Survey}

Table A1: Missing values of trust and confidence in the police (percent)

\begin{tabular}{|c|c|c|c|c|c|}
\hline & \multirow{2}{*}{$\begin{array}{l}\text { Trust in the } \\
\text { police }\end{array}$} & \multirow{2}{*}{$\begin{array}{l}\text { Confidence in } \\
\text { police work }^{1}\end{array}$} & \multicolumn{3}{|c|}{ Procedural fairness } \\
\hline & & & $\begin{array}{l}\text { Respectful } \\
\text { treatment }\end{array}$ & Fair decisions & $\begin{array}{l}\text { Explanation of } \\
\text { decisions }\end{array}$ \\
\hline \multicolumn{6}{|l|}{ Western Europe } \\
\hline Belgium & 0,2 & 0,1 & 0,6 & 2,9 & 2,6 \\
\hline Denmark & 0,3 & 0,4 & 1,5 & 3,8 & 6,8 \\
\hline Finland & 0,5 & 0,5 & 1,9 & 3,4 & 4,4 \\
\hline France & 0,1 & 0,1 & 1,5 & 4,3 & 3,5 \\
\hline Germany & 0,4 & 1,1 & 4,8 & 8,3 & 10,3 \\
\hline Ireland & 1,1 & 1,9 & 4,2 & 6,3 & 10,4 \\
\hline Netherlands & 0,4 & 0,8 & 2,6 & 6,7 & 6,6 \\
\hline Norway & 0,2 & 0,1 & 1,1 & 2,5 & 5,4 \\
\hline Sweden & 0,9 & 0,7 & 3,2 & 5,6 & 10,2 \\
\hline Switzerland & 0,3 & 0,7 & 2,3 & 6,1 & 6,0 \\
\hline United Kingdom & 1,1 & 0,5 & 3,0 & 6,4 & 10,8 \\
\hline \multicolumn{6}{|l|}{ Eastern Europe } \\
\hline Bulgaria & 3,7 & 4,4 & 11,8 & 19,4 & 20,4 \\
\hline Croatia & 2,4 & 2,4 & 8,7 & 15,3 & 16,3 \\
\hline Czech Republic & 1,3 & 1,7 & 11,0 & 13,5 & 14,3 \\
\hline Estonia & 1,7 & 2,5 & 7,3 & 10,7 & 11,4 \\
\hline Hungary & 1,9 & 2,4 & 11,5 & 20,1 & 17,1 \\
\hline Lithuania & 3,9 & 3,7 & 14,1 & 19,7 & 17,8 \\
\hline Poland & 2,6 & 2,2 & 8,0 & 11,4 & 13,4 \\
\hline Slovakia & 2,0 & 3,3 & 13,7 & 15,9 & 16,2 \\
\hline Slovenia & 2,2 & 2,1 & 9,7 & 12,3 & 13,6 \\
\hline
\end{tabular}

Note: Source: ESS2010

${ }^{1}$ Referring to the question of how well the police are doing their job in a given country 
Table A2: Frequency distribution of trust in the police across Eastern Europe, Western Europe, and Switzerland

\begin{tabular}{|lccc|}
\hline Trust in the Police & $\begin{array}{c}\text { Eastern } \\
\text { Europe }\end{array}$ & Western Europe & Switzerland \\
\hline $0-$ no trust at all & $6.0(416)$ & $2.4(539)$ & $1.1(17)$ \\
1 & $5.0(341)$ & $1.4(318)$ & $0.8(12)$ \\
2 & $6.8(465)$ & $3.1(713)$ & $2.0(30)$ \\
3 & $9.9(679)$ & $4.5(1,015)$ & $3.3(49)$ \\
4 & $10.2(699)$ & $6.6(1,492)$ & $4.3(65)$ \\
5 & $20.0(1,379)$ & $14.0(3,179)$ & $9.9(149)$ \\
6 & $11.8(810)$ & $11.5(2,615)$ & $9.7(146)$ \\
7 & $11.9(817)$ & $18.9(4,288)$ & $18.9(284)$ \\
8 & $11.8(810)$ & $21.8(4,948)$ & $27.4(411)$ \\
9 & $3.9(271)$ & $9.8(2,236)$ & $13.6(204)$ \\
$10-$ complete trust & $2.8(194)$ & $6.0(1,366)$ & $9.0(135)$ \\
\hline Total & $100.0(6,882)$ & $100.0(22,709)$ & $100.0(1,502)$ \\
\hline Refusal & $0.0(2)$ & $0.0(1)$ & - \\
Don't know & $2.2(157)$ & $0.5(113)$ & $0.3(4)$ \\
No answer & $0.2(14)$ & $0.0(1)$ & - \\
\hline
\end{tabular}

Note: Source: ESS2010

Percent, number of cases in brackets

Figure A1 and Figure A2: Histograms of trust in the police in Eastern and Western Europe
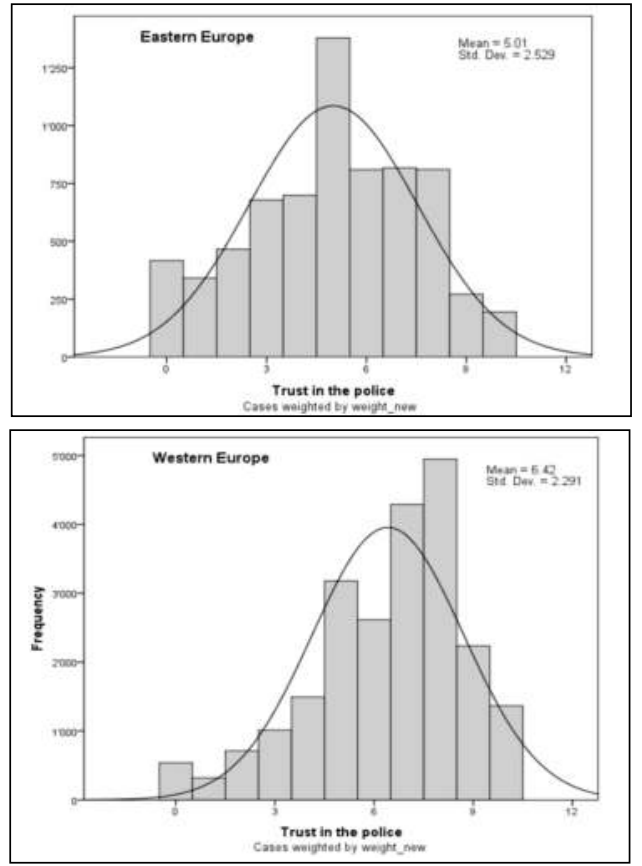
Figure $A_{3}$ and Figure A4: Histogram of trust in the Swiss police before and after log transformation
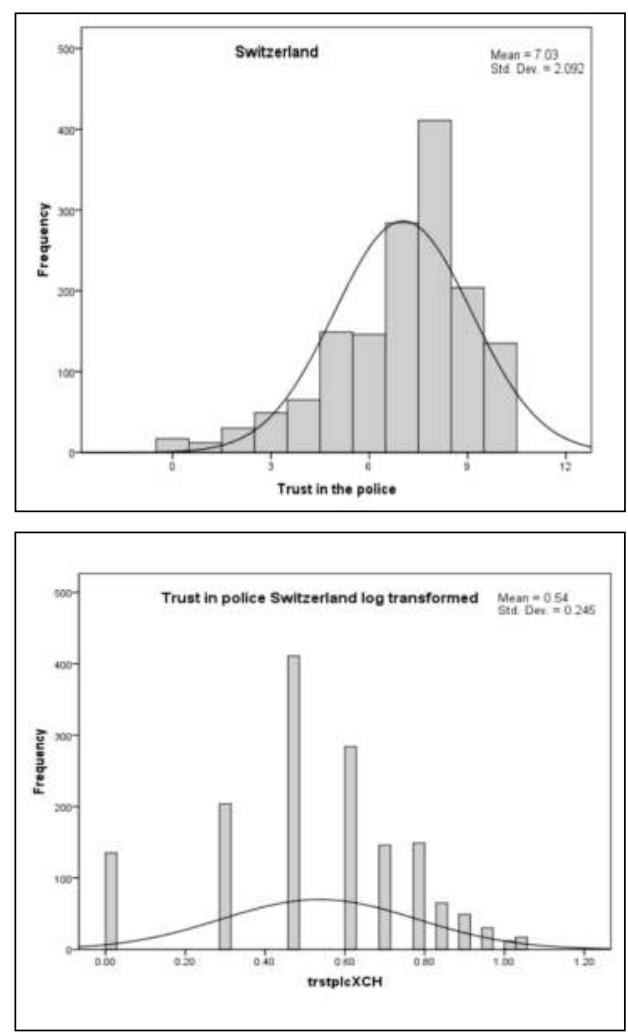

Table A3: Frequency distribution of confidence in police work in Eastern Europe, Western Europe, and Switzerland

\begin{tabular}{|lccc|}
\hline Confidence in police work & Eastern Europe & Western Europe & Switzerland \\
\hline Very good job & $2.5(173)$ & $7.1(1,618)$ & $10.4(155)$ \\
Good job & $48.1(3,311)$ & $64.3(14,585)$ & $70.7(1,057)$ \\
Neither good nor bad job & $37.9(2,612)$ & $22.0(5,003)$ & $15.7(235)$ \\
Bad job & $10.0(688)$ & $5.6(1,273)$ & $2.5(38)$ \\
Very bad job & $1.5(100)$ & $1.0(221)$ & $0.7(11)$ \\
\hline Total & $100.0(6,884)$ & $100.0(22,700)$ & $100.0(1,496)$ \\
\hline Don't know/refusal/no answer & $10.4(170)$ & $0.5(124)$ & $0.7(10)$ \\
\hline
\end{tabular}

Note: Source: ESS2010

Percent, number of cases in brackets 
Figure A5 and Figure A6: Box plot of trust in the police in Switzerland
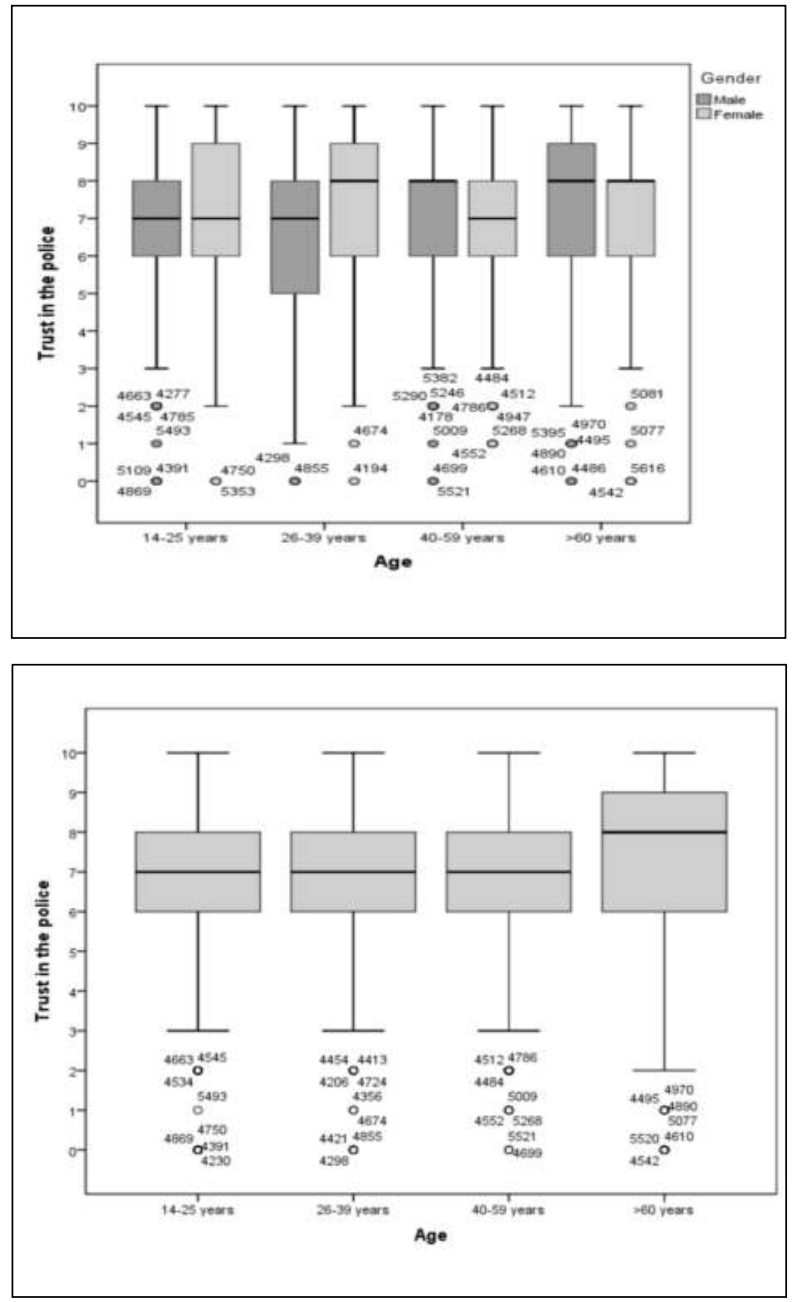
Table A4: Frequency distribution of procedural fairness items in Eastern Europe, Western Europe, and Switzerland

\begin{tabular}{|lccc|}
\hline & Eastern Europe & Western Europe & Switzerland \\
\hline Respectful treatment & & & \\
Not at all often & $4.6(294)$ & $2.3(517)$ & $1.4(20)$ \\
Not very often & $31.4(2,003)$ & $17.3(3,820)$ & $11.1(164)$ \\
Often & $58.0(3,692)$ & $66.3(14,660)$ & $67.7(996)$ \\
Very often & $5.9(379)$ & $14.1(3,110)$ & $19.8(292)$ \\
Total & $100.0(6,367)$ & $100.0(22,108)$ & $100.0(1,472)$ \\
Don't know/refusal/no answer & $9.7(687)$ & $3.1(716)$ & $2.3(34)$ \\
\hline Fair decisions & $3.6(220)$ & & \\
Not at all often & $3.6(220)$ & $2.0(423)$ & $1.8(26)$ \\
Not very often & $34.2(2,075)$ & $18.7(4,010)$ & $15.3(217)$ \\
Often & $57.7(3,501)$ & $69.2(14,823)$ & $71.4(1,010)$ \\
Very often & $4.5(272)$ & $10.2(2,175)$ & $11.4(161)$ \\
Total & $100.0(6,068)$ & $100.0(21,431)$ & $100.0(1,414)$ \\
Don't know/refusal/no answer & $14.0(986)$ & $6.1(1,393)$ & $6.1(92)$ \\
\hline Explanation of Decisions & & & \\
Not at all often & $10.6(612)$ & $6.2(1,275)$ & $3.8(53)$ \\
Not very often & $39.3(2,277)$ & $31.8(6,513)$ & $20.8(291)$ \\
Often & $44.7(2,585)$ & $51.8(10,623$ & $62.1(869)$ \\
Very often & $5.4(314)$ & $10.2(2,081)$ & $13.4(187)$ \\
Total & $100.0(5,787)$ & $100.0(20,492)$ & $100.0(1,400)$ \\
\hline No one ever asks the police to & $3.1(222)$ & $2.3(514)$ & $1.1(16)$ \\
explain their decisions & $14.8(1,045)$ & $7.9(1,818)$ & $6.0(90)$ \\
Don't know/refusal/no answer & & & \\
\hline
\end{tabular}

Note: Source: ESS2010

Percent, number of cases in brackets

Table A5: Correlations between procedural fairness items in Eastern and Western Europe

\begin{tabular}{|lcccccc|}
\hline & \multicolumn{3}{c}{ Western Europe } & \multicolumn{2}{c|}{ Eastern Europe } \\
\hline & $\begin{array}{l}\text { Respectful } \\
\text { treatment }\end{array}$ & Fair decisions & $\begin{array}{l}\text { Explanation } \\
\text { of decisions }\end{array}$ & $\begin{array}{l}\text { Respectful } \\
\text { treatment }\end{array}$ & Fair decisions $\begin{array}{c}\text { Explanation } \\
\text { of decisions }\end{array}$ \\
\hline Respectful treatment & 1,000 & $.553^{* * *}$ & $.382^{* * *}$ & 1,000 & $.614^{* * *}$ & $.448^{* * *}$ \\
Fair decisions & $.553^{* * *}$ & 1,000 & $.404^{* * *}$ & $.614^{* * *}$ & 1,000 & $.468^{* * *}$ \\
Explanation of decisions & $.382^{* * *}$ & $.404^{* * *}$ & 1,000 & $.448^{* * *}$ & $.468^{* * *}$ & 1,000 \\
\hline
\end{tabular}

Note: Source: ESS2010

Pearson's correlation coefficients; significance level: *** $p<0.001$ 
Table A6: Correlations between procedural fairness items in Switzerland

\begin{tabular}{|lccc|}
\hline & $\begin{array}{l}\text { Respectful } \\
\text { treatment }\end{array}$ & Fair decisions & $\begin{array}{l}\text { Explanation of } \\
\text { decisions }\end{array}$ \\
\hline Respectful treatment & 1,000 & $.501^{* * *}$ & $.399^{* * *}$ \\
Fair decisions & $.501^{* * *}$ & 1,000 & $.398^{* * * *}$ \\
Explanation of decisions & $.399^{* * *}$ & $.398^{* * *}$ & 1,000 \\
\hline
\end{tabular}

Note: Source: ESS2010

Pearson's correlation coefficients; significance level: $* * * p<0.001$

Table A7: Frequency of police contact and people's satisfaction with interaction

\begin{tabular}{|lccc|}
\hline & Eastern Europe & Western Europe & Switzerland \\
\hline Police-initiated contact & & & \\
Yes & $69.1(4,853)$ & $61.9(14,101)$ & $42.9(646)$ \\
No & $30.9(2,168)$ & $38.1(8,687)$ & $56.9(857)$ \\
Total & $100.0(7,022)$ & $100.0(22,788)$ & $100.0(1,503)$ \\
\hline Don't know/no answer & $0.5(33)$ & $0.5(124)$ & $0.2(3)$ \\
\hline Satisfaction with treatment & & & \\
\hline Very dissatisfied & $10.3(223)$ & $10.8(936)$ & $11.2(72)$ \\
Dissatisfied & $13.5(292)$ & $12.3(1,069)$ & $9.6(62)$ \\
Neither/nor & $21.2(459)$ & $11.1(960)$ & $12.0(77)$ \\
Satisfied & $45.1(974)$ & $40.8(3,540)$ & $41.9(270)$ \\
Very satisfied & $9.9(214)$ & $25.1(2,179)$ & $25.3(163)$ \\
Total & $100.0(2,161)$ & $100.0(8,684)$ & $100.0(644)$ \\
\hline Don't know/no answer/refusal & $0.3(21)$ & $0.5(124)$ & $0.1(2)$ \\
\hline
\end{tabular}

Note: Source: ESS2010 
Table A8: Descriptive statistics of control variables ESS2010 for Eastern and Western Europe

\begin{tabular}{|c|c|c|c|c|}
\hline \multirow[b]{2}{*}{ Control Variables (ESS) } & \multicolumn{2}{|l|}{ Western Europe } & \multicolumn{2}{|l|}{ Eastern Europe } \\
\hline & Valid & Mean & Valid & Mean \\
\hline Gender & $100.0(22,824)$ & & $100.0(7,052)$ & \\
\hline Male & $48.5(11,078)$ & & $46.7(3,291)$ & \\
\hline Female & $51.5(11,746)$ & & $53.3(3,761)$ & \\
\hline Age & $100.0(17,551)$ & 47,4 & $100.0(7,055)$ & 46,0 \\
\hline $14-25$ years & $16.4(3,737)$ & & $18.6(1,310)$ & \\
\hline $26-39$ years & $19.4(4,420)$ & & $22.0(1,554)$ & \\
\hline $40-59$ years & $36.4(8,312)$ & & $34.1(2,408)$ & \\
\hline$\geq 60$ years & $27.8(6,354)$ & & $25.3(1,783)$ & \\
\hline Years of full-time education & $100.0(22,674)$ & 12,9 & $100.0(6,979)$ & 12,4 \\
\hline Household income & $100.0(18,681)$ & 5,5 & $100.0(5,266)$ & 5,3 \\
\hline Low & $49.6(9,264)$ & & $52.6(2,770)$ & \\
\hline High & $50.4(9,417)$ & & $47.4(2,496)$ & \\
\hline Citizenship & $100.0(22,824)$ & & $100.0(7,044)$ & \\
\hline Yes & $94.0(21,672)$ & & $99.4(7,000)$ & \\
\hline No & $5.0(1,152)$ & & $0.6(44)$ & \\
\hline Ethnic minority & $100.0(22,656)$ & & $100.0(6,934)$ & \\
\hline Yes & $5.4(1,222)$ & & $95.5(6,623)$ & \\
\hline No & $94.6(21,434)$ & & $4.5(312)$ & \\
\hline Religiousness & $100.0(22,751)$ & 4,3 & $100.0(6,977)$ & 5,2 \\
\hline Low & $66.5(15,122)$ & & $52.3(3,652)$ & \\
\hline High & $33.5(7,629)$ & & $47.7(3,325)$ & \\
\hline Political orientation & $100.0(22,824)$ & 4,9 & $100.0(5,905)$ & 5,5 \\
\hline Left (dummy) & $31.1(7,095)$ & & $20.7(1,462)$ & \\
\hline Moderate (dummy) & $32.2(7,350)$ & & $28.1(1,984)$ & \\
\hline Right (dummy) & $28.3(6,452)$ & & $34.9(2,459)$ & \\
\hline Criminal victimization & $100.0(22,787)$ & & $100.0(7,015)$ & \\
\hline Yes & $17.3(3,938)$ & & $11.8(831)$ & \\
\hline No & $82.7(18,849)$ & & $88.2(6,184)$ & \\
\hline Fear of crime & $100.0(22,671)$ & & $100.0(6,930)$ & \\
\hline Very safe & $30.1(6,829)$ & & $19.0(1,314)$ & \\
\hline Safe & $47.9(10,865)$ & & $57.0(3,952)$ & \\
\hline Unsafe & $16.9(3,839)$ & & $20.0(1,387)$ & \\
\hline Very unsafe & $5.0(1,138)$ & & $4.0(276)$ & \\
\hline Life satisfaction & $100.0(22,824)$ & 7,2 & $100.0(7,055)$ & 6,4 \\
\hline Low & $21.4(4,887)$ & & $34.2(2,409)$ & \\
\hline High & $78.6(17,936)$ & & $65.8(4,645)$ & \\
\hline Agglomeration type & $100.0(22,797)$ & & $100.0(7,026)$ & \\
\hline A big city & $14.8(3,371)$ & & $27.5(1,930)$ & \\
\hline Suburbs/outskirts of big city & $13.3(3,037)$ & & $5.2(363)$ & \\
\hline Town or small city & $33.9(7,731)$ & & $30.7(2,159)$ & \\
\hline Country village & $32.0(7,305)$ & & $35.6(2,502)$ & \\
\hline Farm/home in countryside & $5.9(1,355)$ & & $1.0(72)$ & \\
\hline Going out & $100.0(22,796)$ & 2,8 & $100.0(7,014)$ & \\
\hline Up to once a month & $6.8(1,543)$ & & $16.1(1,129)$ & \\
\hline Once/several times a month & $26.9(6,124)$ & & $36.1(2,531)$ & \\
\hline Once/several times a week & $50.6(11,538)$ & & $36.9(2,592)$ & \\
\hline Every day & $15.8(3,591)$ & & $10.9(762)$ & \\
\hline
\end{tabular}


Table Ag: Descriptive statistics of control variables ESS2010 for Switzerland

\begin{tabular}{|c|c|c|c|c|c|c|c|}
\hline Control Variables (ESS) & & Missing & Mean & Min. & Max. & $\begin{array}{r}\text { Skew- } \\
\text { ness }\end{array}$ & $\begin{array}{r}\text { Kurto- } \\
\text { sis } \\
\end{array}$ \\
\hline Gender & $100.0(1,506)$ & 0 & 1,5 & 1 & 2 & & \\
\hline Male & $51.3(772)$ & & & & & & \\
\hline Female & $48.7(734)$ & & & & & & \\
\hline Age & $100.0(1,502)$ & 4 & 47,6 & 15 & 96 & 0,126 & $-0,797$ \\
\hline $14-25$ years & $16.1(243)$ & & & & & & \\
\hline $26-39$ years & $17.9(269)$ & & & & & & \\
\hline $40-59$ years & $37.9(571)$ & & & & & & \\
\hline$\geq 60$ years & $28.1(423)$ & & & & & & \\
\hline Years of full-time education & $100.0(1,499)$ & 7 & 11,4 & 5 & 28 & 1,225 & 1,103 \\
\hline Household income ${ }^{l}$ & $100.0(1,233)$ & 273 & 5,7 & 1 & 10 & $-0,043$ & $-1,115$ \\
\hline Low & $46.7(576)$ & & & & & & \\
\hline High & $53.3(657)$ & & & & & & \\
\hline Citizenship & $100.0(1,506)$ & 0 & & & & & \\
\hline Yes & $84.8(1,277)$ & & & & & & \\
\hline No & $15.2(229)$ & & & & & & \\
\hline Ethnic minority & $100.0(1,502)$ & 4 & & & & & \\
\hline Yes & $93.4(1,403)$ & & & & & & \\
\hline No & $6.6(99)$ & & & & & & \\
\hline Religiousness & $100.0(1,500)$ & 6 & 5,1 & 0 & 10 & $-0,178$ & $-0,93$ \\
\hline Low & $53.9(808)$ & & & & & & \\
\hline High & $46.1(692)$ & & & & & & \\
\hline Political orientation & $100.0(1,424)$ & 82 & 5,1 & 0 & 10 & $-0,005$ & $-0,007$ \\
\hline Left (dummy) & $29.7(448)$ & & & & & & \\
\hline Moderate (dummy) & $30.8(464)$ & & & & & & \\
\hline Right (dummy) & $34.0(512)$ & & & & & & \\
\hline Criminal victimization & $100.0(1,502)$ & 4 & & & & & \\
\hline Yes & $16.2(243)$ & & & & & & \\
\hline No & $83.8(1,259)$ & & & & & & \\
\hline Fear of crime & $100.0(1,505)$ & 1 & & & & & \\
\hline Yes & $14.3(216)$ & & & & & & \\
\hline No & $85.7(1,290)$ & & & & & & \\
\hline Life satisfaction & $100.0(1,505)$ & 1 & 8,1 & 0 & 10 & $-1,435$ & 3,198 \\
\hline Low & $7.8(113)$ & & & & & & \\
\hline High & $2.2(1,389)$ & & & & & & \\
\hline Agglomeration type & $100.0(1,506)$ & 0 & & 1 & 5 & & \\
\hline A big city & $9.9(149)$ & & & & & & \\
\hline Suburbs/outskirts of big city & $9.8(148)$ & & & & & & \\
\hline Town or small city & $23.0(347)$ & & & & & & \\
\hline Country village & $52.7(793)$ & & & & & & \\
\hline Farm/home in countryside & $4.6(69)$ & & & & & & \\
\hline Going out & $100.0(1,506)$ & 0 & & 1 & 4 & & \\
\hline Up to once a month & $4.3(65)$ & & & & & & \\
\hline Once/several times a month & $23.8(359)$ & & & & & & \\
\hline Once/several times a week & $59.0(888)$ & & & & & & \\
\hline Every day & $12.9(194)$ & & & & & & \\
\hline
\end{tabular}

Note: ${ }^{1}$ Income categories are based on the Swiss Household Panel (Source: European Social Survey 2010a). Due to the dichotomization of the variable, they are not listed individually. 


\section{Appendix B: Swiss Crime Survey 2011}

Table B1: Sample before weighing age and gender

\begin{tabular}{|lrrr|}
\hline Age & \multicolumn{1}{l}{ Male } & \multicolumn{1}{l}{ Female } & \multicolumn{1}{l|}{ Total } \\
\hline 16-39 years & $28.6(2,148)$ & $29.5(2,436)$ & $29.1(4,584)$ \\
40-64 years & $48.0(3,609)$ & $48.4(3,994)$ & $48.2(7,603)$ \\
$>65$ years & $23.4(1,757)$ & $22.1(1,828)$ & $22.7(3,585)$ \\
\hline Total & $100.0(7,514)$ & $100.0(8,258)$ & $100.0(15,772)$ \\
\hline
\end{tabular}

Note: Percent, number of cases in brackets

Table B2: Sample after weighing age and gender

\begin{tabular}{|lrrr|}
\hline Age & \multicolumn{1}{l}{ Male } & Female & \multicolumn{1}{l|}{ Total } \\
\hline 16-39 years & $45.0(3,549)$ & $45.0(3,549)$ & $45.0(7,098)$ \\
40-64 years & $35.0(2,760)$ & $35.0(2,760)$ & $35.0(5,520)$ \\
$>65$ years & $20.0(1,577)$ & $20.0(1,577)$ & $20.0(3,154)$ \\
\hline Total & $100.0(7,886)$ & $100.0(7,886)$ & $100.0(15,772)$ \\
\hline
\end{tabular}

Note: Percent, number of cases in brackets

Table B3: Frequency distribution of dependent variable CS2011

\begin{tabular}{|lcc|}
\hline & & \\
Trust in the police & Full sample & National sample \\
\hline No & $27.3(4,306)$ & $26.1(531)$ \\
Yes & $72.7(11,466)$ & $73.9(1,504)$ \\
\hline Total & $100.0(15,772)$ & $100.0(2,035)$ \\
\hline
\end{tabular}

Note: Percent, number of cases in brackets

Samples weighted by gender and age

Table B4: Frequency distribution of independent variable CS2011

\begin{tabular}{|lcc|}
\hline Confidence in police work & Full sample & National sample \\
\hline Very good job & $14.5(1,865)$ & $16.2(271)$ \\
Good job & $71.3(9,183)$ & $72.2(1,205)$ \\
Bad job & $11.9(1,528)$ & $9.9(165)$ \\
Very bad job & $2.4(311)$ & $1.6(27)$ \\
Total & $100.0(12,887)$ & $100.0(1,668)$ \\
\hline Don't know/no answer & $18.3(2,885)$ & $18.0(367)$ \\
\hline
\end{tabular}

Note: Percent, number of cases in brackets 
Table B5: Frequency distribution of control variables CS2011

\begin{tabular}{|c|c|c|}
\hline Control Variables & Full sample & National sample \\
\hline \multicolumn{3}{|l|}{ Gender } \\
\hline Male & $50.0(7,886)$ & $50.0(1,017)$ \\
\hline Female & $50.0(7,886)$ & $50.0(1,018)$ \\
\hline Total & $100.0(15,772)$ & $100.0(2,035)$ \\
\hline \multicolumn{3}{|l|}{ Age } \\
\hline $16-25$ years & $16.3(2,578)$ & $16.9(343)$ \\
\hline 26-39 years & $28.7(4,519)$ & $28.1(572)$ \\
\hline $40-59$ years & $28.4(4,484)$ & $29.2(594)$ \\
\hline$>60$ years & $26.6(4,191)$ & $25.8(526)$ \\
\hline Total & $100.0(15,772)$ & $100.0(2,035)$ \\
\hline \multicolumn{3}{|l|}{ Last visited school } \\
\hline Primary school & $5.2(812)$ & $3.6(72)$ \\
\hline Secondary school & $7.8(1,212)$ & $8.6(174)$ \\
\hline Vocational school & $49.0(7,636)$ & $48.9(986)$ \\
\hline College & $6.1(945)$ & $5.8(117)$ \\
\hline Univ. of applied science & $19.1(2,972)$ & $18.3(368)$ \\
\hline University & $12.9(2,006)$ & $14.8(298)$ \\
\hline Total & $100.0(15,584)$ & $100.0(2,016)$ \\
\hline Don't know / no answer & $1.2(188)$ & 0.9 (19) \\
\hline \multicolumn{3}{|l|}{ Household income } \\
\hline$<2500$ & $5.8(785)$ & $6.2(107)$ \\
\hline 2500-5000.- & $26.3(3,539)$ & $25.9(449)$ \\
\hline 5000-7500.- & $29.2(3,928)$ & $27.5(476)$ \\
\hline$>7500 .-$ & $38.7(5,205)$ & $40.5(702)$ \\
\hline Total & $100.0(13,458)$ & $100.0(1,734)$ \\
\hline Don't know / no answer & $14.7(2,314)$ & $14.8(301)$ \\
\hline \multicolumn{3}{|l|}{ Residence status } \\
\hline Swiss citizen & $89.7(14,121)$ & $88.4(1,794)$ \\
\hline Residence permit (B) & $2.2(342)$ & $2.7(55)$ \\
\hline Resident (C) & $8.0(1,255)$ & $8.8(179)$ \\
\hline Others & $0.2(25)$ & $0.1(2)$ \\
\hline Total & $100.0(15,743)$ & $100.0(2,030)$ \\
\hline Don't know / no answer & $0.2(29)$ & $0.2(5)$ \\
\hline \multicolumn{3}{|l|}{ Agglomeration type $e^{1}$} \\
\hline Core city & $33.9(5,344)$ & \\
\hline Agglomeration & $37.7(5,940)$ & \\
\hline Single city & $3.8(593)$ & \\
\hline Rural & $24.2(3,895)$ & \\
\hline Total & $100.0(15,772)$ & \\
\hline
\end{tabular}

Note: Percent, number of cases in brackets

Samples weighted by gender and age

${ }^{1}$ Only calculated for the full sample, as not needed in analyses based on the national sample 


\section{Social Sciences}

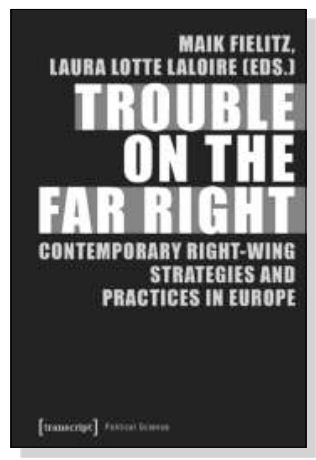

Maik Fielitz, Laura Lotte Laloire (eds.)

Trouble on the Far Right

Contemporary Right-Wing Strategies

and Practices in Europe

2016, 208 p., 19,99€ (DE),

ISBN $978-3-8376-3720-5$

E-Book: $17,99 €(\mathrm{DE})$, ISBN 978-3-8394-3720-9

EPUB: $17,99 €(D E)$, ISBN $978-3-7328-3720-5$

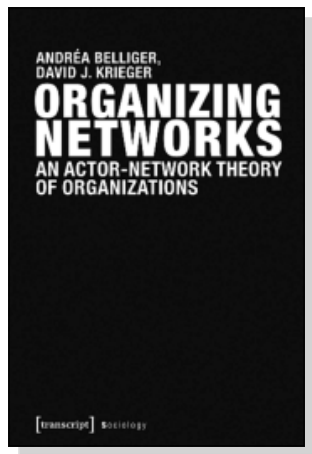

Andréa Belliger, David J. Krieger

Organizing Networks

An Actor-Network Theory of Organizations

2016, 272 p., 34,99€ (DE),

ISBN 978-3-8376-3616-1

E-Book: 34,99 $€(D E)$, ISBN 978-3-8394-3616-5

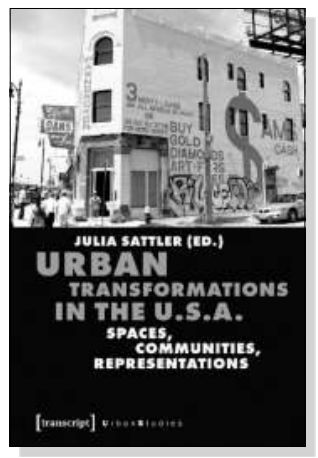

Julia Sattler (ed.)

Urban Transformations in the U.S.A.

Spaces, Communities, Representations

2016, 426 p., 39,99€ (DE),

ISBN 978-3-8376-3111-1

E-Book: 39,99€ (DE), ISBN 978-3-8394-3111-5

All print, e-book and open access versions of the titels in our entire list are available in our online shop www.transcript-verlag.de/en! 


\section{Social Sciences}

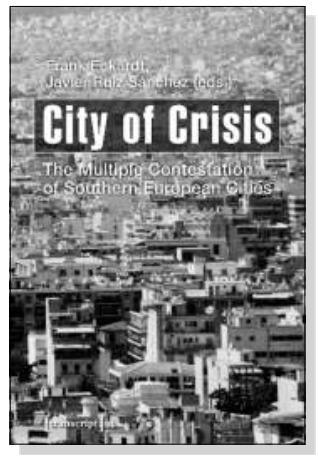

Frank Eckardt, Javier Ruiz Sánchez (eds.)

City of Crisis

The Multiple Contestation

of Southern European Cities

2015, 264 p., 29,99€ (DE),

ISBN $978-3-8376-2842-5$

available as free open access publication

E-Book: ISBN 978-3-8394-2842-9

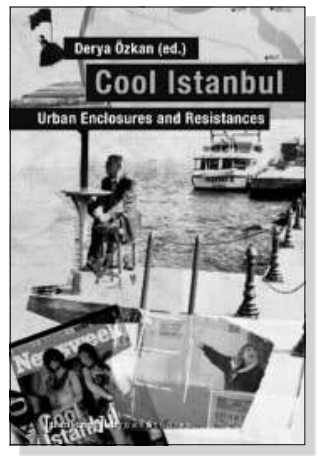

Derya Özkan (ed.)

Cool Istanbul

Urban Enclosures and Resistances

2014, 172 p., 29,99€ (DE),

ISBN 978-3-8376-2763-3

E-Book: $26,99 €(\mathrm{DE})$, ISBN 978-3-8394-2763-7

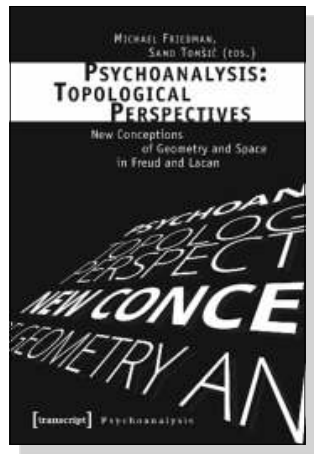

Michael Friedman, Samo Tomsic (eds.) Psychoanalysis: Topological Perspectives New Conceptions of Geometry and Space in Freud and Lacan

2016,256 p., 34,99 $€(\mathrm{DE})$,

ISBN 978-3-8376-3440-2

E-Book: $34,99 €(\mathrm{DE})$, ISBN 978-3-8394-3440-6

All print, e-book and open access versions of the titels in our entire list are available in our online shop www.transcript-verlag.de/en! 